\author{
UNIVERSIDADE DE SÃO PAULO \\ CENTRO DE ENERGIA NUCLEAR NA AGRICULTURA
}

\title{
CAIO FORTES
}

Produtividade de cana-de-açúcar em função da adubação nitrogenada e da decomposição da palhada em ciclos consecutivos

Piracicaba

2010 




\section{CAIO FORTES}

Produtividade de cana-de-açúcar em função da adubação nitrogenada e da decomposição da palhada em ciclos consecutivos

Tese apresentada ao Centro de Energia Nuclear na Agricultura da Universidade de São Paulo, para obtenção do título de Doutor em Ciências

Área de Concentração: Energia Nuclear na Agricultura e no Ambiente.

Orientador: Prof. Dr. Paulo Cesar Ocheuze Trivelin

\section{Piracicaba}


AUTORIZO A DIVULGAÇÃO TOTAL OU PARCIAL DESTE TRABALHO, POR QUALQUER MEIO CONVENCIONAL OU ELETRÔNICO, PARA FINS DE ESTUDO E PESQUISA, DESDE QUE CITADA A FONTE.

Fortes, Caio

Produtividade de cana-de-açúcar em função da adubação nitrogenada e da decomposição da palhada em ciclos consecutivos / Caio Fortes; orientador Paulo Cesar Ocheuze Trivelin. - - Piracicaba, 2010.

153 f.: fig.

Tese (Doutorado - Programa de Pós-Graduação em Ciências. Área de Concentração: Energia Nuclear na Agricultura e no Ambiente) - Centro de Energia Nuclear na Agricultura da Universidade de São Paulo.

1. Celulose 2. Cultivo mínimo 3. Isótopos estáveis 4. Lignina 5. Nitrogênio 15 I. Título 
Aos meus pais,

José Fortes Reina e Clara Maria Raiza Fortes, pela minha criação, educação, carinho e incentivo durante toda minha vida;

À meus irmãos;

Camila e José Fernando e cunhados Marcelo e Erika, pelo convívio e apoio

Aos demais familiares,

Por fazerem parte da minha vida e formação pessoal.

OFEREÇO

À minha querida esposa Mirella Costa Cainelli Fortes,

Pelo amor, companheirismo e por tornar meus dias mais especiais. 



\section{AGRADECIMENTOS}

A Deus, pela vida, minha família, pelo conhecimento e pela inspiração nas horas mais necessárias e que foram mandatórias para a conclusão deste trabalho;

Ao CENA/USP em especial o prof. Dr. Paulo Cesar Ocheuze Trivelin pela amizade, pela estrutura necessária e oportunidade de orientação; aos técnicos do Laboratório de Isótopos Estáveis José A. Bonassi (Pingin), Hugo H. Batagello e Miguel L. Baldessin pelas análises laboratoriais de cinzas, C e N e a bibliotecáriachefe Marília R. G. Henyei pelo auxílio na revisão desta tese;

Ao pesquisador da Apta - Piracicaba, SP, Dr. André César Vitti, pelo auxílio na condução do experimento e correções desta tese e a equipe de pós-graduação do Prof. Trivelin, Rafael Otto, Henrique C. J. Franco, Emídio C. A. Oliveira, Raul H. Sartori e Eduardo Mariano também pela ajuda na condução do ensaio e pelo convívio destes anos;

Ao Centro de Tecnologia Canavieira - CTC onde já tive o privilégio de trabalhar e me capacitar, especialmente Claudimir P. Penatti, Célio Manechini, Carlos E. Faroni e José A. Forti pelo auxílio na concepção, instalação e condução do experimento durante todos estes anos;

Ao grupo São Martinho S.A. nas pessoas de Mario Gandini, Maurício S. Simões, Rene A. Sordi, Marcos Marcari, Luciano Graças, Sr. Vicente e a Turma 124 ("vou ali”) da Usina São Martinho pela disponibilização da área experimental e todos os outros recursos necessários na condução do experimento; Ivan B. Dalri e Paulo de A. e Silva da Usina Iracema pela liberação para este curso de PG e por ter sido meu "braço direito" durante o período que trabalhamos juntos, respectivamente;

Aos estagiários do CENA/USP, Cyntia C. Bonassi, Thiago A. Bonassi, Danilo A. Ferreira, Viviane C. Martins e Maria Stefânia D’Andréa pela ajuda na condução do ensaio de campo e processamento das amostras em laboratório; 
Aos pesquisadores Dr. Heitor Cantarella, Dra. Raffaella Rossetto e ao Prof Dr. Edgar F. de Beauclair pelas valiosas sugestões no exame de qualificação e para confecção deste trabalho;

Aos técnicos do Laboratório de Bromatologia e Nutrição Animal da UNESP de Botucatu, SP, Renato M. S. Diniz e Gisele Setznagl, pela flexibilidade proporcionada na determinação dos carboidratos estruturais apresentados neste trabalho;

Aos Eng. Agr. Gustavo S. Abrão da Mosaic e Erezil dos Santos da Heringer Fertilizantes, respectivamente, pelo histórico de preços de fertilizantes utilizado na análise econômica deste trabalho;

À FAPESP e ao CNPQ pelo auxílio financeiro para o projeto;

Enfim a todos que contribuíram diretamente e indiretamente para este trabalho e fizeram parte desta minha jornada. 
“... Eu sou o Senhor, o teu Deus, que te ensina o que é útil e te guia pelo caminho que deves andar"

Isaías 48:17 



\section{RESUMO}

\section{FORTES, C. Produtividade de cana-de-açúcar em função da adubação}

nitrogenada e da decomposição da palhada em ciclos consecutivos. 2010. 153 f. Tese (Doutorado) - Centro de Energia Nuclear na Agricultura, Universidade de São Paulo, Piracicaba, 2010.

Este trabalho objetivou relacionar a produtividade agroindustrial da cana-de-açúcar com o aproveitamento do nitrogênio $(\mathrm{N})$ das adubações sucessivas em cana-planta e soqueiras, em sistema de cultivo mínimo - sem o revolvimento do solo ou escarificações das entrelinhas na reforma do canavial ou após os cortes, respectivamente - e quantificar a contribuição da palhada proveniente da colheita mecanizada na nutrição da cultura. O experimento foi instalado em março de 2005, em um Latossolo Vermelho Eutrófico muito argiloso da Fazenda Santa Terezinha, Jaboticabal, SP e foi conduzido durante quatro ciclos agrícolas consecutivos até julho de 2009. O delineamento experimental na cana-planta foi blocos casualizados, com quatro tratamentos (doses de $\mathrm{N}$-uréia 0, 40, 80 e $120 \mathrm{~kg} \mathrm{ha}^{-1}$ no sulco de plantio, juntamente com $120 \mathrm{~kg} \mathrm{ha}^{-1}$ de $\mathrm{P}_{2} \mathrm{O}_{5}$ e $\mathrm{K}_{2} \mathrm{O}$ ) e quatro repetições (parcelas de 48 sulcos $\times 15 \mathrm{~m}$ ). Nos ciclos de $1^{\mathrm{a}}$ a $3^{\mathrm{a}}$ soqueiras, as parcelas de cana-planta foram subdivididas em outros quatro tratamentos $\left(0,50,100\right.$ e $150 \mathrm{~kg} \mathrm{ha}^{-1}$ de $\left.\mathrm{N}\right)$ e quatro repetições (subparcelas de 12 linhas $\times 15 \mathrm{~m}$ ). Na $3^{\mathrm{a}}$ soqueira a adubação $\operatorname{com} \mathrm{N}$ foi de $100 \mathrm{~kg} \mathrm{ha}^{-1}$ em todas as parcelas, visando detectar efeitos residuais das fertilizações anteriores na produtividade da cana no $4^{\circ}$ ciclo. Em todas as parcelas dos ciclos de soqueiras também aplicou-se $150 \mathrm{~kg} \mathrm{ha}^{-1}$ de $\mathrm{K}_{2} \mathrm{O}$ como $\mathrm{KCl}$. Na dose $80 \mathrm{~kg} \mathrm{ha}^{-1}$ de $\mathrm{N}$ em cana-planta, foram instaladas microparcelas contendo uréia e/ou material vegetal marcado com ${ }^{15} \mathrm{~N}$, simulando os resíduos anteriores à reforma (palhada, PAR ou rizomas, RAR da variedade RB855536) remanescentes no solo após o cultivo mínimo. O objetivo foi avaliar a contribuição do fertilizante- ${ }^{15} \mathrm{~N}$ e dos resíduos vegetais- ${ }^{15} \mathrm{~N}$ na nutrição nitrogenada da cultura em ciclos consecutivos. Após o corte da cana-planta, novas microparcelas contendo palhada pós colheita (PPC- ${ }^{15} \mathrm{~N}$, variedade SP81-3250) foram dispostas nos tratamentos 80-0 e 80-150 $\mathrm{kg} \mathrm{ha}^{-1}$ de $\mathrm{N}$ em cana-planta e soqueiras, respectivamente, para avaliar a contribuição do N-PPC na nutrição da cultura e a influência do $\mathrm{N}$ aplicado em soqueiras na disponibilização do N-PPC. Um estudo complementar foi desenvolvido em sacos telados contendo PAR- ${ }^{15} \mathrm{~N}$ em cana-planta (dose $80 \mathrm{~kg} \mathrm{ha}^{-1}$ de N) e PPC${ }^{15} \mathrm{~N}$ em soqueiras (doses $80-0$ e $80-150 \mathrm{~kg} \mathrm{ha}^{-1}$ de $\mathrm{N}$ ), visando quantificar a decomposição dos resíduos durante os ciclos agrícolas e possíveis diferenças na intensidade da decomposição devido às aplicações de $\mathrm{N}$ em cana-planta e em soqueiras respectivamente. Nos quatro ciclos consecutivos avaliou-se a: i) produtividade agroindustrial ( $\mathrm{TCH}, \mathrm{Mg}$ de cana ha ${ }^{-1}$ de colmos e $\mathrm{TPH}, \mathrm{Mg} \mathrm{ha}^{-1}$ de pol) e características tecnológicas da matéria-prima (pol \% cana e fibra \%) em função dos tratamentos de $\mathrm{N}$ em cana-planta e soqueiras; ii) recuperação do ${ }^{15} \mathrm{~N}$ uréia, ${ }^{15} \mathrm{~N}-\mathrm{PAR},{ }^{15} \mathrm{~N}-\mathrm{RAR}$ e ${ }^{15} \mathrm{~N}-\mathrm{PPC}$ pela parte aérea da cultura (colmos, folhas secas e ponteiro) e o balanço de carbono (C) e $\mathrm{N}$ no sistema solo-planta e iii) decomposição da PAR e PPC pela redução da matéria seca (MS), do C, 
macronutrientes ( $\mathrm{N}, \mathrm{P}, \mathrm{K}, \mathrm{Ca}, \mathrm{Mg}$ e $\mathrm{S}$ ) e carboidratos estruturais (lignina, celulose e hemicelulose). A TCH e TPH foram influenciadas pelas doses de $\mathrm{N}$ no plantio e nas soqueiras subseqüentes. Houve resposta linear na produtividade agroindustrial da cana-planta às doses de $\mathrm{N}$ do plantio e na média dos quatro ciclos agrícolas. Porém, não houve interação entre as doses de $\mathrm{N}$ em cana-planta e soqueiras. $\mathrm{O}$ tratamento 120-100 kg ha-1 de $\mathrm{N}$ em cana-planta e soqueiras proporcionou a maior $\mathrm{TCH}$ acumulada nos quatro ciclos consecutivos, porém o tratamento $120-50 \mathrm{~kg} \mathrm{ha}^{-1}$ de $\mathrm{N}$ foi o mais viável economicamente. A recuperação do $\mathrm{N}$-uréia de plantio foi mais alta no primeiro ciclo $\left(24,7 \mathrm{~kg} \mathrm{ha}^{-1}\right.$ ou $31 \%$ da dose aplicada) decrescendo ao longo ciclos agrícolas subsequentes (5\%; 4\% e 3\%, respectivamente). O balanço de $\mathrm{N}$ após os quatro ciclos (2006 a 2009) indicou 43\% (34,4 $\left.\mathrm{kg} \mathrm{ha}^{-1}\right)$ de recuperação do Nuréia pela parte aérea da cultura, $0,2 \%$ permaneceu nos rizomas, $20 \%$ no solo e $37 \%$ foram contabilizados como perdas. Para os resíduos vegetais PAR e RAR as recuperações na parte aérea foram de $28 \%$ e $23 \%$ da quantidade inicial (14,2 e 7,4 $\mathrm{kg} \mathrm{ha}^{-1}$, respectivamente). Em média, $0,2 \%$ do $\mathrm{N}$-resíduos vegetais permaneceu nos rizomas, $52 \%$ no solo e $22 \%$ foram perdas. A soma da recuperação do N-PAR e NRAR de foi de $24,4 \mathrm{~kg}$, ou seja, $39 \%$ da contribuição total de $\mathrm{N}$ destes resíduos, indicando serem fontes de $\mathrm{N}$ a longo prazo para a cana-de-açúcar. Houve correlação entre a recuperação acumulada do $\mathrm{N}$-uréia e $\mathrm{N}$-resíduos vegetais com a evapotranspiração acumulada dos quatro ciclos agrícolas. A recuperação do N-PPC pela parte aérea da cultura praticamente dobrou após três ciclos, devido à aplicação de $\mathrm{N}$ em soqueiras, $17 \%$ vs. $31 \%$ (6,9 e $12,6 \mathrm{~kg} \mathrm{ha}^{-1}$ de $\mathrm{N}$, respectivamente). $\mathrm{O}$ restante do N-PPC permaneceu nos rizomas ( $0,3 \%$ e $0,4 \%)$, no solo $(69 \%$ e $61 \%)$ ou resultaram em perdas (13,4\% e 7,6\%). Não houve alterações nos estoques de C e N do solo com a adição de $\mathrm{N}$-uréia ou $\mathrm{N}$-resíduos vegetais. A decomposição da PAR e PPC foi influenciada pelas aplicações de $\mathrm{N}$ em cana-planta e soqueiras e pela ação biológica ao longo dos ciclos agrícolas avaliados. Essa degradação ocorreu devido à redução da relação $\mathrm{C}: \mathrm{N}$, do crescimento de raízes sob a palhada, perdas de $\mathrm{MS}, \mathrm{C}$, $\mathrm{N}$, macronutrientes e carboidratos estruturais da palhada ao longo dos ciclos agrícolas. Para a PAR e PPC, a degradação da MS foi de $96 \%$ e $73 \%$ após quatro e três anos, respectivamente. Os macronutrientes que apresentaram maiores liberações foram o K 98\% e 92\%; Mg 97\% e 70\% e o Ca 95\% e 55\%, da quantidade inicial dos nutrientes $\left(\mathrm{kg} \mathrm{ha}^{-1}\right)$ aplicadas via PAR e PPC, respectivamente. Após quatro ciclos agrícolas os teores $\left(\mathrm{g} \mathrm{kg}^{-1}\right)$ de lignina, celulose e hemicelulose da PAR decresceram $60 \%, 29 \%$ e $70 \%$. Para a PPC a redução foi de $47 \%$, 35\% e $70 \%$ em três ciclos. A degradação dos carboidratos estruturais foi influenciada pelas condições climáticas ocorridas durante os ciclos agrícolas e pela composição bioquímica inicial dos resíduos (carboidratos e nutrientes totais). Não houve diferença na degradação da MS da PPC devido à aplicação de $\mathrm{N}$ em soqueiras, porém houve diferença na degradação do $C$, na liberação de $C a$, na concentração de raízes e na decomposição da lignina quando se realizou a adubação com $\mathrm{N}$ sobre a palhada em soqueiras.

Palavras-chave: Balanço de N. Resíduos vegetais. ${ }^{15} \mathrm{~N}$. Carbono. Celulose. Relação C:N. Cultivo mínimo. Sacos telados. Mineralização. 


\section{ABSTRACT}

FORTES, C. Sugarcane yield related to nitrogen fertilization and trash dcomposition in consecutive cropping cicles. 2010. 153 f. Tese (Doutorado) - Centro de Energia Nuclear na Agricultura, Universidade de São Paulo, Piracicaba, 2010.

This work aimed to relate the agroindustrial yield of sugarcane with nitrogen $(\mathrm{N})$ fertilization in successive cropping cycles in plant-cane and ratoons under minimum tillage system - without soil plowing or interows scarification in crop renewal and after the harvesting seasons, respectively - and to quantify the contribution of straw from mechanical harvesting on crop N nutrition. The field trial was planted in March 2005 in a very clayey Rhodic Eutrustox at Santa Terezinha Farm, Jaboticabal, Sao Paulo State and was conducted during four consecutive cropping cycles until July 2009. The plant-cane trial was designed as randomized blocks with four treatments ( $\mathrm{N}$-urea in increasing rates $0,40,80$ and $120 \mathrm{~kg} \mathrm{ha}^{-1}$ at planting added to $120 \mathrm{~kg} \mathrm{ha}^{-1} \mathrm{P}_{2} \mathrm{O}_{5}$ and $\mathrm{K}_{2} \mathrm{O}$ ) and four replicates (48 furrows of $15 \mathrm{~m}$ length). For the ratoon-cane trial, (1st to $3^{\text {rd }}$ ratoons) the plant-cane plots were subdivided into other four treatments $(0$, 50,100 and $150 \mathrm{~kg} \mathrm{ha}^{-1} \mathrm{~N}$ ) and four replicates (12 rows $\times 15 \mathrm{~m}$ ). The $\mathrm{N}$ fertilization of the $3^{\text {rd }}$ ratoon was leveled to $100 \mathrm{~kg} \mathrm{ha}^{-1}$ in all plots in order to detect residual effects of previous $\mathrm{N}$ fertilizations on sugarcane yield in this cycle. All ratoon cycles also received $150 \mathrm{~kg} \mathrm{ha}^{-1} \mathrm{~K}_{2} \mathrm{O}$ as $\mathrm{KCl}$. It has been installed microplots containing ${ }^{15} \mathrm{~N}$-urea and/or ${ }^{15} \mathrm{~N}$-labeled plant material at the $80 \mathrm{~kg} \mathrm{ha}^{-1} \mathrm{~N}$ dose in plant-cane, simulating the crop residues prior to renewal (trash PAR or rhizomes, RAR of RB855536 variety) and which remained in soil after minimum tillage. The objective was to assess the contribution of $\mathrm{N}$-fertilizer and $\mathrm{N}$-residues in sugarcane $\mathrm{N}$ nutrition in consecutive cycles. After the plant-cane harvesting, new microplots containing post harvest trash (PPC- ${ }^{15} \mathrm{~N}$, variety SP81-3250) were placed in treatments $80-0$ and 80$150 \mathrm{~kg} \mathrm{~N}$ ha $^{-1}$ in plant-cane and ratoons, respectively, aiming to assess the contribution of N-PPC in crop nutrition and the influence of $\mathrm{N}$ applied to ratoons in the N-PPC availability for sugarcane uptake. An additional study was conducted in litter bags containing PAR- ${ }^{15} \mathrm{~N}$ in plant-cane (dose $80 \mathrm{~kg} \mathrm{ha}^{-1} \mathrm{~N}$ ) and PPC- ${ }^{15} \mathrm{~N}$ in ratoons (doses 80-0 and 80-150 kg N ha ${ }^{-1}$ ) in order quantify the decomposition of trash during the crop cycles and possible differences in the decomposition rates due to $N$ applications in plant-cane (PAR) and ratoons (PPC), respectively. In the four consecutive cycles were evaluated: i) Agroindustrial yields $\left(\mathrm{TCH}, \mathrm{Mg}\right.$ cane ha ${ }^{-1}$ stalks and $\mathrm{TPH}, \mathrm{Mg} \mathrm{ha}^{-1}$ of sugar) and raw material quality (pol\% cane and fiber\%) in plantcane and ratoon treatments; ii) Recovery of urea- ${ }^{15} \mathrm{~N}$, PAR- ${ }^{15} \mathrm{~N},{ }^{15} \mathrm{~N}-\mathrm{RAR}$ and ${ }^{15} \mathrm{~N}-$ PPC by crop above ground parts (stalks, dry leaves and tips) and carbon (C) and N balances in the soil-plant system and iii) decomposition of PAR and PPC as reduction of dry matter (DM), C, nutrients ( $N, P, K, C a, M g$ and $S$ ) and structural carbohydrates (lignin cellulose and hemicellulose). The agroindustrial yields (TCH and $\mathrm{TPH}$ ) were influenced by $\mathrm{N}$ rates at planting and subsequent ratoons. It has been found linear response in crop yield due to $\mathrm{N}$ rates at planting and in the average of four crop cycles. However, no responses were detected in the interaction between 
$\mathrm{N}$ doses in plant or ratoon cane. The highest accumulated yield (TCH) in four consecutive cycles was obtained in treatment $120-100 \mathrm{~kg} \mathrm{ha}^{-1} \mathrm{~N}$ in plant-cane and ratoons, but treatment $120-50 \mathrm{~kg} \mathrm{ha}^{-1} \mathrm{~N}$ has been found as the more economically viable. The recovery of $\mathrm{N}$-urea applied in plant-cane was higher in the first cycle (24, $7 \mathrm{~kg} \mathrm{ha}^{-1}$ or $31 \%$ of the applied dose) and decreased over subsequent crop cycles (5\%, $4 \%$ and $3 \%$ respectively). The $\mathrm{N}$ balance after four cycles (2006-2009) showed $43 \%\left(34.4 \mathrm{~kg} \mathrm{ha}^{-1}\right)$ of total $\mathrm{N}$-urea recovery by the crop above ground parts, $0.2 \%$ was found in the rhizomes, $20 \%$ in soil and $37 \%$ were counted as losses. Cane trash $\mathrm{N}-\mathrm{PAR}$ and N-RAR recoveries in the above ground parts were $28 \%$ and $23 \%$ of the initial amount of $\mathrm{N}$ applied as crop residues (14.2 and $7.4 \mathrm{~kg} \mathrm{ha}^{-1}$, respectively). On average, $0.2 \%$ of $\mathrm{N}$-plant residues remained in the rhizomes, $52 \%$ in the soil and $22 \%$ were accounted as losses. The total recovery of N-PAR N-and RAR was 24.4 $\mathrm{kg}$, or $39 \%$ of the total $\mathrm{N}$ of these residues, indicating that they are long term $\mathrm{N}$ sources for the sugarcane crop. There had been found a close correlation between the cumulative recovery of $\mathrm{N}$-urea and $\mathrm{N}$-residues with the accumulated evapotranspiration of the four crop cycles. The N-PPC recovery by sugarcane above ground parts almost doubled after three cycles due to $\mathrm{N}$ application in ratoons, $17 \%$ vs. $31 \%$ (6.9 and $12.6 \mathrm{~kg} \mathrm{ha}^{-1} \mathrm{~N}$, respectively). In other compartments, $0.3 \%$ and $0.4 \%$ of N-PPC remained in the rhizomes, $69 \%$ and $61 \%$ ) in the soil and $13.4 \%$ and $7.6 \%$ ) resulted in losses. There was detected no major changes in soil $\mathrm{C}$ and $\mathrm{N}$ stocks $\mathrm{C}$ due to the addition of $\mathrm{N}$-urea and $\mathrm{N}$-residues. The decomposition of PAR and PPC was influenced by $\mathrm{N}$ fertilizations in plant-cane and ratoons cane and by biological action over the cropping cycles. The major effects detected as trash decomposed over the agricultural cycles were the reduction in residues $\mathrm{C}: \mathrm{N}$ ratio, sugarcane root growth under the trash blanket, and losses of DM, C, N, macronutrients and structural carbohydrates. The DM degradation of PAR and PPC was $96 \%$ and $73 \%$ after four and three years respectively. The nutrients that showed higher release rates were $\mathrm{K} 98 \%$ to $92 \%$, Mg $97 \%$ to $70 \% \mathrm{Ca}$ and $95 \%$ to $55 \%$ of the initial amount of nutrients $\left(\mathrm{kg} \mathrm{ha}^{-1}\right)$ sourced by PAR and PPC residues, respectively. After four agricultural cycles, the levels $\left(\mathrm{g} \mathrm{kg}^{-1}\right)$ of lignin, cellulose and hemicellulose from PAR decreased $60 \%, 29 \%$ and $70 \%$, and for PPC the reduction was $47 \%, 35 \%$ and $70 \%$ in three cycles. The degradation of structural carbohydrates was influenced by climatic conditions that occurred during the agricultural cycles and the initial biochemical composition those residues (total carbohydrates and nutrients content). There was no difference in DM degradation of PPC due to $\mathrm{N}$ application in ratoons, however there were differences in $\mathrm{C}$ degradation, in the release of $\mathrm{Ca}$, concentration of roots and in the decomposition of lignin when $\mathrm{N}$ - fertilizer has been applied over the trash blanket.

Keywords: N Balance. Crop residues. ${ }^{15} \mathrm{~N}$. Carbon. Cellulose. C:N ratio. Minimum tillage. Litter bags. Mineralization. 
1 INTRODUÇÃO. 15

2 PRODUTIVIDADE AGROINDUSTRIAL DE CANA-DE-AÇÚCAR EM FUNÇÃO DA ADUBAÇÃO NITROGENADA DE PLANTIO E SOQUEIRAS ……......................................... 21

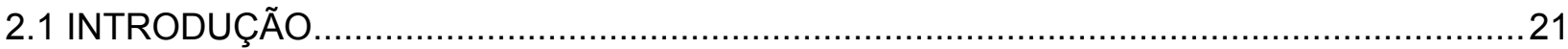

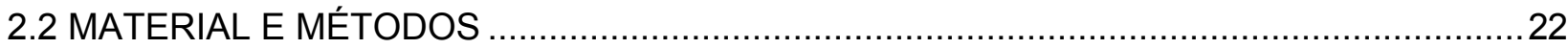

2.2.1 Localização, delineamento experimental e instalação do experimento..............................22

2.2.2 Colheita das parcelas, análises tecnológicas e balanços hídricos do experimento ............26

2.2.3 Análises estatísticas e econômicas dos tratamentos de $\mathrm{N}$ em cana-planta e soqueiras

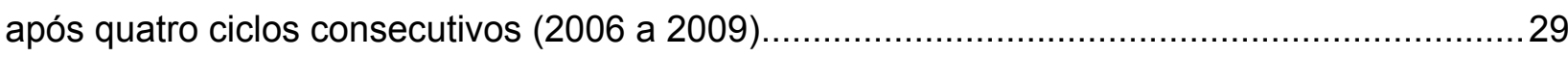

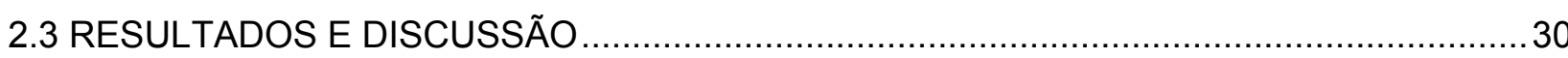

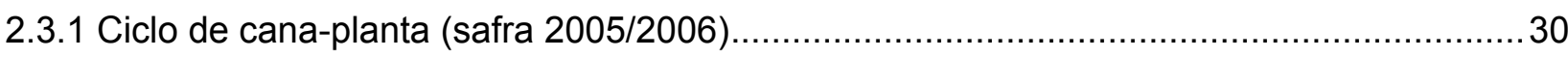

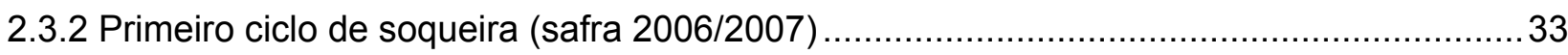

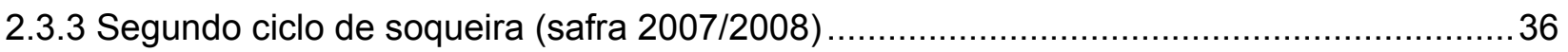

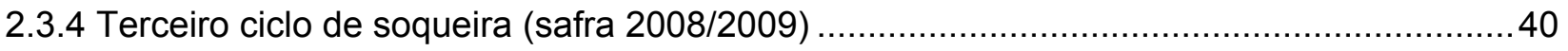

2.3.5 Produtividade agroindustrial média e acumulada de cana-de-açúcar em quatro ciclos

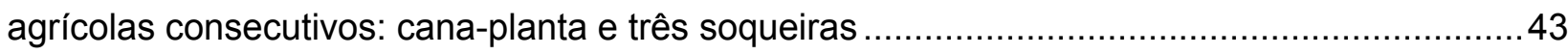

2.3.6 Análise econômica dos tratamentos aplicados em cana-planta e soqueiras após quatro

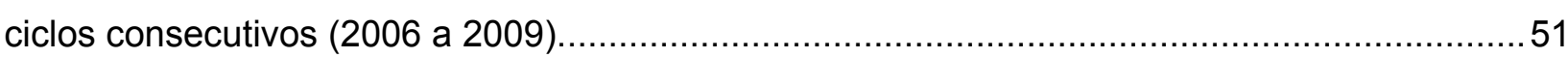

2.4 CONCLUSÕES.

3 RECUPERAÇÃO DO N DA URÉIA E DE RESÍDUOS CULTURAIS PELA CANA-DEAÇÚCAR E BALANÇO DE CARBONO E NITROGÊNIO NO SISTEMA SOLO-PLANTA EM

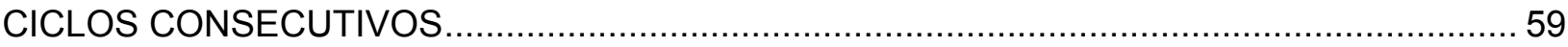

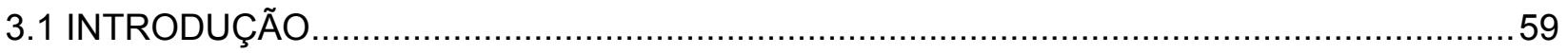

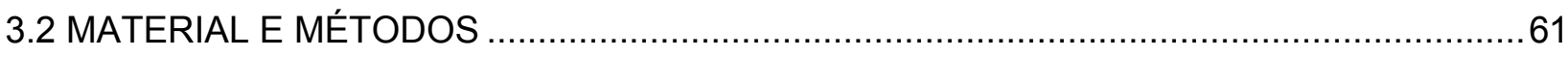

3.2.1 Localização do experimento, obtenção dos materiais marcados com ${ }^{15} \mathrm{~N}$ e instalação

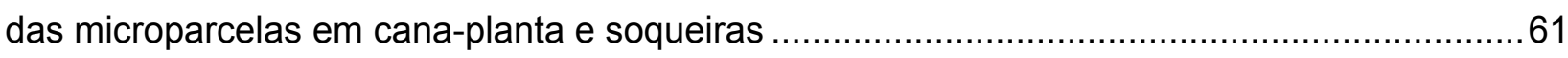

3.2.2 Colheita das microparcelas, processamento das amostras e análises laboratoriais .........66

3.2.3 Cálculos de recuperação de ${ }^{15} \mathrm{~N}$ e análises estatísticas.................................................67

3.2.4 Cálculos do balanço de carbono e nitrogênio no sistema solo-planta após ciclos

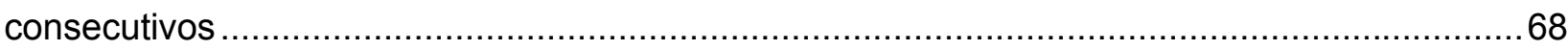

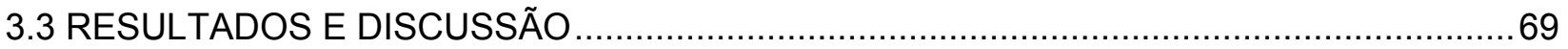

3.3.1 Recuperação do $\mathrm{N}$ da uréia do plantio, palhada e rizomas anteriores à reforma (PAR palhada e RAR - rizomas) após quatro ciclos consecutivos (2006 a 2009) .. 
3.3.2 Recuperação pela cana-de-açúcar do $\mathrm{N}$ de palhada pós colheita (PPC) nos tratamentos com doses de N $80-0$ e $80-150 \mathrm{~kg} \mathrm{ha}^{-1}$ em cana-planta e soqueiras respectivamente, em três ciclos agrícolas consecutivos (2007 a 2009).

3.3.3 Balanço de nitrogênio no sistema solo-planta e estoque de carbono e nitrogênio no solo após quatro ciclos consecutivos

3.4 CONCLUSÕES

4 DECOMPOSIÇÃO DA PALHADA DE CANA-DE-AÇÚCAR EM CICLOS AGRÍCOLAS CONSECUTIVOS DE COLHEITA SEM QUEIMA ............................................................... 93

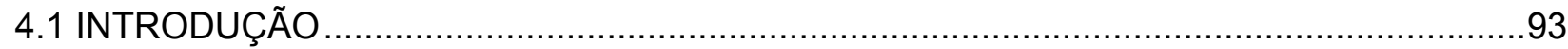

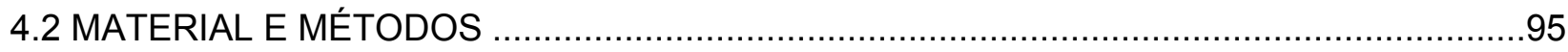

4.2.1 Localização, delineamento experimental e instalação de sacos telados..........................95

4.2.2 Colheita, processamento das amostras e análises em laboratório ...............................97

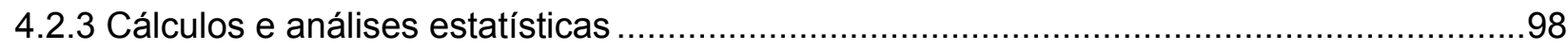

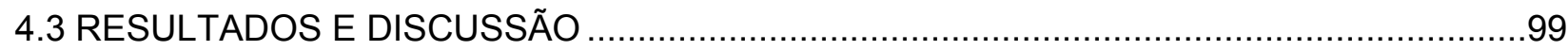

4.3.1 Degradação da palhada anterior à reforma $\left(P A R-{ }^{15} \mathrm{~N}\right)$ em função de doses de $\mathrm{N}$ em cana-planta $\left(0,40,80,120 \mathrm{~kg} \mathrm{ha}^{-1}\right.$ de $\left.\mathrm{N}\right)$

4.3.2 Degradação da palhada anterior à reforma $\left(P A R-{ }^{15} \mathrm{~N}\right)$ no tratamento $80-0 \mathrm{~kg} \mathrm{ha}^{-1} \mathrm{de}$ $\mathrm{N}$ em cana-planta e soqueiras, respectivamente, por quatro ciclos agrícolas consecutivos (2005 a 2008)

4.3.3 Degradação da palhada pós colheita $\left(P P C-{ }^{15} \mathrm{~N}\right)$ no tratamento $80-0 \mathrm{~kg} \mathrm{ha}^{-1}$ de $\mathrm{N} \mathrm{em}$ cana-planta e soqueiras, respectivamente e após três ciclos agrícolas consecutivos

4.3.4 Degradação da palhada pós-colheita $\left(P P C-{ }^{15} \mathrm{~N}\right)$ nos tratamentos $80-0$ e $80-150 \mathrm{~kg}$ ha $^{-1}$ de $\mathrm{N}$ em cana-planta e soqueiras, respectivamente, após três ciclos agrícolas consecutivos

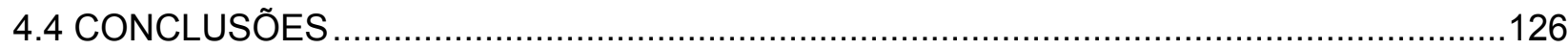

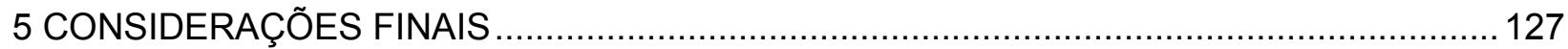

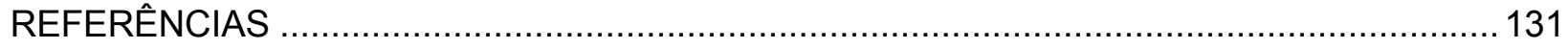

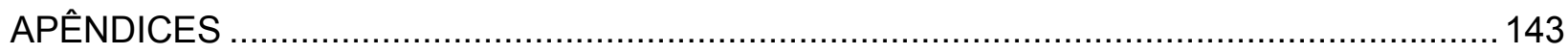




\section{INTRODUÇÃO}

O Brasil é o maior produtor mundial de cana-de-açúcar com aproximadamente 8,5 milhões de hectares e, nas últimas cinco safras, a produção média foi de 450 milhões de toneladas de colmos, 30 milhões de toneladas de açúcar e 20 milhões de metros cúbicos de álcool (BRASIL, 2009).

Mais do que os produtos finais álcool e açúcar, a cana-de-açúcar também é fonte de biomassa para geração de energia elétrica em complemento à hidroeletricidade no inverno, ou seja, o período mais seco do ano (CGEE, 2009) e contribui significativamente para a redução das emissões atmosféricas de gases dos efeito estufa (GEE) $\mathrm{CO}_{2}, \mathrm{CH}_{4}, \mathrm{NO}, \mathrm{NO}_{2}$ e $\mathrm{N}_{2} \mathrm{O}$ devido ao seqüestro de carbono e reciclagem nutrientes no solo, principalmente quando a cultura é colhida mecanicamente e sem despalha à fogo (GRAHAM, HAYNES; MEYER, 2002; HEMWONG et al., 2009; MACEDO; SEABRA; SILVA, 2008; TRIVELIN et al., 2002a).

Além destes benefícios, a colheita mecanizada de cana crua apresenta menor custo unitário se comparado à colheita manual queimada e visa atender a legislação vigente (lei 11.241/2002 do Estado de São Paulo) promulgada devido a grande área explorada pela cultura neste estado e pelos problemas de saúde pública gerados pela emissão de partículas quando se queima a palhada (CANÇADO et al., 2006; SOUZA et al., 2005).

A racionalização do uso de fertilizantes e maquinários, aliado à práticas agrícolas modernas como o cultivo mínimo, apresentam benefícios para a sustentabilidade a longo prazo e para o balanço energético da cadeia produtiva dessa cultura, devido ao menor consumo de combustíveis fósseis e menores custos de produção (SILVA, 2010), menor velocidade de oxidação da matéria orgânica (GRAHAM; HAYNES; MEYER, 2002), maior controle da erosão (WOOD, 1991) e menor acidificação do solo e eutrofização de corpos d'água (LIU et al., 2010).

O cultivo mínimo é um sistema de preparo de solo conservacionista, isto é, preserva parte dos resíduos culturais deixados na superfície do solo na ocasião da reforma da cultura, especialmente em sistema de colheita sem a queima da palhada (PLANALSUCAR, 1985; TRIVELIN et al., 2002b).

O nitrogênio $(N)$ é um elemento essencial para a produção vegetal e a absorção deste nutriente pela cana-de-açúcar varia de 100 a $300 \mathrm{~kg} \mathrm{ha}^{-1}$ para a 
produção de $100 \mathrm{Mg} \mathrm{ha}^{-1}$ de colmos (BALL-COELHO et al., 1993; CANTARELLA; TRIVELIN; VITTI, 2007; GAVA et al., 2005; ROBERTSON; THORBURN, 2007b; TRIVELIN; RODRIGUES; VICTORIA, 1996). Apesar de sua essencialidade aos vegetais, o $\mathrm{N}$ apresenta alto potencial poluente de corpos d'água e da atmosfera, se não for utilizado adequadamente na agricultura (GALDOS; CERRI; CERRI, 2009; LIU et al., 2010).

Modelos globais sugerem que a recuperação do $\mathrm{N}$ aplicado na agricultura é da ordem de $55 \%$, sendo $35 \%$ nos produtos colhidos e $20 \%$ nos restos culturais, porém estes últimos ainda são pouco utilizados na reciclagem de nutrientes em países em desenvolvimento (LIU et al., 2010). Dessa forma, o manejo da adubação nitrogenada é um desafio que vai além da reposição das necessidades das culturas e deve levar em consideração os impactos agronômicos, econômicos e ambientais que os fertilizantes minerais e os resíduos vegetais podem causar no ambiente, bem como o balanço de carbono e demais nutrientes no sistema solo-planta-atmosfera (LIU et al., 2010; MALAVOLTA, 1994).

Além da matéria orgânica do solo que, após a mineralização por ação dos microrganismos, fornece a maior parte do $\mathrm{N}$ utilizado pelos vegetais (BASANTA et al., 2003; GRAHAM; HAYNES; MEYER, 2002), dos fertilizantes nitrogenados e do N da palhada remanescente da colheita realizada sem queima (TRIVELIN et al., $2002 b$ ), existem outras fontes do nutriente para a cana-de-açúcar como o colmosemente do plantio (CARNEIRO; TRIVELIN; VICTORIA, 1995), os rizomas e sistema radicular das soqueiras (VITTI et al., 2007) e a fixação biológica de $\mathrm{N}$ por microrganismos em associação com a cana-de-açúcar (BODDEY et al., 2003).

A cana-de-açúcar é uma cultura semi-perene, porém é comum que seja considerada uma cultura anual em trabalhos científicos, ou seja, os efeitos das adubações e outros tratamentos são avaliados em somente um ano agrícola.

Com o intuito de avaliar o efeito cumulativo de adubações com diferentes fontes e doses de N na produtividade da cana-de-açúcar, Orlando Filho et al. (1999) mantiveram as parcelas experimentais no campo por quatro anos consecutivos. Concluíram que para a cana-planta, primeira e terceira soqueiras a resposta foi linear para as doses de $\mathrm{N}$, independente das fontes e modo de aplicação. $\mathrm{Na}$ segunda soqueira, o efeito positivo das doses de $\mathrm{N}$ foi influenciado pelas fontes $\mathrm{e}$ modo de aplicação. 
Sabe-se que a recuperação do $\mathrm{N}$ proveniente de fertilizantes minerais pela cana-de-açúcar é relativamente baixa, de 10 a $50 \%$ da dose de $\mathrm{N}$ aplicada, como indicam diversos trabalhos utilizando técnicas com traçador isotópico ${ }^{15} \mathrm{~N}$ (BASANTA et al., 2003; CHAPMAN, HAYSON; SAFFIGNA, 1994; GAVA et al., 2005; TRIVELIN; RODRIGUES; VICTORIA, 1996; VITTI et al., 2007; WOOD, 1991). Recuperações inferiores a $6 \%$ foram relatadas por Meier et al. (2006) devido aos intensos regimes pluviométricos encontrados pelos autores (acima de $2.000 \mathrm{~mm} \mathrm{ano}^{-1}$ ).

Deve-se destacar que, apesar do reduzido aproveitamento do $\mathrm{N}$ de fertilizantes pela cana-de-açúcar, não se deve descartar o uso dos mesmos na cultura. Franco et al. (2010) verificaram que a contribuição do $\mathrm{N}$ proveniente do fertilizante durante o ciclo de soqueiras de cana-de-açúcar foi da ordem de $70 \%$ do $\mathrm{N}$-total absorvido pela cultura nos estágios inicias de crescimento, decrescendo para valores da ordem $30 \%$ nos estágios finais, devido a maior absorção do $\mathrm{N}$ nativo do solo. Concluíram que, embora as avaliações de recuperação do $\mathrm{N}$ com uso de ${ }^{15} \mathrm{~N}$ fertilizantes em cana-de-açúcar são realizadas geralmente no fim do ciclo da cultura, a importância do uso de fertilizantes nitrogenados está no aproveitamento do nutriente no início do ciclo agrícola, quando o fornecimento de $\mathrm{N}$ pelo solo não atende as exigências da cultura.

Por outro lado, é comprovado que a quantidade de resíduos vegetais provenientes da colheita de cana sem queima varia entre 10 a $20 \mathrm{Mg} \mathrm{ha}^{-1} \mathrm{ano}^{-1} \mathrm{de}$ material seco que permanece no solo após as colheitas. Isso corresponde a adição de 40 a $80 \mathrm{~kg}$ de $\mathrm{N} \mathrm{ha}^{-1}$ (BALL-COELHO et al., 1993; ABRAMO FILHO, 1995; TRIVELIN; RODRIGUES; VICTORIA., 1996; TUFAILE NETO, 2005), além de aumentar a quantidade de matéria orgânica (WOOD, 1991; GRAHAM; HAYNES; MEYER, 2002) e os teores de macronutrientes no solo (MEIER et al., 2006; OLIVEIRA et al., 2002). Porém, a contribuição destes resíduos na nutrição da cultura geralmente não é considerada no manejo da adubação nos ciclos agrícolas subsequentes (VITTI et al., 2007).

A palhada de cana-de-açúcar contém em média de 390 a $450 \mathrm{~g} \mathrm{~kg}^{-1}$ de carbono (C) e 4,6 a $6,5 \mathrm{~g} \mathrm{~kg}^{-1}$ de nitrogênio $(N)$, ou seja, uma relação $C: N$ de aproximadamente 100:1 (MEIER et al., 2006; NG KEE KWONG et al., 1987; OLIVEIRA et al., 1999; 2002; ROBERTSON; THORBURN, 2007b; SPAIN; HODGEN, 1994). Quando esta relação é superior a 20:1, é esperado que ocorra imobilização do $\mathrm{N}$ pelos microrganismos do solo e conseqüentemente haja uma 
baixa mineralização da matéria orgânica no período de um ciclo agrícola (ABRAMO FILHO, 1995; BASANTA et al., 2003; GALDOS et al., 2009b; GAVA et al., 2005; TRIVELIN et al., 2002b).

Estudos utilizando técnicas isotópicas $\operatorname{com}{ }^{15} \mathrm{~N}$ também indicam que a contribuição da palhada na nutrição de cana-de-açúcar é bastante limitada quando se considera somente um ano agrícola, de $5 \%$ a $30 \%$, portanto é esperado um efeito de médio a longo prazo deste aporte de $\mathrm{N}$ para ciclos subseqüentes (MEIER et al., 2006; NG KEE KWONG et al., 1987; OLIVEIRA et al., 2002; VITTI et al., 2007; 2008b). Deve-se ressaltar que esta contribuição pode estar subestimada devido ao desenvolvimento de raízes junto à palhada de cana-de-açúcar, acarretando um efeito de diluição quando se usa técnicas isotópicas (VITTI, 2003; VITTI et al., 2008a).

A mineralização de resíduos agrícolas da parte aérea ou dos órgãos subterrâneos depende de sua composição bioquímica, ou seja, dos teores totais de C, N e nutrientes, da relação C:N (ABRAMO FILHO, 1995; HEMWONG et al., 2009; MEIER et al., 2006; NG KEE KWONG et al., 1987), teores de lignina, celulose, hemicelulose e polifenóis (AUSTIN; BALLARÉ, 2010; JENSEN et al., 2005; PAULY; KEEGSTRA, 2008), além de fatores ambientais como latitude e temperatura (GONÇALVES et al., 2010; ZHANG et al., 2008), evapotranspiração (ROBERTSON; THORBURN, 2007a), umidade, aeração e temperatura do solo (BALL-COELHO et al., 1993; SOUZA et al., 2005) e a localização e contato destes resíduos com microbiota do solo (ABIVEN et al., 2005; SANOMIYA et al., 2006; SINGH et al., 2008).

Diante do exposto, fica evidente a importância de se quantificar os efeitos das sucessivas adubações da cultura com N, a taxa de decomposição dos resíduos culturais provenientes da colheita mecanizada de cana sem despalha a fogo e sua relação com a nutrição da cultura à longo prazo.

Com base no conhecimento atual sobre o assunto deste trabalho, podem ser levantadas as seguintes hipóteses: (a) a adição de $\mathrm{N}$ mineral ao solo aumenta a produtividade da cultura e, considerando a cana-de-açúcar é semi-perene, a produtividade deve ser avaliada pela produção cumulativa em ciclos sucessivos e não somente em um ano agrícola; (b) o efeito residual da adubação e dos resíduos culturais presentes no solo em cultivo mínimo devem ter relação com a produtividade nos ciclos subseqüentes; (c) o uso de fertilizantes minerais e o crescimento de 
raízes sob a palhada deverão acelerar a mineralização desses resíduos vegetais, pela diminuição da relação $\mathrm{C}: \mathrm{N}$, contribuindo para a nutrição da cultura; (d) os resíduos vegetais incorporados superficialmente ao solo na reforma do canavial sob cultivo mínimo e deixados na superfície em pós-colheita, influirão a longo prazo na produtividade agroindustrial da cana-de-açúcar, devido ao aporte de nutrientes e alterações nas propriedades físicas e biológicas do solo.

Os objetivos do trabalho foram:

- Avaliar as respostas em produtividade da cana-de-açúcar colhida sem queima da palhada à fertilização nitrogenada de cana-planta e em soqueiras subsequentes no sistema de cultivo mínimo;

- Quantificar o aproveitamento do nitrogênio da uréia e de resíduos culturais (palhada ou rizomas anteriores à reforma, PAR e RAR e palhada pós colheita, PPC, respectivamente) no sistema solo-planta por meio de técnicas isotópicas com o traçador ${ }^{15} \mathrm{~N}$;

- Avaliar a dinâmica de decomposição dos resíduos vegetais de cana-de-açúcar palhada e rizomas anteriores à reforma (PAR, RAR) e palhada pós colheita (PPC), quanto sua composição química (carbono, nitrogênio, macronutrientes, lignina, celulose e hemicelulose) e a contribuição destes diferentes componentes orgânicos na nutrição da cultura.

Nesta tese foram abordados os resultados de um experimento conduzido na Usina São Martinho, em área de cultivo comercial de cana-de-açúcar localizada no município de Jaboticabal, SP, em um Latossolo Vermelho Eutrófico muito argiloso, em três capítulos, a saber:

1 Produtividade agroindustrial de cana-de-açúcar em função da adubação nitrogenada de plantio e soqueiras

2 Recuperação do $\mathrm{N}$ da uréia e de resíduos culturais pela cana-de-açúcar e balanço de carbono e nitrogênio no sistema solo-planta em ciclos consecutivos

3 Decomposição da palhada de cana-de-açúcar em ciclos agrícolas consecutivos de colheita sem queima 

2 PRODUTIVIDADE AGROINDUSTRIAL DE CANA-DE-AÇÚCAR EM FUNÇÃO DA ADUBAÇÃO NITROGENADA DE PLANTIO E SOQUEIRAS

\subsection{INTRODUÇÃO}

A obrigatoriedade de colheita da cana-de-açúcar sem a queima da palhada aliada aos custos crescentes de produção torna imprescindível a adoção de novas tecnologias no manejo agrícola desta cultura, como métodos de preparo de solo com menor mobilização do solo e consumo de combustível e no uso racional de fertilizantes (SOUZA et al., 2005; ROSSETTO et al., 2010).

O nitrogênio $(N)$ é um elemento essencial para a produção vegetal e, para uma produção de $100 \mathrm{Mg} \mathrm{ha}^{-1}$ de colmos, a absorção deste nutriente pela cana-deaçúcar varia de 100 a $300 \mathrm{~kg} \mathrm{ha}^{-1}$ (COLETTI et al., 2006; ROBERTSON; THORBURN, 2007b; TRIVELIN et al., 2002b). A cana-de-açúcar é uma cultura semiperene embora na literatura sejam comuns resultados considerando os efeitos das adubações em somente em um ano agrícola. São poucos os trabalhos como o de Basanta et al. (2003), Orlando Filho et al. (1999) e Vitti et al. (2007) que mantiveram as parcelas experimentais mais de um ciclo agrícola no campo com o intuito de avaliar o efeito cumulativo de adubações com $\mathrm{N}$ na produtividade (TCH e TPH) da cana-planta e soqueiras. De maneira geral, estes autores obtiveram respostas significativas na produtividade da cultura e ressaltaram efeitos residuais de aplicações de $\mathrm{N}$ em ciclos subseqüentes.

As adubações nitrogenadas de plantio e soqueiras de cana-de-açúcar promovem o crescimento de raízes e a formação de um estoque nutricional na parte subterrânea da cultura, com influência na produtividade dos cortes subseqüentes. Além do efeito residual de sucessivas adubações na cultura, é sabido que a palhada proveniente da colheita mecanizada sem despalha a fogo constitui um aporte significativo de carbono e nutrientes para a cultura, influenciando na produtividade agroindustrial (TRIVELIN et al., 2002b), longevidade da cultura (VITTI et al., 2007), aumento da atividade biológica (GRAHAM; HAYNES; MEYER, 2002) e infiltração de água no solo (SOUZA et al., 2005). O objetivo deste estudo foi o de avaliar a produtividade agroindustrial de cana-de-açúcar colhida sem a queima da palhada em função das adubações nitrogenadas de plantio e soqueiras, durante quatro ciclos agrícolas consecutivos (2006 a 2009). 


\subsection{MATERIAL E MÉTODOS}

2.2.1 Localização, delineamento experimental e instalação do experimento

O experimento foi instalado na Fazenda Santa Terezinha, propriedade da Usina São Martinho (Latitude $21^{\circ} 17^{\prime} 20^{\prime \prime} \mathrm{S}$, Longitude 48 $12^{\prime} 30^{\prime \prime} \mathrm{O}$ ), com altitude predominante na região de $580 \mathrm{~m}$, precipitação e temperatura média anual de 1.450 $\mathrm{mm}$ e $23^{\circ} \mathrm{C}$, respectivamente (clima Aw, na classificação de Köppen) (ROLIM et al., 2007). O experimento foi conduzido de março de 2005 a julho de 2009, ou seja, durante quatro ciclos agrícolas consecutivos.

O solo do local é um Latossolo Vermelho Eutrófico, textura muito argilosa, LVe (EMBRAPA, 2006) em relevo suave ondulado e sem histórico de doenças ou pragas de solo e/ou aplicações de resíduos agroindustriais, onde se colheu a variedade RB855536 durante sete anos sem a queima da palhada anteriormente à implantação do experimento.

O sistema de preparo de solo adotado foi o cultivo mínimo, ou seja, dessecação da soqueira anterior com herbicida e uma subsolagem em sequência (PLANALSUCAR, 1985). Este tipo de manejo, sem o revolvimento e a incorporação dos resíduos culturais que acontecem no preparo de solo convencional foi uma premissa adotada para que fosse mantida parte da cobertura do solo pela soqueira dessecada (parte aérea, raízes e rizomas) e palhada do ciclo agrícola anterior sem grande incorporação.

Antes da instalação do experimento foram realizadas amostragens do solo para caracterização dos atributos físicos e químicos e, para aferir a profundidade da subsolagem, realizou-se um levantamento de densidade ao longo do perfil do solo. A avaliação da densidade do solo foi realizada segundo Bellinaso et al. (1994) e a caracterização granulométrica e química segundo Raij et al. (2001) (Tabela 1).

O plantio ocorreu em 2 de março de 2005, procedendo-se a sulcação tratorizada (implemento de 3 linhas) com espaçamento de 1,5 m entrelinhas de cana e aplicação de $600 \mathrm{~kg} \mathrm{ha}^{-1}$ da fórmula 00-20-20, ou seja, 0:120:120 kg ha-1 de $\mathrm{N}: \mathrm{P}_{2} \mathrm{O}_{5}: \mathrm{K}_{2} \mathrm{O}$, respectivamente (ESPIRONELLO et al., 1996). 
Tabela 1 - Caracterização granulométrica, física e química do solo LVe (Fazenda Santa Terezinha, Usina São Martinho) em Jaboticabal, SP (Fevereiro de 2004)

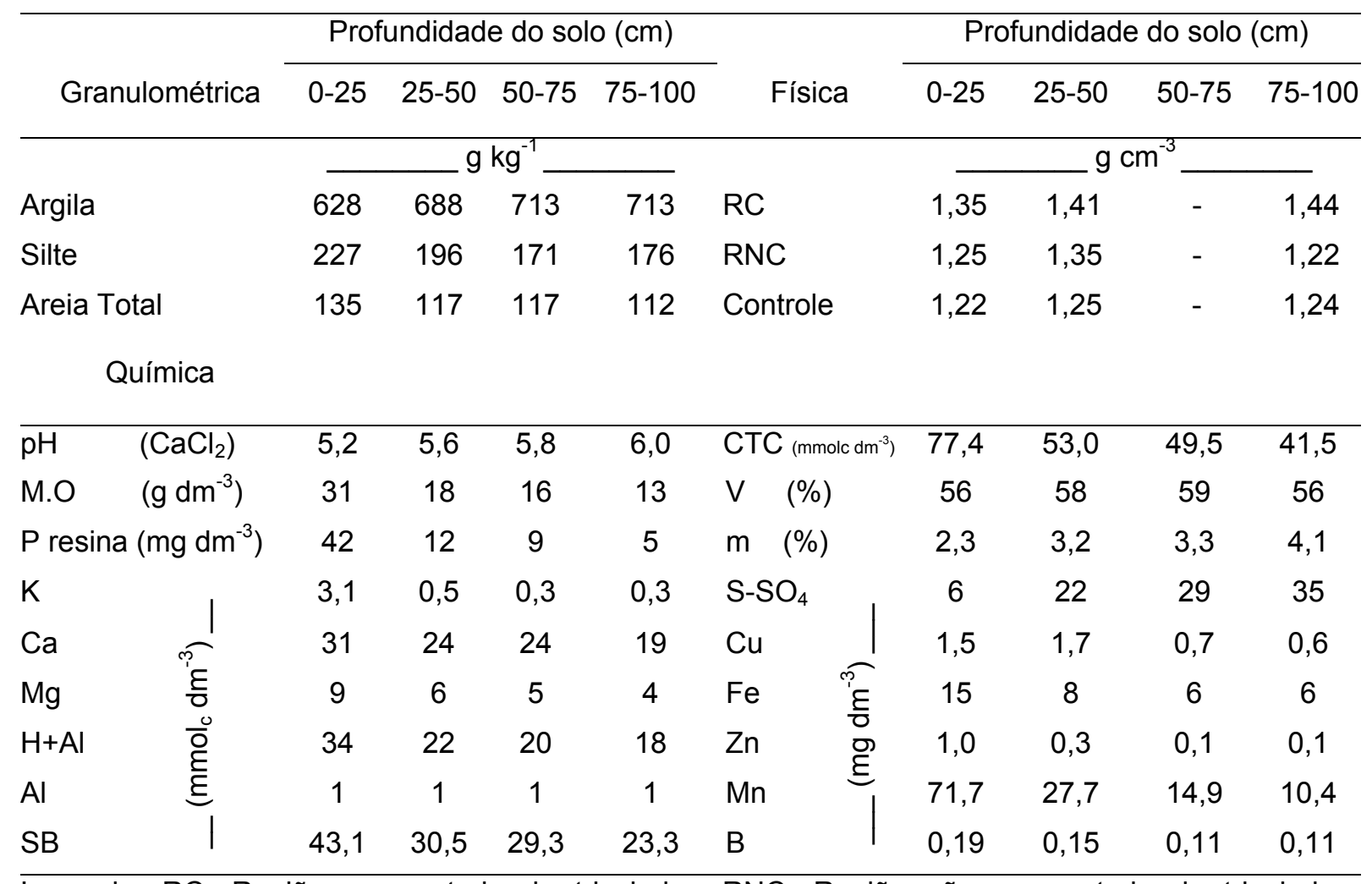

Legenda: RC: Região compactada da trincheira; RNC: Região não compactada da trincheira; Controle: região do perfil abaixo da região de compactação; pH CaCl2, M.O, K, P, Ca, Mg, H+Al, B, $\mathrm{Cu}, \mathrm{Fe}, \mathrm{Mn}, \mathrm{Zn}$ (Raij et al., 2001); S (Vitti, 1988). Fonte: Adaptado de Trivelin (2005)

O delineamento experimental utilizado na cana-planta foi o de blocos casualizados com quatro repetições (parcelas de 48 sulcos de 15 metros). Os tratamentos foram doses de $\mathrm{N}$-uréia 0 (testemunha), 40, 80 e $120 \mathrm{~kg} \mathrm{ha}^{-1}$ de $\mathrm{N}$, aplicadas manualmente no fundo do sulco de plantio e posteriormente cobertos com terra com o auxílio de enxadas, antes da distribuição das mudas de cana do plantio (TRIVELIN, 2005).

O cultivar de cana-de-açúcar utilizado foi o SP81-3250 (CP70-1547 x SP711279) de maturação média e boa brotação de soqueira sob palhada (COPERSUCAR, 1995). A escolha deste cultivar deveu-se a sua alta produtividade agroindustrial e sua utilização em estudos anteriores (VITTI, 2003; VITTI et al., 2007), bem como em outras duas áreas do Projeto Temático da Fapesp $n^{\circ}$. 2002/10.534-8 intitulado "Rendimento da cana-de-açúcar em ciclos consecutivos associado ao efeito residual e às transformações de $\mathrm{N}$ e $\mathrm{S}$ no solo, em sistema 
conservacionista", no qual o presente estudo se inseriu (FARONI, 2008; FRANCO, 2008). Isso foi conveniente nas comparações de resultados das pesquisas do projeto com outros da literatura. No Estado de São Paulo e no Centro-Sul do Brasil, a SP81-3250 representa 13\% de toda área cultivada, respectivamente (CHAPOLA et al., 2010).

O cultivar SP81-3250 pode apresentar alguns inconvenientes agroindustriais, como alta susceptibilidade à cigarrinha das raízes (Mahanarva fimbriolata), devido sua alta produção de palhada (DINARDO-MIRANDA; FERREIRA; CARVALHO, 2001) e florescimento/isoporização intensos em latitudes baixas do Norte-Nordeste e Centro-Oeste do Brasil ou em locais com condições climáticas favoráveis (COPERSUCAR, 1995).

Utilizou-se uma população de 15 a 20 gemas viáveis por metro de sulco de plantio e o consumo de mudas foi de $14,8 \mathrm{Mg} \mathrm{ha}^{-1}\left(3,8 \mathrm{Mg} \mathrm{ha}^{-1}\right.$ de material seco, MS). Foram adicionados ao sistema via colmos-semente 8,$3 ; 1,5 ; 9,0 ; 2,4 ; 2,2 ; 1,7$ $\mathrm{kg} \mathrm{ha}^{-1}$ de N, P, K, Ca, Mg e S, respectivamente (TRIVELIN, 2005). A quantidade de MS e macronutrientes dos colmos-sementes utilizados no plantio do experimento constam da Tabela 2.

Após a aplicação dos tratamentos de $\mathrm{N}$-uréia em cana-planta e esparramação das mudas, completou-se o plantio da área com cobridor mecânico tratorizado. $\mathrm{O}$ controle das ervas daninhas foi realizado em abril de 2005 por meio de capina manual.

Tabela 2 - Massa verde, massa seca e conteúdo de nutrientes de colmos-semente do plantio do experimento na Usina São Martinho (variedade SP813250, março de 2005), em Jaboticabal, SP

\begin{tabular}{|c|c|c|c|c|c|c|c|c|c|c|c|c|}
\hline $\begin{array}{c}\text { Massa } \\
\text { verde }\end{array}$ & $\begin{array}{c}\text { Massa } \\
\text { seca }\end{array}$ & $\mathrm{N}$ & $\mathrm{K}$ & $P$ & $\mathrm{Ca}$ & $\mathrm{Mg}$ & $S$ & B & $\mathrm{Cu}$ & $\mathrm{Fe}$ & $\mathrm{Mn}$ & $\mathrm{Zn}$ \\
\hline \multicolumn{2}{|c|}{$\mathrm{kg}^{\mathrm{n}}$} & \multicolumn{6}{|c|}{$-\mathrm{g} \mathrm{kg}^{-1}$} & \multicolumn{5}{|c|}{$\mathrm{mg} \mathrm{kg}^{-1}$} \\
\hline 11,1 & 2,8 & 2,2 & 2,4 & 0,4 & 0,6 & 0,6 & 0,5 & 3,6 & 1,8 & 123 & 26,6 & 3,4 \\
\hline \multicolumn{2}{|c|}{$\mathrm{Mg} \mathrm{ha}^{-1}$} & \multicolumn{6}{|c|}{$\mathrm{kg} \mathrm{ha}^{-1}$} & \multicolumn{5}{|c|}{$\mathrm{g} \mathrm{ha}^{-1}$} \\
\hline 14,8 & 3,8 & 8,3 & 9,0 & 1,5 & 2,4 & 2,2 & 1,7 & 13,6 & 6,8 & 467 & 101 & 14,1 \\
\hline
\end{tabular}


Nesse mesmo período fez-se o replantio de falhas que apareceram devido à ocorrência da doença podridão abacaxi (Ceratocystis paradoxa). Foram consideradas falhas, espaços maiores que 0,50 metros sem a presença de touceiras de cana nas linhas das parcelas (STOLF, 1986). No replantio foram usados toletes de mudas tratadas com imersão fungicida Propiconazole $(10 \mathrm{~mL}$ produto comercial $100 \mathrm{~L}^{-1}$ de calda). Logo após o replantio foi aplicada uma lâmina de irrigação de 20 $\mathrm{mm}$ de água, usando caminhão e carretel de irrigação auto-propelido, visando garantir uma adequada emergência da cana no início do período frio e seco (TRIVELIN, 2005).

Após o corte da cana-planta em agosto de 2006 adotou-se um delineamento de parcelas subdivididas, ou seja, cada parcela de cana-planta foi dividida em 4 subparcelas (12 linhas de 15 metros) onde foram casualizados os tratamentos de soqueira, doses de N 0,50, 100 e $150 \mathrm{~kg} \mathrm{ha}^{-1}$ na forma de sulfato de amônio (SA) e nitrato de amônio (NA), anualmente reinstalados na $1^{a}$ e $2^{a}$ soqueiras (2007 e 2008). Estas fontes foram escolhidas devido sua maior estabilidade química quando aplicadas em superfície, principalmente sobre a palhada de cana colhida sem queima (TRIVELIN et al., 2002a).

Procurou-se nesse experimento, avaliar o efeito das doses de $\mathrm{N}$ para uma dose fixa de $\mathrm{S}^{-S} \mathrm{~S}_{4}$ de $57 \mathrm{~kg} \mathrm{ha}{ }^{-1}$. O SA foi aplicado em todos os tratamentos na dose de $50 \mathrm{~kg} \mathrm{ha}^{-1}$ de $\mathrm{N}$ somente após o corte da cana-planta (2006, $1^{\text {a }}$ soqueira) e os demais tratamentos 100 e $150 \mathrm{~kg} \mathrm{ha}^{-1}$ de $\mathrm{N}$ foram complementados com a fonte NA. Embora a testemunha não tenha recebido o enxofre contido no SA, o teor no solo foi considerado adequado segundo recomendações de Espironello et al. (1996) e Malavolta, Vitti e Oliveira (1997), isto é, acima de $5 \mathrm{mg} \mathrm{dm}^{-3}$ (Tabela 1). Todas as parcelas nos ciclos de soqueira também receberam anualmente $150 \mathrm{~kg} \mathrm{ha}^{-1}$ de $\mathrm{K}_{2} \mathrm{O}$ na forma de cloreto de potássio $(\mathrm{KCl})$ e, nos demais ciclos ( $3^{\mathrm{a}}$ e $4^{\mathrm{a}}$ soqueiras), a fonte nitrogenada foi sempre o NA.

Após a colheita da $2^{\mathrm{a}}$ soqueira (terceiro corte), a adubação nitrogenada foi de $100 \mathrm{~kg} \mathrm{ha}^{-1}$ de $\mathrm{N}(480 \mathrm{~kg}$ de 21:07:14 + $100 \mathrm{~kg}$ de $\mathrm{KCl}$ ) nas parcelas de todos os tratamentos, com o intuito de verificar possíveis efeitos residuais das adubações anteriores de cana-planta e soqueiras. 
2.2.2 Colheita das parcelas, análises tecnológicas e balanços hídricos do experimento

A colheita da cana-planta foi realizada 14 meses após o plantio (agosto de 2006) e das soqueiras aos 11 a 12 meses após o corte anterior (agosto de 2007 e julho de 2008 e 2009, respectivamente) (Tabela 5). O primeiro corte foi realizado manualmente devido à alta produtividade agrícola obtida na cana-planta, $152 \mathrm{Mg} \mathrm{ha}^{-1}$ na média dos tratamentos. Utilizou-se como parcela útil oito linhas de cana por parcela (dois eitos de 4 linhas) e a cana foi pesada com carregadora acoplada de célula de carga.

Nas soqueiras a colheita foi realizada com colhedora mecânica e as parcelas pesadas com um caminhão-balança instrumentado com célula de carga e computador do CTC - Centro de Tecnologia Canavieira, Piracicaba, SP. Utilizou-se como parcela útil as quatro linhas centrais de cana das parcelas para avaliação da produtividade ( $\mathrm{TCH}, \mathrm{Mg} \mathrm{ha}^{-1}$ de colmos).

Para avaliação da qualidade industrial utilizou-se o sistema Consecana (2006), coletando-se amostras de 10 canas seguidas na linha em cada parcela que foram posteriormente enviadas ao laboratório de PCTS (pagamento de cana pelo teor de sacarose) da Usina São Martinho, onde se analisou a Pol \% cana, Fibra \% e os teores de açúcares redutores (AR) (CESAR; SILVA, 1993).

Durante todos os ciclos da cultura (cana-planta e soqueiras) foram realizadas medidas de pluviosidade, temperaturas máxima e mínima para composição do balanço hídrico, visando auxiliar na explicação de possíveis diferenças de respostas dos tratamentos e na recuperação do N-uréia. Os dados meteorológicos diários de temperatura e pluviosidade foram obtidos do posto meteorológico da Usina São Carlos (LDC-SEV), localizada a menos de $3 \mathrm{~km}$ da área experimental.

Para obter o balanço hídrico da cultura (Figura 1), calculou-se a evapotranspiração potencial (ET0) segundo Penman-Monteith com as parametrizações propostas pela FAO. A evapotranspiração da cultura (ETc) foi obtida multiplicando a ET0 pelo coeficiente da cultura $(\mathrm{Kc})$ nos diversos estágios de crescimento (ALLEN et al., 1998). Foi considerada a capacidade de água disponível (CAD) até 1,0 $\mathrm{m}$ de profundidade e a evapotranspiração real (ETr) foi obtida por meio do cálculo do balanço hídrico de cultura pelo método de Thornthwaite e Mather (1955), utilizando planilhas eletrônicas (ROLIM; SENTELHAS; BARBIERI, 1998). 


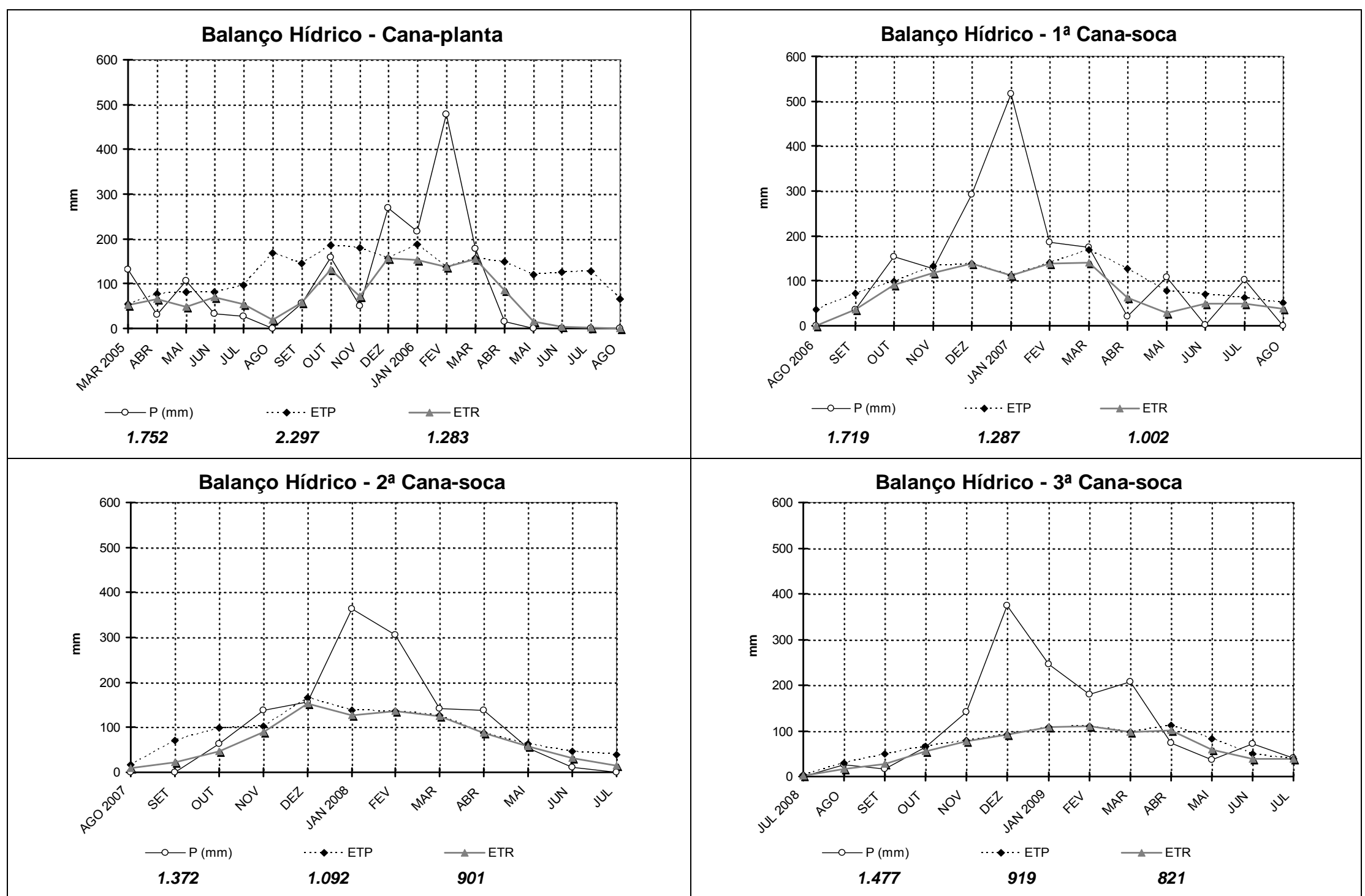

Figura 1 - Balanços hídricos da cana-planta (2006) e soqueiras (2007 a 2009) da área do experimento da Usina São Martinho em Jaboticabal, SP. Legenda: $\mathrm{P}=$ precipitação $(\mathrm{mm})$; ETP e ETR = evapotranspiração potencial e real $(\mathrm{mm})$ 
Um histórico das atividades agrícolas praticadas na área desde a reforma (2004) até a última colheita (2009) consta na Tabela 3. Os croquis dos tratamentos de cana-planta, soqueiras e os extratos dos balanços hídricos (deficiências e excedentes hídricos) encontram-se nos Apêndices.

Tabela 3 - Histórico agrícola da área do experimento de nitrogênio em cana-planta e soqueiras da Usina São Martinho em Jaboticabal, SP, de 2004 a 2009

\begin{tabular}{|c|c|c|c|}
\hline Ano & Atividades & Data & Tratamentos \\
\hline \multirow{2}{*}{ 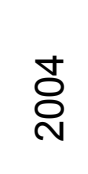 } & \multirow{2}{*}{ Reforma da área } & $12 / 12$ & Dessecação da variedade anterior RB855536 \\
\hline & & $02 / 03$ & Subsolagem (cultivo mínimo) \\
\hline \multirow{3}{*}{$\stackrel{\llcorner}{\circ}$} & Plantio & $02 / 03$ & $\begin{array}{l}\text { Sulcação 00:120:120 kg ha-1 }\left(\mathrm{N}: \mathrm{P}_{2} \mathrm{O}_{5}: \mathrm{K}_{2} \mathrm{O}\right) \\
\left.\text { Variedade SP81-3250 (15 gemas viáveis m}{ }^{-1}\right) \\
\text { Tratamentos CP: } 40,80,120 \mathrm{~kg} \mathrm{ha}^{-1} \mathrm{~N}-\mathrm{Uré}^{-1 a}\end{array}$ \\
\hline & Cultivo CP & $10 / 05$ & Quebra- lombo e herbicida \\
\hline & $\begin{array}{l}\text { Instalação microparcelas } \\
\text { e sacos telados CP }\end{array}$ & $\begin{array}{l}02 / 03 \\
10 / 07\end{array}$ & $\begin{array}{l}\text { Uréia- }{ }^{15} \mathrm{~N}: 80 \mathrm{~kg} \mathrm{ha}{ }^{-1} \mathrm{~N} \\
\text { PAR e RAR- }{ }^{15} \mathrm{~N}: 80 \mathrm{~kg} \mathrm{ha}{ }^{-1} \mathrm{~N}\end{array}$ \\
\hline \multirow{4}{*}{$\stackrel{\bigotimes}{\circ}$} & & & Microparcelas $-{ }^{15} \mathrm{~N}$ e parcelas \\
\hline & Colheita $\mathrm{CP}\left(1^{\circ}\right.$ corte $)$ & 10/08 & $\begin{array}{l}\text { Sacos Telados PAR; Análises C, N, MN, L/C/H } \\
\text { Coleta de solo }(0,60 \mathrm{~m}) \text { microparcelas }{ }^{-15} \mathrm{~N}\end{array}$ \\
\hline & $\begin{array}{l}\text { Instalação microparcelas } \\
\text { e sacos telados } 1^{\mathrm{a}} \mathrm{S}\end{array}$ & $23 / 10$ & PPC $-{ }^{15} \mathrm{~N}: 80-0$ e $80-150\left(\mathrm{~N} \mathrm{CP} \mathrm{e} \mathrm{S}, \mathrm{kg} \mathrm{ha}^{-1}\right)$ \\
\hline & Adubação $N$ - $1^{\text {a }} S$ & $21 / 11$ & $\begin{array}{l}50(\mathrm{SA}) ; 100 \text { e } 150(\mathrm{NA}) \mathrm{kg} \mathrm{ha}^{-1} \mathrm{~N}+150 \mathrm{~kg} \\
\mathrm{~K}_{2} \mathrm{O}(\mathrm{KCL})\end{array}$ \\
\hline \multirow{3}{*}{$\hat{\stackrel{N}{~}}$} & \multirow[b]{2}{*}{ Colheita $1^{\text {a }} \mathrm{S}\left(2^{\circ}\right.$ corte $)$} & \multirow[b]{2}{*}{$21 / 08$} & Microparcelas $-{ }^{15} \mathrm{~N}$ e parcelas \\
\hline & & & $\begin{array}{l}\text { Sacos Telados PAR, PCC; Análises C, N, MN, } \\
\text { L/C/H }\end{array}$ \\
\hline & Adubação $N-2^{a} S$ & $29 / 10$ & 50,100 e $150 \mathrm{~kg} \mathrm{ha}^{-1} \mathrm{~N}(\mathrm{NA})$ \\
\hline \multirow{3}{*}{$\stackrel{\infty}{\circ}$} & \multirow[b]{2}{*}{ Colheita $2^{\text {a }} \mathrm{S}\left(3^{\circ}\right.$ corte $)$} & \multirow[b]{2}{*}{$24 / 07$} & Microparcelas $-{ }^{15} \mathrm{~N}$ e parcelas \\
\hline & & & $\begin{array}{l}\text { Sacos Telados PAR, PCC; Análises } \mathrm{C}, \mathrm{N}, \mathrm{MN} \text {, } \\
\mathrm{L} / \mathrm{C} / \mathrm{H}\end{array}$ \\
\hline & Adubação $N-3^{a} S$ & $21 / 10$ & $100: 34: 67+67 \mathrm{~kg} \mathrm{~K}_{2} \mathrm{O} \mathrm{ha}{ }^{-1}(\mathrm{KCl})$ \\
\hline 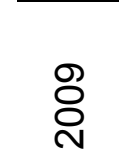 & Colheita $3^{\mathrm{a}} \mathrm{S}\left(4^{\circ}\right.$ corte $)$ & $20 / 07$ & $\begin{array}{l}\text { Microparcelas }{ }^{15} \mathrm{~N} \text { e parcelas. } \\
\text { Coleta de solo }(0,60 \mathrm{~m}) \text { microparcelas- }{ }^{15} \mathrm{~N} \\
\text { Uréia, PAR, RAR e PPC. }\end{array}$ \\
\hline
\end{tabular}

Legenda: $\mathrm{CP}$ = cana-planta; $\mathrm{S}$ = soqueira; $\mathrm{PAR}$ e RAR= palhada e rizomas anteriores a reforma (RB855536); PPC = palhada posterior a colheita (SP81-3250); $C=$ carbono, $N=$ nitrogênio, $M N=$ macronutrientes, $\mathrm{L} / \mathrm{C} / \mathrm{H}=$ lignina, celulose, hemicelulose; $\mathrm{NA}$ = nitrato de amônio; $\mathrm{SA}$ = sulfato de amônio; $\mathrm{KCl}$ = cloreto de potássio. 
2.2.3 Análises estatísticas e econômicas dos tratamentos de $\mathrm{N}$ em cana-planta e soqueiras após quatro ciclos consecutivos (2006 a 2009)

Para avaliação estatística dos dados de produtividade agroindustrial, realizouse análise de variância (ANOVA) e análise de regressão dos resultados das doses de $\mathrm{N}$ em cana-planta e soqueiras dos quatro ciclos avaliados individualmente. $\mathrm{O}$ programa estatístico utilizado foi o Sisvar (FERREIRA, 2000).

Além da análise individual de cada corte, efetuou-se uma avaliação conjunta da produtividade agroindustrial ( $\mathrm{TCH}, \mathrm{t} \mathrm{ha}{ }^{-1}$ de colmos e TPH Mg ha-1 de açúcar) média e acumulada em função das doses de $\mathrm{N}$ em cana-planta e soqueiras e uma análise econômica dos tratamentos. Segundo Fernandes (2003), o método mais assertivo para se avaliar o retorno econômico de um tratamento aplicado à cana-deaçúcar são os cálculos das margens de contribuição agrícola (MCA) e industrial (MCl). A primeira avalia o retorno econômico da matéria prima obtido no campo, e a segunda o obtido com a produção de açúcar e álcool.

Para o cálculo da MCA (equação 1) utilizou-se a produtividade da matériaprima ( $\mathrm{TCH}$ ), os custos variáveis de corte, carregamento e transporte (CCT) e da adubação nitrogenada (equação 1). O custo de arrendamento da terra não foi considerado nesta análise, assumindo-se o uso de terras próprias.

Já para calcular a $\mathrm{MCl}$ (equação 2), consideraram-se as quantidades de álcool $\left(\mathrm{m}^{3}\right)$ e de açúcar $(\mathrm{kg})$ obtidas por $\mathrm{Mg}$ de colmos, os preços médios de mercado de açúcar e álcool bem como a proporção da fabricação de cada um ("mix de produção").

$$
\begin{aligned}
& \mathrm{MCA}=\mathrm{TCH}^{*}(\mathrm{ATR} \times \mathrm{ATRp})-\mathrm{CCTC}-\mathrm{Nc} \\
& \mathrm{MCl}=\mathrm{TCH} *[\mathrm{AÇU} \times(\mathrm{AÇUp}-\mathrm{AÇUc})]+(\mathrm{AA} \times(\mathrm{AAp}-\text { custo } \mathrm{AAc})+ \\
& {[(\mathrm{AH} \times(\mathrm{AHp}-\mathrm{AHC})]-\mathrm{CCTC}-\mathrm{Nc}}
\end{aligned}
$$

Onde: $\mathrm{MCA}$ e $\mathrm{MCl}=$ margem de contribuição agrícola e industrial $\left(\mathrm{R} \$ \mathrm{ha}^{-1}\right) ; \mathrm{TCH}=$ produtividade agrícola $\left(\mathrm{Mg} \mathrm{ha}^{-1}\right) ; \mathrm{ATR}=$ açúcar total recuperável $\left(\mathrm{kg} \mathrm{Mg}^{-1}\right) ; \mathrm{AÇU}=$ produção de açúcar $\left(\mathrm{kg} \mathrm{Mg}^{-1}\right)$; CCTc = custo do corte, carregamento e transporte da cana $\left(\mathrm{R} \$ \mathrm{Mg}^{-1}\right), \mathrm{AA}=$ produção de álcool anidro $\left(\mathrm{m}^{3} \mathrm{Mg}^{-1}\right) ; \mathrm{AH}=$ produção de álcool hidratado $\left(\mathrm{m}^{3} \mathrm{Mg}^{-1}\right) ; \mathrm{Nc}=$ custo do $\mathrm{N} ; \mathrm{p}=$ preço $\left(\mathrm{R} \$ \mathrm{~kg}^{-1}\right.$ ou m $\left.^{-3}\right)$; $\mathrm{c}=$ custo $\left(\mathrm{R} \$ \mathrm{~kg}^{-1}\right.$ ou $\left.\mathrm{m}^{-3}\right)$. 
Tanto para MCA quanto para $\mathrm{MCl}$ foram considerados os custos médios do período analisado (2005 a 2009) dos fertilizantes nitrogenados, do CCT da cana e custos de produção do açúcar e do álcool (Tabela 4).

Também foram calculadas as receitas marginais agrícola e industrial de cada tratamento (RMA e RMI, respectivamente), ou seja, a lucratividade ou prejuízo das doses de $\mathrm{N}$ em cana-planta e soqueiras em relação ao tratamento testemunha.

Tabela 4 - Valores médios de custos de produção e preços de açúcar e álcool utilizados para os cálculos de MCA e MCl do experimento da Usina São Martinho em Jaboticabal, SP

\begin{tabular}{lcc}
\hline Item de custeio & Unidade & Valor médio (2006 a 2009)\# \\
\hline Custo uréia (N cana-planta) & $\mathrm{R} \$ \mathrm{~kg}^{-1}$ & 1,20 \\
Custo nitrato de amônio (N soqueiras) & & 1,65 \\
\cline { 2 - 3 } CCT & $\mathrm{R} \$ \mathrm{t}^{-1}$ & 17,00 \\
\cline { 2 - 3 } Mix Açúcar/Álcool & $\%$ & $50 / 50$ \\
\cline { 2 - 3 } Preço do ATR & $\mathrm{R} \$ \mathrm{~kg}^{-1}$ & 0,30 \\
Custo de produção - açúcar & & 0,45 \\
Preço do açúcar & & 0,59 \\
Custo de produção - álcool anidro & $\mathrm{R} \$ \mathrm{~m}^{-3}$ & 588 \\
Preço do álcool anidro & & 868 \\
Custo de produção - álcool hidratado & & 543 \\
Preço do álcool hidratado & & 737 \\
\hline
\end{tabular}

Legenda: CCT = corte, carregamento e transporte da cana; ATR = açúcar total recuperável; \# Fonte: Mosaic e Heringer Fertilizantes (2009 - comunicação pessoal); UDOP (2010); Orplana (2010).

\subsection{RESULTADOS E DISCUSSÃO}

2.3.1 Ciclo de cana-planta (safra 2005/2006)

Houve resposta linear da produtividade agroindustrial (TCH e TPH em $\mathrm{Mg} \mathrm{ha}^{-1}$ ) às doses de nitrogênio aplicadas na cana-planta (Tabela 5). Cantarella, Trivelin e Vitti (2007) compilaram diversos resultados de instituições de pesquisa como o CTC, IAC e universidades e ressaltaram que, embora existente em algumas situações, a resposta da cana-planta ao nitrogênio é errática e apenas $30 \%$ dos experimentos realizados no Estado de São Paulo em cana-planta mostraram resposta à aplicação de $\mathrm{N}$. 
Tabela 5 - Produtividade agroindustrial e características tecnológicas de cana-deaçúcar em função das doses de nitrogênio no ciclo de cana-planta (2006), Usina São Martinho, Jaboticabal, SP

\begin{tabular}{|c|c|c|c|c|}
\hline \multirow{2}{*}{$\begin{array}{c}\text { Dose de N } \\
\mathrm{kg} \mathrm{ha}^{-1}\end{array}$} & \multirow{2}{*}{$\begin{array}{c}\mathrm{TCH} \\
\mathrm{Mg} \mathrm{ha}^{-1}\end{array}$} & PCC & Fibra & \multirow{2}{*}{$\begin{array}{c}\text { TPH } \\
\text { Mg ha }^{-1}\end{array}$} \\
\hline & & \multicolumn{2}{|c|}{$\%$} & \\
\hline 0 & 141 & 16,7 & 12,7 & 23,5 \\
\hline 40 & 153 & 17,5 & 13,0 & 26,7 \\
\hline 80 & 156 & 16,7 & 12,8 & 25,9 \\
\hline 120 & 159 & 17,2 & 12,7 & 27,4 \\
\hline Média & 152 & 17,0 & 12,8 & 25,9 \\
\hline F Blocos & ns & ns & ns & ns \\
\hline F Tratamentos & $4,3^{* *}$ & ns & ns & $4,8^{*}$ \\
\hline$R^{2}-R L$ & 0,99 & --- & --- & 0,67 \\
\hline$R^{2}-R Q$ & ns & --- & --- & ns \\
\hline CV (\%) & 4,9 & 3,5 & 3,4 & 6,0 \\
\hline
\end{tabular}

Legenda: ns = não significativo; ${ }^{*} \mathrm{e}^{* *}=$ significativos a 1 e $5 \%$ de probabilidade, respectivamente; $\mathrm{TCH}=\mathrm{Mg}$ de colmos industrializáveis por hectare; $\mathrm{PCC}=\mathrm{Pol} \%$ cana; $\mathrm{TPH}=$ toneladas de pol por hectare; $R L$ e $R Q$ = regressão linear e quadrática.

No presente trabalho a diferença dos tratamentos com $\mathrm{N}$ para a testemunha foi de $11 \%$, o equivalente a $18 \mathrm{TCH}$. Entre os tratamentos que receberam $\mathrm{N}$ a diferença foi $2 \%$ menor ( $3 \mathrm{TCH}$ ).

Korndorfer et al. (1997) apontaram resposta positiva às doses crescentes de $\mathrm{N}$-uréia $0,30,60$ e $120 \mathrm{~kg}_{\text {de }} \mathrm{N} \mathrm{ha}^{-1} \mathrm{em}$ cana-planta na média de quatro variedades em Latossolo de textura média álico no triângulo mineiro. Encontraram diferenças na $\mathrm{TCH}$ e características tecnológicas (Pol \% cana e Fibra \%) devido às variedades de cana-de-açúcar utilizadas.

Penatti e Forti (1997) observaram maior freqüência de resposta a $\mathrm{N}$ em cana de ano (ciclo de 12 meses) do que em cana de ano e meio (ciclo de 18 meses), independentemente da textura do solo. Estes autores elucidam que a recomendação de $\mathrm{N}$ para a cana-de-açúcar deve estar baseada na margem de contribuição agroindustrial $\left(\mathrm{R} \$ \mathrm{ha}^{-1}\right)$ e que, portanto, a dose econômica para cana-planta está em torno de $50 \mathrm{~kg} \mathrm{ha}^{-1}$.

O alto potencial produtivo do solo do experimento (Tabela 1), aliado ao sistema de cultivo mínimo, em que parte dos resíduos culturais anteriores à reforma 
foram preservados na superfície do solo, proporcionaram condições para alta resposta às doses de $\mathrm{N}$ em cana-planta. Estes resultados corroboram com os de Orlando Filho et al. (1999) que obtiveram respostas lineares da cana-planta e soqueiras às doses de até $120 \mathrm{~kg} \mathrm{ha}^{-1}$ para a variedade SP71-1406. Enfatizaram que, além da alta fertilidade (solos eutróficos) e do cultivo mínimo, são esperadas respostas positivas da aplicação de $\mathrm{N}$ em cana-planta em locais que se cultiva cana pela primeira vez. Korndorfer et al. (2002) também observaram respostas na produtividade agroindustrial (TCH e TPH) de sete variedades de cana-de-açúcar à aplicação de $60 \mathrm{~kg} \mathrm{~N}$ ha $^{-1}$ em cana-planta.

Trivelin et al. (2002b) encontraram respostas lineares em TCH e Pol \% cana à fertilização de cana-planta com doses crescentes de $\mathrm{N}$-uréia $\left(0,30,60\right.$ e $\left.90 \mathrm{~kg} \mathrm{ha}^{-1}\right)$, porém não obtiveram respostas devido à incorporação de palhada em solo arenoso, na reforma do canavial. Estes autores apontam que a necessidade de $\mathrm{N}$ para a produção da parte aérea da cultura foi de $1,6 \mathrm{~kg}$ de $\mathrm{N}$ por $\mathrm{Mg}$ de colmos e quando se considerou os rizomas e sistema radicular esta quantidade foi em média de $2,2 \mathrm{~kg} \mathrm{~N}$ $\mathrm{Mg}^{-1}$. Ressaltaram que embora a cana-planta possa apresentar respostas a aplicação de $\mathrm{N}$, nesse ciclo a cultura acumula $\mathrm{N}$ de outras fontes como o proveniente da mineralização da matéria orgânica do solo (GRAHAM; HAYNES; MEYER, 2002), fixação biológica (BODDEY et al., 2003) e absorção foliar de amônia da atmosfera (TRIVELIN et al., 2002a).

Por outro lado, Wiedenfeld $(1998 ; 2000)$ não verificou respostas na TCH da cana-planta devido à aplicação de doses crescentes de $\mathrm{N}$. Este autor atribui a falta de resposta na cana-planta devido à quantidade de $\mathrm{N}$ existente no solo na ocasião do plantio da cultura estar em níveis adequados para a nutrição da cultura.

Não houve variação significativa na qualidade tecnológica, Pol \% cana e Fibra \%, entre os tratamentos com $\mathrm{N}$ em cana-planta. Ressalte-se $\mathrm{o}$ alto desempenho agroindustrial (TPH, $\mathrm{Mg} \mathrm{ha}^{-1}$ de açúcar) nesse ciclo, uma vez que a $\mathrm{TCH}$ e o teor de Pol \% cana foram adequados para a variedade SP81-3250 para esta época de corte (Tabela 5). Orlando Filho et al. (1999) também não observaram diferenças significativas na qualidade tecnológica da cana-de-açúcar submetida a doses crescentes de $\mathrm{N}$ em cana-planta e soqueiras.

O decréscimo na quantidade de açúcar na cana-de-açúcar pode muitas vezes ser proporcional ao acúmulo de biomassa, ou seja, devido à partição e acúmulo de carbono pelas plantas (SMITH; INMAN-BAMBER; THORBURN, 2005). Embora não 
tenha ocorrido no presente trabalho, outros autores demonstram que a fertilização com $\mathrm{N}$ pode diminuir o teor de sacarose e atribuem este efeito de diluição ao maior conteúdo de água (turgescência) da planta e consumo maior de energia como decorrência de um maior desenvolvimento vegetativo (KORNDORFER; MARTINS 1992; WIEDENFELD, 1998; 2000).

Assim como ocorreu neste trabalho, Korndorfer et al. (2002) também não observaram diferenças significativas nas características tecnológicas da cana-planta e primeira soqueira devido à aplicação de $\mathrm{N}$ em cana-planta, concluindo que as diferenças na TPH foram devido à produtividade agrícola $(\mathrm{TCH})$ das variedades utilizadas.

A produtividade de açúcar (TPH) apresentou diferença significativa entre tratamentos, porém devido à variação significativa na produtividade de colmos por hectare (Tabela 5). Esses resultados confirmam os obtidos por Korndorfer et al. (1997; 2002), Orlando Filho et al. (1994) e Trivelin et al. (2002a; 2002b) onde a adubação nitrogenada não influenciou a qualidade tecnológica dos colmos, mas proporcionou resposta positiva na produtividade de açúcar (TPH) devido à maior produtividade agrícola $(\mathrm{TCH})$.

\subsubsection{Primeiro ciclo de soqueira (safra 2006/2007)}

As doses de $\mathrm{N}$ na soqueira proporcionaram efeito linear na produtividade agrícola $(\mathrm{TCH})$ da cultura, considerados todos os tratamentos de $\mathrm{N}$ no plantio. As doses de 100 e $150 \mathrm{~kg}_{\text {de }} \mathrm{N}^{-1}{ }^{-1}$ apresentaram maiores aumentos na TCH, cerca de 8\% (7 TCH) em relação à testemunha (Tabela 6). Estes dados são coerentes com Penatti e Forti (1997) e Espironello et al. (1996) que recomendaram esta dose de N para soqueiras nessa idade e com este patamar de produtividade, respectivamente. Entre os tratamentos com N, a diferença foi de no máximo $6 \%$ ou $5 \mathrm{TCH}$. Além disso, não foi detectado efeito residual na $\mathrm{TCH}$ da soqueira das doses de nitrogênio aplicadas no plantio, evidenciado pelo tratamento testemunha no plantio (Tabela 6).

Graham et al. (2002) e Wood (1991) observaram acréscimos na TCH quando em sistemas sem queima da palhada, devido à ciclagem de nutrientes, características biológicas e físicas do solo que recebeu os resíduos vegetais. Orlando Filho et al. (1999) e Vitti et al. (2007) ressaltaram que o efeito residual 
indireto das adubações de cana-planta podem refletir em maior vigor das soqueiras subseqüentes e que a produtividade dos tratamentos que receberam 60 e $120 \mathrm{~kg}$ de $\mathrm{N}$ ha ${ }^{-1}$ foram 20 e $35 \%$ superiores, respectivamente.

Tabela 6 - Produtividade agrícola $\left(\mathrm{TCH}, \mathrm{Mg} \mathrm{ha}^{-1}\right)$ de cana-de-açúcar de segundo ciclo ( $1^{\text {a }}$ soqueira) em função das doses de nitrogênio de plantio e soqueiras

\begin{tabular}{|c|c|c|c|c|c|}
\hline \multirow[b]{3}{*}{$\mathrm{N}-\mathrm{CP}\left(\mathrm{kg} \mathrm{ha}^{-1}\right)$} & \multicolumn{5}{|c|}{ Produtividade Agrícola $\left(\mathrm{TCH}, \mathrm{Mg} \mathrm{ha}^{-1}\right)$} \\
\hline & \multicolumn{4}{|c|}{$\mathrm{N}-1^{\mathrm{a}} \mathrm{S}\left(\mathrm{kg} \mathrm{ha}^{-1}\right)$} & \multirow[b]{2}{*}{ Média } \\
\hline & 0 & 50 & 100 & 150 & \\
\hline 0 & 76 & 79 & 87 & 84 & 82 \\
\hline 40 & 77 & 71 & 77 & 82 & 77 \\
\hline 80 & 73 & 79 & 82 & 79 & 78 \\
\hline 120 & 78 & 81 & 85 & 82 & 82 \\
\hline Média & 76 & 78 & 83 & 82 & 80 \\
\hline F Blocos & $\mathrm{ns}$ & & \multicolumn{2}{|c|}{ F Interação N CPX $1^{a} \mathrm{~S}$} & ns \\
\hline Dose $N C P-R^{2}(R L)$ & ns & & \multicolumn{2}{|c|}{ Dose $N$ 1aS $-R^{2}(R L)$} & $0,80^{*}$ \\
\hline Dose $N C P-R^{2}(R Q)$ & ns & & \multicolumn{2}{|c|}{ Dose $N 1^{\text {a }} S-R^{2}(R Q)$} & ns \\
\hline Dose N CP - CV (\%) & 12,8 & & \multicolumn{2}{|c|}{ Dose N $1^{\text {aS }}$ - CV (\%) } & 12,1 \\
\hline
\end{tabular}

Legenda: $\mathrm{CP}=$ cana-planta (2006); $1^{\text {a }} \mathrm{S}=$ primeiro ciclo de soqueira; $\mathrm{RL}$ e $\mathrm{RQ}=$ regressão linear e quadrática; * e ${ }^{* *} p<0,01$ e $p<0,05$ de probabilidade, ns = não significativo; $C V=$ coeficiente de variação.

A variedade SP81-3250 apresenta intenso florescimento e isoporização, o que pode aumentar consideravelmente $\mathrm{O}$ teor de fibra desta variedade (COPERSUCAR, 1995). Cabe ressaltar que a queda de produtividade do primeiro para o segundo corte foi de $47 \%$, isto é, de 152 para cerca de $80 \mathrm{TCH}$ (Tabelas $5 \mathrm{e}$ 6). Isso ocorreu provavelmente devido a um conjunto de fatores tais como interação do clima com a variedade (ex: stress hídrico, florescimento, isoporização, etc.), danos ocorridos à soqueira devido às operações mecanizadas de colheita e transporte da cana (MANECHINI; RICCI JUNIOR; DONZELLI, 2005) e/ou pela dificuldade de brotação da soqueira sob grande quantidade de palhada (FORTES; CAMPOS; SILVA, 2009).

As características tecnológicas (Pol \% cana e Fibra \%), bem como a produtividade de açúcar (TPH) não apresentaram diferenças significativas para aplicação de nitrogênio. Este ciclo apresentou o menor valor de pol \% cana (PCC) e 
em contrapartida a maior Fibra \%. (Tabelas 7, 8 e 9). Estes resultados diferem dos de Wiedenfeld $(1998 ; 2000)$ que observou pequeno mas significativo decréscimo na PCC devido à aplicações crescentes de $\mathrm{N}$ em soqueiras.

Tabela 7 - Teor de sacarose (Pol \% cana) de cana-de-açúcar de segundo ciclo ( $1^{\text {a }}$ soqueira) em função das doses de nitrogênio de plantio e soqueiras

\begin{tabular}{|c|c|c|c|c|c|}
\hline \multirow[b]{3}{*}{ Dose $N$ - CP $\left(\mathrm{kg} \mathrm{ha}^{-1}\right)$} & \multicolumn{5}{|c|}{ Pol Cana (\%) } \\
\hline & \multicolumn{4}{|c|}{ Dose $\mathrm{N}-1^{\mathrm{a} S}\left(\mathrm{~kg} \mathrm{ha}{ }^{-1}\right)$} & \multirow[b]{2}{*}{ Média } \\
\hline & 0 & 50 & 100 & 150 & \\
\hline 0 & 16,4 & 16,3 & 15,5 & 16,3 & 16,1 \\
\hline 40 & 16,2 & 16,1 & 16,1 & 16,1 & 16,1 \\
\hline 80 & 16,1 & 15,6 & 16,1 & 15,7 & 15,9 \\
\hline 120 & 16,3 & 16,1 & 16,2 & 16,3 & 16,2 \\
\hline Média & 16,3 & 16,1 & 16,0 & 16,1 & 16,1 \\
\hline F Blocos & ns & & \multicolumn{2}{|c|}{ F Interação N CPx1 ${ }^{a} S$} & ns \\
\hline Dose N CP $-R^{2}(R L)$ & ns & & \multicolumn{2}{|c|}{ Dose $N$ 1as $-R^{2}(R L)$} & ns \\
\hline Dose $N C P-R^{2}(R Q)$ & ns & & \multicolumn{2}{|c|}{ Dose $N$ 1a $S-R^{2}(R Q)$} & ns \\
\hline Dose N CP - CV (\%) & 2,6 & & \multicolumn{2}{|c|}{ Dose $N 1^{\text {a }} \mathrm{S}-\mathrm{CV}(\%)$} & 2,7 \\
\hline
\end{tabular}

Legenda: CP = cana-planta (2006); $1^{\text {a }} \mathrm{S}=$ primeiro ciclo de soqueira; $\mathrm{RL}$ e $\mathrm{RQ}=$ regressão linear e quadrática; ${ }^{*}$ e ${ }^{* *} p<0,01$ e $p<0,05$ de probabilidade, ns = não significativo; $C V=$ coeficiente de variação.

Tabela 8 - Teor de fibra (\%) de cana-de-açúcar de segundo ciclo ( (a $^{\text {a }}$ soqueira) em função das doses de nitrogênio de nitrogênio de plantio e soqueiras

\begin{tabular}{|c|c|c|c|c|c|}
\hline \multirow[b]{3}{*}{ Dose $N-C P\left(\mathrm{~kg} \mathrm{ha}^{-1}\right)$} & \multicolumn{5}{|c|}{ Fibra (\%) } \\
\hline & \multicolumn{4}{|c|}{ Dose $N-1^{\text {a }} S\left(\mathrm{~kg} \mathrm{ha}^{-1}\right)$} & \multirow[b]{2}{*}{ Média } \\
\hline & 0 & 50 & 100 & 150 & \\
\hline 0 & 13,6 & 13,5 & 14,0 & 13,5 & 13,7 \\
\hline 40 & 13,7 & 13,5 & 13,6 & 13,7 & 13,6 \\
\hline 80 & 13,4 & 13,6 & 13,1 & 14,1 & 13,6 \\
\hline 120 & 13,9 & 13,9 & 13,9 & 13,9 & 13,9 \\
\hline Média & 13,7 & 13,6 & 13,7 & 13,8 & 13,7 \\
\hline F Blocos & ns & & \multicolumn{2}{|c|}{ F Interação N CPx1 ${ }^{\text {aSS }}$} & ns \\
\hline Dose $N C P-R^{2}(R L)$ & ns & & \multicolumn{2}{|c|}{ Dose $N 1^{\text {a }} S-R^{2}(R L)$} & ns \\
\hline Dose $N C P-R^{2}(R Q)$ & ns & & \multicolumn{2}{|c|}{ Dose $N 1^{\text {a }} S-R^{2}(R Q)$} & ns \\
\hline Dose N CP - CV (\%) & 3,8 & & \multicolumn{2}{|c|}{ Dose N 1as - CV (\%) } & 3,5 \\
\hline
\end{tabular}

Legenda: $C P=$ cana-planta (2006); $1^{\text {a }} \mathrm{S}=$ primeiro ciclo de soqueira; $\mathrm{RL}$ e $\mathrm{RQ}=$ regressão linear $\mathrm{e}$ quadrática; * e ** $p<0,01$ e $p<0,05$ de probabilidade, ns = não significativo; $C V=$ coeficiente de variação. 
Tabela 9 - Produtividade de açúcar (TPH, Mg ha ${ }^{-1}$ ) de cana-de-açúcar de segundo ciclo ( $1^{\text {a }}$ soqueira) em função das doses de nitrogênio de plantio e soqueiras

\begin{tabular}{|c|c|c|c|c|c|}
\hline \multirow[b]{3}{*}{ Dose N-CP $\left(\mathrm{kg} \mathrm{ha}^{-1}\right)$} & \multicolumn{5}{|c|}{ Produtividade agroindustrial (TPH, $\mathrm{Mg} \mathrm{ha}^{-1}$ ) } \\
\hline & \multicolumn{4}{|c|}{ Dose $\mathrm{N}-1^{\text {aS }}\left(\mathrm{kg} \mathrm{ha}^{-1}\right)$} & \multirow[b]{2}{*}{ Média } \\
\hline & 0 & 50 & 100 & 150 & \\
\hline 0 & 12,5 & 12,9 & 13,5 & 13,7 & 13,1 \\
\hline 40 & 12,4 & 11,4 & 12,3 & 13,2 & 12,3 \\
\hline 80 & 11,8 & 12,3 & 13,2 & 12,4 & 12,4 \\
\hline 120 & 12,7 & 13,1 & 13,7 & 13,4 & 13,2 \\
\hline Média & 12,3 & 12,4 & 13,2 & 13,2 & 12,8 \\
\hline F Blocos & ns & & \multicolumn{2}{|c|}{ F Interação N CPx1 ${ }^{\mathrm{a} S}$} & ns \\
\hline Dose $N C P-R^{2}(R L)$ & ns & & \multicolumn{2}{|c|}{ Dose $N 1^{\text {aa }}-\mathrm{R}^{2}(\mathrm{RL})$} & ns \\
\hline Dose $N C P-R^{2}(R Q)$ & ns & & \multicolumn{2}{|c|}{ Dose $N 1^{\text {a }} S-R^{2}(R Q)$} & ns \\
\hline Dose N CP - CV (\%) & 13,7 & & \multicolumn{2}{|c|}{ Dose $N 1^{\text {a }} S-C V(\%)$} & 12,4 \\
\hline
\end{tabular}

Legenda: $\mathrm{CP}=$ cana-planta (2006); $1^{\mathrm{a}} \mathrm{S}=$ primeiro ciclo de soqueira; $\mathrm{RL}$ e $\mathrm{RQ}=$ regressão linear $\mathrm{e}$ quadrática; * e ${ }^{* *} p<0,01$ e $p<0,05$ de probabilidade, ns = não significativo; $C V=$ coeficiente de variação.

Manechini, Ricci Junior e Donzelli (2005) encontraram altas correlações negativas $\left(R^{2}=0,99\right)$ na produtividade agroindustrial $(T P H)$ após seis ciclos consecutivos de cana submetidas a diferentes tratamentos de manejo da palhada $0 \%, 33 \%, 66 \%$ e $100 \%$ de cobertura do solo. Este fato pode estar relacionado às variedades de cana utilizadas na época, que não eram as melhores para utilização no sistema de manejo de colheita mecanizada sem a queima da palhada.

\subsubsection{Segundo ciclo de soqueira (safra 2007/2008)}

A segunda soqueira apresentou a menor $\mathrm{TCH}$ dentre os quatro ciclos avaliados, em média $62 \mathrm{Mg} \mathrm{ha}^{-1}$ (Tabela 10). Isso se deveu a algumas restrições climáticas tais como um período de aproximadamente sessenta dias de deficiência hídrica logo após o corte do ciclo agrícola antecedente (Figura 1) aliado a um intenso ataque de cigarrinhas ( $M$. fimbriolata) e tombamento da cana. Orlando Filho et al. (1994) também relataram que o ataque de cigarrinhas ocorrido nas parcelas de cana colhida sem queima pode ter contribuído para diferenças entre os tratamentos que não as doses de $\mathrm{N}$. 
Tabela 10 - Produtividade agrícola $\left(\mathrm{TCH}, \mathrm{Mg} \mathrm{ha}^{-1}\right)$ de cana-de-açúcar de terceiro ciclo ( $2^{a}$ soqueira) em função das doses de nitrogênio de plantio e soqueiras

\begin{tabular}{|c|c|c|c|c|c|}
\hline \multirow[b]{3}{*}{ Dose N-CP $\left(\mathrm{kg} \mathrm{ha}^{-1}\right)$} & \multicolumn{5}{|c|}{ Produtividade agrícola $\left(\mathrm{TCH}, \mathrm{Mg} \mathrm{ha}^{-1}\right)$} \\
\hline & \multicolumn{4}{|c|}{ Dose $\mathrm{N}-2^{\mathrm{a} S}\left(\mathrm{~kg} \mathrm{ha}^{-1}\right)$} & \multirow[b]{2}{*}{ Média } \\
\hline & 0 & 50 & 100 & 150 & \\
\hline 0 & 55 & 66 & 69 & 66 & 64 \\
\hline 40 & 50 & 54 & 69 & 69 & 60 \\
\hline 80 & 48 & 60 & 63 & 64 & 58 \\
\hline 120 & 58 & 73 & 65 & 62 & 64 \\
\hline Média & 53 & 63 & 66 & 65 & 62 \\
\hline F Blocos & $9,2^{\star \star}$ & & \multicolumn{2}{|c|}{ F Interação N CP×2 ${ }^{\mathrm{a} S}$} & ns \\
\hline Dose N CP $-R^{2}(R L)$ & ns & & \multicolumn{2}{|c|}{ Dose $N 2^{a} S-R^{2}(R L)$} & $0,71^{* *}$ \\
\hline Dose $N C P-R^{2}(R Q)$ & $0,91^{*}$ & & \multicolumn{2}{|c|}{ Dose $N 2^{a} S-R^{2}(R Q)$} & $0,99^{* *}$ \\
\hline Dose N CP - CV (\%) & 11,2 & & \multicolumn{2}{|c|}{ Dose N $2^{a} S-C V(\%)$} & 12,7 \\
\hline
\end{tabular}

Legenda: $\mathrm{CP}=$ cana-planta (2006); $2^{\mathrm{a}} \mathrm{S}=$ segundo ciclo de soqueira; $\mathrm{RL}$ e $\mathrm{RQ}=$ regressão linear $\mathrm{e}$ quadrática; * $e^{* *} p<0,01$ e $p<0,05$ de probabilidade, ns = não significativo; $C V=$ coeficiente de variação.

Nota-se que apesar do ano ter sido restritivo para a produção de biomassa, neste ciclo houve respostas significativas das doses de $\mathrm{N}$ em cana-plana e de soqueiras na produtividade agroindustrial (TCH e TPH) da cultura (Tabelas 10 e 13). $\mathrm{O}$ fato de ter ocorrido resposta das doses de $\mathrm{N}$ em cana-planta também pode estar relacionado à manutenção da capacidade produtiva do solo através de adubações anteriores (VITTI et al., 2007).

A dose de $100 \mathrm{~kg} \mathrm{ha}^{-1}$ apresentou melhor desempenho médio (66 TCH e 11,1 TPH) e muito próximo da dose maior de $150 \mathrm{~kg} \mathrm{ha}^{-1}$, que resultou em $65 \mathrm{TCH}$ e 10,9 TPH, respectivamente. Neste ciclo notou-se maior diferença para TCH e TPH entre os tratamentos com $\mathrm{N}$ em relação ao tratamento testemunha sem a adição de $\mathrm{N}$ em soqueiras, isto é, cerca de $20 \%$ (12 TCH e 2,2 TPH). Entre os tratamentos com N esta diferença caiu para no máximo $5 \%$ (3 TCH e 0,5 TPH), indicando a importância de se investir na fertilização da cana-de-açúcar pensando em seus efeitos para os próximos ciclos (Tabela 10). Wiedenfeld (1998) obtiveram respostas quadráticas na TCH da segunda e terceira soqueiras de cana-de-açúcar no Estado do Texas, EUA, utilizando as mesmas doses de $\mathrm{N}\left(0,50,100\right.$ e $\left.150 \mathrm{~kg} \mathrm{ha}^{-1}\right)$ e, assim como neste trabalho, os autores também verificaram melhor resposta da dose $100 \mathrm{~kg} \mathrm{ha}^{-1}$ de $\mathrm{N}$ 
na TCH da segunda soqueira. Já para a terceira soqueira o resultado melhor situouse na dose $150 \mathrm{~kg} \mathrm{ha}^{-1}$ de $\mathrm{N}$.

As características tecnológicas (pol\% cana e fibra \%) foram influenciadas somente pelas doses de $\mathrm{N}$ em cana-planta (Tabelas 11 e 12). Isso pode estar relacionado ao baixo aproveitamento do $\mathrm{N}$ aplicado em soqueira e da palhada pela cultura devido às condições secas ao início do ciclo agrícola, ou seja, pode ter ocorrido uma maior imobilização do $\mathrm{N}$ pelos microrganismos do solo. Fortes et al. (2010) encontraram decréscimo na recuperação do $\mathrm{N}$ de resíduos culturais marcados no isótopo ${ }^{15} \mathrm{~N}$ neste mesmo experimento e ano agrícola, o que reforça a idéia de imobilização do $\mathrm{N}$ na palhada e, conseqüentemente, menor aproveitamento pela cultura. Portanto, o melhor desempenho dos tratamentos de $\mathrm{N}$ aplicados em cana-planta está relacionado ao efeito residual de tais aplicações, em complemento às fertilizações de soqueira (VITTI et al., 2007).

Outro fato ocorrido é que, a partir deste ciclo, começaram a surgir diferenças de produtividade entre as repetições (blocos), o que de certa forma validou a importância do delineamento experimental em blocos casualizados (Tabelas 10 e 13).

Tabela 11 - Teor de sacarose (Pol \% cana) de cana-de-açúcar de terceiro ciclo (2a soqueira) em função das doses de nitrogênio de plantio e soqueiras

\begin{tabular}{|c|c|c|c|c|c|}
\hline \multirow[b]{3}{*}{ Dose $N-C P\left(\mathrm{~kg} \mathrm{ha}^{-1}\right)$} & \multicolumn{5}{|c|}{ Pol cana (\%) } \\
\hline & \multicolumn{4}{|c|}{ Dose $\mathrm{N}-2^{\mathrm{a}} \mathrm{S}\left(\mathrm{kg} \mathrm{ha}{ }^{-1}\right)$} & \multirow[b]{2}{*}{ Média } \\
\hline & 0 & 50 & 100 & 150 & \\
\hline 0 & 16,9 & 17,1 & 16,8 & 17,0 & 17,0 \\
\hline 40 & 16,7 & 16,7 & 17,0 & 16,1 & 16,6 \\
\hline 80 & 16,7 & 16,8 & 16,2 & 17,2 & 16,7 \\
\hline 120 & 17,0 & 16,6 & 17,3 & 16,9 & 17,0 \\
\hline Média & 16,8 & 16,8 & 16,8 & 16,8 & 16,8 \\
\hline F Blocos & ns & & \multicolumn{2}{|c|}{ F Interação N CPx2as } & ns \\
\hline Dose N CP $-R^{2}(R L)$ & ns & & \multicolumn{2}{|c|}{ Dose $N 2^{a} S-R^{2}(R L)$} & ns \\
\hline Dose N CP - $R^{2}(R Q)$ & $0,96^{*}$ & & \multicolumn{2}{|c|}{ Dose $N 2^{a} S-R^{2}(R Q)$} & ns \\
\hline Dose N CP - CV (\%) & 2,9 & & \multicolumn{2}{|c|}{ Dose N 2as - CV (\%) } & 3,8 \\
\hline
\end{tabular}

Legenda: $\mathrm{CP}=$ cana-planta (2006); $2^{\mathrm{a} S}=$ segundo ciclo de soqueira; $\mathrm{RL}$ e $\mathrm{RQ}=$ regressão linear e quadrática; * ${ }^{* *} p<0,01$ e $p<0,05$ de probabilidade, ns = não significativo; $C V=$ coeficiente de variação. 
Tabela 12 - Teor de fibra (\%) de cana-de-açúcar de terceiro ciclo ( $2^{\mathrm{a}}$ soqueira) em função das doses de nitrogênio de plantio e soqueiras

\begin{tabular}{|c|c|c|c|c|c|}
\hline \multirow[b]{3}{*}{ Dose N-CP $\left(\mathrm{kg} \mathrm{ha}^{-1}\right)$} & \multicolumn{5}{|c|}{ Fibra (\%) } \\
\hline & \multicolumn{4}{|c|}{ Dose $N-2^{\text {aS }}\left(\mathrm{kg} \mathrm{ha}^{-1}\right)$} & \multirow[b]{2}{*}{ Média } \\
\hline & 0 & 50 & 100 & 150 & \\
\hline 0 & 12,5 & 12,7 & 12,5 & 12,5 & 12,6 \\
\hline 40 & 12,6 & 12,1 & 12,3 & 12,3 & 12,3 \\
\hline 80 & 12,6 & 12,4 & 12,0 & 12,2 & 12,3 \\
\hline 120 & 12,4 & 12,2 & 12,1 & 12,3 & 12,3 \\
\hline Média & 12,5 & 12,4 & 12,2 & 12,3 & 12,4 \\
\hline F Blocos & ns & & \multicolumn{2}{|c|}{ F Interação N CPx2 $2^{\mathrm{a} S}$} & ns \\
\hline Dose $N C P-R^{2}(R L)$ & ns & & \multicolumn{2}{|c|}{ Dose $N 2^{a} S-R^{2}(R L)$} & ns \\
\hline Dose N CP $-R^{2}(R Q)$ & $0,77^{*}$ & & \multicolumn{2}{|c|}{ Dose $N 2^{\text {a }} S-R^{2}(R Q)$} & ns \\
\hline Dose N CP - CV (\%) & 2,2 & & \multicolumn{2}{|c|}{ Dose N $2^{\text {aS }}$ - CV (\%) } & 4,5 \\
\hline
\end{tabular}

Legenda: CP = cana-planta (2006); $2^{\mathrm{a}} \mathrm{S}$ = segundo ciclo de soqueira; $\mathrm{RL}$ e $\mathrm{RQ}$ = regressão linear e quadrática; * ${ }^{* *} p<0,01$ e $p<0,05$ de probabilidade, $n s=$ não significativo; $C V=$ coeficiente de variação.

Tabela 13 - Produtividade de açúcar (TPH, $\mathrm{Mg} \mathrm{ha}^{-1}$ ) de cana-de-açúcar de terceiro ciclo ( $2^{a}$ soqueira) em função das doses de nitrogênio de plantio e soqueiras

\begin{tabular}{|c|c|c|c|c|c|}
\hline \multirow[b]{3}{*}{ Dose N-CP $\left(\mathrm{Kg} \mathrm{ha}^{-1}\right)$} & \multicolumn{5}{|c|}{ Produtividade Agroindustrial (TPH, $\mathrm{Mg} \mathrm{ha}^{-1}$ ) } \\
\hline & \multicolumn{4}{|c|}{ Dose $\mathrm{N}-2^{\mathrm{a} S}\left(\mathrm{~kg} \mathrm{ha}^{-1}\right)$} & \multirow[b]{2}{*}{ Média } \\
\hline & 0 & 50 & 100 & 150 & \\
\hline 0 & 9,3 & 11,2 & 11,5 & 11,3 & 10,8 \\
\hline 40 & 8,4 & 9,1 & 11,7 & 11,1 & 10,1 \\
\hline 80 & 8,0 & 9,9 & 10,1 & 10,9 & 9,7 \\
\hline 120 & 9,9 & 12,1 & 11,1 & 10,3 & 10,9 \\
\hline Média & 8,9 & 10,6 & 11,1 & 10,9 & 10,4 \\
\hline F Blocos & $7,0^{* *}$ & & \multicolumn{2}{|c|}{ F Interação N CPx $2^{\mathrm{a} S}$} & ns \\
\hline Dose $N C P-R^{2}(R L)$ & ns & & \multicolumn{2}{|c|}{ Dose $N 2^{\text {aS }}-R^{2}(R L)$} & $0,70^{* *}$ \\
\hline Dose N CP $-R^{2}(R Q)$ & $0,94^{* *}$ & & \multicolumn{2}{|c|}{ Dose $N 2^{\text {aS }}-R^{2}(R Q)$} & $0,99^{*}$ \\
\hline Dose N CP - CV (\%) & 11,0 & & \multicolumn{2}{|c|}{ Dose N 2aS - CV (\%) } & 13,6 \\
\hline
\end{tabular}

Legenda: $C P=$ cana-planta (2006); $2^{\mathrm{a}} \mathrm{S}$ = segundo ciclo de soqueira; $\mathrm{RL}$ e $\mathrm{RQ}$ = regressão linear e quadrática; * e ** $p<0,01$ e $p<0,05$ de probabilidade, ns = não significativo; $C V=$ coeficiente de variação. 
2.3.4 Terceiro ciclo de soqueira (safra 2008/2009)

Após o corte da segunda soqueira em 2008, todas as parcelas receberam 100 $\mathrm{kg} \mathrm{ha}^{-1}$ de $\mathrm{N}$, com o objetivo de avaliar o efeito residual das aplicações anteriores de $\mathrm{N}$ em cana-planta e nas duas primeiras soqueiras na produtividade da terceira. Nesta terceira soqueira ocorreram boas condições de desenvolvimento, devido uma distribuição de chuvas regular e baixa evapotranspiração real (Figura 1). Conseqüentemente, foi possível observar recuperação da produtividade da cana-deaçúcar $(\mathrm{TCH})$ que foi em média de $89 \mathrm{Mg} \mathrm{ha}^{-1}$, com resposta linear $\left(\mathrm{R}^{2}=0,65\right)$ às doses nominais de $\mathrm{N}$ aplicadas nas soqueiras anteriores (Tabela 14).

A TCH desta soqueira ciclo superou a dos dois ciclos anteriores (80 e 62 no primeiro e no segundo ciclos de soqueira, respectivamente) sendo inferior somente à cana-planta, cuja TCH foi de $152 \mathrm{Mg} \mathrm{ha}^{-1}$ na média dos tratamentos (Tabela 5, $6 \mathrm{e}$ 10). A maior produtividade agrícola deste ciclo foi de $92 \mathrm{TCH}$, obtida com a dose nominal de 120 e $150 \mathrm{~kg} \mathrm{~N} \mathrm{ha}^{-1}$, em plantio e soqueiras respectivamente (Tabela 14). A diferença deste tratamento de soqueira e a testemunha sem aplicação de $N$ foi de $9 \%$, isto é, $8 \mathrm{TCH}$. Para as doses de $\mathrm{N}$ em cana-planta, detectou-se pouca diferença entre os tratamentos, no máximo $3 \%$, isto é, $4 \mathrm{TCH}$.

Tabela 14 - Produtividade agrícola $\left(\mathrm{TCH}, \mathrm{Mg} \mathrm{ha}^{-1}\right)$ de cana-de-açúcar de quarto ciclo ( $3^{\text {a }}$ soqueira) em função das doses de nitrogênio de plantio e soqueiras

\begin{tabular}{|c|c|c|c|c|c|}
\hline \multirow[b]{3}{*}{ Dose N-CP $\left(\mathrm{kg} \mathrm{ha}^{-1}\right)$} & \multicolumn{5}{|c|}{ Produtividade Agrícola $\left(\mathrm{TCH}, \mathrm{Mg} \mathrm{ha}^{-1}\right)$} \\
\hline & \multicolumn{4}{|c|}{ Dose $\mathrm{N}-3^{\mathrm{a}} \mathrm{S} \#\left(\mathrm{~kg} \mathrm{ha}^{-1}\right)$} & \multirow[b]{2}{*}{ Média } \\
\hline & 0 & 50 & 100 & 150 & \\
\hline 0 & 81 & 93 & 90 & 90 & 89 \\
\hline 40 & 87 & 80 & 89 & 98 & 88 \\
\hline 80 & 82 & 91 & 92 & 94 & 90 \\
\hline 120 & 86 & 100 & 90 & 86 & 91 \\
\hline Média & 84 & 91 & 90 & 92 & 89 \\
\hline F Blocos & $4,1^{*}$ & & \multicolumn{2}{|c|}{ F Interação N CPx3as } & ns \\
\hline Dose $N C P-R^{2}(R L)$ & ns & & \multicolumn{2}{|c|}{ Dose $N 3^{\text {aS }}-R^{2}(R L)$} & $0,65^{*}$ \\
\hline Dose $N C P-R^{2}(R Q)$ & ns & & \multicolumn{2}{|c|}{ Dose $N 3^{a} S-R^{2}(R Q)$} & ns \\
\hline Dose N CP - CV (\%) & 13,1 & & \multicolumn{2}{|c|}{ Dose N 3as - CV (\%) } & 10,0 \\
\hline
\end{tabular}

Legenda: $\mathrm{CP}=$ cana-planta (2006); $3^{\mathrm{a}} \mathrm{S} \#=3^{\mathrm{a}}$ soqueira e $\mathrm{N}=100 \mathrm{~kg}^{-1} ; \mathrm{RL}$ e $\mathrm{RQ}=$ regressão linear e quadrática; * $e^{* *} p<0,01$ e $p<0,05$ de probabilidade, $n s=$ não significativo; $C V=$ coeficiente de variação. 
Embora não tenham sido detectadas diferenças significativas para as doses de $\mathrm{N}$ em cana-planta, as doses maiores aplicadas neste ciclo (80 e $120 \mathrm{~kg} \mathrm{~N} \mathrm{ha}^{-1}$ ) apresentaram melhores resultado em valores absolutos, 90 e $91 \mathrm{TCH}$, em comparação aos demais tratamentos 0 e $40 \mathrm{~kg} \mathrm{ha}^{-1}$ (Tabela 14).

Apesar destes resultados indicarem pouco efeito residual das doses maiores de $\mathrm{N}$ em cana-planta, foram detectadas diferenças na $\mathrm{TCH}$ devido às maiores doses de $\mathrm{N}$ aplicadas nas soqueiras anteriores. Como na terceira soqueira a dose de $\mathrm{N}$ foi igualada em $100 \mathrm{~kg} \mathrm{ha}^{-1}$ para todos os tratamentos (inclusive na testemunha que não recebeu $\mathrm{N}$-fertilizante nos ciclos agrícolas anteriores) pode-se afirmar que esta resposta obtida na $\mathrm{TCH}$ deste ciclo ocorreu devido ao efeito residual das doses de $\mathrm{N}$ aplicadas nas soqueiras anteriores.

Novamente não foram obtidas respostas nas características tecnológicas pol $\%$ cana (PCC) e fibra \% para às aplicações de $N$ (Tabelas 15 e 16). Por outro lado, houve resposta na produtividade de açúcar (TPH) devido à maior TCH (Tabela 17).

Tabela 15 - Teor de sacarose (Pol \% cana) de cana-de-açúcar de quarto ciclo ( $3^{a}$ soqueira) em função das doses de nitrogênio de plantio e soqueiras

\begin{tabular}{|c|c|c|c|c|c|}
\hline \multirow[b]{3}{*}{ Dose N - CP $\left(\mathrm{Kg} \mathrm{ha}^{-1}\right)$} & \multicolumn{5}{|c|}{ Pol cana $(\%)$} \\
\hline & \multicolumn{4}{|c|}{ Dose $\mathrm{N}-3^{\mathrm{a}} \mathrm{S} \#\left(\mathrm{~kg} \mathrm{ha}^{-1}\right)$} & \multirow[b]{2}{*}{ Média } \\
\hline & 0 & 50 & 100 & 150 & \\
\hline 0 & 17,3 & 16,9 & 16,4 & 17,1 & 16,9 \\
\hline 40 & 16,5 & 17,1 & 16,7 & 16,9 & 16,8 \\
\hline 80 & 16,9 & 16,8 & 16,8 & 16,6 & 16,8 \\
\hline 120 & 16,6 & 16,3 & 16,2 & 17,1 & 16,6 \\
\hline Média & 16,8 & 16,8 & 16,6 & 16,9 & 16,8 \\
\hline F Blocos & $12,7^{* \star}$ & & F Interaç & $2 P \times 3^{a} S$ & ns \\
\hline Dose $N C P-R^{2}(R L)$ & ns & & Dose $\mathrm{N}$ & $2^{2}(R L)$ & ns \\
\hline Dose N CP - $R^{2}(R Q)$ & ns & & Dose $N 3$ & $2^{2}(R Q)$ & ns \\
\hline Dose N CP - CV (\%) & 3,8 & & Dose $N 3$ & $\mathrm{CV}(\%)$ & 3,3 \\
\hline
\end{tabular}

Legenda: $C P=$ cana-planta (2006); $3^{\text {a }}$ \# $=3^{\text {a }}$ soqueira e $N=100 \mathrm{~kg} \mathrm{ha}^{-1} ; \mathrm{RL}$ e $\mathrm{RQ}=$ regressão linear e quadrática; * $e^{* *} p<0,01$ e $p<0,05$ de probabilidade, ns = não significativo; $C V=$ coeficiente de variação. 
Tabela 16 - Teor de fibra (\%) de cana-de-açúcar de quarto ciclo (3a soqueira) em função das doses de nitrogênio de plantio e soqueiras

\begin{tabular}{|c|c|c|c|c|c|}
\hline \multirow[b]{3}{*}{ Dose $\mathrm{N}-\mathrm{CP}\left(\mathrm{Kg} \mathrm{ha}^{-1}\right)$} & \multicolumn{5}{|c|}{ Fibra (\%) } \\
\hline & \multicolumn{4}{|c|}{ Dose $\mathrm{N}-3^{\mathrm{a}} \mathrm{S} \#\left(\mathrm{~kg} \mathrm{ha}^{-1}\right)$} & \multirow[b]{2}{*}{ Média } \\
\hline & 0 & 50 & 100 & 150 & \\
\hline 0 & 13,0 & 12,7 & 12,4 & 12,7 & 12,7 \\
\hline 40 & 12,4 & 12,4 & 12,5 & 12,3 & 12,4 \\
\hline 80 & 12,7 & 12,7 & 12,3 & 12,4 & 12,5 \\
\hline 120 & 12,6 & 12,9 & 12,5 & 12,8 & 12,7 \\
\hline Média & 12,7 & 12,7 & 12,4 & 12,6 & 12,6 \\
\hline F Blocos & $11,4^{* *}$ & & \multicolumn{2}{|c|}{ F Interação N CPx3as } & ns \\
\hline Dose N CP $-R^{2}(R L)$ & ns & & \multicolumn{2}{|c|}{ Dose $N 3^{\text {a }} S-R^{2}(R L)$} & ns \\
\hline Dose N CP $-R^{2}(R Q)$ & $0,83^{*}$ & & \multicolumn{2}{|c|}{ Dose $N 3^{\text {a }} S-R^{2}(R Q)$} & ns \\
\hline Dose N CP - CV (\%) & 3,1 & & \multicolumn{2}{|c|}{ Dose N $3^{\mathrm{a} S}$ - CV (\%) } & 3,5 \\
\hline
\end{tabular}

Legenda: $\mathrm{CP}=$ cana-planta (2006); $3^{\mathrm{a}} \mathrm{S} \#=3^{\mathrm{a}}$ soqueira e $\mathrm{N}=100 \mathrm{~kg} \mathrm{ha}^{-1} ; \mathrm{RL}$ e $\mathrm{RQ}=$ regressão linear e quadrática; * $e^{* *} p<0,01$ e $p<0,05$ de probabilidade, $n s=$ não significativo; $C V=$ coeficiente de variação.

Tabela 17 - Produtividade de açúcar (TPH, Mg ha $\left.{ }^{-1}\right)$ de cana-de-açúcar de quarto ciclo ( $3^{a}$ soqueira) em função das doses de nitrogênio de plantio e soqueiras

\begin{tabular}{|c|c|c|c|c|c|}
\hline \multirow[b]{3}{*}{ Dose $\mathrm{N}-\mathrm{CP}\left(\mathrm{Kg} \mathrm{ha}^{-1}\right)$} & \multicolumn{5}{|c|}{ Produtividade Agroindustrial (TPH, $\mathrm{Mg} \mathrm{ha}^{-1}$ ) } \\
\hline & \multicolumn{4}{|c|}{ Dose $\mathrm{N}-3^{\mathrm{a}} \mathrm{S} \#\left(\mathrm{Kg} \mathrm{ha}^{-1}\right)$} & \multirow[b]{2}{*}{ Média } \\
\hline & 0 & 50 & 100 & 150 & \\
\hline 0 & 14,0 & 15,8 & 14,9 & 15,5 & 15,0 \\
\hline 40 & 14,3 & 13,6 & 14,8 & 16,5 & 14,8 \\
\hline 80 & 13,7 & 15,3 & 15,4 & 15,5 & 15,0 \\
\hline 120 & 14,3 & 16,4 & 14,6 & 14,7 & 15,0 \\
\hline Média & 14,1 & 15,3 & 14,9 & 15,5 & 15,0 \\
\hline F Blocos & ns & & \multicolumn{2}{|c|}{ F Interação N CPx3as } & ns \\
\hline Dose N CP $-R^{2}(R L)$ & ns & & \multicolumn{2}{|c|}{ Dose $N 3^{\text {a }} S-R^{2}(R L)$} & ns \\
\hline Dose N CP $-R^{2}(R Q)$ & ns & & \multicolumn{2}{|c|}{ Dose $N 3^{a} S-R^{2}(R Q)$} & $0,66^{*}$ \\
\hline Dose N CP - CV (\%) & 14,8 & & \multicolumn{2}{|c|}{ Dose N 3as - CV (\%) } & 10,2 \\
\hline
\end{tabular}

Legenda: $\mathrm{CP}=$ cana-planta (2006); $3^{\mathrm{a}} \mathrm{S} \#=3^{\mathrm{a}}$ soqueira e $\mathrm{N}=100 \mathrm{~kg} \mathrm{ha}^{-1} ; \mathrm{RL}$ e $\mathrm{RQ}=$ regressão linear e quadrática; * $e^{* *} p<0,01$ e $p<0,05$ de probabilidade, ns = não significativo; $C V=$ coeficiente de variação. 
2.3.5 Produtividade agroindustrial média e acumulada de cana-de-açúcar em quatro ciclos agrícolas consecutivos: cana-planta e três soqueiras

Houve efeito positivo da adubação nitrogenada na produtividade média da cultura colhida sem a queima da palhada por quatro ciclos consecutivos (Tabela $18 \mathrm{e}$ Figura 2). As produtividades agroindustriais, TCH e TPH médias dos quatro ciclos, apresentaram respostas significativas para as fertilizações de cana-soqueira, regressão quadrática $\left(R^{2}=0,99\right)$ e linear $\left(R^{2}=0,77\right)$, respectivamente (Figura 2, Tabelas 18, 19, 20 e 21).

Wiedenfeld (2000) verificou respostas na TCH, PCC e TPH em ensaio de cinco ciclos de cana colhida queimada no Texas, EUA e verificaram que as dose de $\mathrm{N}$ em soqueiras para máxima TCH oscilaram entre 140 a $175 \mathrm{~kg} \mathrm{ha}^{-1}$ de $\mathrm{N}$ enquanto que, para a PCC, a dose ótima foi de aproximadamente $137 \mathrm{~kg} \mathrm{ha}^{-1}$. Neste trabalho a máxima TCH média (98 $\mathrm{Mg} \mathrm{ha}^{-1}$ ) foi obtida com a aplicação de $120 \mathrm{~kg} \mathrm{~kg} \mathrm{ha}^{-1} \mathrm{de} \mathrm{N}$ e para TPH obteve-se resposta linear (Figura 2).

Tabela 18 - Produtividade agrícola $\left(\mathrm{TCH}, \mathrm{Mg} \mathrm{ha}^{-1}\right)$ média de quatro ciclos de canade-açúcar em função das doses de nitrogênio de plantio e soqueiras

\begin{tabular}{cccccc}
\hline & \multicolumn{5}{c}{ Produtividade Agrícola $\left(\mathrm{TCH}, \mathrm{Mg} \mathrm{ha}^{-1}\right)$} \\
\cline { 2 - 5 } Dose N - CP $\left(\mathrm{Kg} \mathrm{ha}^{-1}\right)$ & 0 & 50 & 100 & 150 & Média \\
\cline { 2 - 5 } & 08 & 95 & 97 & 95 & 94 \\
40 & 92 & 89 & 97 & 101 & 95 \\
80 & 90 & 96 & 98 & 97 & 95 \\
120 & 96 & 105 & 100 & 97 & 99 \\
\hline Média & 91 & 96 & 98 & 98 & 96 \\
\hline F Blocos & $\mathrm{ns}$ & & $\mathrm{F}$ Interação N CPxCS & $\mathrm{ns}$ \\
Dose N CP - $\mathrm{R}^{2}(\mathrm{RL})$ & $\mathrm{ns}$ & & Dose N CS - $\mathrm{R}^{2}(\mathrm{RL})$ & $0,74^{* *}$ \\
Dose N CP - $\mathrm{R}^{2}(\mathrm{RQ})$ & $\mathrm{ns}$ & & Dose N CS $-\mathrm{R}^{2}(\mathrm{RQ})$ & $0,99^{\star}$ \\
Dose N CP $-\mathrm{CV}(\%)$ & 8,1 & & Dose N CS $-\mathrm{CV}(\%)$ & 4,9 \\
\hline
\end{tabular}

Legenda: CP = cana-planta (2006); CS = soqueiras de 2007 a 2009; $R L$ e RQ = regressão linear e quadrática; * e ${ }^{* *} p<0,01$ e $p<0,05$ de probabilidade, ns = não significativo; $C V=$ coeficiente de variação. 

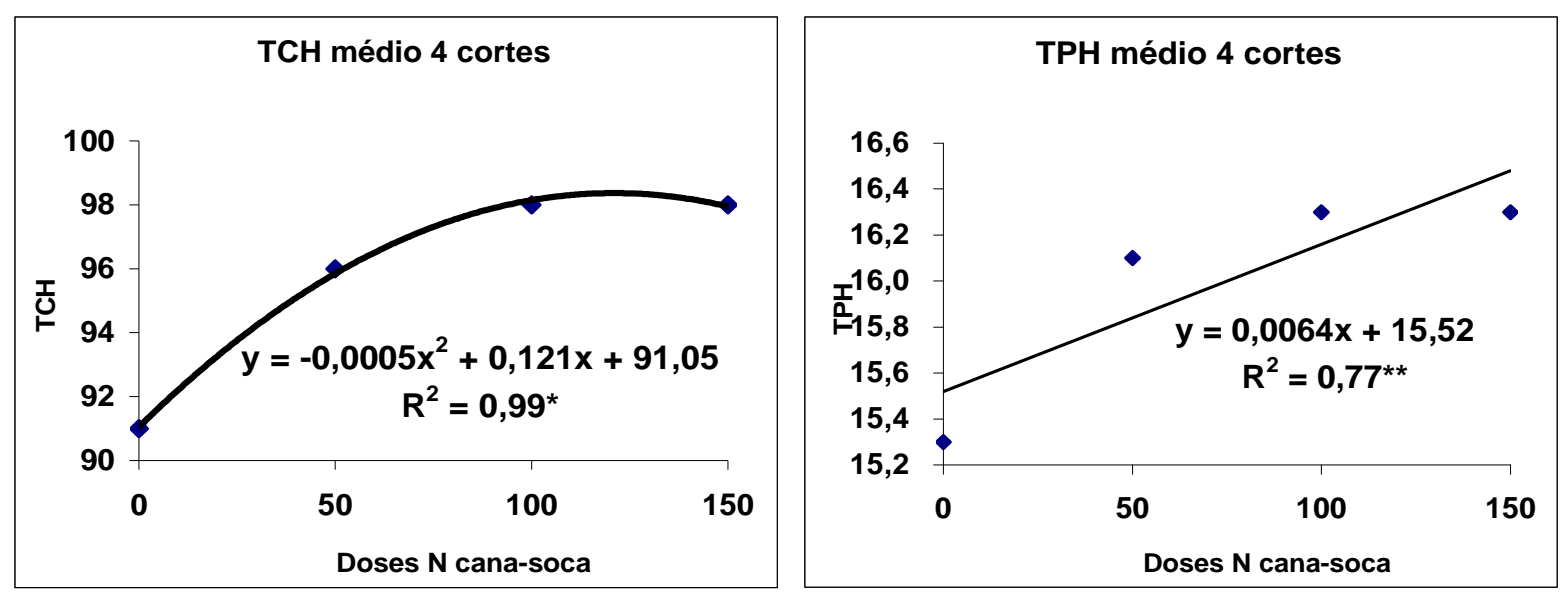

Figura 2 - Regressões quadrática e linear para as produtividades agrícola (TCH) e agroindustrial (TPH) médias de quatro ciclos consecutivos (2006 a 2009) no experimento da Usina São Martinho em Jaboticabal, SP

Observou-se que as doses 100 e $150 \mathrm{~kg} \mathrm{ha}^{-1}$ de $\mathrm{N}$ apresentaram respostas praticamente iguais em $\mathrm{TCH}$ e $\mathrm{TPH}$, sendo cerca de $7 \%(7 \mathrm{TCH})$ superiores relativamente à testemunha. Ressalta-se que, embora sem diferença estatística, a maior dose de $\mathrm{N}$ em cana-planta (120 kg ha ${ }^{-1}$ ) foi a que apresentou maiores $\mathrm{TCH}$ médias, isto é, cerca de $5 \%$ maior $(5 \mathrm{TCH})$ que a do tratamento testemunha em cana-planta, dando novamente indícios do efeito residual das adubações nitrogenadas antecedentes na produtividade de ciclos subsequentes (Tabela 18).

A manutenção da palhada no solo e as doses de $\mathrm{N}$ fertilizante afetaram a produtividade da cana-de-açúcar e os efeitos são complexos, pois envolvem fatores como adaptação de variedades, brotação da soqueira sob a palhada, pressão de pragas e doenças, disponibilidade de água, além da nutrição da cultura com $\mathrm{N}$. Manechini, Ricci Junior e Donzelli (2005) obtiveram reduções em TCH, pol\% cana e TPH em experimentos na Usina São Martinho durante seis ciclos consecutivos. Os autores conservaram parcelas com 100,66, 33 e $0 \%$ de palhada. Além da cobertura pela palhada os autores ressaltaram que diferenças também foram causadas pelas condições locais de clima, variedade de cana e infestação por pragas e ervas daninhas, maiores nas áreas com a retenção da palhada.

Além dos tratamentos com aplicação de $\mathrm{N}$, existem vários outros fatores que interferiram na produtividade dos ciclos consecutivos como a própria presença da palhada e os aspectos climáticos de cada ano agrícola. Orlando Filho et al. (1994) relataram que a presença de palha provocou redução acentuada na produção de colmos, mas o problema parecia estar relacionado à variedade usada. Basanta et al. 
(2003) também relataram produções menores em áreas de cana sem despalha a fogo em relação à cana queimada, em solo argiloso. Por outro lado, em solo arenoso, Trivelin et al. (2002a; 2002b) não encontraram diferenças em produtividade de colmos em experimento com ou sem queima da palha. Na região de Piracicaba, Fortes, Campos e Silva (2009) encontraram incrementos médios de $14 \%$ na produtividade de colmos em dois tipos de solos (arenoso e argiloso) somente com o manejo da palhada, ou seja, tratamentos em que a palhada foi aleirada ou removida da linha de cana após a colheita mecanizada.

Em alguns estudos, os rendimentos não foram afetados após três anos de adoção da colheita sem queima (SOUZA et al., 2005), ou após 15 anos (THORBURN et al., 1999), ao passo que Resende et al. (2006) e Ball-Coelho et al. (1993) conseguiram maiores produtividades em cana sem queima na maioria dos ciclos avaliados. Wood (1991) observou produtividades de até $10 \mathrm{Mg} \mathrm{ha}^{-1}$ a mais na média de cinco experimentos em solos bem drenados, porém não detectou diferenças para locais mal drenados. Em experimentos de longa duração (39 colheitas) na África do Sul, áreas manejadas, mantendo-se a palhada, apresentaram incremento médio na produção de colmos de $9 \mathrm{Mg} \mathrm{ha}^{-1} \mathrm{ano}^{-1}$ (GRAHAM; HAYNES; MEYER, 2002). Portanto, embora este fator não tenha sido investigado neste trabalho, existe influência direta da palhada na produtividade de cana-de-açúcar que não somente os tratamentos de nitrogênio.

As doses de $\mathrm{N}$ no plantio não apresentaram efeitos diretos na qualidade tecnológica da matéria-prima (pol \% cana e fibra \%) na média dos quatro ciclos agrícolas, bem como não foram detectadas diferenças nas características tecnológicas médias nas quatro safras (Tabela 19 e 20). Esses resultados diferem dos de Wiedenfeld (1998; 2000) que verificaram pequenos mas significativos decréscimos no conteúdo de açúcar (PCC) da cana em experimentos de longa duração, 3 e 5 ciclos consecutivos, respectivamente. Portanto este autor concluiu que no caso de respostas negativas na PCC, é esperado que as doses de $\mathrm{N}$ que maximizem este fator sejam inferiores àquelas que proporcionam a maior $\mathrm{TCH}$. 
Tabela 19 - Teor de sacarose (pol \% cana) média de quatro ciclos de cana-deaçúcar em função das doses de nitrogênio de plantio e soqueiras

\begin{tabular}{|c|c|c|c|c|c|}
\hline \multirow[b]{3}{*}{ Dose N-CP $\left(\mathrm{Kg} \mathrm{ha}^{-1}\right)$} & \multicolumn{5}{|c|}{ Pol cana $(\%)$} \\
\hline & \multicolumn{4}{|c|}{ Dose N-S $\left(\mathrm{Kg} \mathrm{ha}^{-1}\right)$} & \multirow[b]{2}{*}{ Média } \\
\hline & 0 & 50 & 100 & 150 & \\
\hline 0 & 16,8 & 16,7 & 16,3 & 16,7 & 16,7 \\
\hline 40 & 16,7 & 16,9 & 16,8 & 16,7 & 16,8 \\
\hline 80 & 16,6 & 16,5 & 16,4 & 16,5 & 16,5 \\
\hline 120 & 16,8 & 16,6 & 16,7 & 16,9 & 16,7 \\
\hline Média & 16,7 & 16,7 & 16,6 & 16,7 & 16,7 \\
\hline F Blocos & $5,8^{*}$ & & \multicolumn{2}{|c|}{ F Interação N CPxS } & ns \\
\hline Dose $N C P-R^{2}(R L)$ & ns & & \multicolumn{2}{|c|}{ Dose N S- $R^{2}(R L)$} & ns \\
\hline Dose N CP - $R^{2}(R Q)$ & ns & & \multicolumn{2}{|c|}{ Dose N S-R $(R Q)$} & ns \\
\hline Dose N CP - CV (\%) & 2,6 & & \multicolumn{2}{|c|}{ Dose N S - CV (\%) } & 1,4 \\
\hline
\end{tabular}

Legenda: $\mathrm{CP}$ = cana-planta (2006); $\mathrm{S}$ = soqueiras de 2007 a 2009; RL e RQ = regressão linear e quadrática; * $e^{* *} p<0,01$ e $p<0,05$ de probabilidade, ns = não significativo; $C V=$ coeficiente de variação.

Tabela 20 - Teor de fibra (\%) média de quatro ciclos de cana-de-açúcar em função das doses de nitrogênio de plantio e soqueiras

\begin{tabular}{|c|c|c|c|c|c|}
\hline \multirow[b]{3}{*}{ Dose N-CP $\left(\mathrm{Kg} \mathrm{ha}^{-1}\right)$} & \multicolumn{5}{|c|}{ Fibra (\%) } \\
\hline & \multicolumn{4}{|c|}{ Dose $N-S\left(K g h a^{-1}\right)$} & \multirow[b]{2}{*}{ Média } \\
\hline & 0 & 50 & 100 & 150 & \\
\hline 0 & 12,9 & 12,9 & 12,9 & 12,9 & 12,9 \\
\hline 40 & 12,9 & 12,7 & 12,8 & 12,8 & 12,8 \\
\hline 80 & 12,9 & 12,9 & 12,6 & 12,9 & 12,8 \\
\hline 120 & 12,9 & 12,9 & 12,8 & 12,9 & 12,9 \\
\hline Média & 12,9 & 12,9 & 12,8 & 12,9 & 12,9 \\
\hline F Blocos & ns & & \multicolumn{2}{|c|}{ F Interação N CPxS } & ns \\
\hline Dose N CP $-R^{2}(R L)$ & ns & & \multicolumn{2}{|c|}{ Dose N S - R ${ }^{2}(R L)$} & ns \\
\hline Dose $N C P-R^{2}(R Q)$ & ns & & \multicolumn{2}{|c|}{ Dose $N S-R^{2}(R Q)$} & ns \\
\hline Dose N CP - CV (\%) & 2,2 & & \multicolumn{2}{|c|}{ Dose N S - CV (\%) } & 1,3 \\
\hline
\end{tabular}

Legenda: $\mathrm{CP}$ = cana-planta (2006); CS = soqueiras de 2007 a 2009; $\mathrm{RL}$ e $\mathrm{RQ}$ = regressão linear e quadrática; * ${ }^{* *} p<0,01$ e $p<0,05$ de probabilidade, ns = não significativo; $C V=$ coeficiente de variação. 
A diferença de produtividade agroindustrial (TPH) dos tratamentos com 100 e $150 \mathrm{~kg} \mathrm{ha}^{-1}$ de $\mathrm{N}$ em soqueiras foram idênticas e $6 \%$ superiores ao tratamento testemunha com 0 de N. Malavolta e Moraes (2007) ressaltaram que, para cada ponto porcentual a mais de $\mathrm{TCH}$, é possível que ocorra uma diminuição de $0,01 \%$ na PCC. Porém, a produtividade agroindustrial (TPH) geralmente é compensada pela maior produção de colmos, assim como ocorreu no presente trabalho (Tabela 21).

Em nenhum ciclo houve efeito significativo da interação entre doses de canaplanta e soqueira. Houve alta variabilidade espacial da produtividade agroindustrial a partir da segunda soqueira (terceiro corte) em diante, uma vez que foi detectado efeito significativo para blocos. Isso pode ter como explicação o aumento de falhas no canavial causado pela própria colheita mecanizada, infestação de pragas e ervas daninhas.

Tabela 21 - Produtividade de açúcar (TPH, Mg ha ${ }^{-1}$ ) média de quatro ciclos de canade-açúcar em função das doses de nitrogênio de plantio e soqueiras

\begin{tabular}{|c|c|c|c|c|c|}
\hline \multirow[b]{3}{*}{ Dose $\mathrm{N}-\mathrm{CP}\left(\mathrm{Kg} \mathrm{ha}^{-1}\right)$} & \multicolumn{5}{|c|}{ Produtividade Agroindustrial (TPH, $\mathrm{Mg} \mathrm{ha}^{-1}$ ) } \\
\hline & \multicolumn{4}{|c|}{ Dose $\mathrm{N}-\mathrm{S}\left(\mathrm{Kg} \mathrm{ha}^{-1}\right)$} & \multirow[b]{2}{*}{ Média } \\
\hline & 0 & 50 & 100 & 150 & \\
\hline 0 & 14,8 & 15,9 & 15,9 & 16,0 & 15,6 \\
\hline 40 & 15,5 & 15,2 & 16,4 & 16,9 & 16,0 \\
\hline 80 & 14,9 & 15,9 & 16,1 & 16,0 & 15,7 \\
\hline 120 & 16,1 & 17,5 & 16,7 & 16,5 & 16,7 \\
\hline Média & 15,3 & 16,1 & 16,3 & 16,3 & 16,0 \\
\hline F Blocos & ns & & \multicolumn{2}{|c|}{ F Interação N CPxS } & ns \\
\hline Dose N CP $-\mathrm{R}^{2}(\mathrm{RL})$ & ns & & \multicolumn{2}{|c|}{ Dose N S - R ${ }^{2}(R L)$} & $0,77^{* *}$ \\
\hline Dose N CP $-R^{2}(R Q)$ & ns & & \multicolumn{2}{|c|}{ Dose N S - $R^{2}(R Q)$} & ns \\
\hline Dose N CP - CV (\%) & 9,7 & & \multicolumn{2}{|c|}{ Dose N S - CV (\%) } & 4,9 \\
\hline
\end{tabular}

Legenda: CP = cana-planta (2006); CS = soqueiras de 2007 a 2009; $R L$ e $R Q$ = regressão linear e quadrática; * $e^{* *} p<0,01$ e $p<0,05$ de probabilidade, ns = não significativo; $C V=$ coeficiente de variação.

A produtividade cumulativa ao longo dos quatro ciclos agrícolas foi influenciada pelas doses de $\mathrm{N}$ aplicadas em cana-planta e soqueiras. A maior produtividade agrícola $(\mathrm{TCH})$ acumulada nos quatro ciclos foi obtida no tratamento 120 - $100 \mathrm{~kg} \mathrm{ha}^{-1}$ de $\mathrm{N}$ em cana-planta e soqueiras, respectivamente (Tabela $22 \mathrm{e}$ Figura 3). 
Tabela 22 - Produtividades agrícolas $\left(\mathrm{Mg} \mathrm{ha}^{-1}\right)$ acumuladas em dois, três e quatro ciclos consecutivos de cana-de-açúcar em função das doses de nitrogênio no plantio e soqueiras no experimento da Usina São Martinho em Jaboticabal, SP

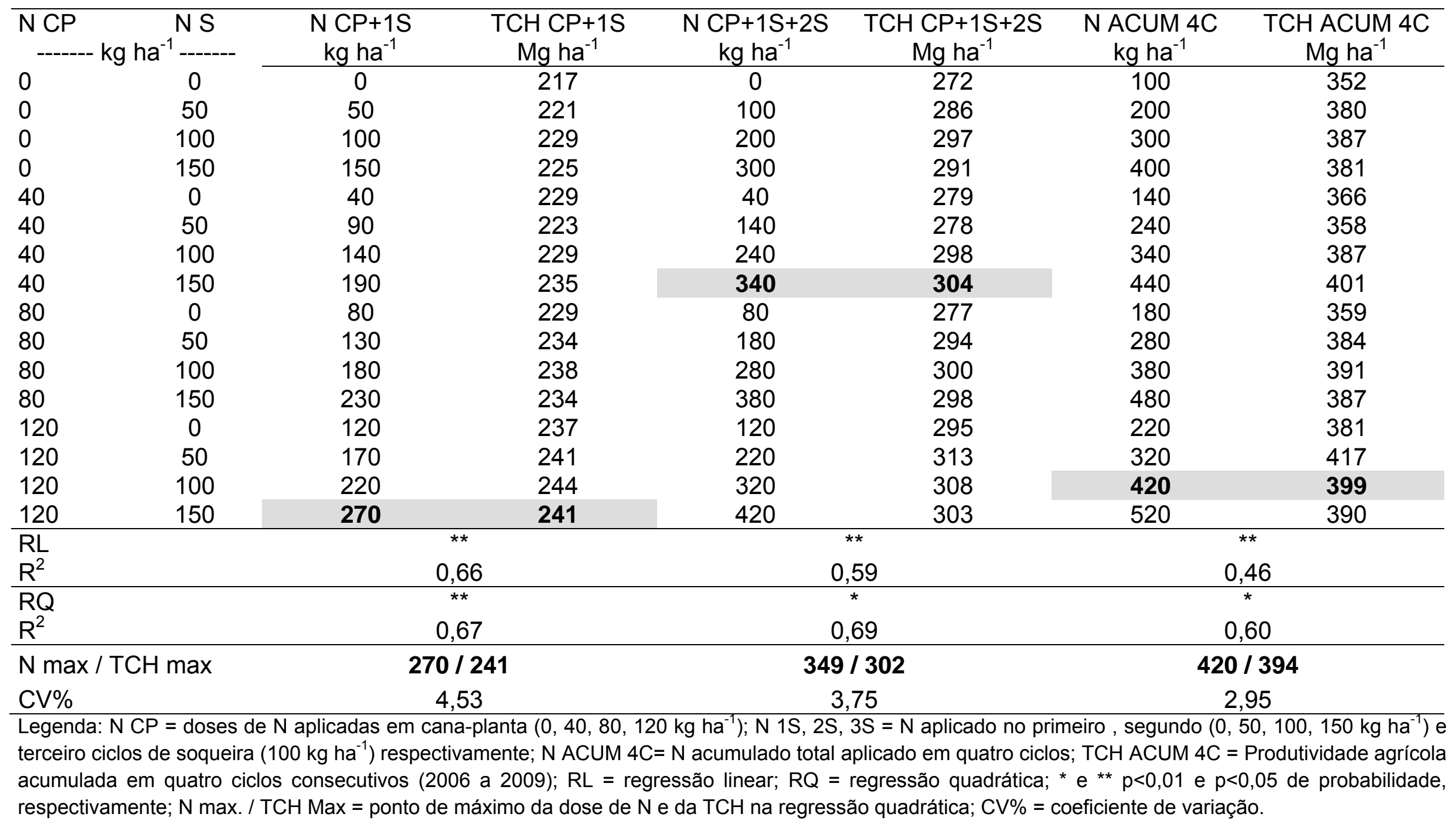



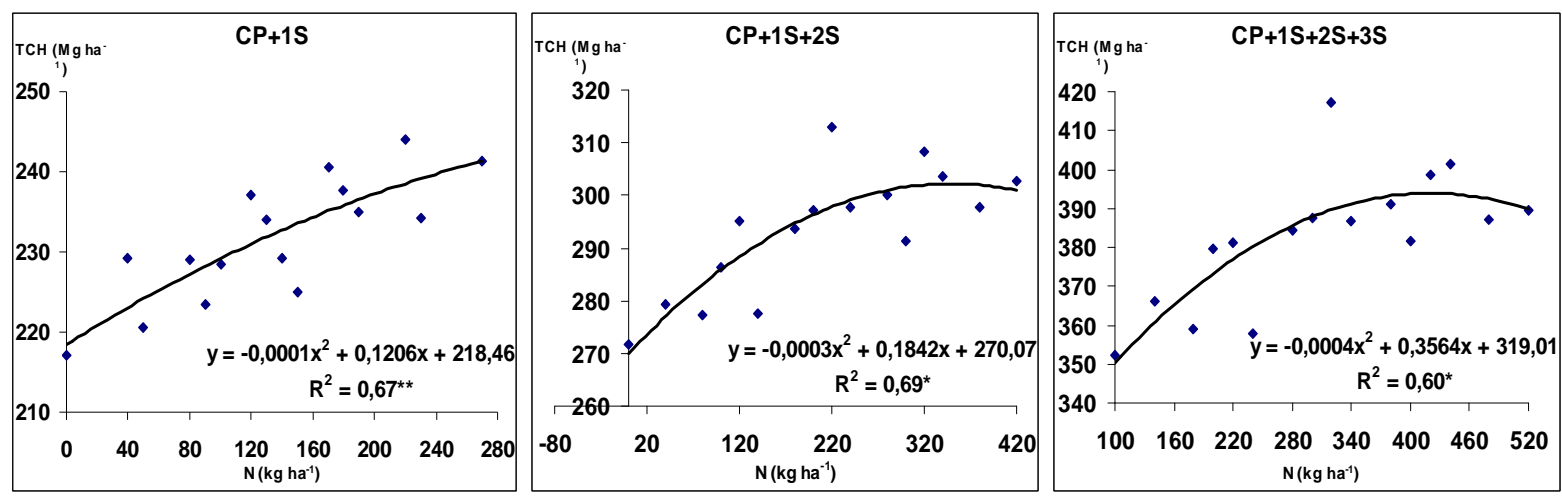

Figura 3 - Produtividade agrícola de cana-de-açúcar cumulativa em quatro ciclos consecutivos em função das doses acumuladas de $\mathrm{N} \mathrm{em}\left(\mathrm{kg} \mathrm{ha}^{-1}\right)$ canaplanta e soqueiras

Já o tratamento de pior performance foi o $0-0 \mathrm{~kg} \mathrm{ha}^{-1}$ de $\mathrm{N}$ em cana-planta e soqueiras como era de se esperar. Esta diferença na produtividade se iniciou a partir do terceiro ciclo e perdurou até o quarto, quando a fertilização nitrogenada foi nivelada a $100 \mathrm{~kg} \mathrm{~N} \mathrm{ha}^{-1} \mathrm{em}$ todos os tratamentos.

Portanto, embora não tenham sido detectadas diferenças significativas de produtividade devido ao efeito residual e/ou interação com os tratamentos de canaplanta nos ciclos isoladamente, a análise do acumulado dos quatro cortes indicou que houve manutenção da produtividade de doses de nitrogênio em ciclos de soqueira anteriores (Figura 3).

Assim como no presente trabalho, Korndorfer et al. (2002) obtiveram respostas em TCH (6\% ou $10 \mathrm{TCH}$ ) devido a aplicação de N em cana-planta (60 kg $\mathrm{ha}^{-1}$ ) em um PVA de textura arenosa, porém obtiveram decréscimo de cerca de $10 \%$ (14 $\mathrm{TCH}$ ) na produtividade da primeira soqueira no tratamento que recebeu $\mathrm{N}$ em cana-planta comparado à testemunha. Concluíram que não houve efeito residual positivo da adubação de cana-planta na produtividade agrícola da soqueira seguinte e que as diferenças em TCH foram devido somente às variedades de cana-deaçúcar utilizadas. Os autores também não obtiveram diferenças na PCC e Fibra \% devido à aplicação de $\mathrm{N}$.

Determinações químicas do solo dos tratamentos indicaram que as doses de $\mathrm{N}$ aplicadas no plantio exerceram efeitos nos teores de macronutrientes após a colheita da cana-planta. As doses de $\mathrm{N}$ aplicadas na soqueira diminuíram o $\mathrm{pH}$ e os teores de bases trocáveis no solo após a colheita das safras seguintes, especialmente na camada superficial (OTTO et al., 2009a). Esta diminuição de pH 
com as doses crescentes de $\mathrm{N}$ também foi encontrada por Prado e Pancelli (2008). Em sistemas de produção com elevado aporte de nitrogênio e elevada produção de biomassa, é necessário fornecer quantidades adequadas de nutrientes ao sistema solo-planta, visando altas produtividades e sustentabilidade agroambiental.

A falta de nitrogênio absoluta do tratamento testemunha não foi recuperada quando o nutriente foi aplicado em todo o experimento após o corte da segunda soqueira, o que confirma a necessidade de se manter a adubação com nitrogênio ao longo dos ciclos de modo a manter a produtividade e longevidade da cultura (Tabela 22; Figura 4)

No acumulado dos quatro ciclos, foram necessários $1,3 \mathrm{~kg}$ de $\mathrm{N}$ para a produção de $1 \mathrm{Mg}$ de colmos, considerando a dose de $40 \mathrm{~kg} \mathrm{ha}^{-1}$ de $\mathrm{N}$ em canaplanta (Figura 4). Estes resultados corroboram com os de Coletti et al. (2006) que obtiveram 1,2 e $1,4 \mathrm{~kg}$ de $\mathrm{N} \mathrm{Mg}^{-1}$ de colmos para a cana-planta e soqueira, respectivamente da variedade SP81-3250 e Korndorfer et al. (1997) cujo resultado foi $1,4 \mathrm{~kg} \mathrm{Mg}^{-1}$ na média de quatro variedades em cana-planta.

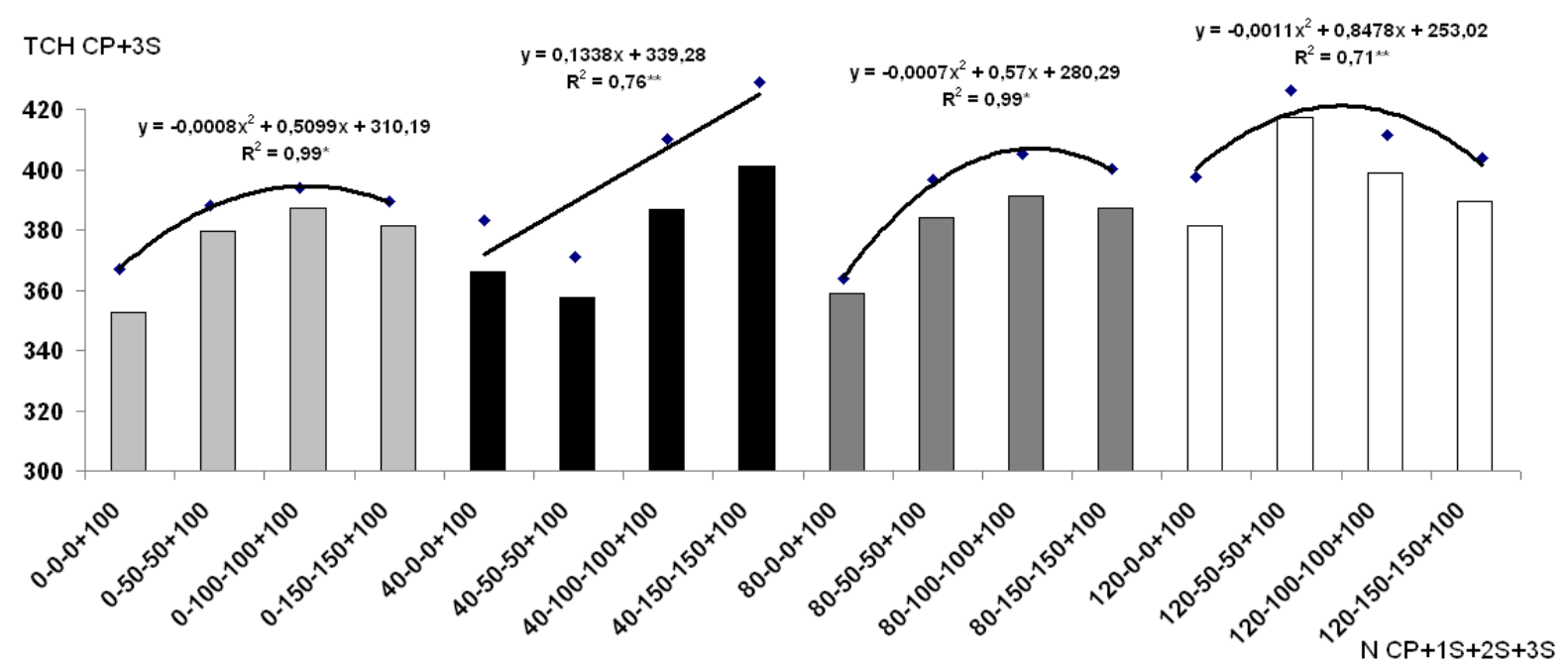

Legenda: $\mathrm{TCH} C P+3 S$ = produtividade agrícola acumulada cana-planta $(\mathrm{CP})$ e três ciclos de soqueira (S) consecutivos; $\mathrm{N} \mathrm{CP}+1 \mathrm{~S}+2 \mathrm{~S}+3 \mathrm{~S}=\mathrm{N}$ aplicado em cana-planta e soqueiras subsequentes

Figura 4 - Produtividades agrícolas acumuladas de cana-de-açúcar decorrentes dos tratamentos com $\mathrm{N}\left(\mathrm{kg} \mathrm{ha}^{-1}\right)$ em cana-planta $(0,40,80$ e 120) e soqueiras $(0,50,100,150)$ durante quatro ciclos agrícolas consecutivos (2006 a 2009) 
2.3.6 Análise econômica dos tratamentos aplicados em cana-planta e soqueiras após quatro ciclos consecutivos (2006 a 2009).

O tratamento que na média de quatro ciclos agrícolas apresentou melhor resultado econômico para MCA foi a dose 120 - $50 \mathrm{~kg} \mathrm{ha}^{-1}$ de $\mathrm{N}$ em cana-planta e soqueiras, respectivamente, (Tabela 23).

Este resultado enaltece a importância de investimentos em adubações nitrogenadas, principalmente nos ciclos iniciais da cultura visando a manutenção da população de perfilhos, menor matocompetição e resistência a adversidades climáticas. Estes resultados são coerentes com os de Vale, Prado e Pancelli (2009) que comparando doses de N-uréia em duas soqueiras (2005 e 2006) da variedade SP79-1011 na região de Jaboticabal, encontraram o maior benefício-custo, para a dose $50 \mathrm{~kg} \mathrm{ha}^{-1}$. Os autores ressaltam que não houve diferença na produtividade agrícola da primeira soqueira, provavelmente devido às condições climáticas daquele ano, porém na segunda soqueira obtiveram respostas na produtividade agrícola até $150 \mathrm{~kg} \mathrm{ha}^{-1}$. Mencionaram que, no período analisado, ocorrem elevados preços da uréia (acima de $R \$ 1.700,00 \mathrm{t}^{-1}$ ) e baixos preços da cana $\left(R \$ 29,70 \mathrm{Mg}^{-1}\right)$, portanto, uma maior atenção deve ser dada às aplicações de $\mathrm{N}$ quando em épocas de crise visando não comprometer a rentabilidade nem a longevidade do canavial, como demonstraram Vitti et al. (2007) e no presente trabalho. Por outro lado, os tratamentos $40-150$ e $40-100 \mathrm{~kg} \mathrm{ha}^{-1}$ de $\mathrm{N}$ em cana-planta e soqueiras também apresentaram MCA média superior a $\mathrm{R} \$ 3.000 \mathrm{ha}^{-1}$, e representam as doses atualmente aplicadas à cultura de cana-de-açúcar (CANTARELLA; TRIVELIN; VITTI, 2007; ESPIRONELLO et al., 1996; PENATTI; FORTI, 1997).

Para a $\mathrm{MCl}$, isto é, o retorno econômico envolvendo os custos de processamento industrial, notou-se que os tratamentos $40-0$ e $120-0 \mathrm{~kg} \mathrm{ha}^{-1} \mathrm{de} \mathrm{N}$ em cana-planta e soqueiras, respectivamente foram os que proporcionaram os melhores resultados ( $R \$ 466,00$ e $R \$ 459,00$ ha $^{-1}$, respectivamente). Embora não seja tecnicamente viável deixar de aplicar nitrogênio em soqueiras, a pouca economicidade da fertilização das soqueiras esteve relacionada ao alto preço da fonte nitrato de amônio e aos medianos preços de matéria-prima (cana-de-açúcar), açúcar e álcool, considerando o período estudado (2006 a 2009). Neste caso, o tratamento 120 - 0 apresentou-se novamente como o mais adequado com $\mathrm{MCl}$ de $\mathrm{R} \$ 449 \mathrm{ha}^{-1}$ (Tabela 23). 
Tabela 23 - Margens de contribuição agrícola (MCA) e agroindustrial (MCl) médias de quatro ciclos agrícolas em função da adubação nitrogenada de cana-planta e soqueiras do experimento da Usina São Martinho, Jaboticabal, SP

\begin{tabular}{|c|c|c|c|c|c|c|c|c|c|c|}
\hline \multirow{3}{*}{$\begin{array}{l}\text { Doses N - } \\
\text { CP }\left(\mathrm{kg} \mathrm{ha}^{-1}\right)\end{array}$} & \multicolumn{8}{|c|}{ Doses $N-S\left(\mathrm{~kg} \mathrm{ha}^{-1}\right)$} & \multirow{2}{*}{\multicolumn{2}{|c|}{ Média }} \\
\hline & \multicolumn{2}{|c|}{0} & \multicolumn{2}{|c|}{50} & \multicolumn{2}{|c|}{100} & \multicolumn{2}{|c|}{150} & & \\
\hline & MCA & $\mathrm{MCl}$ & MCA & $\mathrm{MCl}$ & MCA & $\mathrm{MCl}$ & MCA & $\mathrm{MCl}$ & MCA & $\mathrm{MCl}$ \\
\hline & & & & & & & & & & \\
\hline 0 & 2.802 & 444 & 2.954 & 428 & 2.881 & 355 & 2.903 & 356 & 2.885 & 396 \\
\hline 40 & 2.932 & 466 & 2.851 & 426 & 3.033 & 419 & 3.074 & 382 & 2.973 & 423 \\
\hline 80 & 2.781 & 407 & 2.920 & 389 & 2.921 & 352 & 2.835 & 302 & 2.864 & 362 \\
\hline 120 & 3.021 & 459 & 3.233 & 449 & 3.047 & 385 & 2.989 & 357 & 3.073 & 413 \\
\hline Média & 2.884 & 444 & 2.989 & 423 & 2.970 & 378 & 2.950 & 349 & 2.949 & 398 \\
\hline $\mathrm{dpm}$ & \pm 57 & \pm 13 & \pm 84 & \pm 12 & \pm 41 & \pm 16 & \pm 52 & \pm 17 & \pm 48 & \pm 13 \\
\hline
\end{tabular}

Embora tenham sido detectadas oscilações nos valores de MCA para os tratamentos com aplicação de $\mathrm{N}$, principalmente devido às variações na $\mathrm{TCH}$ e conseqüentemente na TPH nos ciclos individualmente, de forma geral os tratamentos com aplicação de $\mathrm{N}$ em cana-planta e soqueiras apresentaram desempenho econômico superior à testemunha. No acumulado dos quatro ciclos avaliados, os tratamentos com melhores resultados de MCA foram 120 - 50, seguido de 40 - $150 \mathrm{~kg} \mathrm{ha}^{-1}$ de $\mathrm{N}$ em cana-planta e soqueiras, respectivamente, com $\mathrm{R} \$ 12.930,00 \mathrm{ha}^{-1}$ e $\mathrm{R} \$ 12.215,00$ (Figura 6).

A MCA acumulada dos quatro ciclos agrícolas estudados foi influenciada diretamente pela TCH $\left(R^{2}=0,67\right)$ e pela TPH $\left(R^{2}=0,83\right)$, sendo detectada influência mais intensa da segunda neste indicador econômico (Figura 6). 

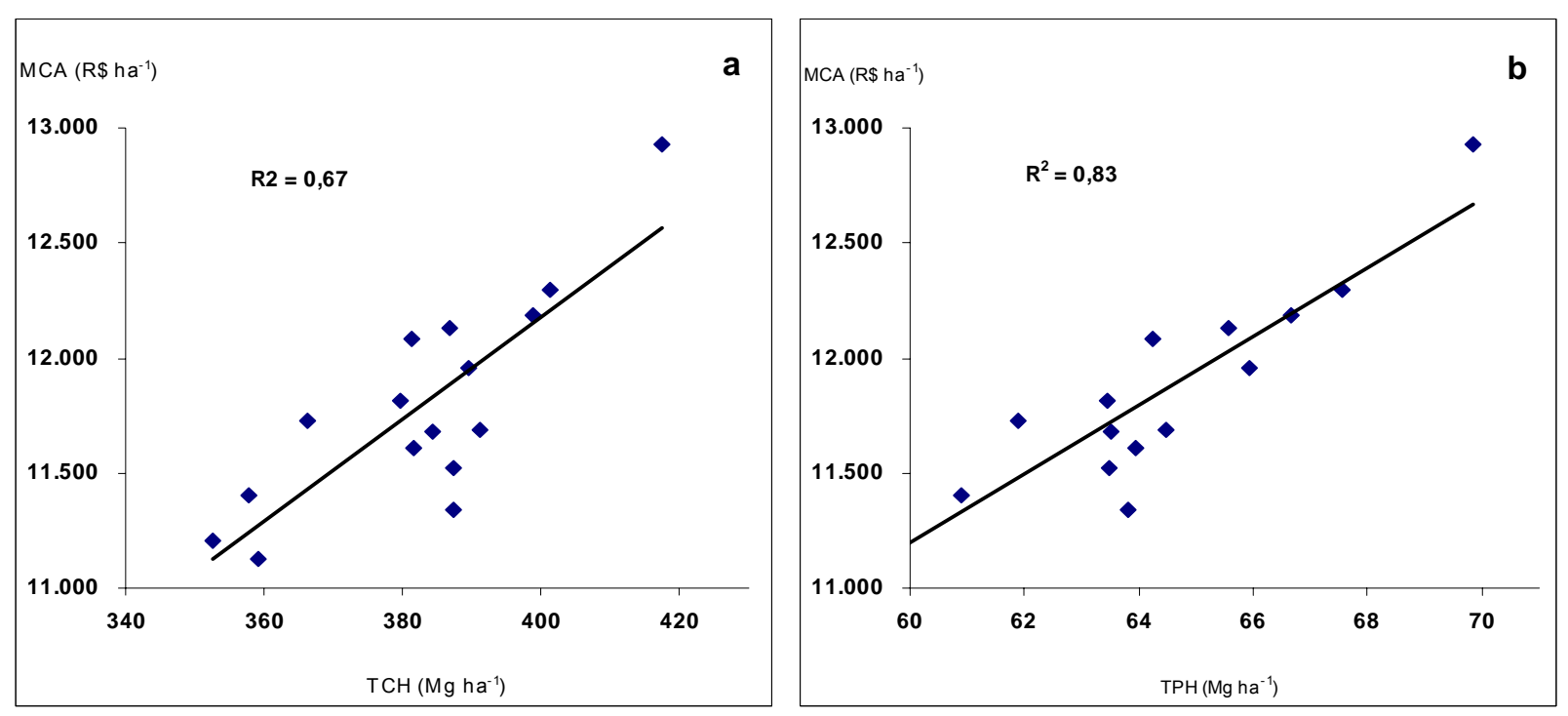

Figura 5 - Margem de contribuição agrícola (MCA) acumulada de quatro ciclos vs. $\mathrm{TCH}(\mathrm{a})$ e TPH (b)

Já para a $\mathrm{MCl}$, observaram-se oscilações mais significativas nos ciclos agrícolas individualmente. Um exemplo foram os baixos resultados econômicos para a dose mais alta de $\mathrm{N}$ em soqueiras (150 $\mathrm{kg} \mathrm{ha}^{-1}$ de $\mathrm{N}$ ) no segundo e terceiro ciclos (primeira e segunda soqueiras, respectivamente) quando comparado ao quarto ciclo, em que houve recuperação da produtividade agrícola devido às melhores condições climáticas deste ciclo (Figura 6).

No acumulado de quatro safras, os maiores valores de $\mathrm{MCl}$ foram obtidos nos tratamentos que não receberam $\mathrm{N}$ em soqueiras, $40-0$ e $120-0 \mathrm{~kg} \mathrm{ha}^{-1}$ de $\mathrm{N} \mathrm{em}$ cana-planta e soqueiras, respectivamente apresentaram praticamente iguais, $\mathrm{R} \$ 1.850,00 \mathrm{ha}^{-1}$. Porém, utilizando o mesmo raciocínio mencionado anteriormente, a ausência da adubação nitrogenada principalmente em canaviais colhidos sem a queima da palhada pode comprometer a longevidade (VITTI et al., 2007) e logo, o tratamento 120 - $50 \mathrm{~kg} \mathrm{ha}^{-1}$ de $\mathrm{N}$ em cana-planta e soqueiras, foi o que proporcionou também o melhor resultado acumulado de $\mathrm{MCl}\left(\mathrm{R} \$ 1.800,00 \mathrm{ha}^{-1}\right)$ (Figura 6). 

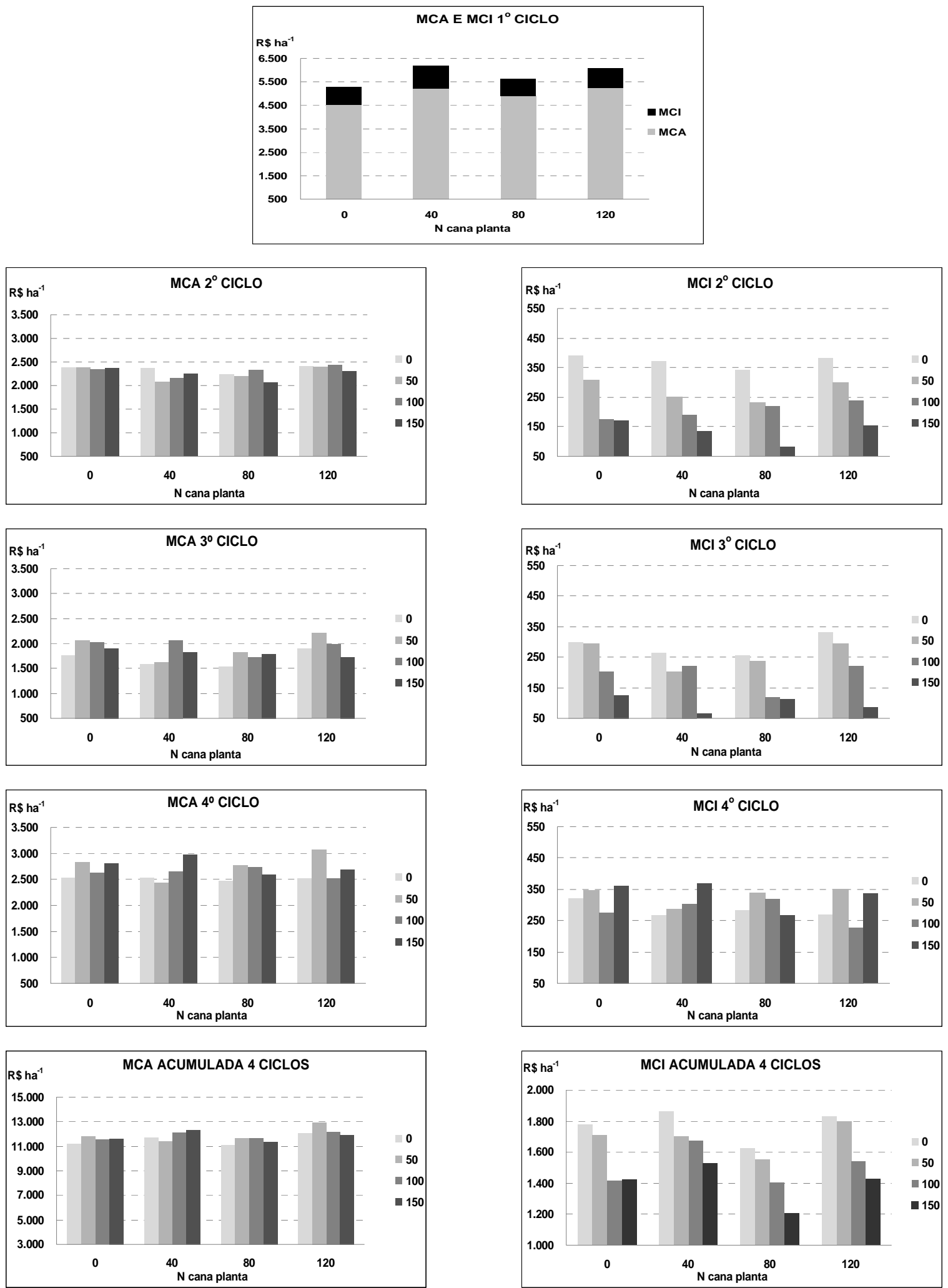

Figura 6 - MCA e MCl de quatro ciclos consecutivos (2006 a 2009) em função da adubação nitrogenada em cana-planta e soqueiras, experimento Usina São Martinho Jaboticabal em Jaboticabal, SP 
Portanto, mais uma vez ressaltou-se a importância da manutenção da adubação nitrogenada mesmo em situações de crise. Porém, o maior ou menor investimento em fertilizantes e qualquer outro insumo dependerão substancialmente do momento financeiro da empresas agrícola em questão e do cenário macroeconômico específico de cada ano agrícola.

É importante ressaltar que na avaliação econômica deste trabalho não se considerou a situação específica de cada ano agrícola, mas sim uma média dos custos para quatro ciclos (2006 a 2009). Exemplos de peculiaridades econômicas ocorridas no período estudado foram os recordes históricos de preços de açúcar e álcool nos anos de 2006 (PIRES, 2006) e 2009 (TREVETHAN; BROUGH, 2009), a alta dos preços do barril de petróleo em 2008 (FOLHA ONLINE, 2008) e conseqüentemente no diesel e fertilizantes, a crise mundial ocorrida em setembro de 2008, ou seja, justamente no pico de maturação desta safra (O ESTADO DE SÃO PAULO, 2008) e o excesso de chuvas ocorrido nas safra 2008/09 e 2009/10 (FIORIN, 2009).

Foram calculadas as receitas marginais líquidas, agrícola e industrial (RMA e $\mathrm{RMI}$ ), isto é, a MCA e $\mathrm{MCl}$ obtidas nos tratamentos de $\mathrm{N}$ em cana-planta e soqueiras deduzidas daquelas dos tratamentos testemunha sem aplicação de $\mathrm{N}$. Individualmente nos ciclos agrícolas, verificou-se que as doses intermediárias de $\mathrm{N}$ em kg ha-1 em cana-planta (40 e 80$)$ e soqueiras (50 - 100) foram as que de maneira geral proporcionaram os melhores resultados de RMA. Novamente foi possível verificar que no acumulado de quatro ciclos agrícolas, o tratamento que proporcionou maior RMA foi o 120 - 50, R\$850,00 ha-1 (Figura 7). Já para a RMI, o pequeno prejuízo de $\mathrm{R} \$ 35,00$ apresentado por este tratamento pode ser considerado o ponto de equilíbrio para este indicador.

Verificou-se que os tratamentos 80 - 100 e $40-150 \mathrm{~kg} \mathrm{ha}^{-1}$ de $\mathrm{N}$ foram semelhantes do ponto de vista econômico agrícola (RMA), em média $R \$ 560,00 \mathrm{ha}^{-1}$. Por outro lado, quando se considera a RMI, estes últimos tratamentos apresentaram prejuízos de aproximadamente $\mathrm{R} \$ 220,00$ e $\mathrm{R} \$ 330,00 \mathrm{ha}^{-1}$, respectivamente. Este resultado ressalta a importância de que em solos de alto potencial, doses maiores de fertilizantes nitrogenados no plantio visam a manutenção da produtividade da canade-açúcar e melhoram as condições de recuperação do canavial ante condições adversas. 


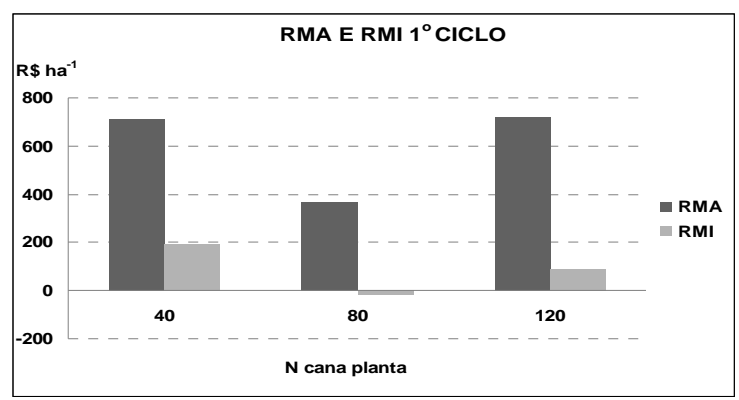

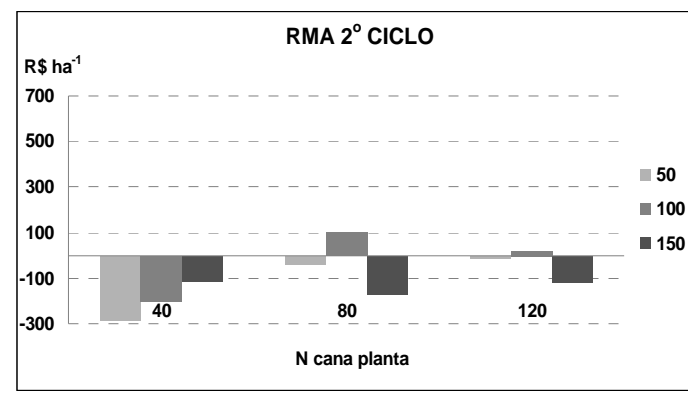
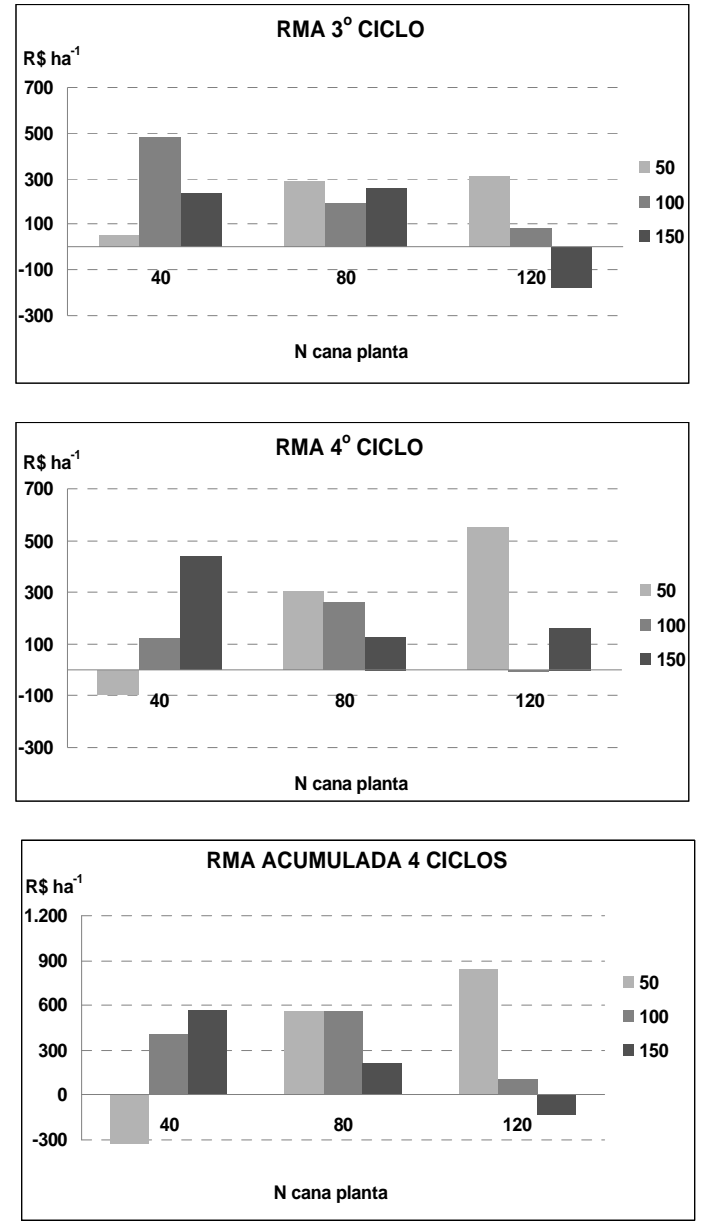
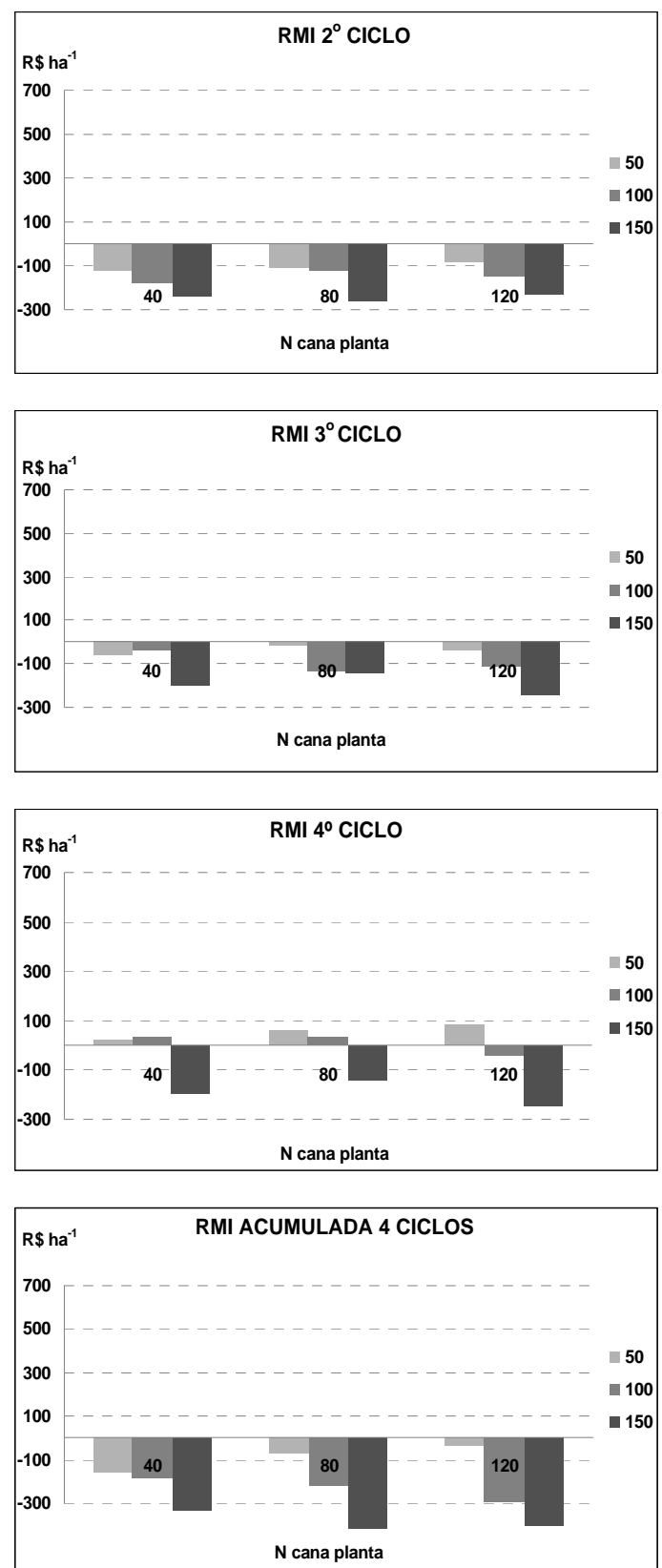

Figura 7 - RMA e RMI de quatro ciclos consecutivos ciclos consecutivos (2006 a 2009) em função da adubação nitrogenada em cana-planta e soqueiras, experimento Usina São Martinho Jaboticabal em Jaboticabal, SP 
Estes resultados diferem dos recentemente publicados por Rossetto et al. (2010). Em quinze experimentos, visando a recalibração da fertilização NK de soqueiras colhidas sem queimar $\left(0,60,120\right.$ e $180 \mathrm{~kg} \mathrm{ha}^{-1}$ de $\mathrm{N}$ e $0,70,140 \mathrm{e}$ $210 \mathrm{~kg} \mathrm{ha}^{-1}$ de $\mathrm{K}_{2} \mathrm{O}$ ), indicaram respostas às fertilizações em 14 experimentos para $\mathrm{N}$ e 7 para $\mathrm{K}$. As doses de maior produtividade agrícola foram $\mathrm{N}=148 \mathrm{e}$ $\mathrm{K}_{2} \mathrm{O}=125 \mathrm{~kg} \mathrm{ha}^{-1}$, respectivamente. Porém, as doses econômicas foram de $120 \mathrm{~kg}$ de $\mathrm{N}$ e $70 \mathrm{~kg} \mathrm{~K}_{2} \mathrm{O}$ ha $^{-1}$, destacando-se a contribuição significativa da palhada para a redução das fertilizações com o nutriente potássio, como elucidou Demattê (2004).

Neste trabalho, a maioria dos tratamentos resultou em prejuízo quando se considera toda a cadeia de produção do açúcar e álcool e, somente na cana-planta e no quarto ciclo (terceira soqueira) obteve-se resultados positivos de RMI (Figura 7). Isso se deveu às premissas macroeconômicas utilizadas serem a média dos quatro ciclos agrícolas e, para um ponto de equilíbrio seria necessária uma produtividade agroindustrial de aproximadamente $17 \mathrm{TPH}$, um valor bastante elevado quando se considera as atuais agroindústrias brasileiras. Chaves (2007) enumerou cinco faixas de TPH (ou Mg ha-1 de ATR) na qual as usinas deveriam operar para serem rentáveis utilizando as premissas econômicas daquele ano. Concluíram que usinas de altíssima performance operam acima de $13 \mathrm{TPH}$, ou seja, $31 \%$ a menos que o mínimo necessário para empatar os custos de produção deste trabalho.

Portanto, somente os tratamentos com $\mathrm{N}$ não foram suficientes para melhorar os resultados econômicos agroindustriais devido principalmente o alto custo dos insumos agrícolas no período estudado e à baixa remuneração da cana. Estes resultados econômicos poderiam ser altamente influenciados se considerássemos a economia gerada por sistemas conservacionistas, como o cultivo mínimo na reforma (Figura 7).

Silva (2010) obteve uma redução de $34 \%$ no custo de preparo de solo em um latossolo muito argiloso utilizando duas subsolagens seqüenciais ao invés do preparo convencional com o uso de gradagens e subsolagem. Além do menor consumo de diesel ( $\mathrm{L} \mathrm{ha}^{-1}$ ), observou que o cultivo sem revolvimento do solo apresentou melhor qualidade técnica na descompactação do solo para plantio de cana-de-açúcar.

Neste trabalho a redução no custo de preparo utilizando o cultivo mínimo (somente uma subsolagem) não foi considerada, uma vez que foi utilizado em todos 
os tratamentos e utilizou-se valores médios de custo de produção do Estado de São Paulo. Ressalta-se que no caso específico deste trabalho, o cultivo mínimo apresentou alguns inconvenientes na cobrição da cana, devido a grande quantidade de palhada do ciclo anterior, isto é, criaram-se bolsões de ar entre os colmossemente e o solo resultando numa maior porcentagem de falhas e infestação por ervas daninhas (item 2.2.1). Além disso, a distância favorável da área utilizada neste trabalho $(<10 \mathrm{~km}$ ) em relação à usina e seu alto potencial de produtividade, são fatores que determinam a viabilidade de maiores investimentos na adubação.

Portanto, embora o resultado econômico industrial acumulado do trabalho tenha sido negativo, os resultados positivos na produção agrícola indicaram que se deve adotar o máximo possível de práticas agrícolas que visem a redução de custos para que não comprometam a qualidade da matéria prima e longevidade do canavial.

\subsection{CONCLUSÕES}

A aplicação de doses de nitrogênio em cana-planta e soqueiras proporcionou incremento da produtividade agrícola $(\mathrm{TCH})$ e agroindustrial (TPH) da cultura nos ciclos agrícolas estudados, embora não tenha havido alterações nas características tecnológicas (pol \% cana e fibra \%) da cultura e tampouco efeito de interação das doses de $\mathrm{N}$ em cana-planta e soqueiras.

As doses de $\mathrm{N}$ em cana-planta e soqueiras que proporcionaram maior $\mathrm{TCH}$ acumulada em quatro ciclos consecutivos de cana-de-açúcar foram 120 e $100 \mathrm{Kg} \mathrm{ha}^{-1}$, respectivamente. Porém, as margens de contribuição agrícola (MCA) e agroindustrial (MCl) indicaram que a dose de $50 \mathrm{~kg} \mathrm{ha}^{-1}$ de $\mathrm{N}$ em soqueira foi a mais econômica para a cultura neste trabalho. 
3 RECUPERAÇÃO DO N DA URÉIA E DE RESÍDUOS CULTURAIS PELA CANADE-AÇÚCAR E BALANÇO DE CARBONO E NITROGÊNIO NO SISTEMA SOLOPLANTA EM CICLOS CONSECUTIVOS

\subsection{INTRODUÇÃO}

A colheita de cana sem queima da palhada tem sido adotada por muitos produtores em todo o mundo visando atender as demandas ambientais de redução das emissões de gases de efeito estufa (GEE), conservação do solo, água e biodiversidade (MACEDO; SEABRA; SILVA, 2008). Na safra 2010/11, é esperado que $70 \%$ de toda a cana do Estado de São Paulo seja colhida sem a queima prévia da palhada (JANK, 2010).

$\mathrm{Na}$ colheita da cana-de-açúcar sem a queima da palhada, uma cobertura de 10 a $20 \mathrm{t} \mathrm{ha}^{-1} \mathrm{ano}^{-1}$ de material seco permanece na superfície do solo (MANECHINI; RICCI JUNIOR; DONZELLI, 2005; TRIVELIN et al., 2002a; 2002b). Esta cobertura é denominada palhada (ou palhiço) e contribui para o aumento da quantidade de carbono (GALDOS, CERRI; CERRI, 2009; LUCA et al., 2008), nutrientes (OLIVEIRA et al., 2002) e matéria orgânica (GRAHAM, HAYNES, MEYER, 2002) do solo, além de proporcionar melhorias nas qualidades físicas (SOUZA et al., 2005) e na biodiversidade da meso e microfauna (SPAIN; HODGEN, 1994). Em áreas de reforma do canavial, além da palhada, também ficam a parte aérea e o sistema radicular das soqueiras anteriores, que também contribuem para o aporte de nutrientes para o sistema solo-planta (FRANCO et al., 2007; HEMWONG et al., 2009).

As taxas de decomposição e mineralização de resíduos vegetais são dependentes de fatores ambientais, como precipitação, temperatura, evapotranspiração, umidade e aeração do solo (OLIVEIRA et al., 2002; ZHANG et al., 2009). No entanto, a composição química dos resíduos, como a relação C:N, os teores de lignina, celulose, hemicelulose e polifenóis também desempenham um papel importante na decomposição da palhada e na dinâmica de liberação de nutrientes (MEIER et al., 2006; OLIVEIRA et al., 2002; SPAIN; HODGEN, 1994).

A composição da palhada de cana apresenta em média 390 a $450 \mathrm{~g} \mathrm{~kg}^{-1}$ de C e 4,6 a 6,5 $\mathrm{g} \mathrm{kg}^{-1}$ de $\mathrm{N}$, portanto, uma relação C:N de aproximadamente 100:1. É de se esperar uma intensa imobilização do $\mathrm{N}$ no solo pela biomassa microbiana e uma 
reduzida mineralização líquida deste $\mathrm{N}$ para a safra posterior, como apontado por vários experimentos com traçador ${ }^{15} \mathrm{~N}$ (FRANCO, 2008; GAVA et al., 2005; NG KEE KWONG et al., 1987; MEIER et al., 2006; OLIVEIRA et al., 2002).

Uma melhor compreensão da dinâmica de decomposição dos resíduos culturais provenientes da cana colhida sem queima pode auxiliar na gestão de fertilização da cana-de-açúcar. Com este tipo de manejo, vários nutrientes são disponibilizados ao solo e às plantas, e devem ser considerados na reposição mineral para a cana-de-açúcar a médio e longo prazo, uma vez que estes resíduos podem fornecer 40 a $120 \mathrm{~kg} \mathrm{ha}^{-1}$ de $\mathrm{N}$ por ano (MEIER et al., 2006; OLIVEIRA et al., 2002; ROBERTSON; THORBURN, 2007b; TRIVELIN; RODRIGUES; VICTORIA, 1996).

Experimentos com o uso do traçador ${ }^{15} \mathrm{~N}$ indicam que a recuperação do $\mathrm{N}$ fertilizante pela cultura da cana-de-açúcar varia entre $5 \%$ (MEIER et al., 2006) e $40 \%$ (AMBROSANO et al., 2005; BASANTA et al., 2003; CHAPMAN; HAYSSOM; SAFFIGNA et al., 1992; 1994; GAVA et al., 2005; TRIVELIN; RODRIGUES; VICTORIA, 1996). Estas baixas taxas de recuperação podem estar relacionadas a perdas de $\mathrm{N}$ do solo por desnitrificação ou lixiviação, volatilização da amônia (principalmente quando a fonte utilizada é a uréia), perdas de gases pelo dossel das plantas e imobilização microbiana de $\mathrm{N}$ no solo (GAVA et al., 2005; TRIVELIN; RODRIGUES; VICTORIA, 1996; TRIVELIN et al., 2002a).

Já para os resíduos culturais incorporados ao solo, a recuperação do nitrogênio em um ano é baixa e varia de $2 \%$ a $15 \%$ do $\mathrm{N}$ total contido nos resíduos. Esta taxa de recuperação depende basicamente da qualidade dos resíduos, isto é, se o conteúdo de $\mathrm{N}$ for superior a $20 \mathrm{~g} \mathrm{~kg}^{-1}$ e a relação $\mathrm{C}: \mathrm{N}$ for menor que 25 , é esperado que ocorra mineralização, permitindo maior absorção de $\mathrm{N}$ pelas plantas a partir dessas fontes orgânicas (CHAPMAN; HAYSSOM; SAFFIGNA, 1992; GAVA et al., 2005; NG KEE KWONG et al., 1987). A maioria dos resultados da literatura tem considerado apenas uma ou duas épocas de colheita para avaliar o efeito da recuperação de $\mathrm{N}$ de fertilizantes e resíduos vegetais (AMBROSANO et al., 2005; CHAPMAN; HAYSSOM; SAFFIGNA, 1992; GAVA et al., 2005; HEMWONG, et al., 2009; ROBERTSON, 2003). Portanto são necessários outros estudos multitemporais que avaliem a contribuição de resíduos vegetais após ciclos consecutivos, como demonstrado por Basanta et al. (2003) para cana-de-açúcar e Kumar et al. (2001) para o trigo cultivado sobre resíduos de leguminosas e gramíneas. 
Da mesma forma, o cultivo mínimo, isto é, o não revolvimento da camada superficial do solo, também constitui uma técnica conservacionista e apresenta benefícios na otimização do uso dos recursos naturais solo e água bem como na redução de custos de produção. Dentre os fatores de redução de custos está a reciclagem de carbono e nutrientes no sistema de produção e o menor consumo de energia (combustíveis fósseis) por área, seja devido ao uso racional dos fertilizantes minerais ou pelo menor consumo de diesel (GALDOS; CERRI; CERRI, 2009; GONÇALVES et al., 2010; MACEDO; SEABRA; SILVA, 2008, WOOD, 1991).

Este estudo teve como objetivo avaliar as taxas de recuperação do nitrogênio proveniente da uréia, palhada e dos rizomas de cana-de-açúcar anteriores à reforma (PAR- ${ }^{15} \mathrm{~N}$ e RAR- ${ }^{15} \mathrm{~N}$, variedade RB855536) e da palhada pós colheita (PPC- ${ }^{15} \mathrm{~N}$, variedade SP81-3250) em sistema de cultivo mínimo, durante quatro e três ciclos consecutivos, respectivamente.

\subsection{MATERIAL E MÉTODOS}

3.2.1 Localização do experimento, obtenção dos materiais marcados $\operatorname{com}{ }^{15} \mathrm{~N}$ e instalação das microparcelas em cana-planta e soqueiras

A cana-de-açúcar foi plantada em 2 de março de 2005 em Jaboticabal, Estado de São Paulo (Latitude $21^{\circ} 17^{\prime} 20^{\prime \prime} \mathrm{S}$, Longitude $48^{\circ} 12^{\prime} 30^{\prime \prime} \mathrm{O}$ ) em um solo Latossolo Vermelho Eutrófico de textura muito argilosa (EMBRAPA, 2006) e sob sistema de cultivo mínimo (PLANALSUCAR, 1985). Nesta área, anteriormente, colheu-se sete ciclos da variedade RB855536 sem a queima da palhada, que foi posteriormente dessecada com herbicida, previamente a reforma do canavial. 0 preparo de solo da área deu-se por uma única operação de subsolagem, com o intuito de preservar parte dos resíduos de cultura anteriores à reforma na superfície do solo.

A análise de solo da camada 0 - 0,25 m indicou: 135, 227 e $628 \mathrm{~g} \mathrm{~kg}^{-1}$ de areia total, silte e argila, respectivamente, $\mathrm{pH}\left(\mathrm{CaCl}_{2}\right)$ 5,2; matéria orgânica (MO) 31 $\left(\mathrm{g} \mathrm{dm} \mathrm{dm}^{-3}\right)$, P $42\left(\mathrm{mg} \mathrm{dm}{ }^{-3}\right)$ e K 3,1, Ca 31, Mg 9 e CTC 77,4 (mmol $\left.\mathrm{dm}^{-3}\right)$, respectivamente (Tabela 1 ; item 2.2.1). Também efetuou-se uma avaliação prévia da quantidade de resíduos vegetais recobrindo a superfície do solo antes da reforma (FRANCO et al., 2007). 
O delineamento experimental utilizado na cana-planta foi o de blocos casualizados, com quatro repetições e as parcelas constaram de 48 linhas de $15 \mathrm{~m}$ de comprimento e espaçadas a 1,5 m. A adubação de plantio foi $00: 120: 120 \mathrm{~kg} \mathrm{ha}^{-1}$ de $\mathrm{N}: \mathrm{P}_{2} \mathrm{O}_{5}: \mathrm{K}_{2} \mathrm{O}$, respectivamente e utilizou-se uma densidade de doze gemas viáveis por metro da variedade SP81-3250.

Após o corte da cana-planta (agosto de 2006) adotou-se um delineamento de parcelas subdivididas, ou seja, cada parcela de cana-planta foi dividida em 4 subparcelas (12 linhas de 15 metros) onde foram casualizados os tratamentos de soqueira. Estes últimos foram as doses $0,50,100$ e $150 \mathrm{~kg} \mathrm{ha}^{-1}$ de $\mathrm{N}$ anualmente reinstalados na $1^{\text {a }}$ soqueira (2007) utilizando-se sulfato de amônio (SA) na dose 50 $\mathrm{kg} \mathrm{ha}^{-1}$ e nitrato de amônio (NA) em complementação para os tratamentos 100 e 150 $\mathrm{kg} \mathrm{ha}^{-1}$ de $\mathrm{N}$, respectivamente e na $2^{\mathrm{a}}$ soqueira (2008) somente com a fonte NA. Na terceira soqueira (2009) a fertilização com $\mathrm{N}$ foi nivelada em $100 \mathrm{~kg} \mathrm{ha}^{-1}$ de $\mathrm{N}$ para todos os tratamentos. Estas fontes foram escolhidas devido sua maior estabilidade química quando aplicadas em superfície, principalmente sobre a palhada de cana colhida sem queima (TRIVELIN et al., 2002a). Além do $\mathrm{N}$, as soqueiras também receberam $150 \mathrm{~kg} \mathrm{ha}^{-1}$ de $\mathrm{K}_{2} \mathrm{O}$ via $\mathrm{KCl}$, aplicadas sobre a linha de cana após cada colheita.

Para o estudo de recuperação de $\mathrm{N}$ da uréia e dos resíduos culturais foram utilizados somente os tratamentos $80-0$ e $80-150 \mathrm{~kg} \mathrm{ha}^{-1}$ de $\mathrm{N}$ em cana-planta e soqueiras, respectivamente, nos quais foram instaladas microparcelas contendo uréia e resíduos culturais (palhada e rizomas) marcados com o isótopo ${ }^{15} \mathrm{~N}$. A microparcela de uréia- ${ }^{15} \mathrm{~N}$ foi constituída de um segmento único de $2,0 \mathrm{~m}$ de comprimento e o fertilizante contendo $5,17 \%$ de átomos de ${ }^{15} \mathrm{~N}$ foi enterrado no sulco de plantio como foi realizado na área restante da parcela (Figura 8). A uréia- ${ }^{15} \mathrm{~N}$ deste e de outros ensaios (FRANCO, 2008; FARONI, 2008) foi obtida no laboratório de Isótopos Estáveis do CENA/USP em Piracicaba, SP.

As microparcelas em campo contendo os resíduos vegetais foram instaladas com dimensões de 2,0 $\mathrm{m} \times 1,5 \mathrm{~m}$ e dispostas perpendicularmente às linhas de cana, ou seja, utilizando duas metades de entrelinhas. A quantidade de material aplicado obedeceu a um levantamento prévio realizado na área de estudo (FRANCO et al., 2007) e foi equivalente a 9,0 e $5,0 \mathrm{Mg} \mathrm{ha}^{-1}$ de palhada (PAR) e rizomas (RAR) marcados com ${ }^{15} \mathrm{~N}$ respectivamente (Figura 8 e Tabela 24 ). 

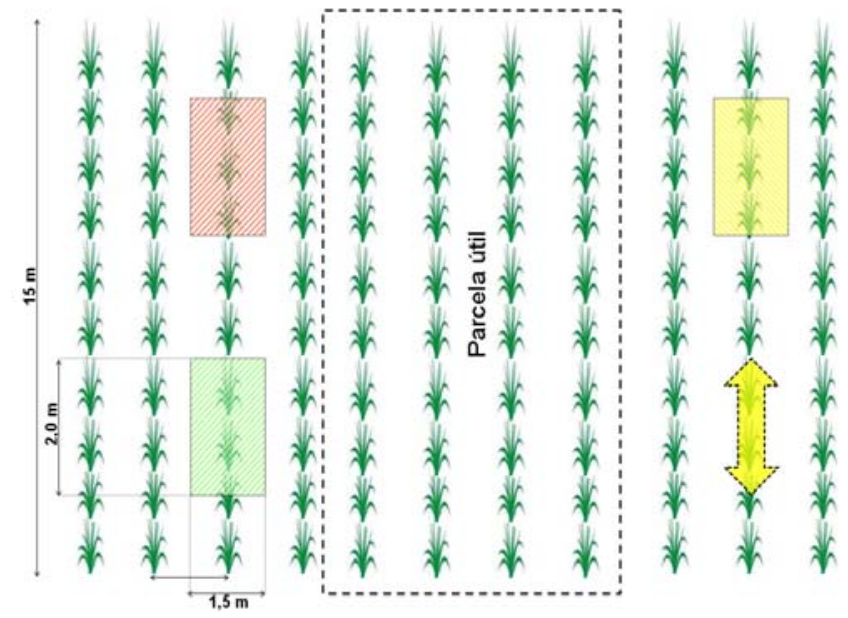

\begin{tabular}{|c|c|c|c|c|c|c|c|}
\hline \multicolumn{2}{|c|}{ MICROPARCELA } & Dimensōes & 15N & Total N & Quantidade & Napicado & \multirow{2}{*}{ 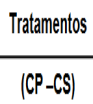 } \\
\hline & & (m) & \multicolumn{2}{|c|}{$\%$} & \multicolumn{2}{|c|}{ (kghant") } & \\
\hline $\begin{array}{c}a \\
1 \\
1 \\
\vdots \\
\vdots \\
\vdots\end{array}$ & Ureía-15N & 2,0 & 5,17 & 45 & 178 & 80 & 80.0 \\
\hline 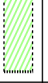 & PAR.15N & $2,0 \times 1,5$ & 1,08 & 0,57 & 9.000 & 51 & 80.0 \\
\hline 1 & RAR.'5N & $2,0 \times 1,5$ & 0,81 & 0,66 & 5.000 & 33 & 80.0 \\
\hline & PPC.15N & $2,0 \times 1,5$ & 0,83 & 0,41 & 10,000 & 41 & $80 \cdot 0$ e 80.150 \\
\hline
\end{tabular}

Figura 8 - Esquema da parcela e disposição das microparcelas de uréia e resíduos culturais PAR, RAR e PPC marcados com ${ }^{15} \mathrm{~N}$ do experimento da Usina São Martinho em Jaboticabal, SP

Tabela 24 - Avaliação dos resíduos culturais da rebrota da cana-de-açúcar (RB855536) realizada antes da reforma do canavial e após a dessecação química

\begin{tabular}{|c|c|c|c|c|c|c|c|c|c|c|c|}
\hline \multicolumn{12}{|c|}{ Palhada do ciclo anterior à reforma ${ }^{n}$} \\
\hline \multirow{2}{*}{$\begin{array}{c}M S \\
M^{M g} a^{-1}\end{array}$} & $\mathrm{~N}$ & $\mathrm{~K}$ & $P$ & $\mathrm{Ca}$ & $\mathrm{Mg}$ & S & B & $\mathrm{Cu}$ & \multirow{2}{*}{$\begin{array}{c}\mathrm{Fe} \\
\mathrm{mg} \mathrm{kg}^{-1}\end{array}$} & $\mathrm{Mn}$ & \multirow[t]{2}{*}{$\mathrm{Zn}$} \\
\hline & 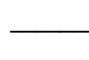 & -1 & $-\varsigma$ & & & & & & & & \\
\hline \multirow[t]{3}{*}{9,4} & 4,1 & 0,7 & 0,4 & 2,3 & 0,5 & 0,8 & 7,3 & 4,3 & \multirow{2}{*}{$\mathrm{g} \mathrm{ha}^{* *}$} & 146 & \multirow[t]{2}{*}{12,7} \\
\hline & & & $\mathrm{kc}$ & $a^{-1}$ & & & & & & & \\
\hline & 38,7 & 6,2 & 3,7 & 21,9 & 4,7 & 7,5 & 0,07 & 0,04 & - & 1,37 & 0,12 \\
\hline \multicolumn{12}{|c|}{ Rizomas da rebrota antes da reforma e após aplicação de herbicida } \\
\hline \multirow[b]{2}{*}{$\mathrm{Mg} \mathrm{ha}^{-1}$} & $\mathrm{~N}$ & K & $\mathrm{P}$ & $\mathrm{Ca}$ & $\mathrm{Mg}$ & S & B & $\mathrm{Cu}$ & \multirow{2}{*}{$\begin{array}{c}\mathrm{Fe} \\
\mathrm{mg} \mathrm{kg}^{-1}\end{array}$} & $\mathrm{Mn}$ & $\mathrm{Zn}$ \\
\hline & & 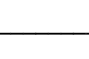 & \multicolumn{2}{|c|}{$-\mathrm{g} \mathrm{kg}^{-1}$} & & & & & & & \\
\hline \multirow[t]{2}{*}{4,6} & 5,2 & 4,0 & 0,4 & 1,3 & 0,6 & 0,9 & 8,1 & 10,4 & $\mathrm{~g} \mathrm{ha}^{* *}$ & 157,8 & 18,3 \\
\hline & 24.0 & 18.5 & 2.0 & 6.1 & 3.0 & 4.2 & 37.5 & 48.2 & - & 729.6 & 84.4 \\
\hline
\end{tabular}

Legenda: $\mathrm{n}=$ média 10 pontos $\left(0,099 \mathrm{~m}^{2}\right) ;{ }^{* *}$ valores superestimados e, portanto, não apresentados; ${ }^{\varphi}$ $=$ médias de 5 pontos $\left(0,099 \mathrm{~m}^{2}\right)$; Fonte: Adaptado de Franco et al. (2007).

Para detectar a recuperação do $\mathrm{N}$ contido na palhada e em rizomas (PAR e $R A R$, respectivamente), simularam-se tais resíduos em um campo fora da área experimental, utilizando-se a mesma variedade anterior (RB855536) e técnicas isotópicas. As plantas foram marcadas através de pulverizações foliares com uma solução de uréia enriquecida com ${ }^{15} \mathrm{~N}$ ( $28 \%$ de átomos) em três pulverizações, 
fevereiro, março e abril de 2005, segundo metodologia desenvolvida por Faroni et al. (2007).

Ao final das três pulverizações (junho de 2005), as folhas secas e ponteiros, bem como os rizomas desta cana foram colhidos, picados com facão em fragmentos de 50 - $100 \mathrm{~mm}$, simulando a colheita mecanizada e o cultivo mínimo efetuado na reforma do canavial, respectivamente. Em seguida foram secos em estufa e homogeneizados para a composição das microparcelas.

As concentrações de $\mathrm{C}, \mathrm{N}\left(\mathrm{g} \mathrm{kg}^{-1}\right)$ e abundância de ${ }^{15} \mathrm{~N}(\%)$ obtidas para a PAR e RAR foram 402, 5,7, 1,07\% e 334, 6,6, 0,81\%, respectivamente. Portanto a relação C:N dos materiais foi 70:1 para PAR e 51:1 para os RAR (Tabela 25).

A PAR- ${ }^{15} \mathrm{~N}$ foi aplicada levemente incorporada ao solo (aproximadamente $0,05 \mathrm{~m}$ ), coberta com tela de náilon ( $0,03 \mathrm{~m}$ de malha) e fixada com grampos para evitar a entrada de palhada da senescência natural da cultura e/ou após a colheita mecanizada das parcelas bem como também para que não houvesse perdas de material do interior das microparcelas que não pela decomposição natural, como ressaltaram Robertson e Thorburn (2007b).

Os rizomas marcados $\left(\operatorname{RAR}-{ }^{15} \mathrm{~N}\right)$ foram enterrados ao solo $(0,10$ a $0,20 \mathrm{~m}$ de profundidade) com ajuda de enxadão dois meses após o plantio da cana-de-açúcar (junho de 2005) e após a operação de cultivo de cana-planta ("quebra lombo"). Os totais de $\mathrm{N}$ aplicados via PAR e RAR foram 51 e $33 \mathrm{~kg} \mathrm{ha}^{-1}$ respectivamente (Tabela 25). 
Tabela 25 - Composição química e isotópica, data de aplicação e quantidade aplicada $\left(\mathrm{kg} \mathrm{ha}^{-1}\right.$ de uréia e $\mathrm{Mg}$ ha ${ }^{-1}$ dos resíduos culturais) nas microparcelas de uréia (cana-planta) e resíduos culturais (cana-planta e soqueiras) na Usina São Martinho

\begin{tabular}{|c|c|c|c|c|c|c|c|c|c|c|c|c|}
\hline \multicolumn{2}{|c|}{$\begin{array}{c}\text { Material e } \\
\text { Data de Aplicação }\end{array}$} & $\begin{array}{c}\text { Qtd } \\
{ }^{*} \mathrm{Kg} \mathrm{ha}^{-1} \\
{ }^{* *} \mathrm{Mg} \mathrm{ha}^{-1}\end{array}$ & $\begin{array}{c}\mathrm{N} \\
\text { Aplicado } \\
\mathrm{kg} \mathrm{ha}^{-1}\end{array}$ & $\mathrm{~N}$ & ${ }^{15} \mathrm{~N}$ & C & $\mathrm{C}: \mathrm{N}$ & $P$ & $\mathrm{~K}$ & $\mathrm{Ca}$ & $\begin{array}{c}\mathrm{Mg} \\
\mathrm{g} \mathrm{kg}^{-1}\end{array}$ & $S$ \\
\hline Uréia* & 05/03/05 & 178 & 80 & 45 & 5,17 & na & na & na & na & na & na & na \\
\hline $\mathrm{RAR}^{* *}$ & $15 / 08 / 05$ & 5,0 & 33 & 0,66 & 0,81 & 33,4 & 50,5 & 0,52 & 4,2 & 2,2 & 2,0 & 0,6 \\
\hline$P P C^{* *}$ & $30 / 10 / 06$ & 10 & 41 & 0,41 & 0,83 & 44,4 & 108,3 & 0,30 & 4,7 & 3,4 & 1,2 & 0,7 \\
\hline
\end{tabular}

Legenda: PAR e RAR = palhada e rizomas anteriores à reforma (variedade RB855536, obtida em experimento prévio); PPC: palhada pós colheita (variedade SP81-3250 obtida da colheita das microparcelas deste e dos outros experimentos do projeto temático); Qtd = quantidade aplicada das fontes marcadas em $\mathrm{kg} \mathrm{ha}^{-1}$ (uréia- ${ }^{15} \mathrm{~N}$ ) ou $\mathrm{Mg} \mathrm{ha}^{-1}$ (resíduos vegetais- $\left.{ }^{15} \mathrm{~N}\right)$; na: não analisado. 
Após a colheita da cana-planta e avaliação nas microparcelas correspondentes, outro estudo foi endereçado com o objetivo de quantificar a contribuição do $\mathrm{N}$ da palhada pós-colheita (PPC) na nutrição das soqueiras subseqüentes. Para tanto, foram instaladas após o corte da cana-planta outras quatro microparcelas $(2,0 \mathrm{~m} \times 1,5 \mathrm{~m})$ nos tratamentos 0 e $150 \mathrm{~kg} \mathrm{ha}^{-1}$ de $\mathrm{N}$ em soqueiras e que receberam $80 \mathrm{~kg} \mathrm{ha}^{-1}$ de $\mathrm{N}$ em cana-planta. A escolha destes tratamentos visou testar a hipótese que existem diferenças na recuperação do $\mathrm{N}$ da palhada quando se aplica nitrogênio ao solo, devido à diminuição da relação C:N e conseqüentemente maior atividade microbiana (GAVA et al., 2005; VITTI et al., 2007).

A palhada PPC- ${ }^{15} \mathrm{~N}$ utilizada em soqueira foi proveniente da colheita da canaplanta deste e de outros dois experimentos, com o mesmo cultivar de cana-deaçúcar, do Projeto Temático "Cana-Perene", nas Usinas Santa Adélia, também em Jaboticabal e São Luiz, em Pirassununga, ambos utilizados por Faroni (2008) e Franco (2008). A quantidade de palhada pós-colheita (PPC) empregada nas microparcelas foi equivalente a $10 \mathrm{Mg} \mathrm{ha}^{-1}$ de matéria seca e se encontrava enriquecida com $0,83 \%$ em ${ }^{15} \mathrm{~N}$. Esta foi fixada com tela de náilon $(0,03 \mathrm{~m}$ de malha) e grampos substituindo e simulando a palhada pós colheita original da superfície do solo. O esquema de instalação das microparcelas consta na Figura 8.

A quantidade de $\mathrm{N}$ aplicado via PPC foi de $41 \mathrm{~kg} \mathrm{ha}^{-1}$ e os respectivos teores de $\mathrm{C}, \mathrm{N}$ e macronutrientes se encontram na Tabela 25. A pluviosidade durante as safras foi de $1.750,1.720,1.370$ e 1.480 milímetros para a cana-planta e três soqueiras subsequentes, respectivamente nas safras 2005/06, 2006/07, 2007/08 e 2008/09 (Figura 1).

3.2.2 Colheita das microparcelas, processamento das amostras e análises laboratoriais

O experimento foi conduzido durante quatro ciclos consecutivos para avaliações da uréia, PAR e RAR e três ciclos para a PPC. As colheitas ocorreram aproximadamente 12 meses após a instalação das microparcelas (cana-planta) ou após a colheita anterior (soqueiras). 
A colheita das microparcelas compreendeu a coleta da parte aérea da cultura contidos no 1,0 m central do segmento de 2,0 metros e das duas linhas adjacentes, na mesma posição contígua, conforme descrito em Trivelin et al. (1994) e realizada em vários outros experimentos (BASANTA et al., 2003; GAVA et al., 2005; TRIVELIN; RODRIGUES; VICTORIA, 1996). Todas as partes da planta foram colhidas separadamente (colmos, folhas secas e ponteiros) e sua massa fresca foi obtida diretamente no campo com o auxílio de uma balança eletrônica com $100 \mathrm{~kg}$ de fundo de escala e precisão de $10 \mathrm{~g}$. Após a pesagem da massa verde, as partes foram trituradas em forrageira mecânica e subamostradas $( \pm 0,500 \mathrm{~kg}$ de material) como descrito em Franco (2008).

No Laboratório de Isótopos Estáveis do CENA/USP em Piracicaba, SP, as subamostras foram preparadas de acordo com Trivelin, Rodrigues e Victoria (1996), isto é, secagem em estufa de ventilação forçada a $65{ }^{\circ} \mathrm{C}$ por $72 \mathrm{~h}$ para a determinação da matéria seca dos colmos, folhas secas e ponteiros coletados nas microparcelas. Posteriormente, as amostras foram finamente moídas em moinho tipo Willey (peneira de 60 mesh) e analisou-se o carbono (C) e nitrogênio $(N)$ totais $\left(\mathrm{g} \mathrm{kg}^{-}\right.$ $\left.{ }^{1}\right)$ e a abundância em átomos de ${ }^{15} \mathrm{~N}$ por espectrometria de massas em espectrômetro modelo Hydra 20-20 SerCon Co., UK, acoplado a um analisador automático de N ANCA-SGL (BARRIE; PROSSER, 1996).

\subsubsection{Cálculos de recuperação de ${ }^{15} \mathrm{~N}$ e análises estatísticas}

A quantificação do $\mathrm{N}$ na planta proveniente das fontes marcadas (NPPf em $\mathrm{kg} \mathrm{ha}{ }^{1}$ ), ou seja, uréia- ${ }^{15} \mathrm{~N}, \mathrm{PAR}-{ }^{15} \mathrm{~N}, \mathrm{RAR}^{-}{ }^{-15} \mathrm{~N}$ e PPC- ${ }^{15} \mathrm{~N}$, foi realizada segundo $\mathrm{o}$ cálculo de diluição isotópica (GAVA et al., 2005; TRIVELIN; RODRIGUES; VICTORIA, 1996), descrito na equação 3. O cálculo da recuperação (R\%) do N-uréia e N-resíduos culturais pela cana-de-açúcar consta na equação 4.

$$
\begin{aligned}
& \text { NPPf }\left(k g h a^{-1}\right)=[(A-C) /(B-C)] \times N T \\
& R(\%)=(N P P f / N A) \times 100
\end{aligned}
$$

Onde: $\mathrm{NPPf}=\mathrm{N}$ da planta proveniente da fonte marcada (uréia, PAR, RAR ou PPC, $\mathrm{kg} \mathrm{ha}^{-1}$ ); $\mathrm{A}=$ abundância de ${ }^{15} \mathrm{~N}$ da parte da planta (\% de átomos); $\mathrm{B}=$ abundância de ${ }^{15} \mathrm{~N}$ da fonte marcada (\% de átomos); $\mathrm{C}=$ abundância natural de ${ }^{15} \mathrm{~N}(0,367 \%$ de átomos); NT = nitrogênio total na parte da planta $\left(\mathrm{kg} \mathrm{ha}^{-1}\right) ; \mathrm{R}=$ recuperação percentual do ${ }^{15} \mathrm{~N}$-palhada na parte da planta; $\mathrm{NA}=$ dose de $\mathrm{N}$ aplicada via fontes marcadas $\left(\mathrm{kg} \mathrm{ha}^{-1}\right)$; PAR e RAR = palhada ou rizomas anteriores à reforma (variedade RB855536); PPC = palhada pós colheita (variedade SP81-3250). 
Ressalta-se que a recuperação do $\mathrm{N}$ proveniente das fontes marcadas ao longo dos ciclos foi calculada sem se descontar a quantidade de $\mathrm{N}$ que já havia sido exportada pelos colmos do ciclo anterior, ou seja, considerou-se sempre a dose inicial de $\mathrm{N}$ (em kg ha-1) aplicada através dos materiais marcados.

Isso se deveu porque, na metodologia de microparcelas todo o material vegetal é retirado do campo, o que não acontece na colheita de cana comercial (TRIVELIN et al., 1994; TRIVELIN; RODRIGUES; VICTORIA, 1996). As folhas secas, ponteiros e uma parte dos colmos (perdas) voltam ao campo e constituem a palhada (ou palhiço) que é fonte de $\mathrm{N}$ e outros nutrientes ao sistema (ABRAMO FILHO, 1995; KUMAR et al., 2001; MANECHINI; RICCI JUNIOR; DONZELLI, 2005; MEIER et al., 2006; OLIVEIRA et al., 2002).

Foi realizada análise de variância (ANOVA) dos resultados e, para as médias detectadas como significativas pelo teste $\mathrm{F}$, utilizou-se o teste de Tukey a $1 \%, 5 \%$ e $10 \%$ de probabilidade.

3.2.4 Cálculos do balanço de carbono e nitrogênio no sistema solo-planta após ciclos consecutivos

Após os quatro ciclos consecutivos para a uréia- ${ }^{15} \mathrm{~N}, \mathrm{PAR}-{ }^{15} \mathrm{~N}, \mathrm{RAR}-{ }^{15} \mathrm{~N}(2006$ a 2009) e três para a PPC- ${ }^{15} \mathrm{~N}$ (2007 a 2009), realizou-se a coleta do solo $(0-0,30$ e 0,30 - 0,60 m) e uma amostragem destrutiva dos rizomas da cultura nas microparcelas com o objetivo de avaliar o balanço de carbono e nitrogênio presentes no sistema solo-planta, após os períodos mencionados. Como testemunha, o "tempo zero", utilizou-se o solo coletado em 2006, isto é, após o ciclo de cana-planta.

O solo em cada microparcela foi coletado em amostras composta de 3 posições (sobre a linha de cana, 0,30 e 0,60 metros da linha central) e em cinco profundidades: 0 a 0,05; 0,06 a 0,10; 0,11 a 0,20; 0,21 a 0,40 e 0,41 a 0,60 m como em Basanta et al. (2003) e Gava et al. (2005). O solo das três posições amostradas na microparcela foi homogeneizado e seco ao ar para posteriores análises de $\mathrm{C}$ e $\mathrm{N}$ totais e ${ }^{15} \mathrm{~N}$ segundo Barrie e Prosser (1996) no Laboratório de Isótopos Estáveis do CENA/USP em Piracicaba, SP.

A profundidade considerada para o balanço foi de $0,60 \mathrm{~m}$, onde se encontra mais de $80 \%$ do sistema radicular da cana-de-açúcar (SMITH; INMAN-BAMBER; 
THORBURN, 2005; OTTO et al., 2009b). Para as duas primeiras camadas utilizouse uma sonda amostradora de raízes (0,055 m de diâmetro) e para as camadas mais profundas utilizou-se uma sonda específica para solo (0,03 m de diâmetro), visando maior precisão na detecção de traços do ${ }^{15} \mathrm{~N}$ aplicados em cana-planta via uréia, PAR e RAR e em soqueiras via PPC em profundidade.

Os rizomas contidos no metro central das microparcelas foram coletados com auxílio de um enxadão. Após a retirada de todas as raízes e do solo aderido nos rizomas, o material foi lavado, pesado em balança analítica e seco em estufa de ventilação forçada ( $65^{\circ} \mathrm{C}$ até peso constante) para determinação da $M S$, segundo Malavolta, Vitti e Oliveira (1997). Assim como nas demais amostras vegetais (colmos, folhas secas e ponteiros), os rizomas também foram finamente moídos em moinho tipo Willey para análise de $\mathrm{C}$ e $\mathrm{N}$ totais $\left(\mathrm{g} \mathrm{kg}^{-1}\right)$ e a abundância em átomos de ${ }^{15} \mathrm{~N}$ por espectrometria de massas (BARRIE; PROSSER, 1996).

Através da equação 5 , calculou-se $\circ \mathrm{C}$ e $\circ \mathrm{N}$ proveniente das fontes marcadas remanescente no solo após os períodos considerados, como descrito em Basanta et al. (2003); Gava et al. (2005).

$$
\mathrm{NSPf}=\mathrm{Ds} \times \mathrm{Vs} \times \mathrm{NT}
$$

Onde: $\mathrm{NSPf}=\mathrm{N}$ do solo proveniente da fonte marcada (uréia, palhada ou rizomas, $\mathrm{kg} \mathrm{ha}^{-1}$ ); Ds = densidade do solo $\left(\mathrm{Mg} \mathrm{m}^{-3}\right) ; \mathrm{Vs}=$ volume do solo na camada 0 a $0,60 \mathrm{~m}\left(\mathrm{~m}^{3}\right.$ ha $\left.{ }^{-1}\right) ; \mathrm{N}=$ nitrogênio total do solo (\%)

\subsection{RESULTADOS E DISCUSSÃO}

3.3.1 Recuperação do $\mathrm{N}$ da uréia do plantio, palhada e rizomas anteriores à reforma (PAR - palhada e RAR - rizomas) após quatro ciclos consecutivos (2006 a 2009)

A recuperação do $\mathrm{N}$-uréia no ciclo de cana-planta foi de $24,7 \mathrm{~kg} \mathrm{ha}^{-1}$, ou seja, equivalente a $31 \%$ do $\mathrm{N}$ aplicado. Este resultado é consistente com os $28 \%$ (22 kg ha ${ }^{-1}$ de N-uréia) recuperados em média pela cana-planta obtidos por Franco (2008), que avaliou dois experimentos de campo utilizando a mesma variedade, dose e fonte nitrogenada no plantio (80 kg N-uréia ha $\left.{ }^{-1}\right)$ e os de Chapman, Hayssom e Saffigna (1992). Estes últimos autores constataram uma recuperação de $32 \%$ do 
N-uréia aplicado no sulco de plantio no primeiro ciclo agrícola, apesar da dose aplicada por ter sido duas vezes superior ao deste experimento (160 kg ha-1) (Tabela 26).

Bologna-Campbell (2007) também utilizou $80 \mathrm{~kg} \mathrm{ha}^{-1}$ de $\mathrm{N}$-uréia, porém com a variedade SP80-3280 plantada em vasos e obtiveram $35 \%$ de recuperação do $\mathrm{N}$ pela planta inteira (parte aérea, raízes e rizomas). Basanta et al. (2003), utilizando a dose de $63 \mathrm{~kg} \mathrm{~N}^{-1}$ via sulfato de amônio aplicado 50 dias após o plantio concluíram que $63 \%$ (40 kg ha-1) deste $\mathrm{N}$ foi recuperado pela cana-planta. Korndorfer et al. (1997) encontraram 53\% de recuperação aparente do N-uréia aplicado na cana-planta, usando o método da diferença (não isotópico), porém salientaram que o método superestimou a real recuperação do $\mathrm{N}$-fertilizante pelas plantas.

Houve uma recuperação decrescente do $N$-uréia por toda a parte aérea, 31\%, $4,9 \%$ e $3,6 \%$, na cana-planta, primeira e segunda soqueiras respectivamente, como demonstrado por Fortes et al. (2010) (Tabela 26). Tais resultados concordam com os de Chapman, Hayssom e Saffigna (1992) que obtiveram 32\% do N-uréia recuperados pela cana-planta e $5 \%$ pela parte aérea da cultura no segundo ciclo. 
Tabela 26 - Recuperação do ${ }^{15} \mathrm{~N}$-uréia aplicada no plantio (dose $80 \mathrm{~kg} \mathrm{ha}{ }^{-1}$ ), ${ }^{15} \mathrm{~N}-\mathrm{PAR}$ e ${ }^{15} \mathrm{~N}-\mathrm{RAR}$ pela cana-de-açúcar em quatro ciclos consecutivos (2006 a 2009), experimento Usina São Martinho em Jaboticabal, SP

\begin{tabular}{|c|c|c|c|c|c|c|c|c|c|c|c|c|c|}
\hline & & \multicolumn{3}{|c|}{ COLMOS } & \multicolumn{3}{|c|}{ FOLHAS SECAS } & \multicolumn{3}{|c|}{ PONTEIROS } & \multicolumn{3}{|c|}{ PARTE AÉREA } \\
\hline \multirow{8}{*}{ 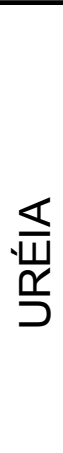 } & & $\mathrm{kg} \mathrm{ha}^{-1}$ & $\mathrm{R} \%$ & & $\mathrm{~kg} \mathrm{ha}^{-1}$ & $\mathrm{R} \%$ & & $\mathrm{~kg} \mathrm{ha}^{-1}$ & $\mathrm{R} \%$ & & $\mathrm{~kg} \mathrm{ha}^{-1}$ & $\mathrm{R} \%$ & \\
\hline & 2006 & 18,9 & 23,6 & a & 3,1 & 3,9 & $a$ & 2,7 & 3,4 & ns & 24,7 & 30,9 & a \\
\hline & 2007 & 1,3 & 1,6 & $\mathrm{~b}$ & 0,6 & 0,8 & $\mathrm{~b}$ & 2,0 & 2,5 & & 3,9 & 4,9 & $\mathrm{~b}$ \\
\hline & 2008 & 0,9 & 1,1 & $\mathrm{~b}$ & 0,6 & 0,7 & $\mathrm{bc}$ & 1,4 & 1,8 & & 2,9 & 3,6 & $b$ \\
\hline & 2009 & 1,3 & 1,7 & $b$ & 0,1 & 0,2 & C & 1,3 & 1,6 & & 2,8 & 3,5 & $b$ \\
\hline & 2006-2009 & 22,4 & 27,9 & & 4,5 & 5,6 & & 7,4 & 9,3 & & 34,3 & 42,8 & \\
\hline & DMS & 1,9 & 7,0 & ** & 0,5 & 0,5 & \# & 1,9 & 2,4 & ns & 3,0 & 3,8 & ** \\
\hline & $\mathrm{CV} \%$ & 11,6 & 11,5 & & 23,4 & 23,6 & & 54,6 & 54,5 & & 18,7 & 18,8 & \\
\hline \multirow{7}{*}{$\frac{\alpha}{\alpha}$} & 2006 & 5,9 & 11,2 & $a$ & 0,5 & 0,9 & $\mathrm{~b}$ & 0,3 & 0,7 & $b$ & 6,7 & 12,8 & $\bar{a}$ \\
\hline & 2007 & 1,9 & 3,7 & $\mathrm{~b}$ & 0,7 & 1,4 & $a$ & 1,2 & 2,3 & a & 3,7 & 7,3 & $b$ \\
\hline & 2008 & 0,9 & 1,8 & C & 0,2 & 0,4 & C & 0,3 & 0,5 & $b$ & 1,3 & 2,6 & C \\
\hline & 2009 & 1,2 & 2,3 & $\mathrm{bc}$ & 0,1 & 0,2 & C & 1,2 & 2,3 & a & 2,4 & 4,7 & $\mathrm{bc}$ \\
\hline & 2006-2009 & 9,8 & 18,9 & & 1,5 & 2,8 & & 2,9 & 5,7 & & 14,2 & 27,5 & \\
\hline & DMS & 0,9 & 1,7 & * & 0,2 & 0,4 & ** & 0,7 & 1,4 & ** & 1,8 & 3,5 & ** \\
\hline & $\mathrm{CV} \%$ & 16,2 & 16,6 & & 18,8 & 18,3 & & 33,0 & 33,1 & & 17,0 & 17,2 & \\
\hline \multirow{7}{*}{ 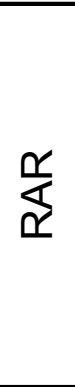 } & 2006 & 1,5 & 4,5 & $a b$ & 0,3 & 0,9 & $\mathrm{~b}$ & 0,2 & 0,7 & $b$ & 2,0 & 6,1 & $a b$ \\
\hline & 2007 & 1,6 & 4,8 & $a$ & 0,7 & 2,1 & $a$ & 0,9 & 2,6 & a & 3,1 & 9,4 & a \\
\hline & 2008 & 0,2 & 0,6 & C & 0,1 & 0,2 & C & 0,2 & 0,7 & $b$ & 0,5 & 1,5 & c \\
\hline & 2009 & 1,1 & 3,3 & $b$ & 0,1 & 0,2 & C & 0,6 & 1,8 & $a b$ & 1,8 & 5,3 & $\mathrm{~b}$ \\
\hline & 2006-2009 & 4,3 & 13,2 & & 1,1 & 3,4 & & 1,9 & 5,7 & & 7,4 & 22,4 & \\
\hline & DMS & 0,5 & 2,1 & \# & 0,2 & 1,0 & \# & 0,6 & 1,9 & ** & 1,2 & 3,7 & ** \\
\hline & CV\% & 21,9 & 21,8 & & 36,8 & 36,9 & & 42,7 & 43,2 & & 22,4 & 22,4 & \\
\hline
\end{tabular}

Legenda: Letras iguais nas colunas não diferem estatisticamente segundo teste Tukey $\# 10 \%,{ }^{*} 5 \%$ e ${ }^{* *} 1 \%$, respectivamente $(n=4)$; DMS $=$ diferença mínima significativa; PAR e RAR = palhada ou rizomas anteriores à reforma (variedade RB855536); CV\% = coeficiente de variação. 
O mesmo padrão decrescente de recuperação foi obtido por Basanta et al. (2003), 63\%, 11\%, 4\%, para o primeiro, segundo e terceiro ciclos, respectivamente, ou seja, $78 \%$ (49 $\mathrm{kg} \mathrm{ha}^{-1}$ ) do $\mathrm{N}$ do fertilizante do plantio foram recuperados após três ciclos de cultivo. Wiedenfeld (1998) obteve uma recuperação média do $\mathrm{N}$ fertilizante de $10 \%$ ao ano após três ciclos agrícolas, porém sem utilizar técnicas isotópicas.

A diferença deste trabalho em relação a outros da literatura foi à avaliação de um quarto ciclo, onde se obteve uma recuperação de 3,5\%, encontrada como constante após a terceira soqueira. A quantidade do $\mathrm{N}$-uréia recuperada pela cultura após os quatro ciclos avaliados (2006 a 2009) foi de $34,3 \mathrm{~kg} \mathrm{ha}^{-1}$, isto é, uma recuperação total de $43 \%$ do $\mathrm{N}$ aplicado como fertilizante (uréia). Deste $\mathrm{N}$ total acumulado, $65 \%(22,4 \mathrm{~kg})$ foram encontrados nos colmos, $13 \%(4,5 \mathrm{~kg})$ nas folhas secas e $22 \%(7,4 \mathrm{~kg})$ nos ponteiros (Tabela 26$)$.

Basanta et al. (2003) encontraram após três ciclos que $53 \%$ do $\mathrm{N}$ aplicado no plantio havia sido exportado pelos colmos, $24 \%$ nas folhas secas e $23 \%$ pelos ponteiros embora tenham utilizado o ciclo de doze meses, uma vez que o plantio deu-se em outubro. Korndorfer et al. (1997) constataram que $56 \%$ do N-uréia foi recuperado pelos colmos, $16 \%$ nas folhas secas e $28 \%$ nos ponteiros, respectivamente, utilizando cana-planta de 18 meses, ou seja, plantada em março. Franco (2008) obteve $54 \%$ do $\mathrm{N}$ acumulado nos colmos, $22 \%$ nas folhas secas e $24 \%$ nos ponteiros, na média de duas áreas em cana-planta de 18 meses.

Este acúmulo maior de $\mathrm{N}$ nos colmos obtido neste trabalho comparado aos demais da literatura pode estar relacionado à alta produtividade agrícola obtida na cana-planta neste solo (em média $152 \mathrm{Mg} \mathrm{ha}^{-1}$, item 2.3.1), que pode ter demandado maior acúmulo do $\mathrm{N}$ para formação dos colmos industrializáveis, já que a recuperação do $\mathrm{N}$ em folhas e em ponteiros foi praticamente a metade dos valores comumente encontrados na literatura. Nos ponteiros não houve diferenças significativas em quatro ciclos consecutivos para esta parte específica da planta, 0 que reforça a idéia de maior demanda pelos colmos (Tabela 26). Nos demais ciclos (1 a a $3^{a}$ soqueiras: 2007 a 2009), a recuperação do N-uréia manteve-se praticamente constante, ou seja, sem diferenças estatísticas e variou decrescentemente de $4,9 \%, 3,6 \%$ e $3,5 \%$ da dose inicial aplicada que foi de $80 \mathrm{~kg} \mathrm{ha}^{-1}$ de $\mathrm{N}$.

Cabe mencionar que, após o primeiro ano, o N-uréia provavelmente tenha se transformado em matéria orgânica do solo e/ou em biomassa microbiana, porém 
permaneceu no solo como um estoque ("pool") de $\mathrm{N}$ disponível para a recuperação da cultura, como sugeriram Graham, Haynes e Meyer (2002), Galdos, Cerri e Cerri (2009), Trivelin et al. (2002a; 2002b) e Vitti et al., (2007b).

A recuperação do nitrogênio dos resíduos culturais ${ }^{15} \mathrm{~N}-\mathrm{PAR}$ e ${ }^{15} \mathrm{~N}-\mathrm{RAR}$ pela cana-planta foi de $6,7 \mathrm{~kg} \mathrm{~N} \mathrm{ha}^{-1}(13 \%)$ e $2,0 \mathrm{~kg} \mathrm{~N} \mathrm{ha}^{-1}(6 \%)$, respectivamente (Tabela 26). Estes resultados são consistentes com os de $\mathrm{Ng}$ Kee Kwong et al. (1987) que observaram até $14 \%$ do $\mathrm{N}$ da palhada de cana-de-açúcar recuperados pela cultura, após dezoito meses em condições de campo. Bologna-Campbell (2007) encontrou $14 \%$ de recuperação do $\mathrm{N}$ de resíduos culturais em doze meses após o plantio, utilizando uma mistura de palhada (ponteiros + folhas secas) e rizomas + raízes da variedade SP81-3250 marcadas com ${ }^{15} \mathrm{~N}$ e incorporada ao solo.

A recuperação do N-PAR foi decrescente do primeiro ao terceiro ciclo de colheita, 13\%, 7\% e 3\%, respectivamente (FORTES et al., 2010). No quarto ciclo notou-se uma recuperação superior, 4,7\%, devido provavelmente as melhores condições climáticas do período (Figura 1) e que proporcionaram, além de maior produtividade agrícola da cultura, uma maior mineralização do $\mathrm{N}$ da palhada. Meier et al. (2006) encontraram baixas recuperações de $\mathrm{N}$ proveniente de fertilizantes e da palhada, aproximadamente $6 \%$ e $5 \%$ para ambas as fontes, devido às altas taxas de pluviosidade e encharcamento do solo nos locais estudados na Austrália.

No total dos quatro ciclos, foram recuperados $14 \mathrm{~kg} \mathrm{ha}^{-1}$ de $\mathrm{N}$ da PAR, isto é, $27,5 \%$ do conteúdo inicial deste nutriente. A quantidade de $\mathrm{N}$ encontrada nos colmos foi de $69 \%, 11 \%$ em folhas secas e $20 \%$ nos ponteiros (Tabela 27 ). Esta distribuição está de acordo com resultados de Gava et al. (2005) que encontraram recuperação de $52 \%$ colmos, $7 \%$ nas folhas secas e $29 \%$ nos ponteiros, utilizando palhada- ${ }^{15} \mathrm{~N}$ da variedade SP80-1842.

Nota-se também que a recuperação do N-PAR teve o mesmo comportamento da recuperação do $\mathrm{N}$-uréia, ou seja, foi notavelmente maior no primeiro ciclo e diminuiu nos ciclos agrícolas subsequentes. Tal fato indica que o $\mathrm{N}$-uréia adicionado ao solo com palhada de cana e em sistema de cultivo mínimo pode ter aumentado a mineralização dos resíduos vegetais devido à diminuição da relação C:N (GAVA et al., 2005; VITTI et al., 2007) (Tabela 27). 
Tabela 27 - Recuperação de ${ }^{15} \mathrm{~N}$ dos tratamentos de uréia, PAR e RAR, produtividade agroindustrial (TCH e TPH), precipitação e evapotranspiração ocorrida nos ciclos consecutivos de cana (2005 a 2009) na Usina São Martinho, Jaboticabal, SP

\begin{tabular}{|c|c|c|c|c|c|c|c|c|c|}
\hline $\begin{array}{c}\text { Tratamentos } \\
\text { N CP - S }\end{array}$ & Ciclo & $\mathrm{TCH}$ & $\mathrm{TPH}$ & \multicolumn{3}{|c|}{ Recuperação ${ }^{15} \mathrm{~N}$} & $\begin{array}{c}\operatorname{Rec}{ }^{15} \mathrm{~N} \\
\text { Acum }\end{array}$ & Etr & $\begin{array}{c}\text { Etr } \\
\text { Acum }\end{array}$ \\
\hline $\mathrm{kg} \mathrm{ha}^{-1}$ & & \multicolumn{2}{|c|}{-- Mg ha-1 -- } & $\mathrm{kg} \mathrm{ha}^{-1}$ & $\mathrm{R} \%$ & & $\mathrm{~kg} \mathrm{ha}^{-1}$ & \multicolumn{2}{|c|}{$\mathrm{mm}$} \\
\hline \multirow{4}{*}{ 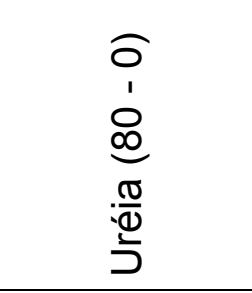 } & $2005 / 06$ & 156 & 16,7 & 24,7 & 30,9 & $a^{* *}$ & 24,7 & 1.283 & 1.283 \\
\hline & $2006 / 07$ & 73 & 11,8 & 3,9 & 4,9 & $b$ & 28,6 & 1.002 & 2.285 \\
\hline & $2007 / 08$ & 48 & 8,0 & 2,9 & 3,6 & $\mathrm{~b}$ & 31,5 & 901 & 3.186 \\
\hline & $2008 / 09$ & 82 & 13,7 & 2,8 & 3,5 & $b$ & 34,3 & 821 & 4.007 \\
\hline \multirow{4}{*}{$\begin{array}{l}0 \\
1 \\
1 \\
\frac{1}{0} \\
\frac{\alpha}{\alpha} \\
\underline{\alpha}\end{array}$} & $2005 / 06$ & 156 & 16,7 & 6,7 & 12,8 & $a^{* *}$ & 6,7 & 1.283 & 1.283 \\
\hline & $2006 / 07$ & 73 & 11,8 & 3,7 & 7,3 & $\mathrm{~b}$ & 10,4 & 1.002 & 2.285 \\
\hline & $2007 / 08$ & 48 & 8,0 & 1,3 & 2,6 & c & 11,8 & 901 & 3.186 \\
\hline & $2008 / 09$ & 82 & 13,7 & 2,4 & 4,7 & bc & 14,2 & 821 & 4.007 \\
\hline \multirow{4}{*}{ 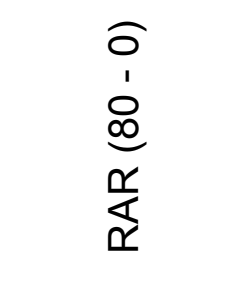 } & $2005 / 06$ & 156 & 16,7 & 2,0 & 6,1 & $a b^{* *}$ & 2,0 & 1.283 & 1.283 \\
\hline & $2006 / 07$ & 73 & 11,8 & 3,1 & 9,4 & a & 5,1 & 1.002 & 2.285 \\
\hline & $2007 / 08$ & 48 & 8,0 & 0,5 & 1,5 & c & 5,6 & 901 & 3.186 \\
\hline & $2008 / 09$ & 82 & 13,7 & 1,8 & 5,3 & b & 7,4 & 821 & 4.007 \\
\hline
\end{tabular}

Legenda: $\mathrm{CP}=$ cana-planta; $\mathrm{S}=$ soqueira; $\mathrm{PAR}$ e $\mathrm{RAR}^{-15} \mathrm{~N}=$ palhada e rizomas, (variedade RB855536 marcada com ${ }^{15} \mathrm{~N}$ ); Letras iguais na coluna de Recuperação ${ }^{15} \mathrm{~N}$ não diferem estatisticamente segundo teste Tukey $\# 10 \%,{ }^{*} 5 \%$ e ${ }^{* *} 1 \%$, respectivamente $(n=4)$; Rec Acum $=$ recuperação de $\mathrm{N}$ acumulada; Etr = evapotranspiração real $(\mathrm{mm})$; Etr Acum = evapotranspiração real acumulada.

Em contraste, notou-se uma maior quantidade do N-RAR recuperado no segundo ciclo, $9 \%$, seguido os $6 \%$ no primeiro e $2 \%$ no terceiro ciclo, respectivamente (FORTES et al., 2010). A quantidade de $\mathrm{N}$ aplicada através dos resíduos vegetais PAR e RAR, isto é, palhada e rizomas anteriores à reforma foi da ordem de $84 \mathrm{~kg} \mathrm{ha}^{-1}$ de $\mathrm{N}$, dos quais $17,4 \mathrm{~kg} \mathrm{ha}^{-1}(21 \%)$ foram absorvidos pela cultura nos três primeiros ciclos. Após os quatro ciclos a contribuição do $\mathrm{N}$ dos resíduos vegetais anteriores à reforma foi de $21,6 \mathrm{~kg} \mathrm{ha}^{-1}$, ou seja, $26 \%$ do total de $\mathrm{N}$ aplicado via estes resíduos (Tabela 27).

Fortes et al. (2010) ressaltaram que isto pode ter ocorrido devido à incorporação desses rizomas ao solo num sistema de cultivo mínimo em solo 
argiloso, que num primeiro momento, pode ter apresentado capacidade limitada de aeração, levando a menores taxas de mineralização no primeiro ano (GAVA et al., 2005; TRIVELIN et al., 2002b). Notou-se desde o início do experimento uma alta densidade ao longo de todo perfil de solo que continuou até o ultimo ciclo, em média $1,25 \mathrm{Mg} \mathrm{m}^{-3}$. Bellinaso et al. (1994) preconizaram que para latossolos argilosos, as densidades acima de $1,3 \mathrm{Mg} \mathrm{m}^{-3}$ começam a tornar limitante o crescimento radicular da cana-de-açúcar, como pode-se notar pela baixa produção de matéria seca do sistema radicular neste experimento (dados não apresentados, porém utilizados no balanço de $\mathrm{C}$ e $\mathrm{N}$, item 3.3.3).

No quarto ciclo, observou-se elevação na recuperação do N-RAR comparado ao terceiro devido às condições climáticas mais favoráveis à degradação destes resíduos (Figura 1). No total foram recuperados $7,4 \mathrm{~kg} \mathrm{~N}^{-1}$ provenientes dos rizomas anteriores à reforma, portanto $22 \%$ do inicialmente aplicado através destes resíduos. A distribuição do total de N-RAR recuperado pela cultura foi de $58 \%$ nos colmos, $16 \%$ nas folhas secas e $26 \%$ nos ponteiros (Tabelas 26 e 27 ).

Este resultado difere dos obtidos por Chapman, Hayssom e Saffigna (1992) e Meier et al. (2006) que afirmam que somente $4 \%$ do $\mathrm{N}$ de resíduos vegetais marcados (raízes e rizomas) foram assimilados pela cana em diferentes locais na Austrália. Mencionaram que as inundações temporárias ocorridas nas regiões estudadas podem ter contribuído para menores taxas de decomposição dos resíduos vegetais e conseqüentemente reduzido a disponibilidade de $\mathrm{N}$ para as plantas.

Na cultura de trigo cultivado na Nova Zelândia, Kumar et al. (2001) obtiveram recuperações de 11 a $15 \%$ do $\mathrm{N}$ proveniente de palhada de azevém e do próprio trigo em três ciclos consecutivos. Já os valores encontrados de recuperação de $\mathrm{N}$ de raízes somado ao $\mathrm{N}$ de fertilizante residual foram de aproximadamente $5 \%$. Segundo estes autores esta menor recuperação do $\mathrm{N}$ proveniente de raízes pode estar relacionada à composição química das mesmas, geralmente apresentando maiores teores de compostos resistentes à decomposição da cutina (lignina, polifenóis). Encontraram relação $\mathrm{C}: \mathrm{N}$ das raízes maiores que dos resíduos de parte aérea, o que não aconteceu no presente trabalho onde a relação C:N da PAR foi 70:1 e RAR 51:1, respectivamente. Assim como neste trabalho, a marcação dos resíduos bem como a avaliação de recuperação de $\mathrm{N}$ foram conduzidos à campo, portanto as principais diferenças na recuperação foram a cultura de ciclo mais curto quando 
comparada à cana-de-açúcar, a localidade, o clima, o tipo de solo e principalmente ao sistema de cultivo mínimo.

Vitti et al. (2008b) e Franco et al. (2010) evidenciaram uma maior recuperação do $\mathrm{N}$-uréia no início do ciclo da cultura, ao passo que a contribuição do $\mathrm{N}$ dos resíduos culturais (palhada e rizomas) ocorre mais próxima a colheita da cana-deaçúcar. Ressaltaram que o total de $\mathrm{N}$ recuperado pela cana-de-açúcar geralmente é subestimado nos trabalhos científicos, uma vez que se avalia a recuperação na época de colheita, e a maior recuperação de $\mathrm{N}$ antecede este período. $\mathrm{Na}$ ocasião da colheita é esperado que tenham ocorrido perdas de $\mathrm{N}$ pela parte aérea da cultura quando esta se encontra em maturação, ou seja, devido à senescência das folhas (TRIVELIN et al., 2002a). Ressaltaram, ainda, que em condições de deficiência hídrica, as plantas aceleram a degradação das proteínas, diminuem sua síntese, levando, conseqüentemente, à perda de $\mathrm{N}$ pela parte aérea, podendo alcançar até $90 \mathrm{~kg} \mathrm{ha}^{-1}$ em soqueiras.

Ng Kee Kwong e Deville (1994), nas Ilhas Maurício, fazendo uso da técnica com ${ }^{15} \mathrm{~N}$, observaram queda do conteúdo de $\mathrm{N}$-fertilizante na parte aérea da canade-açúcar a partir de fevereiro, onde se inicia a maturação. Apontam que nos meses frios e secos da safra favorecem a senescência acentuada das folhas dos ponteiros. Franco et al. (2010) também observaram que, em soqueiras de cana da variedade SP81-3250 em três localidades do estado de São Paulo, a maior parte do N fertilizante foi aproveitada nos estágios iniciais de desenvolvimento (cerca de $70 \%$ ) e que este $\mathrm{N}$ na planta derivado do fertilizante decresceu aproximadamente para $30 \%$ na ocasião da colheita.

Além disso, o manejo de cana crua adicionado ao sistema de cultivo mínimo pode tornar o sistema radicular da cana mais superficial, auxiliando no aproveitamento dos nutrientes dos restos de cultura depositados ao longo das colheitas (MEIER et al., 2006; OLIVEIRA et al., 2002; ROBERTSON; THORBURN, 2007b).

Após quatro ciclos consecutivos, a recuperação de N-PAR e N-RAR pela parte aérea da cana foi de 14,2 e $7,4 \mathrm{~kg} \mathrm{ha}^{-1}$, respectivamente. Como a contribuição inicial destes resíduos foi de 51 e $33 \mathrm{~kg} \mathrm{ha}^{-1}$ de $\mathrm{N}$ a recuperação total foi de aproximadamente $28 \%$ e $22 \%$. A soma da recuperação de $\mathrm{N}$ da PAR e RAR foi de $21,6 \mathrm{~kg}$, ou seja, $25,7 \%$ da contribuição total dos resíduos anteriores à reforma que somada foi de $84 \mathrm{~kg} \mathrm{~N}$ ha $^{-1}$ (Tabela 27). Em geral, a quantidade de $\mathrm{N}$ recuperado 
diminuiu ao longo dos ciclos na seguinte ordem colmos > ponteiros > folhas secas. Estes resultados são consistentes com os de Basanta et al. (2003), Gava et al. (2005) e Ng Kee Kwong et al. (1987), indicando que, apesar do N de resíduos apresentarem liberação lenta e encontrar-se principalmente imobilizado no solo, ele pode se tornar uma fonte complementar de $\mathrm{N}$ para ciclos subseqüentes.

Estes valores são maiores do que os encontrados por $\mathrm{Ng}$ Kee Kwong et al. (1987) e Gava et al. (2005), 14\% e 9\%, respectivamente. Além do menor período avaliado por estes autores, esta menor recuperação pode ser atribuída à menor relação C:N dos resíduos utilizados neste trabalho (PAR: 70:1 e RAR: 51:1) em comparação aos utilizados pelos autores, 128:1 e 97:1, respectivamente. BolognaCampbell (2007) obtiveram valores similares de relação C:N, em comparação com o presente trabalho, 89:1 e 57:1 para a palhada e para o sistema radicular da variedade SP81-3250 e 14\% de recuperação do N destes resíduos após 12 meses.

Basanta et al. (2003) concluíram que $7 \mathrm{~kg} \mathrm{ha}^{-1}(5 \%)$ do $\mathrm{N}$-palhada recuperado pela cana-de-açúcar em dois ciclos consecutivos, dos quais $51 \%$ foi encontrados nos colmos, $24 \%$ nas folhas secas e $29 \%$ nos ponteiros da cultura. Estes autores também ressaltam que, embora a liberação e recuperação do $\mathrm{N}$ de resíduos vegetais seja pequena em um ciclo agrícola, estes são uma importante fonte deste e outros nutrientes para o solo e ciclos subsequentes.

Quando se consideram resíduos de outras culturas de rotação como amendoim e soja, Hemwong et al. (2009) obtiveram recuperações do N-palhada maiores (41-80\%) que a do $\mathrm{N}$-fertilizante $\left(94 \mathrm{~kg} \mathrm{ha}^{-1}\right.$ de $\mathrm{N}$ como sulfato de amônio${ }^{15} \mathrm{~N}$ ) que foi $30 \%$ após 14 meses. Ressaltam que a maior recuperação do N-palhada de soja teve relação com sua degradação mais lenta e que proporcionou menores perdas de $\mathrm{N}$ no sistema uma vez que foi sincronizada com a demanda deste nutriente pela cultura de cana.

Robertson (2003) ressaltou que a baixa degradabilidade da palhada de canade-açúcar é devida principalmente a sua alta relação $\mathrm{C}: \mathrm{N}$, variando em seus experimentos de 80:1 a 120:1. Outro fator determinante na dinâmica de decomposição de resíduos vegetais é o teor de nutrientes totais, como mencionam Zhang et al. (2008).

Há evidências que a composição da palhada é dependente de características da variedade (CONDE, PENATTI; BELLINASO, 2005). Meier et al. (2006) usaram uma palhada marcada da variedade Q166 (C:N 105:1) em sua pesquisa em 
Queensland na Austrália, mas afirmaram que essa relação normalmente varia de 70:1 a 120:1. Oliveira et al. (2002) encontraram em média $C: N=95: 1$ em palhada recém-colhidas de duas variedades distintas (SP79-1011 e SP80-1842) e em dois locais no Estado de São Paulo.

Spain e Hodgen (1994) encontraram relação C:N da palhada de cana de 170:1, um dos valores mais altos da literatura. Robertson e Thorburn (2007a) e Oliveira et al. (1999) encontraram 87:1 e 97:1, respectivamente. Gava et al. (2005) elucidaram que relações $\mathrm{C}: \mathrm{N}$ superiores a 120:1 podem diminuir significativamente as taxas de mineralização e disponibilização de nutrientes para a cultura. Este número é cerca de 12 vezes acima à dos microrganismos, o que causa imobilização do N (SIQUEIRA; FRANCO, 1988; JADHAV, 1996).

Além da relação $\mathrm{C}: \mathrm{N}$, a liberação de nutrientes dos resíduos vegetais está relacionada à qualidade do resíduo (OLIVEIRA et al., 2002) e ao grau de partição e transferência ("turnover") no solo do nitrogênio mineralizado do resíduo vegetal (MYERS et al., 1994). Estes últimos autores relataram que, durante a decomposição de restos culturais, existe uma partição do nitrogênio em três compartimentos ("pools"), o $\mathrm{N}$-mineral (solo e fertilizante), o $\mathrm{N}$-húmico e o $\mathrm{N}$-imobilizado pela biomassa microbiana do solo, e concluíram que existe uma contínua transformação desse $N$ dentre os compartimentos do sistema solo-planta. Jadhav (1996) e Robertson (2003) observaram que ao longo do tempo, pela descarboxilação dos resíduos vegetais, praticamente havia liberação do $\mathrm{CO}_{2}$, mantendo-se $\circ \mathrm{N}$ no sistema, onde a relação C:N passou de aproximadamente 100:1 a 20:1. Essa relação $\mathrm{C}: \mathrm{N}$ é próxima a encontrada nos microrganismos, proporcionando maior mineralização da palhada e resultando em maior disponibilidade desse $\mathrm{N}$ para as plantas (HEMWONG et al., 2009).

Wood (1991) afirmou que em manejo de cana colhida sem queimar, a recuperação do $\mathrm{N}$ uréia excedeu $50 \%$ em comparação a menos de $40 \%$ em cana queimada, mas salientou que a adequação variedade para este tipo de manejo é obrigatória para o cultivo de cana bem sucedido. Manechini, Ricci Junior e Donzelli (2005) e Fortes, Campos e Silva (2009) também verificaram respostas positivas no manejo da palhada, isto é, quando se retirou o excesso de resíduos provenientes da colheita de cima das linhas de cana na região da Usina São Martinho (Pradópolis, SP) e usina Iracema na região de Piracicaba, SP, respectivamente. Os autores ressaltaram a importância do melhoramento genético em proporcionar variedades de 
cana que sejam mais bem adaptadas ao manejo de cana colhida mecanicamente sem a queima da palhada.

Outro ponto a ser considerado é o tempo total de cada experimento, quatro ciclos neste trabalho, contra geralmente um ciclo agrícola nos demais da literatura. A temperatura e precipitação pluviométricas locais também são fatores importantes a serem considerados na avaliação de recuperação do $\mathrm{N}$ (MANECHINI; RICCI JUNIOR; DONZELLI, 2005; OLIVEIRA et al., 2002; ZHANG et al., 2009).

A Figura 9 indica que houve correlação entre as taxas de recuperação do Nuréia, N-PAR e N-RAR com a evapotranspiração real (ETr) acumulada durante os quatro ciclos consecutivos (2006 a 2009).

Estes resultados concordam com Coûteaux, Bottner e Berg (1995) e Robertson e Thorburn (2007b), que obtiveram correlações positivas da degradação e da recuperação de $\mathrm{N}$ da palhada de cana com variáveis climáticas. A recuperação do $N-R A R\left(R^{2}=0,93\right)$ foi ligeiramente inferior à recuperação do N-PAR $\left(R^{2}=0,96\right)$ em função da evapotranspiração acumulada do período, assim como elucidaram Abiven et al. (2005). Estudando a decomposição de resíduos de culturas no cerrado do Brasil (soja, braquiária, sorgo e arroz) e sua contribuição para os estoques de $\mathrm{C}$ e $\mathrm{N}$ no solo, estes autores ressaltaram que a degradação das raízes tende a ser mais lenta que a de resíduos de parte aérea devido além da sua composição bioquímica, também às menores temperaturas e condições de aeração na subsuperfície.

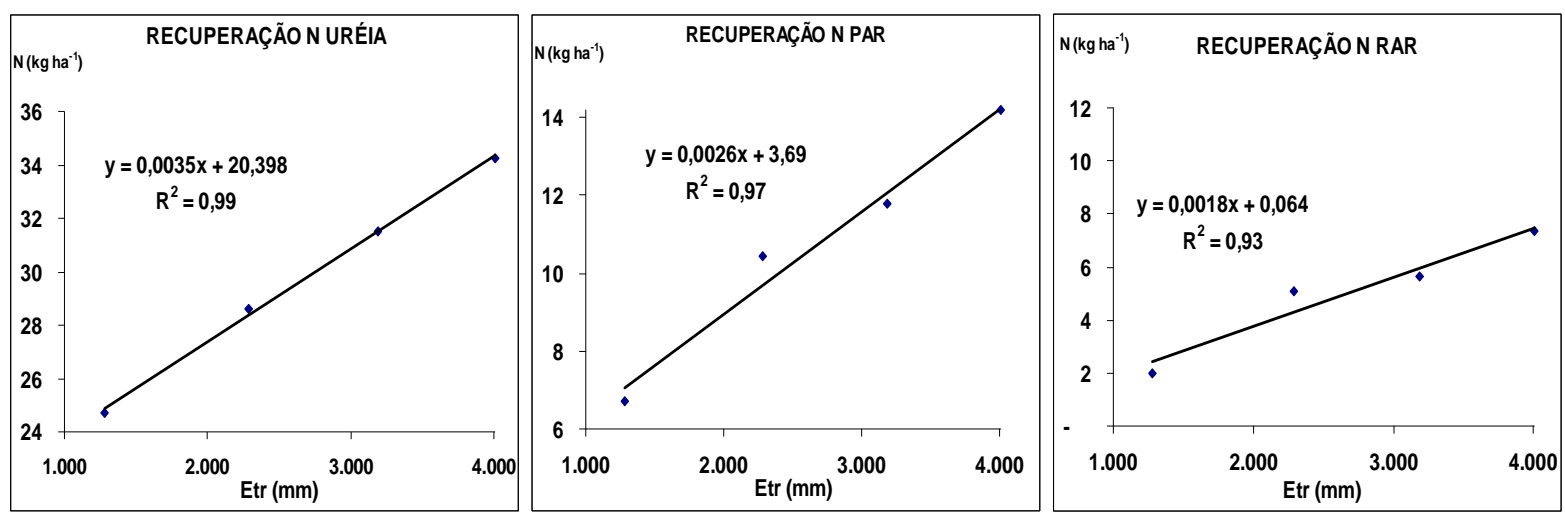

Figura 9 - Recuperação do ${ }^{15} \mathrm{~N}$ de uréia, palhada (PAR) e rizomas (RAR) pela canade-açúcar em função da evapotranspiração acumulada em quatro ciclos agrícolas consecutivos (2006 a 2009) 
3.3.2 Recuperação pela cana-de-açúcar do $\mathrm{N}$ de palhada pós colheita (PPC) nos tratamentos com doses de N 80 - 0 e 80 - $150 \mathrm{~kg} \mathrm{ha}^{-1}$ em cana-planta e soqueiras respectivamente, em três ciclos agrícolas consecutivos (2007 a 2009)

A recuperação do $\mathrm{N}$ pela parte aérea da cana soca apresentou diferenças significativas nos três ciclos agrícolas devido a aplicação de $\mathrm{N}$ sobre a palhada após a colheita (Tabela 28). Estes resultados diferem dos de Ambrosano et al. (2005) que não obtiveram diferenças significativas de recuperação de $\mathrm{N}$ de resíduos de Crotalária juncea marcados com ${ }^{15} \mathrm{~N}$ devido à aplicação de $\mathrm{N}$ mineral. Esta diferença se deve provavelmente à qualidade do resíduo utilizado ser diferente quando comparado à palhada de cana-de-açúcar, isto é, menor relação C:N da leguminosa. Estes autores encontraram recuperação de $34 \%$ do fertilizante e de $10 \%$ do resíduo vegetal.

$\mathrm{Ng}$ Kee Kwong et al. (1987) também afirmaram que, embora tenham utilizado grandes quantidades de $\mathrm{N}$ em experimento de campo (450 $\mathrm{kg} \mathrm{ha}^{-1}$ ) não foram capazes de detectar nenhuma diferença no aproveitamento do N-palhada pela canade-açúcar pela adição de $\mathrm{N}$ mineral.

Considerando somente o primeiro ciclo agrícola (2007), as recuperações pela parte aérea observadas nos tratamentos sem e com N (7,5\% e 11,3\%, Tabela 28) foram coerentes com as observações de Chapman, Hayssom e Saffigna (1992) e Ng Kee Kwong et al. (1987) e que obtiveram valores de 5\% a 15\%, respectivamente. Gava et al. (2005) conseguiram 8\% de recuperação de N-palhada pela parte aérea da cultura após um ciclo de soqueira com adubação de $100 \mathrm{~kg} \mathrm{ha}^{-1}$ de N-uréia aplicado sobre a palhada.

Houve diferença de produção de matéria seca e acúmulo de $\mathrm{N}$ total na parte aérea somente no segundo ciclo de rebrota (2008), que foi um ano mais restritivo do ponto de vista climático (Figura 1 e Apêndice $C$ ). Notou-se também que neste ano, a recuperação do N-PPC foi inferior ao primeiro e terceiro ciclos, respectivamente (Tabela 28). Robertson e Thorburn (2007b) e Zhang et al. (2008) ressaltaram que além da disponibilidade de $\mathrm{N}$ no solo, fatores que apresentam grande influência na degradação dos resíduos vegetais são a evapotranspiração, soma térmica e temperaturas médias dos locais. 
Tabela 28 - Massa seca da cana-de-açúcar e recuperação do $\mathrm{N}$ de palhada pós colheita $\left({ }^{15} \mathrm{~N}-\mathrm{PPC}\right)$ pela planta nos tratamentos com doses de $\mathrm{N}$ : $80-0$ e $80-150 \mathrm{~kg} \mathrm{~N} \mathrm{ha}^{-1}$ em cana-planta e soqueiras, respectivamente e após três ciclos agrícolas consecutivos (2007 a 2009)

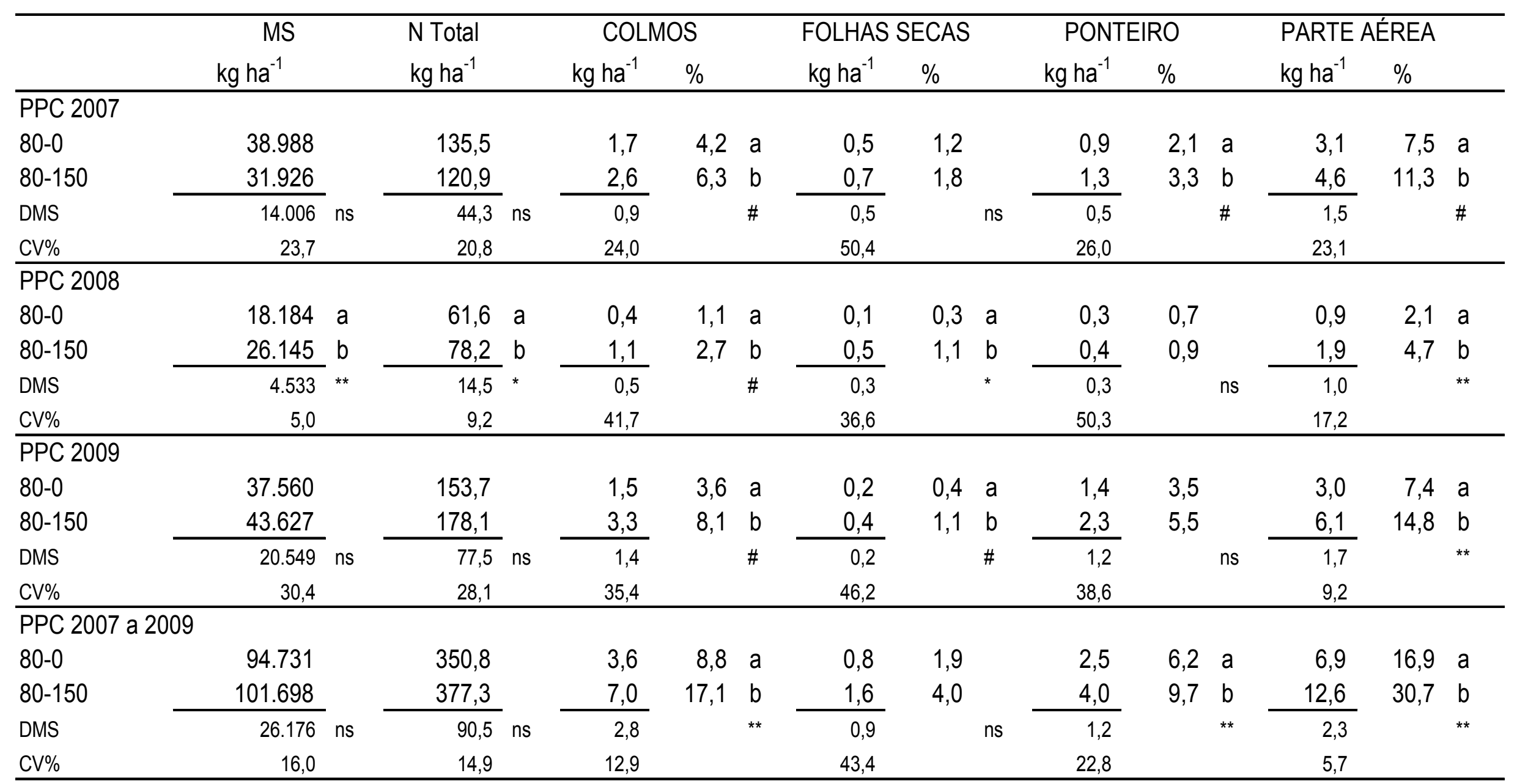

Legenda: Letras iguais na coluna não diferem estatisticamente pelo teste Tukey \# 10\%; ${ }^{*} \%$ e ${ }^{* *} 1 \%$; PPC = palhada pós-colheita (variedade SP81-3250) DMS $=$ diferença mínima significativa; $\mathrm{MS}$ = matéria seca; $\mathrm{CV}=$ coeficiente de variação. 
A recuperação acumulada nos dois primeiros ciclos foi de $9,6 \%$ e $16 \%$ da dose de N-PPC inicialmente aplicada, para os tratamentos sem e com N, respectivamente. Estes resultados superaram os de Basanta et al. (2003) que observaram aproximadamente $7 \%$ (3,9 e 2,8 $\mathrm{kg} \mathrm{N} \mathrm{ha}^{-1}$ no primeiro e segundo ciclos, respectivamente) de recuperação de $\mathrm{N}$-palhada em dois anos, embora as quantidades de $\mathrm{N}$ recuperadas tenham sido coerentes 3,1 e $0,9 \mathrm{~kg} \mathrm{ha}^{-1}$ de $\mathrm{N}$ no tratamento sem $\mathrm{N}$ e 4,6 e 1,9 $\mathrm{kg} \mathrm{ha}^{-1}$ de $\mathrm{N}$ no tratamento com $\mathrm{N}$ (Tabela 28).

Para o terceiro ciclo de soqueira (2009) observou-se recuperação superior a dos anteriores no tratamento com $\mathrm{N}$-adubo. A recuperação neste caso apresentou valores de 7,4 e $14,8 \%$ sem e com $N$, respectivamente. De maneira geral a recuperação do N-PPC praticamente dobrou em todos os ciclos avaliados devido a aplicação de $\mathrm{N}$ sobre a palhada e no acumulado observou-se que foram recuperados $17 \%\left(7 \mathrm{~kg} \mathrm{ha}^{-1}\right)$ e $31 \%\left(12,6 \mathrm{~kg} \mathrm{ha}^{-1}\right)$ do $\mathrm{N}$ da palhada na testemunha sem $\mathrm{N}$ e no tratamento com $150 \mathrm{~kg} \mathrm{~N} \mathrm{ha}^{-1}$ (Tabela 28).

A avaliação de três ciclos consecutivos e a influência da adubação com $\mathrm{N}$ mineral da disponibilização do $\mathrm{N}$ da palhada foi a maior diferença deste trabalho com os encontrados na literatura relacionada à cultura de cana-de-açúcar. Ao final dos três ciclos a diferença de recuperação do ${ }^{15} \mathrm{~N}$ pela parte aérea foi $55 \%$ maior quando se aplicou $\mathrm{N}$ na soqueira. A recuperação do N-PPC nos colmos nos tratamentos 80 0 e foi de 44 a $48 \%$ do $N$, respectivamente.

3.3.3 Balanço de nitrogênio no sistema solo-planta e estoque de carbono e nitrogênio no solo após quatro ciclos consecutivos

O nitrogênio proveniente da uréia foi em sua maior parte recuperado pela cultura $34,3 \mathrm{~kg} \mathrm{ha}^{-1}$, ou seja, $43 \%$ dos $80 \mathrm{~kg} \mathrm{ha}^{-1}$ aplicados via fertilizante. Já para os resíduos culturais palhada e rizomas (PAR e RAR), a maior parte do $\mathrm{N}$ permaneceu no solo, 23 e 19,5 $\mathrm{kg} \mathrm{ha}^{-1}$, isto é, 45 e $59 \%$ do $\mathrm{N}$ total aplicado via estes resíduos culturais (41 e $33 \mathrm{~kg} \mathrm{ha}^{-1}$ ), respectivamente (Tabela 29). 
Tabela 29 - Balanço de nitrogênio no sistema solo-planta sob fontes marcadas com ${ }^{15} \mathrm{~N}$ (uréia, palhada e rizomas anteriores à reforma) e após quatro ciclos consecutivos (2006 a 2009)

\begin{tabular}{|c|c|c|c|}
\hline \multirow{2}{*}{$\begin{array}{c}\text { Tratamento } \\
\mathrm{N} \text { aplicado }\left(\mathrm{kg} \mathrm{ha}^{-1}\right)\end{array}$} & \multirow[t]{2}{*}{ Compartimento } & \multicolumn{2}{|c|}{ Recuperação ${ }^{15} \mathrm{~N}$} \\
\hline & & $\mathrm{kg} \mathrm{ha}^{-1}$ & $\%$ \\
\hline \multirow{4}{*}{$\begin{array}{l}\text { Uréia- }{ }^{15} \mathrm{~N} \\
\left(80 \mathrm{~kg} \mathrm{~N} \mathrm{ha}{ }^{-1}\right)\end{array}$} & Parte Aérea & $34,3( \pm 1,51)$ & 42,8 \\
\hline & Rizomas & $0,14( \pm 0,03)$ & 0,2 \\
\hline & Solo $(0-0,60 \mathrm{~m})$ & $16,1( \pm 2,98)$ & 20,1 \\
\hline & NOC & $29,5( \pm 1,92)$ & 36,9 \\
\hline \multirow{4}{*}{$\begin{array}{l}\text { PAR }-{ }^{15} \mathrm{~N} \\
\left(51 \mathrm{~kg} \mathrm{~N} \mathrm{ha}^{-1}\right)\end{array}$} & Parte Aérea & $14,2( \pm 0,95)$ & 27,8 \\
\hline & Rizomas & $0,10( \pm 0,01)$ & 0,2 \\
\hline & Solo $(0-0,60 \mathrm{~m})$ & $23,1( \pm 2,83)$ & 45,3 \\
\hline & NOC & $13,6( \pm 0,89)$ & 26,7 \\
\hline \multirow{4}{*}{$\begin{array}{l}\text { RAR }-^{15}{ }^{-1} \\
\left(33 \mathrm{~kg} \mathrm{~N} \mathrm{ha}^{-1}\right)\end{array}$} & Parte Aérea & $7,58( \pm 0,24)$ & 23,0 \\
\hline & Rizomas & $0,12( \pm 0,01)$ & 0,4 \\
\hline & Solo $(0-0,60 \mathrm{~m})$ & $19,5( \pm 2,83)$ & 59,1 \\
\hline & NOC & $5,80( \pm 0,77)$ & 17,6 \\
\hline
\end{tabular}

Legenda: PAR e RAR = palhada e rizoma anteriores à reforma (variedade RB855536); NOC = nitrogênio em outros compartimentos (lixiviação abaixo de 0,60 m, volatilização, desnitrificação).

Por outro lado, nota-se que o N-NOC (N em outros compartimentos como (perdas por lixiviação, volatilização, desnitrificação, etc.) proveniente da uréia foi maior ( $37 \%$ do total aplicado) do que o proveniente dos resíduos vegetais, 27 e 17\% do $\mathrm{N}$ total aplicado através da palhada (PAR) e dos rizomas (RAR) anteriores à reforma, respectivamente (Tabela 29).

Mesmo enterrada o $\mathrm{N}$-uréia pode ter sido em parte perdido por volatilização, uma vez que havia grande quantidade de palhada na superfície do solo quando foi realizada a sulcação para o plantio. A palhada de cana-de-açúcar apresenta quantidade considerável da enzima urease e as perdas de amônia $\left(\mathrm{NH}_{3}\right)$ podem superar $50 \%$ se a quantidade de água não for suficiente para incorporar a uréia ao solo (FORTES et al., 2008).

Utilizando doses crescentes de nitrato de amônio em soqueiras, Vitti et al. (2007) concluíram que $32 \%$ do $\mathrm{N}$-fertilizante permaneceu no solo após um ciclo agrícola, $22 \%$ foi recuperado pela parte aérea da cana-de-açúcar, $7 \%$ pelas raízes e $33 \%$ não recuperado, portanto contabilizados como perdas. 
Detectaram-se menores quantidades do N-RAR em outros compartimentos (NOC) quando comparado ao N-PAR. Por outro lado, houve maior aproveitamento do N-PAR em relação ao N-RAR após os quatro ciclos (Figura 10).

Trivelin et al. (2002a) obtiveram $88 \%$ e $81 \%$ de recuperação total do $\mathrm{N}$-uréia aplicado em cana-planta e soqueira respectivamente. Os balanços de N, ou seja, a recuperação do $\mathrm{N}$-fertilizante nos diferentes compartimentos do sistema solo-planta neste experimento foram $35 \%$ e $30 \%$ no solo, $53 \%$ e $43 \%$ na planta e de $10 \%$ a $19 \%$ foram contabilizados como perdas. Observaram também que o aumento da dose de $\mathrm{N}$ resultou em acúmulo crescente de $\mathrm{N}$ na parte subterrânea de plantas de cana, na qual o teor total do nutriente $\left(4,3 \mathrm{~g} \mathrm{~kg}^{-1}\right)$ era maior do que o da parte aérea $\left(2,9 \mathrm{~g} \mathrm{~kg}^{-1}\right)$ e também muito superior ao valor encontrado no presente trabalho $\left(0,1 \mathrm{~kg} \mathrm{ha}^{-1}\right)$. Outro ponto ressaltado por estes autores foi que as perdas do N-uréia podem ser por volatilização do próprio fertilizante e pela parte aérea das plantas, principalmente em situações de stress hídrico ou biótico (pragas e doenças).

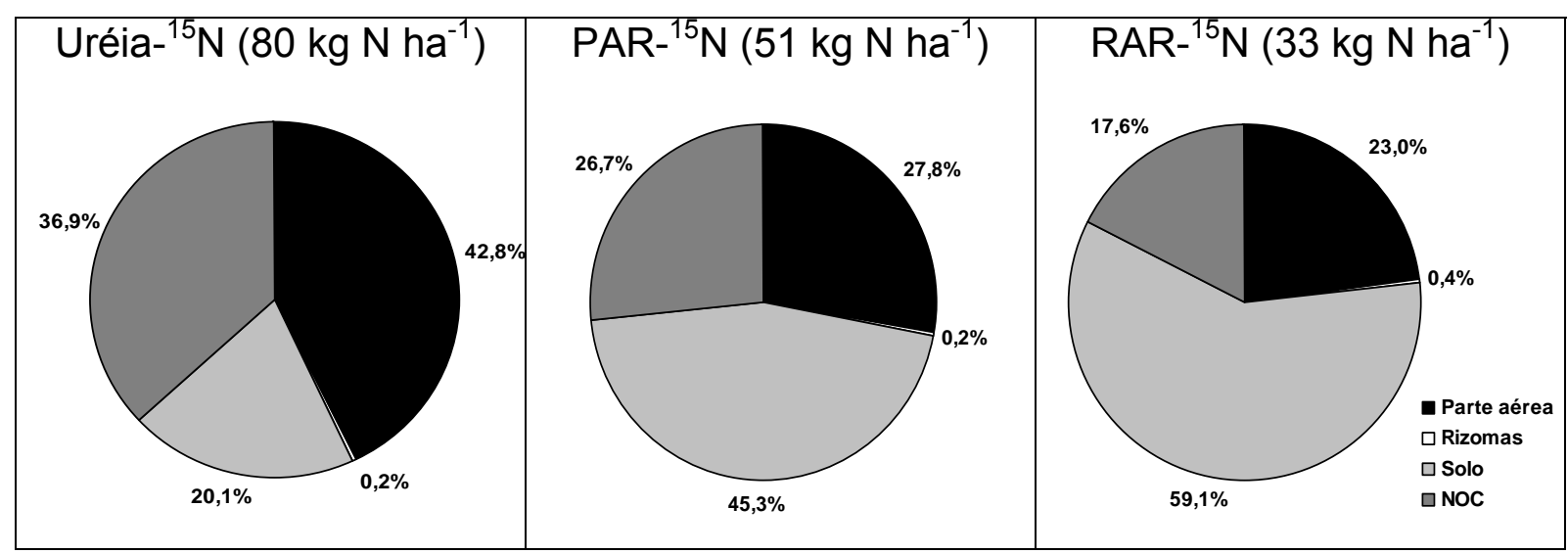

Legenda: PAR e RAR = palhada e rizoma anteriores à reforma (variedade RB855536); NOC = nitrogênio em outros compartimentos (lixiviação abaixo de 0,60 m, volatilização, desnitrificação).

Figura 10 - Balanços de nitrogênio no sistema solo-planta nos tratamentos uréia- ${ }^{15} \mathrm{~N}$, PAR- ${ }^{15} \mathrm{~N}$ e RAR- ${ }^{15} \mathrm{~N}$ aplicados na cana-planta (dose $80 \mathrm{~kg} \mathrm{~N}$ ha ${ }^{-1}$ ) após quatro ciclos consecutivos (2006 a 2009) 
A baixa recuperação do $\mathrm{N}$ nos rizomas $\left(0,1 \mathrm{~kg} \mathrm{ha}^{-1}\right)$, foi devido provavelmente a baixa produção de matéria seca e da ordem de $1,8 \mathrm{Mg} \mathrm{ha}^{-1}$. Otto et al. (2009b) verificaram produção de $2,2 \mathrm{Mg} \mathrm{ha}^{-1}$ somente de raízes (sem rizomas) em área de cana-de-açúcar com a mesma variedade, porém em solo com textura média e sob cultivo convencional de cana-de-açúcar. Este solo sendo de textura muito argilosa e sob cultivo mínimo pode ter inibido o crescimento pleno do sistema radicular, o que pode comprometer a produtividade em anos com deficiência hídrica, como ocorrido em 2008 (item 2.3.3).

Basanta et al. (2003) obtiveram recuperações de N-fertilizante após três anos experimento de $29 \%$ no solo, $42 \%$ na planta e $29 \%$ em outros compartimentos e/ou perdas. Já para o N-palhada, nos dois ciclos de soqueiras estudados, o balanço obtido por estes autores foi de $89 \%$ no solo, $6 \%$ na planta e $5 \%$ para outros compartimentos. Estes autores ressaltam que o $\mathrm{N}$-palhada pouco contribui para na nutrição do ciclo presente da cana-de-açúcar, devido a falta de sincronia entre a mineralização dos resíduos vegetais e a demanda de $\mathrm{N}$ pela cultura (Meyers et al., 1994).

No somatório de contribuição do $\mathrm{N}$ dos resíduos vegetais PAR e RAR, 42,6 kg permaneceram no solo, portanto a contribuição total destes resíduos para os sistema solo planta foi de aproximadamente $50 \%$ do total de $\mathrm{N}$ aplicado através destes resíduos após quatro ciclos consecutivos (Tabela 29 e Figura 10).

Estes resultados são coerentes com os obtidos por Kumar et al. (2001). Estes autores estudaram o balanço de $\mathrm{N}$ proveniente de palhada e raízes de gramíneas (azevém e trigo) e de leguminosas (trevo e ervilha) após 3 ciclos consecutivos para a cultura de trigo na Nova Zelândia. Obtiveram 10 a $60 \%$ de recuperação do $\mathrm{N}$ da palhada pela cultura ( $27,8 \%$ deste trabalho), 30 a $70 \%$ permaneceu no solo $(45,3 \%)$ e 10 a $20 \%$ foram perdidos do sistema. Considerando a recuperação do $\mathrm{N}$ proveniente das raízes das gramíneas, $5 \%$ foi absorvido pela cultura, $70 \%$ permaneceu no solo e $25 \%$ foi perdido. Neste trabalho os resultados para RAR foram 23\%, 59\% e 18\%, respectivamente (Tabela 29 e Figura 10).

Com respeito à mineralização da palhada pós-colheita (PPC), foi possível observar grande contribuição no nitrogênio para o estoque de $\mathrm{N}$ do solo. $\mathrm{A}$ recuperação do N-PPC no solo foi de $69 \%\left(28,5 \mathrm{~kg} \mathrm{ha}^{-1}\right)$ no tratamento testemunha $(80-0)$ e $61 \%\left(25,1 \mathrm{~kg} \mathrm{ha}^{-1}\right)$ quando se utilizou $\mathrm{N}$ em soqueiras (80 - 150). Quando se analisou o N-NOC proveniente da PPC, notou-se que houve maior perda de $\mathrm{N}$ 
quando não se utilizou $\mathrm{N}$ em soqueiras sobre a palhada, $13,4 \%\left(5,4 \mathrm{~kg} \mathrm{ha}^{-1}\right)$ contra $7,6 \%\left(3,1 \mathrm{~kg} \mathrm{ha}^{-1}\right)$, respectivamente (Tabela 30 e Figura 11).

Estes resultados indicam que, com a aplicação de $\mathrm{N}$ mineral em soqueira, o aproveitamento do N-PPC pela cana-de-açúcar foi maior, confirmando a importância destes resíduos na nutrição da cultura com $\mathrm{N}$ e outros nutrientes a longo prazo como ressaltaram Robertson (2003) e Vitti et al. (2008a).

Gava et al. (2005) concluíram que, após um ano, 60\% do N-uréia aplicado em soqueira permaneceu no solo e na palhada superficial, $16 \%$ foi recuperado pela planta e $40 \%$ havia sido perdido no sistema solo-planta. Já o N-palhada, $90 \%$ foi encontrado no solo e na palhada superficial, $9 \%$ foi recuperado pela planta (parte aérea e subterrânea) e somente $1 \%$ não fora encontrado, ou seja, foi considerado como perdas (N-NOC).

$\mathrm{Ng}$ Kee Kwong et al. (1987) observaram que a recuperação do N-fertilizante (sulfato de amônio) foi de $25 \%$ no solo, $55 \%$ na planta e $20 \%$ perdido. Para o Npalhada estes autores observaram em média $78 \%$ permaneceu no solo, $12 \%$ foi aproveitado pela planta e $10 \%$ foi considerado como perdas.

Tabela 30 - Balanço de nitrogênio no sistema solo-planta sob palhada pós colheita (PPC) marcada com ${ }^{15} \mathrm{~N}$ aplicada nos tratamentos $80-0$ e $80-150$ (doses $\mathrm{N} \mathrm{kg} \mathrm{ha}^{-1}$ cana-planta e soqueira, respectivamente) e após três ciclos consecutivos (2007 a 2009)

\begin{tabular}{|c|c|c|c|}
\hline \multirow{2}{*}{$\begin{array}{c}\text { Tratamento } \\
\mathrm{N} \text { aplicado }\left(\mathrm{kg} \mathrm{ha}^{-1}\right)\end{array}$} & \multirow[t]{2}{*}{ Compartimento } & \multicolumn{2}{|c|}{ Recuperação ${ }^{15} \mathrm{~N}$} \\
\hline & & $\mathrm{kg} \mathrm{ha}^{-1}$ & $\%$ \\
\hline \multirow[b]{2}{*}{ PPC- ${ }^{15} \mathrm{~N}, 80-0$} & Parte Aérea & $6,94( \pm 0,46)$ & 16,9 \\
\hline & Rizomas & $0,12( \pm 0,02)$ & 0,3 \\
\hline \multirow[t]{3}{*}{$\left(41 \mathrm{~kg} \mathrm{~N} \mathrm{ha}^{-1}\right)$} & Solo $(0-0,60 \mathrm{~m})$ & $28,5( \pm 7,23)$ & 69,4 \\
\hline & NOC & $5,47( \pm 0,39)$ & 13,4 \\
\hline & Parte Aérea & $12,6( \pm 0,51)$ & 30,7 \\
\hline \multirow{3}{*}{$\begin{array}{l}\text { PPC- }{ }^{15} \mathrm{~N}, 80-150 \\
\left(41 \mathrm{~kg} \mathrm{~N} \mathrm{ha}{ }^{-1}\right)\end{array}$} & Rizomas & $0,18( \pm 0,02)$ & 0,4 \\
\hline & Solo $(0-0,60 \mathrm{~m})$ & $25,1( \pm 3,33)$ & 61,2 \\
\hline & NOC & $3,11(0,31)$ & 7,6 \\
\hline
\end{tabular}

Legenda: $\mathrm{PPC}=$ palhada pós colheita (variedade SP81-3250); $\mathrm{NOC}=$ nitrogênio em outros compartimentos (lixiviação abaixo de $0,60 \mathrm{~m}$, volatilização, desnitrificação). 


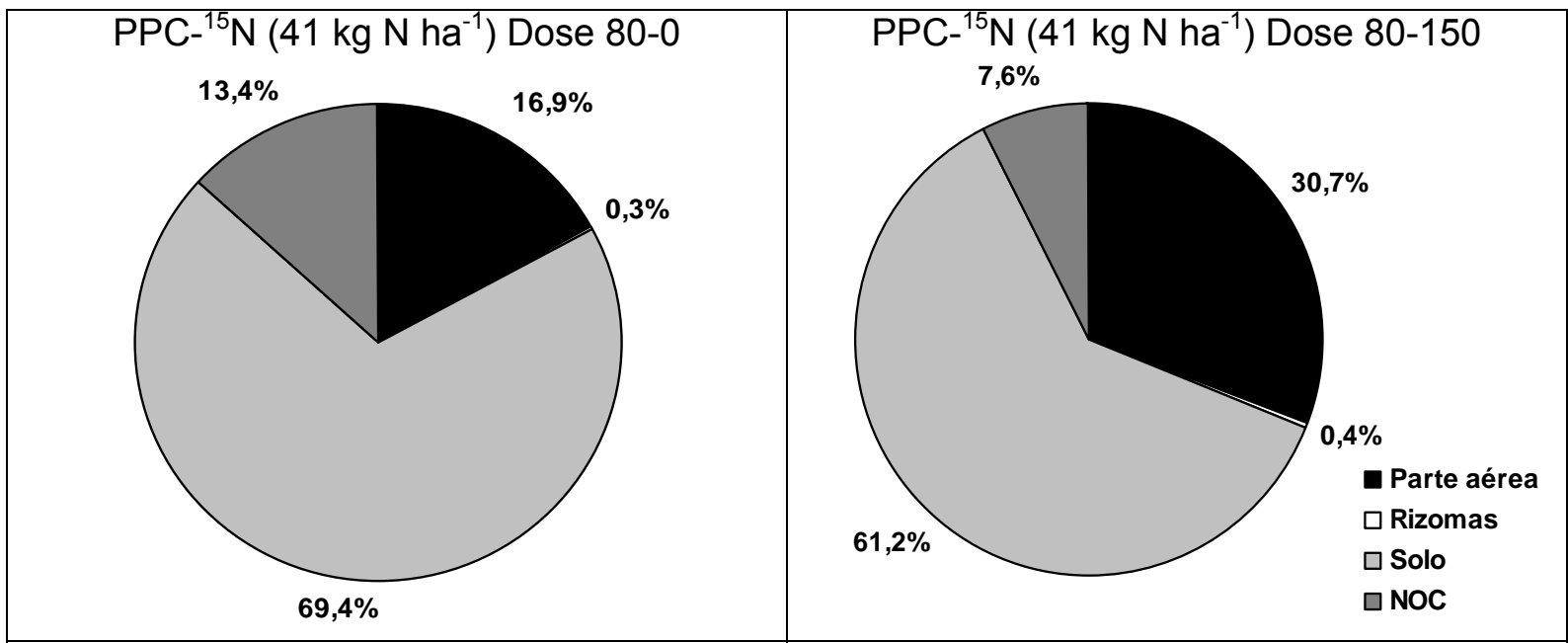

Legenda: PPC $=$ palhada pós colheita (variedade SP81-3250); NOC = nitrogênio em outros compartimentos (lixiviação abaixo de $0,60 \mathrm{~m}$, volatilização, desnitrificação).

Figura 11 - Balanço de nitrogênio no sistema solo-planta nos tratamentos $80-0$ e $80-150 \mathrm{~kg} \mathrm{~N} \mathrm{ha}^{-1}$ sob palhada pós colheita (PPC) e após três ciclos consecutivos (2007 a 2009)

Após 14 meses utilizando resíduos de culturas de rotação (amendoim e soja) e fertilizante nitrogenado marcados com ${ }^{15} \mathrm{~N}$ na Tailândia, Hemwong et al. (2009) obtiveram recuperações de 2 a $3 \%$ do $\mathrm{N}$ proveniente destes resíduos vegetais pela cana-planta, 42 a $81 \%$ permaneceu no solo e nas ervas daninhas e 15 a $57 \%$ foram contabilizados como perdas. Já para o $\mathrm{N}$-fertilizante a recuperação pela cana foi de somente $7 \%$, no solo e ervas daninhas $31 \%$ e as perdas foram de $63 \%$. Os autores ressaltam que, principalmente em condições de alta precipitação pluviométrica (acima de $2.000 \mathrm{~mm} \mathrm{ano}^{-1}$ ) a manutenção de resíduos vegetais é fundamental para a nutrição adequada da cultura, devido a liberação gradual do $\mathrm{N}$ mitigar as perdas no sistema.

Outro aspecto deste trabalho foi o fato de ter conduzido em cultivo mínimo, isto é, sem o revolvimento do solo desde a ocasião da colheita e os fertilizantes de soqueira foram sempre aplicados sobre a palhada remanescente da colheita mecanizada sem queimar. Este manejo proporciona degradação mais lenta da matéria vegetal e liberação gradual dos nutrientes para o sistema solo-planta. Kumar et al. (2001) obtiveram maior aproveitamento do nitrogênio proveniente de resíduos culturais por ciclos consecutivos de trigo quando os mesmos foram deixados como "mulch" na superfície do solo ao invés de serem incorporados anualmente. 
O estoque de carbono no solo $(0-0,60 \mathrm{~m})$ ao longo dos ciclos agrícolas avaliados não apresentou diferenças significativas conforme os resultados das Tabelas 31 e 32. Galdos, Cerri e Cerri (2009) e Luca et al. (2008) ressaltam que as estimativas de estoque de carbono para locais distintos ou em comparativos de diferentes tipos de manejo devem ser corrigidos dos efeitos da densidade do solo para "massa equivalente". Porém, neste trabalho o conteúdo de carbono do solo não foi corrigido, tendo em vista a pouca variação de densidade do solo detectada nos tratamentos de 2006 daquele coletado em 2009, da ordem de 0,016 $\mathrm{Mg} \mathrm{m}^{-3}$.

Meier et al. (2006) obtiveram recuperação superior a $100 \%$ do total de $\mathrm{N}$ aplicado via palhada e fertilizante marcados com ${ }^{15} \mathrm{~N}$ pelo sistema solo-planta em um oxissolo da Austrália. Tais resultados foram atribuídos à supersestimativa de densidade do solo pelo método utilizado por estes autores. Por outro lado detectaram em duas safras que somente $5 \%$ do $\mathrm{N}$-fertilizante foi recuperado pelas plantas de cana devido às altas precipitações ocorridas, 2.154 e $2.900 \mathrm{~mm}$ nos anos de 2002 e 2003 respectivamente, e, portanto, muito superiores às condições deste trabalho.

Tabela 31 - Estoque de nitrogênio e carbono no solo $(0-0,60 \mathrm{~m}$ de profundidade) sob as microparcelas de uréia, palhada e rizomas marcados com ${ }^{15} \mathrm{~N}$ após quatro ciclos consecutivos (2006 a 2009), experimento Usina São Martinho em Jaboticabal, SP

\begin{tabular}{|c|c|c|c|c|c|c|c|c|}
\hline \multirow[t]{2}{*}{ Solo $(0-0,60 \mathrm{~m})$} & \multirow{2}{*}{$\begin{array}{c}\mathrm{D} \\
\mathrm{Mg} \mathrm{m}^{-3}\end{array}$} & ${ }^{15} \mathrm{~N}$ & $\mathrm{~N}$ & C & $\mathrm{N}$ & $\mathrm{C}$ & \multicolumn{2}{|c|}{ NSPf } \\
\hline & & \multicolumn{3}{|c|}{ - - } & \multicolumn{2}{|c|}{-- Mg ha ${ }^{-1}--$} & $\mathrm{kg} \mathrm{ha}^{-1}$ & $\%$ \\
\hline 2006 (Testemunha) & 1,240 & $0,371 b$ & 0,13 & 1,84 & 9,8 & 137,1 & & \\
\hline 2009, Uréia & 1,256 & $0,378 a$ & 0,14 & 1,83 & 10,2 & 137,8 & 16,1 & 20,1 \\
\hline 2009, PAR & 1,256 & $0,372 b$ & 0,12 & 1,80 & 9,3 & 135,5 & 23,1 & 45,3 \\
\hline 2009, RAR & 1,256 & $0,370 \mathrm{~b}$ & 0,13 & 1,87 & 9,5 & 140,9 & 19,5 & 59,1 \\
\hline dms & ns & $0,03^{* *}$ & ns & ns & ns & ns & & \\
\hline CV\% & 8,7 & 1,4 & 4,4 & 9,9 & 4,4 & 10,1 & & \\
\hline
\end{tabular}

Legenda: $\mathrm{D}=$ densidade do solo; PAR e RAR = palhada e rizomas anteriores à reforma (variedade RB855536); $\mathrm{NSPf}=\mathrm{N}$ que permaneceu no solo $(0-0,60 \mathrm{~m})$ proveniente da fonte marcada das microparcelas (Uréia, PAR e RAR); dms = diferença mínima significativa teste Tukey a ** $1 \%$ e * $5 \%$ de probabilidade; ns = não significativo. 
Tabela 32 - Estoque de nitrogênio e carbono no solo $(0-0,60 \mathrm{~m}$ de profundidade) sob as microparcelas de palhada pós colheita marcadas com ${ }^{15} \mathrm{~N}$ após três ciclos (2007 a 2009), experimento Usina São Martinho em Jaboticabal, SP

\begin{tabular}{|c|c|c|c|c|c|c|c|c|}
\hline \multirow[t]{2}{*}{ Solo $(0-0,60 \mathrm{~m})$} & \multirow{2}{*}{$\begin{array}{c}\mathrm{D} \\
\mathrm{Mg} \mathrm{m}^{-3}\end{array}$} & ${ }^{15} \mathrm{~N}$ & $\mathrm{~N}$ & C & $\mathrm{N}$ & C & \multicolumn{2}{|c|}{ NSPf } \\
\hline & & \multicolumn{3}{|c|}{---------- \% ---------- } & \multicolumn{2}{|c|}{--- Mg ha ${ }^{-1}---$} & $\mathrm{kg} \mathrm{ha}^{-1}$ & $\%$ \\
\hline 2006 (Testemunha) & 1,240 & 0,371 & 0,13 & 1,84 & 9,8 & 137,1 & & \\
\hline 2009 (PPC 80-0) & 1,256 & 0,371 & 0,12 & 1,74 & 9,4 & 131,3 & 28,5 & 69,4 \\
\hline 2009 (PPC 80-150) & 1,256 & 0,370 & 0,12 & 1,78 & 9,2 & 134,4 & 25,1 & 61,3 \\
\hline dms & ns & ns & ns & ns & ns & ns & & \\
\hline CV\% & 12,4 & 0,2 & 6,6 & 7,8 & 7,4 & 7,8 & & \\
\hline
\end{tabular}

Legenda: $\mathrm{D}=$ densidade do solo; PPC = palhada pós colheita (variedade SP81-3250); $\mathrm{NSPf}=\mathrm{N}$ que permaneceu no solo $(0-0,60 \mathrm{~m})$ proveniente da fonte marcada das microparcelas $(\mathrm{PPC})$; $\mathrm{dms}=$ diferença mínima significativa teste Tukey $a{ }^{* *} 1 \% e^{*} 5 \%$ de probabilidade; ns = não significativo.

Não houve alteração significativa do conteúdo de $\mathrm{N}$ ou $\mathrm{C}$ no solo devido a aplicação dos tratamentos de uréia, PAR, RAR e PPC. Foi detectado somente um maior enriquecimento do solo com ${ }^{15} \mathrm{~N}$ na parcela de uréia (Tabelas 31 e 32).

Khan et al. (2007) verificaram que a fertilização excessiva com $N$ diminuiu os estoques de carbono orgânico do solo em experimentos de longa duração no norte dos Estados Unidos. Ressaltaram que naquela região as fertilizações com $\mathrm{N}$ são mais pesadas (acima de $200 \mathrm{~kg}_{\text {de N ha- }} \mathrm{ano}^{-1}$ ), o que contribui significativamente para uma maior velocidade na degradação da palhada remanescente de culturas de cereais, devido redução na relação $\mathrm{C}: \mathrm{N}$ e pelo maior aporte de nutrientes para os microrganismos do solo. Por outro lado Galdos, Cerri e Cerri (2009), Graham, Haynes e Meyer (2002) e Luca et al. (2008) encontraram enriquecimento de carbono oriundo da palhada de cana-de-açúcar principalmente nas camadas superficiais do solo, de 0 a 0,20 $\mathrm{m}$ de profundidade, em experimentos de média ( 3 anos) e longa duração (acima de 20 anos).

Vallis et al. (1996) e Meier et al. (2006) sugeriram que a manutenção da palhada de cana-de-açúcar sobre a superfície do solo por longo prazo (20 anos) pode proporcionar uma queda de até $40 \mathrm{~kg} \mathrm{ha}^{-1}$ na adubação mineral com $\mathrm{N}$. Robertson e Thorburn (2007a) também concordaram com possíveis reduções na adubação mineral em cana colhida por longos períodos sem queimar e elucida que 
toda a palhada pode ser decomposta pelas atuais doses aplicadas (acima de $100 \mathrm{~kg}$ de $\mathrm{N} \mathrm{ha}^{-1}$ ), sem comprometer $\mathrm{o}$ aporte deste nutriente para a cultura.

Em experimento de campo, $\mathrm{Ng}$ Kee Kwong et al. (1987) observaram que a palhada de cana-de-açúcar não é uma fonte de $\mathrm{N}$ significativa para a cultura, uma vez que o estoque de $\mathrm{N}$ do solo era da ordem de $3.000 \mathrm{~kg} \mathrm{ha}^{-1} \mathrm{e}$ o da palhada por volta de $40 \mathrm{~kg} \mathrm{ha}^{-1}$. Bologna-Campbell (2007) ressaltou que $74 \%$ do $\mathrm{N}$ proveniente de resíduos vegetais palhada + rizomas permaneceu no solo no final da época de colheita.

Não houve diferença significativa no estoque de carbono do solo de 0 a 0,60 $\mathrm{m}$ de profundidade devido aos tratamentos com resíduos vegetais durante o período estudado. Os estoques de carbono e nitrogênio na referida camada foram da ordem de 135 e 9,5 $\mathrm{Mg} \mathrm{ha}^{-1}$, respectivamente, portanto, uma relação $\mathrm{C}: \mathrm{N}$ do solo de 14:1 (Tabelas 31 e 32). Estes resultados concordam com Luca et al. (2008) que obtiveram 12:1 e 25:1 para um latossolo e um neossolo e $\mathrm{Ng}$ Kee Kwong et al. (1987), cujas relações C: $\mathrm{N}$ foram 12:1 e 22:1 para um nitossolo e um acrissolo húmico das llhas Mauricio, respectivamente.

Luca et al. (2008) concluíram que, embora o estoque de $\mathrm{C}$ e $\mathrm{N}$ no solo se estabeleça de forma lenta, a manutenção da palhada de cana-de-açúcar no campo funciona como um dreno para as emissões de C e N atmosféricas. Galdos, Cerri e Cerri (2009) observaram que o teor de carbono do solo após cinqüenta anos de cultivo de cana foram menores do que aqueles comparados com mata nativa e que ciclos de dois a oito anos de cana colhida sem queima aumentaram significativamente o teor de $\mathrm{C}$ do solo, quando comparado ao sistema de cana queimada. Ressaltaram que as operações de preparo e revolvimento do solo na ocasião da reforma do canavial é o que mais contribui para alterar os estoques de $\mathrm{C}$ no solo.

Para Souza et al. (2005) a matéria orgânica e conseqüentemente o carbono é consumido do solo devido ao preparo pela destruição dos agregados e à maior aeração do solo, o que pode também ocasionar erosão, dependendo do tipo de solo e relevo. Portanto, práticas que visem à otimização do uso de fertilizantes e combustíveis fósseis devem ser consideradas no manejo sustentável e a longo prazo da cultura. 


\subsection{CONCLUSÕES}

As recuperações do N-uréia, N-PAR e N-RAR pela parte aérea da cana-deaçúcar após quatro ciclos consecutivos de colheita foram de 43\%, 28\% e 23\%, respectivamente.

O balanço de $\mathrm{N}$ indicou que, após quatro ciclos agrícolas, $20 \%$ do nitrogênio da uréia permaneceu no solo como matéria orgânica e/ou meso e microfauna, enquanto $45 \%$ e $59 \%$ do N-PAR e N-RAR ainda se encontravam no solo, indicando que o $\mathrm{N}$ de resíduos de culturas é uma fonte importante a longo prazo de nitrogênio para cana e para o estoque deste nutriente no solo. Em contrapartida, o N-uréia, em outros compartimentos (perdas e/ou imobilização/desnitrificação) foi superior ao destes resíduos vegetais, $37 \%$ contra $27 \%$ e $18 \%$, respectivamente.

A recuperação pela cana-de-açúcar do N-PPC praticamente dobrou após três ciclos quando utilizou-se $\mathrm{N}$ mineral em soqueiras sobre a palhada (17\% vs. 31\%, 6,9 vs. $12,6 \mathrm{~kg} \mathrm{ha}^{-1}$ de $\mathrm{N}$, respectivamente). O aumento na disponibilidade do N-PPC se deveu principalmente à diminuição da relação $\mathrm{C}: \mathrm{N}$, o que proporcionou maior mineralização da palhada e conseqüentemente maior recuperação do $\mathrm{N}$ pela cultura. Por outro lado, o N-PPC remanescente no solo foi inferior quando se aplicou $\mathrm{N}$ em soqueiras, $61 \%$ vs. $69 \%$ (28,5 vs. $25,1 \mathrm{~kg} \mathrm{ha}^{-1}$ de $\left.\mathrm{N}\right)$, ressaltando a maior disponibilização do $\mathrm{N}$ da palhada quando se fertiliza as soqueiras com $\mathrm{N}$ mineral.

De forma geral, as maiores quantidades do nitrogênio recuperado da uréia e dos resíduos da colheita pela cana-de-açúcar foram encontradas nos colmos seguidos por ponteiros e folhas secas.

Não houve alteração no estoque de carbono do solo de 0 a $0,60 \mathrm{~m}$ de profundidade devido aos tratamentos de uréia no plantio e resíduos vegetais PAR e RAR, tampouco devido à aplicação de $\mathrm{N}$ em soqueiras sobre a PPC após o período estudado. Os estoques de carbono e nitrogênio na referida camada foram da ordem de 135 e 9,5 $\mathrm{Mg} \mathrm{ha}^{-1}$, respectivamente. 



\section{DECOMPOSIÇÃO DA PALHADA DE CANA-DE-AÇÚCAR EM CICLOS AGRÍCOLAS CONSECUTIVOS DE COLHEITA SEM QUEIMA}

\subsection{INTRODUÇÃO}

A produção de energia renovável por meio de biomassa de cana-de-açúcar e a sustentabilidade do setor sucroenergético requerem racionalização do uso de insumos e a reciclagem de nutrientes no sistema de produção, visando à redução dos impactos ambientais e das emissões atmosféricas de gases de efeito estufa (HEMWONG et al., 2009; MACEDO; SEABRA; SILVA, 2008). Não só a cultura de cana-de-açúcar, mas a agricultura de um modo geral proporciona resíduos vegetais que podem e devem ser considerados para este fim, ou seja, possuem valor energético, biológico e nutricional para o solo (LIU et al., 2010).

A quantidade de resíduos vegetais deixados no campo após a colheita da cana sem a queima da palhada é função direta das características das variedades, como a facilidade de despalha do colmo, hábito de crescimento da touceira, uniformidade de altura e tamanho dos ponteiros (TUFAILE NETO et al., 2005). Além destes fatores, sabe-se que a produção dos resíduos vegetais está relacionada à produtividade agrícola, estágio de corte, umidade das folhas e da palhada na ocasião da colheita e a capacidade de exaustão desta última pela colhedora (MANECHINI, 1997).

O trabalho pioneiro sobre a decomposição da palhada de cana-de-açúcar a campo no Brasil foi o de Abramo Filho et al. (1993) que verificaram uma quantidade de $15 \mathrm{Mg} \mathrm{ha}^{-1}$ de MS da variedade SP71-6163 cuja composição foi de $69,7 \%$ de celulose + hemicelulose, $19,2 \%$ de lignina e 6,8\% de cinzas. Além disso, estes autores elucidaram que, em áreas de colheita de cana mecanizada sem a queima da palhada, a temperatura do solo foi menor e a umidade do solo maior. Por outro lado detectaram um retardamento na brotação devido à variedades não adaptadas à este tipo de manejo e um possível aumento em certas pragas.

Na Austrália, Spain e Hodgen (1994) verificaram que, além de prevenir as temperaturas excessivas, o "mulch" proporcionado pela palhada também protegia o solo da alta energia das gotas de chuva que causam a erosão. Para estes autores, o entendimento das taxas de decomposição e liberação dos nutrientes da palhada de cana-de-açúcar era importante principalmente em solos tropicais altamente intemperizados. Também observaram uma quantidade de palhada de cana-de- 
açúcar de 15,8 Mg ha-1 de matéria seca (MS) cujos teores de cinzas e carbono (C) $\left(\mathrm{em} \mathrm{g} \mathrm{kg}^{-1}\right.$ ) eram de 37,4 e 437, respectivamente e de macronutrientes $\mathrm{N}: 4,4 ; \mathrm{P}$ : 0,7; K: 11,0; Ca: 0,6 e Mg: 0,4 $\mathrm{g} \mathrm{kg}^{-1}$.

A composição média de carboidratos estruturais da palhada de cana-deaçúcar, segundo outros autores (CGEE, 2009, FONSECA, SUAREZ-RODRIGUEZ; BOIZÁN, 2009; PAULY; KEEGSTRA, 2008; SINGH et al., 2008) é de 7 a $20 \%$ de lignina, 45 a $48 \%$ de celulose, 26 a $31 \%$ de hemicelulose (pentosanos) e 1,2 a $8 \%$ de cinzas (matéria mineral). Estes teores, bem como o conteúdo de nutrientes liberados pela palhada de cana-de-açúcar variam de acordo com a variedade, tipo de solo (ambiente de produção) e com as práticas de manejo adotadas no cultivo (CONDE, PENATTI; BELLINASO, 2005; MEIER et al., 2006; OLIVEIRA et al., 1999; 2002, FARONI et al., 2003).

Oliveira et al. (2003), estudando a composição química da palhada de dez diferentes variedades de cana, encontraram as seguintes faixas de quantidades de macronutrientes em kg ha-1: N: 39 a 69; P: 10 a 23; K: 112 a 148; Ca: 47 a 81 e $\mathrm{Mg}: 17$ a 26. As faixas de MS encontradas destes autores foi 11,5 a $18,5 \mathrm{Mg} \mathrm{ha}^{-1}$.

Conde, Penatti e Bellinaso (2005) encontraram a produção de 10,5 a 15,7 $\mathrm{Mg} \mathrm{ha}^{-1}$ de matéria seca na média de quatro variedades. Nesse trabalho, apontaram os seguintes teores de macronutrientes nas folhas secas (em g kg${ }^{-1}$ ): N: 3,2; P: 0,2; $\mathrm{K}: 3,4$; Ca: 4,2; MG: 1,9 e S: 1,1 Já as contribuições totais destes nutrientes da palhada em kg ha-1 foram: N: 54,7; P: 4,4; K: 76,0; Ca: 54,9; Mg: 25,5 e S: $15,1$.

Os microrganismos do solo que tem capacidade de degradar resíduos vegetais são denominados celulolíticos devido a produção de enzimas específicas, como as celulases. Sanomiya et al. (2006) elucidam que $38 \%$ dos fungos e $80 \%$ das bactérias do total destas espécias existentes no solo exibem essa característica, respectivamente.

Abramo Filho (1995) e Singh et al. (2008) mencionaram que, a principal alteração proporcionada por microrganismos nos resíduos vegetais é a diminuição da relação $\mathrm{C}: \mathrm{N}$ devido ao consumo de $\mathrm{C}$ e da respiração de $\mathrm{CO}_{2}$. Dentre os microrganismos que degradam tecidos vegetais destacaram os fungos dos gêneros Aspergillus, Trichoderma, Penicillium, Chaetomium e Acromonium e as bactérias Zymomonas e Cellulomonas.

Há evidências que um volume considerável de raízes cresce sob e dentro da cobertura de palhada no sistema de cana colhida sem despalha a fogo (VITTI et al., 
2007b). Como é difícil separar as raízes da palhada em decomposição, a avaliação da taxa de decomposição da palhada e da mineralização do $\mathrm{N}$ e do $\mathrm{C}$ podem ser subestimadas se medidas por meio da variação de massa e conteúdo de nutrientes do material de cobertura ao longo do tempo. O uso de técnica isotópica pode contribuir para uma melhor compreensão da taxa de decomposição e fornecimento de nutrientes presentes na palhada para a cana em crescimento (CHAPMAN; HAYSSOM; SAFFIGNA, 1994; FARONI et al., 2003; OLIVEIRA et al., 2002; VITTI et al., 2007).

A degradação de resíduos vegetais pode ser representada por modelos exponenciais, isto é, apresentam rápida intensidade no início do período, enquanto existem compostos menos recalcitrantes (celulose e outros carboidratos simples) e diminui ao longo do tempo, a medida que restam substâncias mais resistentes ou mesmo que inibem $\mathrm{o}$ ataque microbiano como as ligninas e os polifenóis (GONÇALVES et al., 2010).

O objetivo deste estudo foi quantificar anualmente a decomposição da palhada de cana-de-açúcar ao longo de ciclos agrícolas consecutivos e em duas situações: palhada aplicada anteriormente à reforma do canavial (PAR) e em pós colheita da cana (PPC) bem como verificar a influência da aplicação de $\mathrm{N}$ mineral em soqueira na dinâmica de decomposição da PPC.

\subsection{MATERIAL E MÉTODOS}

\subsubsection{Localização, delineamento experimental e instalação de sacos telados}

A decomposição dos resíduos vegetais foi estudada ao longo do tempo, isto é, em quatro ciclos agrícolas (safras agrícolas) para a palhada anterior à reforma (PAR) e três ciclos agrícolas para a palhada pós colheita (PPC). Para tanto, o mesmo material vegetal da PAR- ${ }^{15} \mathrm{~N}$ e $\mathrm{PPC}-{ }^{15} \mathrm{~N}$, utilizado nas microparcelas do estudo de recuperação de ${ }^{15} \mathrm{~N}$ (item 3.2.4), foram colocados no interior de sacos telados, tecnicamente denominados "litter bags" ou saco de serrapilheira, com dimensões 0,75 $\mathrm{m} \times 0,50 \mathrm{~m}$ e malha de 0,03 $\mathrm{m}$, na mesma quantidade em $\mathrm{Mg} \mathrm{ha}^{-1}$ verificada na cobertura do solo (Tabela 25). O diâmetro da tela teve como objetivo manter a palhada o mais próximo da condição original no campo, isto é, permitindo a entrada e saída da mesofauna do solo, o crescimento das raízes da cana em meio 
aos resíduos culturais e ao mesmo tempo permitir que estes últimos fossem coletados e analisados ao longo de ciclos agrícolas consecutivos.

A metodologia de sacos telados já foi utilizada na avaliação de degradação de resíduos culturais tais como de cana-de-açúcar (FARONI et al., 2003; ROBERTSON; THORBURN, 2007a; 2007b), culturas de cobertura anuais e cereais (AMBROSANO et al., 2005; CARVALHO et al., 2008; GONÇALVES et al., 2010; HEMWONG et al., 2009), liteira de árvores (COÛTEAUX; BOTTNER; BERG, 1995) e em outros estudos de escala global decomposição de resíduos vegetais (ZHANG et al., 2008).

Os sacos telados contendo resíduos vegetais de cana-de-açúcar foram colocados em cada repetição dos tratamentos da linha de cana em sentido à entrelinha, de modo que recobrisse metade do espaçamento de $1,5 \mathrm{~m}$ da cultura, isto é, $0,75 \mathrm{~m}$. Ao todo foram instaladas doze repetições de "litter bags" para a palhada anterior à reforma $\left(\mathrm{PAR}^{-15} \mathrm{~N}\right.$ instalada em 2005 no tratamento $80-0 \mathrm{~kg} \mathrm{ha}^{-1}$ de $\mathrm{N}$ ) e oito para a palhada pós-colheita (PPC- ${ }^{15} \mathrm{~N}$ instalada em 2007 nos tratamentos $80-0$ e $80-150 \mathrm{~kg} \mathrm{~N} \mathrm{ha}^{-1}$ em cana-planta e soqueiras, respectivamente). Ressalte que antes da instalação das unidades de sacos telados com os resíduos marcados com ${ }^{15} \mathrm{~N}$, todo o material vegetal original e com composição isotópica natural foi removido do campo e substituído pelo material dos sacos telados, simulando os resíduos depositados pela colheita de cana sem a queima da palhada.

O objetivo do estudo com uso dos sacos telados foi avaliar temporalmente a decomposição dos resíduos culturais de cana-de-açúcar, ou seja, a dinâmica de degradação dessa palhada e verificar as possíveis diferenças na intensidade dessa degradação quando se utiliza em soqueiras adubação nitrogenada sobre a palhada que permanece sobre o solo, após a colheita sem queima. A quantidade e composição química dos resíduos utilizados nos sacos telados foram descritos anteriormente no item 3.2.1 e encontram-se na Tabela 25.

Além de avaliar a dinâmica da decomposição dos resíduos culturais ao longo do tempo, o uso dos sacos telados teve como objetivo quantificar o sistema radicular que cresceu junto à palhada de cana durante os ciclos agrícolas consecutivos. Segundo Vitti et al. (2007), as raízes de cana-de-açúcar com composição isotópica natural ao crescerem junto à palhada marcada tendem a causar a diluição isotópica do material dos sacos telados, sendo possível quantificar a massa do sistema radicular que se desenvolveu junto à palhada pelo princípio da técnica de diluição 
isotópica. Portanto, para quantificar a decomposição dos resíduos vegetais e a real contribuição das raízes de cana na composição da palhada, foram realizados quatro estudos, a saber:

i) Palhada Anterior à Reforma (PAR- ${ }^{15} \mathrm{~N}$, variedade RB855536) adicionada nos tratamentos de cana-planta $\left(0,40,80\right.$ e $\left.120 \mathrm{Kg} \mathrm{N}^{-1}\right)$. Este estudo refere-se à continuação do trabalho de Vitti et al. (2008a), porém com a avaliação dos macronutrientes;

ii) Palhada Anterior à Reforma (PAR $-{ }^{15} \mathrm{~N}$, variedade RB855536) aplicada no tratamento $80 \mathrm{Kg} \mathrm{N}^{-1}$ em cana-planta e avaliada após quatro ciclos consecutivos (2005 a 2008);

iii) Palhada Pós-Colheita (PPC- ${ }^{15} \mathrm{~N}$, variedade SP81-3250) aplicada nas doses 80-0 Kg N ha ${ }^{-1}$, respectivamente, em cana-planta e avaliada após três ciclos consecutivos de socas (2006 a 2008);

vi) Palhada Pós-Colheita (PPC- ${ }^{15} \mathrm{~N}$, variedade SP81-3250) aplicada nas doses 80-0 e 80-150 Kg N ha-1, em cana-planta e soqueiras, respectivamente. Ressalta-se que este último estudo visou detectar diferenças na relação $\mathrm{C}: \mathrm{N}$ e na intensidade de decomposição da palhada devido aplicação de $\mathrm{N}$ em soqueira sobre a palhada.

\subsubsection{Colheita, processamento das amostras e análises em laboratório}

Os sacos telados contendo resíduos culturais de cana-de-açúcar foram retirados da área do experimento após cada ciclo agrícola, ou seja, aproximadamente a cada 12 meses, para a quantificação do material seco (MS) remanescente de resíduos (mais raízes incorporadas), do conteúdo de macronutrientes e dos carboidratos estruturais (lignina, celulose e hemicelulose). $\mathrm{O}$ material dos sacos foi cuidadosamente separado do solo, peneirado, homogeneizado, subamostrado ( \pm 500 g), moído como em Oliveira et al. (2002) e analisado quanto à concentração do ${ }^{15} \mathrm{~N}$ e $\mathrm{C}$ em espectrômetro de massas ANCA GSL modelo HYDRA 20/20 da SERCON Co., UK, no Laboratório de Isótopos Estáveis do CENA/USP, segundo Barrie e Prosser (1996).

O teor de cinzas (\% matéria mineral) foi obtido por incineração da amostra em mufla $\left(600^{\circ} \mathrm{C}\right.$ por 5 horas) através da diferença de peso do material antes e após a incineração. Subtraindo-se o teor de cinzas da matéria seca, obteve-se a 
porcentagem de matéria orgânica da palhada, que inclui todos os outros compostos diferentes dos minerais (OLIVEIRA et al., 1999; ROBERTSON, 2003). Os macronutrientes foram analisados como descrito em Malavolta, Vitti e Oliveira (1997) e Vitti (1989) no Laboratório de Solos e Recursos Agroambientais do Instituto Agronômico de Campinas (IAC), SP.

As determinações dos carboidratos estruturais ( $\mathrm{g} \mathrm{kg}^{-1}$ de $\mathrm{MS}$ ) foram realizadas no Laboratório de Bromatologia e Nutrição Animal da FCA/UNESP de Botucatu, SP segundo a metodologia Van Soest, descrita em Silva e Queiroz (2006) e utilizada em outros trabalhos desta natureza (AUSTIN; BALLARÉ, 2010; OLIVEIRA et al., 2002). Foram obtidos os teores de FDN (fibra detergente neutro ou conteúdo celular), FDA, (fibra detergente ácido ou fração insolúvel e estrutural), lignina e matéria seca a $105{ }^{\circ} \mathrm{C}$ dos resíduos e raízes remanescentes coletados nos sacos telados. O aparelho utilizado foi um determinador de fibra FDN e FDA modelo TE149, Tecnal. Detalhes da metodologia do preparo de amostras e avaliação de carboidratos estruturais de materiais vegetais podem ser encontrados em Van Soest, Robertson e Lewis (1991) e em Silva e Queiroz (2006).

\subsubsection{Cálculos e análises estatísticas}

Conhecendo-se o peso do material adicionado em cada saco e o quanto permaneceu, bem como a composição isotópica da palhada (inicial e final) foi possível determinar o quanto desse substrato se degradou no período estudado e quantificar a contribuição do sistema radicular da cultura que passou a fazer parte da palhada. Estas medidas foram feitas com base no princípio da técnica diluição isotópica em ${ }^{15} \mathrm{~N}$, elucidada em Vitti et al. (2008a). O cálculo para determinação de raízes $\left(\mathrm{Mg} \mathrm{ha}^{-1}\right)$ pelo princípio da diluição isotópica é indicado na equação 6 .

$R P=\left[\left({ }^{15} N_{\text {Rem }} \times M S_{\text {Rem }}\right)-\left({ }^{15} N_{\text {Inicial }} \times M S_{\text {Inicial }}\right)\right] /\left({ }^{15} N_{\text {Inicial }}-0.367\right) \times 26666,7$

Onde: $\mathrm{RP}=$ Raízes na palhada $\left(\mathrm{Mg} \mathrm{ha}^{-1}\right) ;{ }^{15} \mathrm{~N}_{\mathrm{Rem}}={ }^{15} \mathrm{~N}$ remanescente nos resíduos após 1 ano; $\mathrm{MS}_{\text {Rem }}$ = massa seca remanescente; ${ }^{15} \mathrm{~N}_{\text {Inicial }}=$ conteúdo inicial de ${ }^{15} \mathrm{~N}$ dos resíduos vegetais (PAR, PPC); $\mathrm{MS}_{\text {Inicial }}=\mathrm{MS}$ inicial dos sacos telados; 0.367 = abundância isotópica natural de ${ }^{15} \mathrm{~N}$. 
Nas equações 7 e 8 encontram-se os cálculos para determinação dos carboidratos estruturais (celulose e hemicelulose), segundo Silva e Queiroz (2006):

$\mathrm{CEL}=\mathrm{FDA}-\mathrm{LIG}$

HCEL = FDA - FDN, onde:

Onde: $\mathrm{CEL}$ = celulose; $\mathrm{HCEL}$ = hemicelulose; $\mathrm{LIG}$ = lignina $\left(\mathrm{g} \mathrm{kg}^{-1}\right.$ de $\left.\mathrm{MS}\right) ; \mathrm{FDN}$ = fibra em detergente neutro; FDA = fibra em detergente ácido.

Para avaliação estatística dos dados de decomposição da palhada dos sacos telados, realizou-se análise de variância (ANOVA) das médias das repetições coletadas a cada ano e que posteriormente foram submetidas à análise de regressão no caso da PAR e teste de Tukey a 1\%, 5\% e 10\% de probabilidade para a PPC.

\subsection{RESULTADOS E DISCUSSÃO}

4.3.1 Degradação da palhada anterior à reforma $\left(P A R-{ }^{15} N\right)$ em função de doses de $\mathrm{N}$ em cana-planta $\left(0,40,80,120 \mathrm{~kg} \mathrm{ha}^{-1}\right.$ de $\left.\mathrm{N}\right)$

Após o ciclo de cana-planta (12 meses da instalação dos sacos telados contendo PAR), houve uma diminuição da matéria seca (MS) de $63 \%$ no tratamento sem a adição de $\mathrm{N}$, isto é, de 8,95 para 3,25 $\mathrm{Mg} \mathrm{ha}^{-1}$. Houve diferença significativa para os tratamentos que receberam $\mathrm{N}$ no plantio e esta diminuição foi em média de $75 \%$ do conteúdo original de matéria seca, de 8,9 para 2,3 $\mathrm{Mg} \mathrm{ha}^{-1}$ (Tabela 33).

A redução da MS foi influenciada pela perda de carbono que foi de 18\% (402 para $330 \mathrm{~g} \mathrm{~kg}^{-1}$ ) na média entre a testemunha e os tratamentos com $\mathrm{N}$ em canaplanta. A relação $\mathrm{C}: \mathrm{N}$ diminuiu devido à mineralização do carbono da palhada e pela adição de $\mathrm{N}$ no plantio da cultura, o que favoreceu também a atividade biológica do solo (KHAN et al., 2007; SPAIN; HODGEN, 1994). Esta diminuição foi de $39 \%$ (70,3 para 42,6$)$ e $32 \%(70,3$ para 46,3$)$ para a testemunha e na média dos tratamentos com N-uréia, respectivamente (Tabela 33).

Os resultados deste trabalho estão alinhados com os obtidos por Oliveira et al. (2002), em que observaram variação na redução de massa de matéria seca de 
$22 \%$ a $70 \%$ em dois ambientes agrícolas, sendo que a maior degradação foi influenciada, possivelmente pelas irrigações com vinhaça. A maior decomposição da palhada e liberação de carbono podem estar relacionadas ao próprio resíduo orgânico, uma vez que, em condições de campo, encontram-se pedaços de colmos, provenientes da colheita mecânica, que elevam a relação $\mathrm{C}: \mathrm{N}$, diminuindo a taxa de mineralização (CONDE, PENATTI; BELLINASO, 2005). Gonçalves et al. (2010) também ressaltaram esta mesma variabilidade na composição da palhada de milho e sua disposição no campo, composta por diferentes proporções de folhas, colmos e pendões comparados com os resíduos de soja, que se apresentam mais uniformemente distribuídos no campo e são compostos por folhas e hastes.

Por outro lado, a degradação da MS obtida neste trabalho foi inferior à obtida por Roberston e Thorburn (2007a) que verificaram após 12 meses uma degradação de $82 \%$ a $98 \%$ da MS da palhada (variedade Q124), e perdas de $84 \%$ a $98 \%$ do C. Os autores ressaltaram que a degradação também foi relacionada a fatores climáticos, como a soma térmica, variável composta pela temperatura média diária do ar subtraída da temperatura basal do período estudado. Outro fator que pode ter contribuído para esta maior degradação foram as doses de $\mathrm{N}$-uréia mais pesadas que as utilizadas neste trabalho (160 a $200 \mathrm{~kg} \mathrm{ha}^{-1}$ ). A palhada utilizada por estes autores apresentou de 3 a $5 \mathrm{Mg} \mathrm{ha}^{-1}$ de $\mathrm{C}$ e 28 a $54 \mathrm{~kg} \mathrm{ha}^{-1}$ de $\mathrm{N}$, portanto coerentes com os resultados deste trabalho, 3,6 $\mathrm{Mg} \mathrm{ha}^{-1}$ de C e $51,2 \mathrm{~kg} \mathrm{ha}^{-1}$ de $\mathrm{N}$, respectivamente (Tabela 33). 
Tabela 33 - Composição isotópica de ${ }^{15} \mathrm{~N}(\%)$, teores $\left(\mathrm{g} \mathrm{kg}^{-1}\right)$ e quantidade $\left(\mathrm{kg} \mathrm{ha}^{-1}\right)$ de resíduos culturais, carbono e macronutrientes da palhada de sacos telados, nos tratamentos com doses de N em cana-planta (2005) e após um ano de sua permanência no campo (2006), simulando a adição de palhada anterior à reforma (PAR- $\left.{ }^{15} \mathrm{~N}\right)$

\begin{tabular}{|c|c|c|c|c|c|c|c|c|c|c|c|c|c|c|c|c|c|c|c|c|c|c|}
\hline \multirow[b]{3}{*}{ PAR (2005) } & \multirow{2}{*}{\multicolumn{2}{|c|}{$\frac{\mathrm{MS}}{\mathrm{kg} \mathrm{ha}^{-1}}$}} & \multirow{2}{*}{\multicolumn{4}{|c|}{ Cinzas }} & \multicolumn{3}{|c|}{$\mathrm{C}$} & \multicolumn{5}{|c|}{$\mathrm{N}$} & \multicolumn{2}{|l|}{$\mathrm{C}: \mathrm{N}$} & \multicolumn{4}{|c|}{ Raizes na palhada } & & \\
\hline & & & & & & & \multicolumn{2}{|l|}{$\mathrm{g} \mathrm{kg}^{-1}$} & $\mathrm{~kg} \mathrm{ha}^{-1}$ & \multirow[b]{2}{*}{ a } & \multicolumn{2}{|l|}{$\mathrm{g} \mathrm{kg}^{-1}$} & \multicolumn{2}{|l|}{$\mathrm{kg} \mathrm{ha}^{-1}$} & \multirow{2}{*}{\multicolumn{2}{|c|}{70,3 a }} & \multicolumn{2}{|l|}{$\mathrm{g} \mathrm{kg}^{-1}$} & \multicolumn{2}{|l|}{$\mathrm{kg} \mathrm{ha}^{-1}$} & & \\
\hline & 8.951 & a & 4,9 & $\mathrm{C}$ & 1,07 & a & 402 & $a$ & 3.596 & & 5,75 & $b$ & 51,2 & a & & & & & & & & \\
\hline PAR (2006) CP 0 & 3.245 & b & 21,4 & a & 0,80 & $b$ & 336 & $b$ & 1.097 & $b$ & 7,90 & a & 25,7 & $b$ & $42,6 \mathrm{c}$ & c & 350 & $b$ & 1.180 & a & & \\
\hline PAR (2006) CP 40 & 2.230 & c & 27,0 & a & 0,74 & bc & 305 & $b$ & 682 & C & 6,74 & $b$ & 15,0 & c & $45,3 b$ & bc & 423 & $a b$ & 1.009 & a & & \\
\hline PAR (2006) CP 80 & 2.391 & c & 24,4 & a & 0,61 & c & 345 & $b$ & 829 & $b c$ & 6,70 & $b$ & 16,0 & $c$ & $51,6 \mathrm{~b}$ & $b$ & 592 & a & 1.505 & a & & \\
\hline PAR (2006) CP 120 & 2.242 & C & 24,9 & a & 0,74 & $b c$ & 334 & $b$ & 754 & C & 7,30 & $a b$ & 16,5 & $\mathrm{C}$ & $45,8 \mathrm{~b}$ & $b c$ & 428 & $a b$ & 1.002 & a & & \\
\hline $\mathrm{dms}$ & 718 & & 5,9 & & 0,15 & & 50 & & 321,0 & & 0,88 & & 6,9 & & 7,2 & & 214 & & 534 & & & \\
\hline F-Blocos & ns & & ns & & ns & & ns & & ns & & ns & & ns & & ns & & ns & & ns & & & \\
\hline F-Trats & $* *$ & & ** & & ** & & ** & & ** & & ** & & $* *$ & & ** & & * & & ns & & & \\
\hline \multirow[t]{3}{*}{ CV\% } & 8,4 & & 12,8 & & 8,8 & & 6,4 & & 10,2 & & 5,7 & & 13,8 & & 6,3 & & 21,6 & & 39,0 & & & \\
\hline & & $\mathrm{N}$ & & & & $\mathrm{P}$ & & & & K & & & & $\mathrm{Ca}$ & & & & $\mathrm{Mg}$ & & & $S$ & \\
\hline & $\mathrm{g} \mathrm{kg}^{-1}$ & & $\mathrm{~kg} \mathrm{ha}^{-1}$ & & $\mathrm{~g} \mathrm{~kg}^{-1}$ & & $\mathrm{~kg} \mathrm{ha}^{-1}$ & & $\mathrm{~g} \mathrm{~kg}^{-1}$ & & $\mathrm{~kg} \mathrm{ha}^{-1}$ & & $\mathrm{~g} \mathrm{~kg}^{-1}$ & & $\mathrm{~kg} \mathrm{ha}^{-1}$ & & $\mathrm{~g} \mathrm{~kg}^{-1}$ & & $\mathrm{~kg} \mathrm{ha}^{-1}$ & & $\mathrm{~g} \mathrm{~kg}^{-1}$ & $\mathrm{~kg} \mathrm{ha}^{-1}$ \\
\hline PAR (2005) & 5,75 & $b$ & 51,2 & $a$ & 0,53 & $b$ & 4,7 & $a$ & 4,1 & $a$ & 37,0 & a & 4,1 & $a$ & 37,4 a & a & 1,6 & $\mathrm{a}$ & 14,0 & a & $0,7 a$ & $\overline{5,8} \mathrm{a}$ \\
\hline PAR (2006) CP 0 & 7,90 & a & 25,7 & $b$ & 0,60 & a & 2,0 & $b$ & 1,3 & $b$ & 4,1 & $b$ & 4,8 & a & $15,5 b$ & $b$ & 1,2 & $b$ & 4,0 & $b$ & $0,7 \mathrm{a}$ & $2,4 \mathrm{~b}$ \\
\hline PAR (2006) CP 40 & 6,74 & $b$ & 15,0 & C & 0,60 & a & 1,3 & $b$ & 1,1 & $b$ & 2,4 & $b$ & 3,9 & $b$ & $8,7 \quad c$ & c & 1,1 & $b$ & 2,5 & $\mathrm{C}$ & $0,6 \mathrm{~b}$ & $1,3 \mathrm{c}$ \\
\hline PAR (2006) CP 80 & 6,70 & $b$ & 16,0 & C & 0,57 & a & 1,4 & $b$ & 1,0 & $b$ & 2,4 & $b$ & 3,8 & $b$ & $9,2 \mathrm{c}$ & c & 1,0 & $b$ & 2,5 & C & $0,6 \mathrm{~b}$ & $1,4 \mathrm{c}$ \\
\hline PAR (2006) CP 120 & 7,30 & $a b$ & 16,5 & $\mathrm{C}$ & 0,60 & a & 1,4 & $\mathrm{~b}$ & 1,0 & $b$ & 2,3 & $b$ & 4,3 & $a b$ & $9,7 \quad 0$ & C & 1,1 & $b$ & 2,5 & $\mathrm{C}$ & $0,6 a b$ & $1,4 \mathrm{c}$ \\
\hline $\mathrm{dms}$ & 0,88 & & 6,9 & & 0,08 & & 0,7 & & 0,7 & & 5,5 & & 0,6 & & 3,9 & & 0,2 & & 1,3 & & 0,1 & 0,7 \\
\hline F-Blocos & ns & & ns & & * & & ns & & ns & & ns & & ns & & ns & & ns & & ns & & ns & ns \\
\hline F-Trats & $* *$ & & ** & & * & & ** & & $* *$ & & ** & & $* *$ & & ** & & ** & & ** & & * & ** \\
\hline CV\% & 5,7 & & 12,4 & & 5,9 & & 15,1 & & 17,4 & & 26,1 & & 6,5 & & 10,8 & & 7,9 & & 10,7 & & 8,2 & 13,3 \\
\hline
\end{tabular}

Legenda: PAR = palhada anterior à reforma (variedade RB855536); C = carbono; $\mathrm{N}=$ nitrogênio; $\mathrm{P}=$ fósforo, $\mathrm{K}=$ potássio; Ca = cálcio, Mg = magnésio; $\mathrm{S}=$ enxofre. 
Abramo Filho (1995) obteve uma queda de $60 \%$ na MS (15 para $6 \mathrm{Mg} \mathrm{ha}^{-1}$ ) da palhada da variedade SP71-6163 após 10,5 meses de avaliação, ou seja, praticamente a mesma degradação encontrada neste trabalho. $O$ autor ressaltou que a relação C:N passou de 78:1 para 33:1 após o período analisado, ou seja, uma redução de $58 \%$ e superior à deste trabalho cuja redução foi em média $35 \%$. Já Oliveira et al. (1999) verificaram que, após 11 meses de permanência da palhada da variedade SP79-1011 ( $2^{\circ}$ corte) no campo, houve redução na massa de aproximadamente $22 \%$, portanto inferior à obtida neste trabalho $(63 \%$ a $75 \%)$. A relação C:N destes autores passou de $97: 1$ para 68:1, ou seja, uma redução de $30 \%$ e ligeiramente menor que as obtidas neste trabalho (Tabela 33).

Constatou-se que embora o fertilizante nitrogenado tenha sido enterrado no plantio, ocorreu maior decomposição dos resíduos orgânicos por reduzir a relação $\mathrm{C}: \mathrm{N}$, devido maior liberação de $\mathrm{C}$ em relação ao nitrogênio, que provavelmente permaneceu imobilizado nos microrganismos do solo (GAVA et al., 2005; ROBERTSON e THORBURN, 2007b). Portanto, a contribuição do $\mathrm{N}$ da palhada, nesse período, na nutrição da cana-de-açúcar foi pequena, uma vez que a decomposição desses resíduos, com alta relação $\mathrm{C}: \mathrm{N}$ pode ter estabelecido uma competição entre as próprias raízes da cultura e os microrganismos do solo (GRAHAM; HAYNES; MEYER, 2002; MEIER et al., 2006).

Os valores de redução de MS obtidos neste trabalho também foram próximos aos de Urquiaga et al. (1991), 81\% de degradação da palhada em 5 anos, no árido nordeste brasileiro. Este também foi o mesmo resultado encontrado por Spain e Hodgen (1994), porém em um único ano no nordeste super úmido da Austrália. Estes autores verificaram que, para a palhada ter condições ótimas de degradação, é necessário além de temperatura e água, um bom contato ou interface da palhada com o solo, assim como também apontaram Thorburn, Probert e Robertson (2001).

Gonçalves et al. (2010) obtiveram taxas semelhantes de decomposição de resíduos de milho e soja em experimento de longa duração (12 anos) em solos argilosos sob plantio direto no Estado do Paraná. Ressaltaram que, embora não tenham encontrado diferenças entre os resíduos, a degradação foi mais lenta no plantio direto (sem revolvimento do solo) quando comparado ao cultivo convencional, onde $17 \%$ a mais de resíduos permaneceram no sistema de plantio direto após o ciclo avaliado. 
Thorburn, Probert e Robertson (2001) modelaram a distribuição da palhada de cana na superfície do solo como sendo composta por duas camadas, uma de maior e outra de menor contato com o solo e, obviamente a camada inferior teria condições mais favoráveis à decomposição. O material dos sacos telados foi colocado sobre o solo e estes últimos foram encobertos com palhada da colheita mecanizada após a colheita ao fim do ciclo agrícola de cana-planta. As condições climáticas favoráveis, aliadas aos tratamentos com $\mathrm{N}$ no plantio favoreceram a degradação do material vegetal contido nos sacos telados.

Houve diferença na disponibilização de $\mathrm{N}\left(\mathrm{em} \mathrm{kg} \mathrm{ha}^{-1}\right)$ entre os tratamentos testemunha e com N-uréia em cana-planta, restaram 25,7 e $16 \mathrm{~kg} \mathrm{ha}^{-1}$ do conteúdo original de $\mathrm{N}$ da PAR, respectivamente. Isto equivaleu a uma liberação de $50 \%$ e $70 \%$ e deveu-se principalmente às condições climáticas, a redução mais intensa da MS, do $\mathrm{C}$ e ao maior crescimento de raízes sob a palhada nos tratamentos com aplicação de $\mathrm{N}$-uréia no plantio. A concentração de raízes na palhada nos tratamentos com $\mathrm{N}$ foi em média 480 contra $350 \mathrm{~g} \mathrm{~kg}^{-1}$ no tratamento testemunha, ou seja, houve um crescimento de raízes ligeiramente superior quando se aplicou $\mathrm{N}$ uréia no plantio (Tabela 33). Estes resultados foram coerentes com os de Thorburn e Robertson (2007a) que verificaram uma liberação de $67 \%$ a $95 \%$ do $\mathrm{N}$ contido na palhada após 12 meses de avaliação em três ambientes (solo e clima) contrastantes da Austrália.

Vitti et al. (2007) ressaltaram que a contribuição do $N$ da palhada na nutrição da cana-de-açúcar pode ser subestimada devido ao desenvolvimento de raízes junto à palhada de cana-de-açúcar. Vitti et al. (2008a) verificaram que a degradação média da palhada em todos os tratamentos no ciclo de cana-planta deste experimento foi de $85 \%$, quando obtidos pelo balanço de massa. A explicação para esse resultado, em parte, pode ser atribuída à presença de microrganismos, na maioria hifas de fungos, que se desenvolveram junto aos resíduos. Siqueira e Franco (1988) apontaram que a biomassa de fungos, verificada por diferentes autores, pode variar de 400 a $5000 \mathrm{~kg} \mathrm{ha}^{-1}$. Spain e Hodgen (1994) encontraram de 50 a $90 \mathrm{~kg} \mathrm{ha}^{-1}$ de oligoquetas (minhocas) nos $0,40 \mathrm{~m}$ superficiais de um solo muito arenoso sob palhada de cana-de-açúcar e concluíram que existem dois momentos na degradação da palhada de cana-de-açúcar: um primeiro de rápida lixiviação e um segundo de maior interação do material vegetal com o solo por meio da micro e mesofauna. 
Vitti et al. (2007) e Robertson (2003) também apontaram a contribuição das raízes da cana em crescimento na degradação e modificação da composição da palhada ao longo do tempo. Esta imobilização de $\mathrm{N}$ pode se tornar prejudicial ao desenvolvimento da cana-de-açúcar principalmente no estágio de formação e elongação de colmos, uma vez que a cultura requer o $\mathrm{N}$ em grande quantidade (FRANCO et al., 2010; GAVA et al., 2005; VITTI, 2003; WOOD, 1991).

Por outro lado, Hemwong et al. (2009) observaram nas condições da Tailândia que, devido à intensa precipitação pluviométrica, ocorreu atraso na decomposição dos resíduos vegetais de soja e amendoim provavelmente devido à falta de aeração durante o período chuvoso, o que foi de certo modo benéfico para a recuperação de $\mathrm{N}$ dos resíduos vegetais pela cana-de-açúcar e evitar perdas do nutriente por lixiviação.

Outra explicação refere-se à presença de raízes, que se desenvolvem na superfície do solo, beneficiadas pelas condições microclimáticas sob a cobertura, que acabam fazendo parte da amostra de palhada (TRIVELIN et al., 2002b). Tanto os microrganismos como as raízes de cana-de-açúcar com composição isotópica natural, cresceram junto da palhada e diluíram a composição isotópica $\left({ }^{15} \mathrm{~N}\right)$ do material. Através dessa diluição, verificou-se que a quantidade do material remanescente nos sacos telados foi praticamente composta metade de palhada e a outra metade de raízes, microrganismos e o próprio solo que passou a fazer parte da palhada- ${ }^{15} \mathrm{~N}$ residual, isto é, $448 \mathrm{~g} \mathrm{~kg}^{-1}$ de raízes na média dos tratamentos de $\mathrm{N}$-uréia em cana planta (Tabela 33).

Trabalhos realizados no Brasil mencionaram que a palhada de cana-deaçúcar apresentaram uma pequena mineralização de $\mathrm{N}$ no período de um ano agrícola, disponibilizando no solo uma pequena quantidade de $\mathrm{N}$, de $3 \%$ a $30 \%$ do total de $\mathrm{N}$ aplicado via resíduos vegetais (BASANTA et al., 2003; FARONI al., 2003; GAVA et al., 2002; OLIVEIRA et al., 1999; TRIVELIN et al.; 2002b). Para demais os nutrientes presentes na forma iônica ou ligados a compostos de alta solubilidade a liberação é intensa e rápida após o primeiro ciclo (NG KEE KWONG et al., 1987; OLIVEIRA et al., 1999).

Em experimentos de longa duração na África do Sul, Graham, Haynes e Meyer (2002) afirmaram que o C e N, prontamente mineralizáveis, aumentaram significativamente nos primeiros $20 \mathrm{~cm}$ de solo, devido à adição de palhada ao longo dos anos, mesmo em um vertissolo altamente fértil. Galdos, Cerri e Cerri (2009) 
encontraram aumento significativo do carbono da biomassa microbiana em solos da mesma área da Usina São Martinho e para experimentos em outras localidades como nordeste do Brasil, África do Sul e Austrália, comparando o sistema de cana colhida com e sem a queima da palhada.

Houve três tendências distintas quanto à concentração de nutrientes $\left(\mathrm{g} \mathrm{kg}^{-1}\right)$ contidos no material remanescente dos sacos telados: diminuição (ou liberação) dos nutrientes $\mathrm{K}$ e Mg, aumento (ou enriquecimento) para o $\mathrm{N}$ e $\mathrm{P}$, enquanto que $\mathrm{Ca}$ e $\mathrm{S}$ permaneceram constantes (Tabela 33). Spain e Hodgen (1994) também detectaram rápida depleção do $\mathrm{K}$ e do $\mathrm{Mg}$ porém um enriquecimento com $\mathrm{N}$ e Ca. Robertson e Thorburn (2007a) também encontraram um intenso enriquecimento da palhada de cana com $\mathrm{N}$ após um ano de estudo. Da mesma forma Hemwong et al. (2009) observaram um acréscimo de $\mathrm{N}$ na palhada de soja nos primeiros três meses de um período de 14 meses avaliação. Abramo Filho (1995) verificou intenso enriquecimento com N $(77 \%)$ e perdas de K $(73 \%)$ e Ca $(46 \%)$ da palhada de canade-açúcar no campo após 10,5 meses de avaliação. Para os demais nutrientes $P$, Mg e S os teores permaneceram constantes.

Esta dinâmica de elevação e depleção na concentração de nutrientes contidos no material remanescente dos sacos telados está relacionada ao processo de mineralização e a atividade microbiológica do solo quando se adicionam resíduos ricos em $\mathrm{C}$ e fertilizantes contendo $\mathrm{N}$ no agroecossistema (KHAN et al., 2007) bem como ao crescimento das raízes da cultura (VITTI et al., 2007) e da microbiota do solo (ABRAMO FILHO, 1995; SPAIN; HODGEN, 1994).

A quantidade de macronutrientes iniciais disponíveis na palhada (PAR) deste trabalho (em kg ha-1) foi $\mathrm{N}: 51 ; \mathrm{P}: 4,7 ; \mathrm{K}: 37$; Ca: 37,$4 ; \mathrm{Mg}: 14$ e S: 5,8, respectivamente (Tabela 33 ). Em valores relativos, os resultados deste trabalho são coerentes com os de Oliveira et al. (2003), em que a composição nutricional da palhada da cana-planta de dez variedades apresentou a contribuição de ( $\left.\mathrm{kg} \mathrm{ha}^{-1}\right)$, $\mathrm{N}$ : 58; P: 18; K: 133; Ca: 64 e Mg: 22. As diferenças no aporte dos nutrientes $\mathrm{P}, \mathrm{K}$, $\mathrm{Ca}$ e $\mathrm{Mg}$ foram devido à quantidade de MS encontradas pelos autores tenha sido o dobro (18 $\mathrm{Mg} \mathrm{ha}^{-1}$ ) da utilizada nas microparcelas e sacos telados com palhada deste experimento, ou seja, $9 \mathrm{Mg} \mathrm{ha}^{-1}$, como fora elucidado anteriormente no item 3.2.1.

A quantidade de nutrientes liberados pela palhada após um ano agrícola no tratamento testemunha foi (em $\mathrm{kg} \mathrm{ha}^{-1}$ e \% do total inicial, respectivamente): 
$\mathrm{N}(25,5$ e $49,8 \%) ; \mathrm{P}(2,7$ e $57 \%) \mathrm{K}(32,9$ e $89 \%) ; \mathrm{Ca}(21,9$ e $59 \%) ; \mathrm{Mg}(10$ e $71 \%)$ e $\mathrm{S}(3,4$ e $59 \%)$. Houve efeito significativo dos tratamentos com $\mathrm{N}$-uréia no plantio na liberação dos macronutrientes N (12,5 e 76\%); Ca (28,2 e 75\%), Mg (11,5 e 82\%) e $S(4,4$ e $76 \%)$ (Tabela 33). Estes resultados de liberação de nutrientes corroboram em parte com os de $\mathrm{Ng}$ Kee Kwong et al. (1987) que encontraram uma liberação de $27 \%$ do N após 18 meses nas Ilhas Maurício e com os de Oliveira et al. (1999) que obtiveram em onze meses valores de liberação do conteúdo original de $\mathrm{N}: 18 \%$, K: $85 \%$, Ca: $44 \%$, Mg: $39 \%$ e S: $11 \%$ na região de Piracicaba, SP. Ambos os autores não detectaram alteração na quantidade de $P$ liberado pela palhada por hectare, diferente deste trabalho onde se verificou uma pequena, mas significativa liberação de $\mathrm{P}\left(\mathrm{kg} \mathrm{ha}^{-1}\right)$ (Tabela 33).

Estes resultados concordam com os de Oliveira et al. (2002), cujas \% de liberação dos nutrientes foram em média N: 19\%, P: 60\%, K: 92\%, Ca: $60 \%$, Mg e S: $68 \%$, respectivamente, em área da região de Ribeirão Preto. Também são coerentes com os resultados apresentados nos itens 3.3.2 e 3.3.3 do Capítulo II, onde fica claro uma maior recuperação do $\mathrm{N}$ de resíduos vegetais pela parte aérea da cana quando se aplicou $\mathrm{N}$ mineral em soqueiras ao sistema solo-planta.

Fica evidente que tais diferenças estão relacionadas também à variedade utilizada nos trabalhos, e também às condições climáticas em cada situação. Para os nutrientes presentes na forma iônica ou ligados a compostos de alta solubilidade, a liberação é elevada e rápida (NG KEE KWONG et al., 1987; OLIVEIRA et al., 2002), assim como a degradação dos carboidratos solúveis (sacarose e amido) também é maior e mais rápida que a dos carboidratos estruturais (lignina, celulose e hemicelulose) e o que diminui consideravelmente suas taxas de decomposição (COÛTEAUX; BOTTNER; BERG, 1995; OLIVEIRA et al., 1999).

4.3.2 Degradação da palhada anterior à reforma $\left(\mathrm{PAR}^{-15} \mathrm{~N}\right)$ no tratamento $80-0 \mathrm{~kg}$ $\mathrm{ha}^{-1}$ de $\mathrm{N}$ em cana-planta e soqueiras, respectivamente, por quatro ciclos agrícolas consecutivos (2005 a 2008)

Houve redução de $96 \%$ na MS (8.951 para $338 \mathrm{Kg} \mathrm{ha}^{-1}$ ), $66 \%$ na abundância de ${ }^{15} \mathrm{~N}(1,08$ para $0,37 \%)$ e $97 \%$ do C (3.596 para $87 \mathrm{Kg} \mathrm{ha}^{-1}$ ) (Tabela 34). A quantidade de $\mathrm{N}$ proveniente da palhada teve redução de $93 \%$ do conteúdo original 
(51,2 para $\left.3,8 \mathrm{~kg} \mathrm{ha}^{-1}\right)$, devido principalmente à decomposição do $\mathrm{C}$ e dos carboidratos estruturais da palhada. Notou-se acréscimo na concentração de $\mathrm{N}$ e P na palhada, provavelmente devido à biomassa microbiana e o crescimento de raízes sob a palhada como enfatizaram Spain e Hodgen (1994) e Vitti et al. (2007a; 2008b).

$\mathrm{O}$ diâmetro da malha do saco telado de $0,03 \mathrm{~m}$ praticamente não influenciou no contato da palha com o solo e na entrada e saída da mesofauna responsável, principalmente pelos primeiros estágios de decomposição da palhada (ABRAMO FILHO, 1995; VITTI et al., 2008a). A malha do saco telado também foi eficaz em separar a palhada dos sacos telados das folhas secas senescentes do canavial no outono-inverno, evitando alteração no conteúdo de resíduos culturais marcados com ${ }^{15} \mathrm{~N}$ por material externo, como ressaltaram Robertson e Thorburn (2007a).

Do mesmo modo, a relação $\mathrm{C}: \mathrm{N}$ da palhada também foi reduzida de cerca de 70:1 para 22:1 (68\% de decréscimo) após os quatro ciclos agrícolas. Embora a relação C: $\mathrm{N}$ tenha sido significativamente diferente após cada ciclo, nota-se que a degradação da MS permaneceu constante após o terceiro ciclo, de 2007 para 2008. Notou-se também que não houve alterações significativas na concentração do carbono $\left(\mathrm{g} \mathrm{kg}^{-1}\right)$ do material remanescente dos sacos telados nos três primeiros ciclos, ocorrendo diminuição somente no último ciclo em 2008. Isso de deveu, provavelmente, à permanência do $\mathrm{N}$ da palhada que é liberado lentamente, ao crescimento das raízes da cana junto à palhada e à intensa atividade microbiana que ocorreu na interface palhada-solo. A taxa de decréscimo na relação C:N da palhada ao longo do tempo foi de aproximadamente 16 pontos a cada ano (Tabela 34 e Figura 12). 
Tabela 34 - Composição isotópica de ${ }^{15} \mathrm{~N}(\%)$, teores $\left(\mathrm{g} \mathrm{kg}^{-1}\right)$ e quantidades $\left(\mathrm{kg} \mathrm{ha}^{-1}\right)$ de resíduos vegetais, carbono, carboidratos estruturais e macronutrientes da palhada de sacos telados simulando palhada anterior à reforma (PAR- $\left.{ }^{15} \mathrm{~N}\right)$ instalados no tratamento $80-0 \mathrm{~kg} \mathrm{ha}^{-1}$ de $\mathrm{N}$ em cana-planta e soqueiras, respectivamente e após quatro ciclos consecutivos (2005 a 2008)

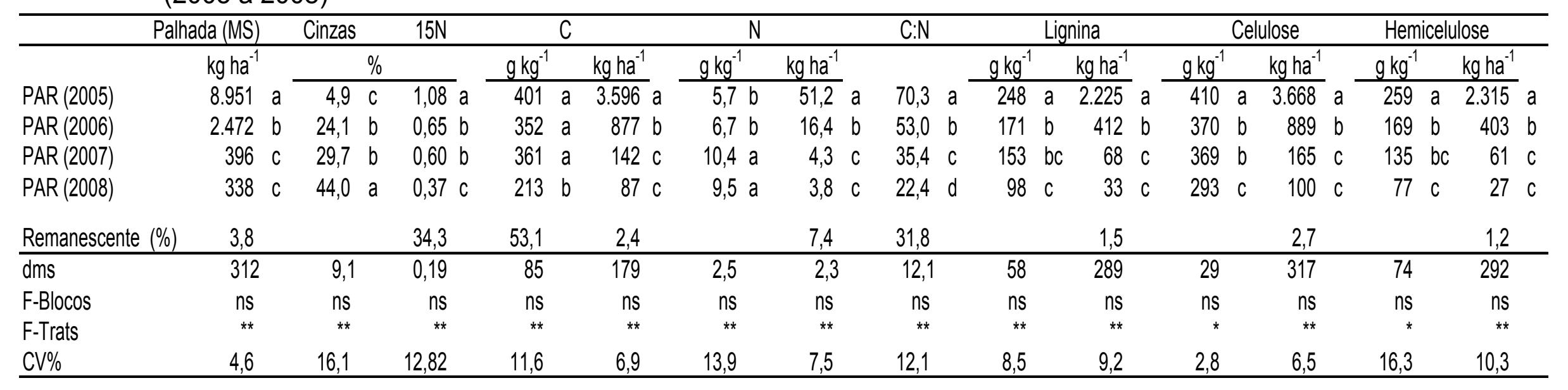

\begin{tabular}{|c|c|c|c|c|c|c|c|c|c|c|c|c|c|c|c|c|c|c|}
\hline & \multicolumn{2}{|c|}{ Raizes na palhada } & \multicolumn{3}{|c|}{$\mathrm{N}$} & \multicolumn{2}{|l|}{$\mathrm{P}$} & \multicolumn{2}{|l|}{$\mathrm{K}$} & & \multicolumn{2}{|r|}{$\mathrm{Ca}$} & & \multicolumn{2}{|l|}{$\mathrm{Mg}$} & \multicolumn{3}{|c|}{$S$} \\
\hline & $\mathrm{g} \mathrm{kg}^{-1}$ & $\mathrm{~kg} \mathrm{ha}^{-1}$ & $\mathrm{~g} \mathrm{~kg}^{-1}$ & $\mathrm{~kg} \mathrm{ha}^{-1}$ & & $\mathrm{~g} \mathrm{~kg}^{-1}$ & $\mathrm{~kg} \mathrm{ha}^{-1}$ & $\mathrm{~g} \mathrm{~kg}^{-1}$ & $\mathrm{~kg} \mathrm{ha}^{-1}$ & & $\mathrm{~g} \mathrm{~kg}^{-1}$ & $\mathrm{~kg} \mathrm{ha}^{-1}$ & & $\mathrm{~g} \mathrm{~kg}^{-1}$ & $\mathrm{~kg} \mathrm{ha}^{-1}$ & & $\mathrm{~g} \mathrm{~kg}^{-1}$ & $\mathrm{~kg} \mathrm{ha}^{-1}$ \\
\hline PAR (2005) & & & $5,7 b$ & 51,2 & $a$ & $0,53 \mathrm{~b}$ & 4,7 & $4,1 a$ & 37,0 & $a$ & 4,1 & 37,4 & $a$ & $1,6 \quad$ a & 14,0 & $a$ & $0,7 a$ & $\overline{5,8} a$ \\
\hline $\operatorname{PAR}(2006)$ & 545 a & $1.312 \mathrm{a}$ & $6,7 \mathrm{~b}$ & 16,4 & $b$ & $0,58 \mathrm{~b}$ & 1,4 & $1,3 \mathrm{~b}$ & 2,6 & $b$ & 3,9 & 9,7 & $b$ & $1,0 \mathrm{~b}$ & 2,5 & $b$ & 0,6 a & $1,5 b$ \\
\hline $\operatorname{PAR}(2007)$ & 610 a & $232 b$ & $10,4 a$ & 4,3 & C & $0,85 a$ & 0,4 & $1,2 b$ & 0,5 & $b$ & 5,3 & 2,3 & C & $1,2 a b$ & 0,5 & $c$ & 0,9 a & $0,4 \mathrm{c}$ \\
\hline PAR (2008) & 589 a & $199 \mathrm{~b}$ & 9,5 a & 3,8 & c & $0,90 a$ & 0,4 & $1,5 b$ & 0,5 & $b$ & 4,6 & 1,8 & c & $1,2 a b$ & 0,5 & c & 0,8 a & $0,3 \mathrm{c}$ \\
\hline Remanescente $(\%)$ & & & & 7,4 & & & 7,7 & & 1,4 & & & 4,8 & & & 3,4 & & & 5,2 \\
\hline $\mathrm{dms}$ & 276 & 581 & 2,5 & 2,3 & & 0,21 & 0,7 & 1,4 & 6,0 & & 2,2 & 2,1 & & 0,43 & 0,96 & & 0,42 & 0,5 \\
\hline F-Blocos & ns & ns & ns & ns & & ns & ns & ns & ns & & ns & ** & & ns & ns & & ns & * \\
\hline F-Trats & ns & ** & $* *$ & ** & & ** & $* *$ & ** & ** & & ns & ** & & * & ** & & ns & ** \\
\hline CV\% & 21,9 & 46,1 & 13,9 & 7,5 & & 13,4 & 17,8 & 32,2 & 27,7 & & 21,9 & 7,6 & & 15,5 & 9,8 & & 26,6 & 19,9 \\
\hline
\end{tabular}

Legenda: PAR = palhada ${ }^{15} \mathrm{~N}$ simulando palhada anterior à reforma (variedade RB855536); $\mathrm{C}=$ carbono; $\mathrm{N}=$ nitrogênio; $\mathrm{P}=$ fósforo, $\mathrm{K}=$ potássio; $\mathrm{Ca}=$ cálcio, $\mathrm{Mg}$ = magnésio; $\mathrm{S}$ = enxofre. 


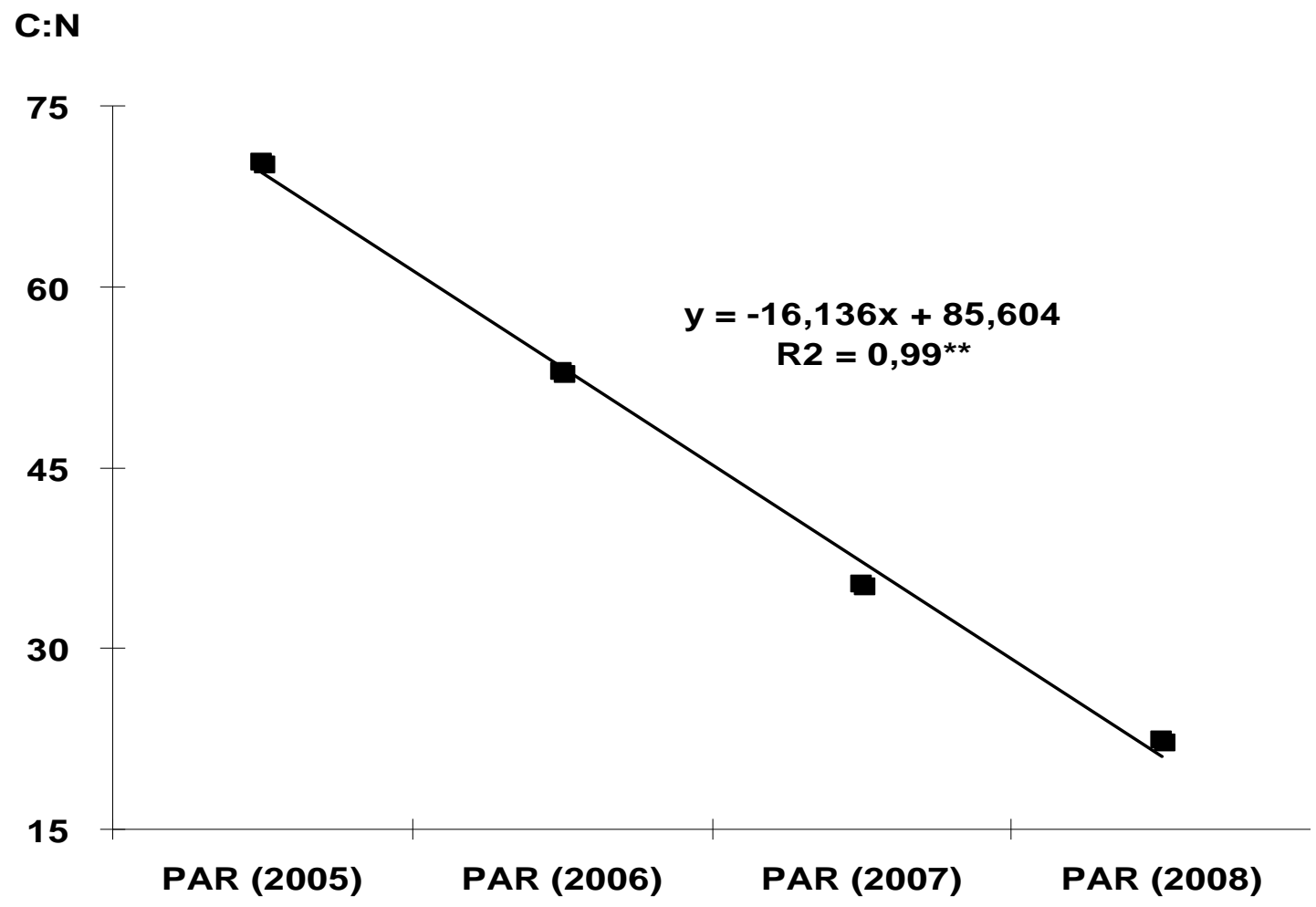

Ciclo Agrícola

Figura 12 - Relação carbono:nitrogênio (C:N) da palhada de cana anterior à reforma (PAR, variedade RB855536) adicionada na cana-planta após quatro ciclos consecutivos (2005 a 2008)

Faroni et al. (2003) utilizaram sacos telados contendo palhada da mesma variedade SP81-3250 e obtiveram redução de 55\% na MS e 60\% na relação C:N que passou de 85:1 para 34:1 após um ano agrícola. O teor de cinzas (\%) da palhada aplicada em superfície aumentou de 4,9 a $44 \%$ ao longo dos ciclos agrícolas avaliados. Isto pode ter ocorrido pelo recobrimento dos sacos telados com solo e palhada das colheitas sucessivas além do crescimento de raízes e/ou microbiota sob a tela utilizada (VITTI et al., 2008a) (Tabela 34).

É importante ressaltar que o material remanescente dos sacos telados foi àquele possível de ser coletado no interior dos mesmos, ou seja, a palhada que já se encontrava finamente fragmentada e/ou aderida ao solo foi deixada na superfície. Portanto, esta pode ser considerada uma deficiência da metodologia dos sacos telados, uma vez que parte deste material pode não ter sido totalmente decomposto (mineralizado) e também não ter sido contabilizado no total de MS.

Uma diferença deste trabalho para os demais da literatura, é que os resultados de degradação de resíduos vegetais dificilmente ultrapassaram um ano 
de avaliação. Neste caso, a degradação da MS da PAR foi de $72 \%$ (8.951 para $2472 \mathrm{~kg} \mathrm{ha}^{-1}$ ) após o primeiro ano (2005 a 2006) (Tabela 34).

Oliveira et al. (2002), avaliando a degradação de palhada de cana em dois ambientes de produção (solo e clima) no Estado de São Paulo, nos municípios de Ribeirão Preto e Piracicaba, apontaram reduções na matéria seca (MS) de 22 e 70\% respectivamente. Os autores ressaltaram que a menor perda de MS em Ribeirão Preto em relação a Piracicaba, poderia estar relacionada à irrigação com vinhaça aplicada no segundo local. A relação $\mathrm{C}: \mathrm{N}$ da palhada destes dois locais foi alterada de 97:1 para 68:1 (30\%) em Ribeirão Preto e 94:1 para 60:1 (36\%) em Piracicaba.

Embora tenham encontrado uma palhada com relação $\mathrm{C}: \mathrm{N}$ superior à deste trabalho 170:1 contra 70:1, Spain e Hodgen (1994) verificaram degradação de $81 \%$ da MS e ressaltam que as maiores taxas de degradação a partir dos 75 dias aconteceram até os o final do período de um ano no nordeste da Austrália. Após aproximadamente 200 dias a relação $\mathrm{C}: \mathrm{N}$ passou a ser constante.

Para outras culturas Kumar et al. (2001) verificaram que $65 \%$ a $70 \%$ dos resíduos vegetais de leguminosas e gramíneas foram degradados após um ano de avaliação e Bertol, Leite e Zoldan (2004) obtiveram redução de 40 a 53\% na massa inicial de 8,8 $\mathrm{Mg} \mathrm{ha}^{-1}$ de palhada de milho após dez meses de avaliação, ou seja, praticamente a mesma quantidade de PAR utilizada neste trabalho (Tabela 34). Esta menor taxa de degradação da palhada de milho encontrada por estes autores foi devido provavelmente às condições climáticas mais amenas de temperatura da região de estudo (Estado de Santa Catarina) e a menor relação C:N do resíduo de milho utilizado por estes autores 55:1 quando comparado a da PAR, 70:1, respectivamente.

Carvalho et al. (2008) estudando a decomposição de diversas plantas de cobertura em sistema de plantio direto ou com resíduos incorporados ao solo notaram que após 180 dias a relação $\mathrm{C}: \mathrm{N}$ do milheto caiu de 50:1 para 25:1 e que após esse período não houve degradação significativa do conteúdo dos sacos telados. Apesar de também ser uma gramínea, a produção de matéria seca do milheto foi inferior a da palhada de cana, ao redor de $2,1 \mathrm{Mg} \mathrm{ha}^{-1}$, contra 9 a $10 \mathrm{Mg} \mathrm{ha}^{-1}$ da palhada de cana deste trabalho.

Robertson e Thorburn (2007b) verificaram que, após um ano, a relação C:N iniciais das palhadas foram de 120:1 para 70:1 e caíram para menos de 40:1, em três localidades da Austrália, portanto um decréscimo na relação $\mathrm{C}: \mathrm{N}$ de 
aproximadamente 58\%. Robertson (2003) e Spain e Hodgen (1994), também encontraram enriquecimento da palhada com $\mathrm{N}$ e redução no conteúdo de $\mathrm{C}$ ao longo do tempo, assim como foi o caso deste trabalho (Tabela 34 e Figura 13). A queda acentuada de $C$ é em parte devido à intensa decomposição da hemicelulose (OLIVEIRA et al., 1999; JENSEN et al., 2005).

Houve intensa degradação dos carboidratos estruturais da PAR. A redução dos teores $\left(\mathrm{g} \mathrm{kg}^{-1}\right)$ da lignina, celulose e hemicelulose após os quatro ciclos avaliados foi de $60 \%, 29 \%$ e $70 \%$, respectivamente (Tabela 34 e Figura 13).

Estes resultados são coerentes com os de Faroni et al. (2003) que encontraram $62 \%$ de degradação da lignina quando a palhada foi aplicada sobre o solo e $47 \%$ quando a palhada foi incorporada ao solo, após um ano agrícola. Obtiveram um decréscimo médio de $70 \%$ da celulose e $62 \%$ da hemicelulose, independente da forma de aplicação da palhada (sobre o solo ou incorporada). Embora não os tenham quantificado, afirmaram que metade da matéria seca remanescente nos sacos telados após um ano de estudo foi composta de raízes e microrganismos, como observado neste trabalho (Tabela 34).

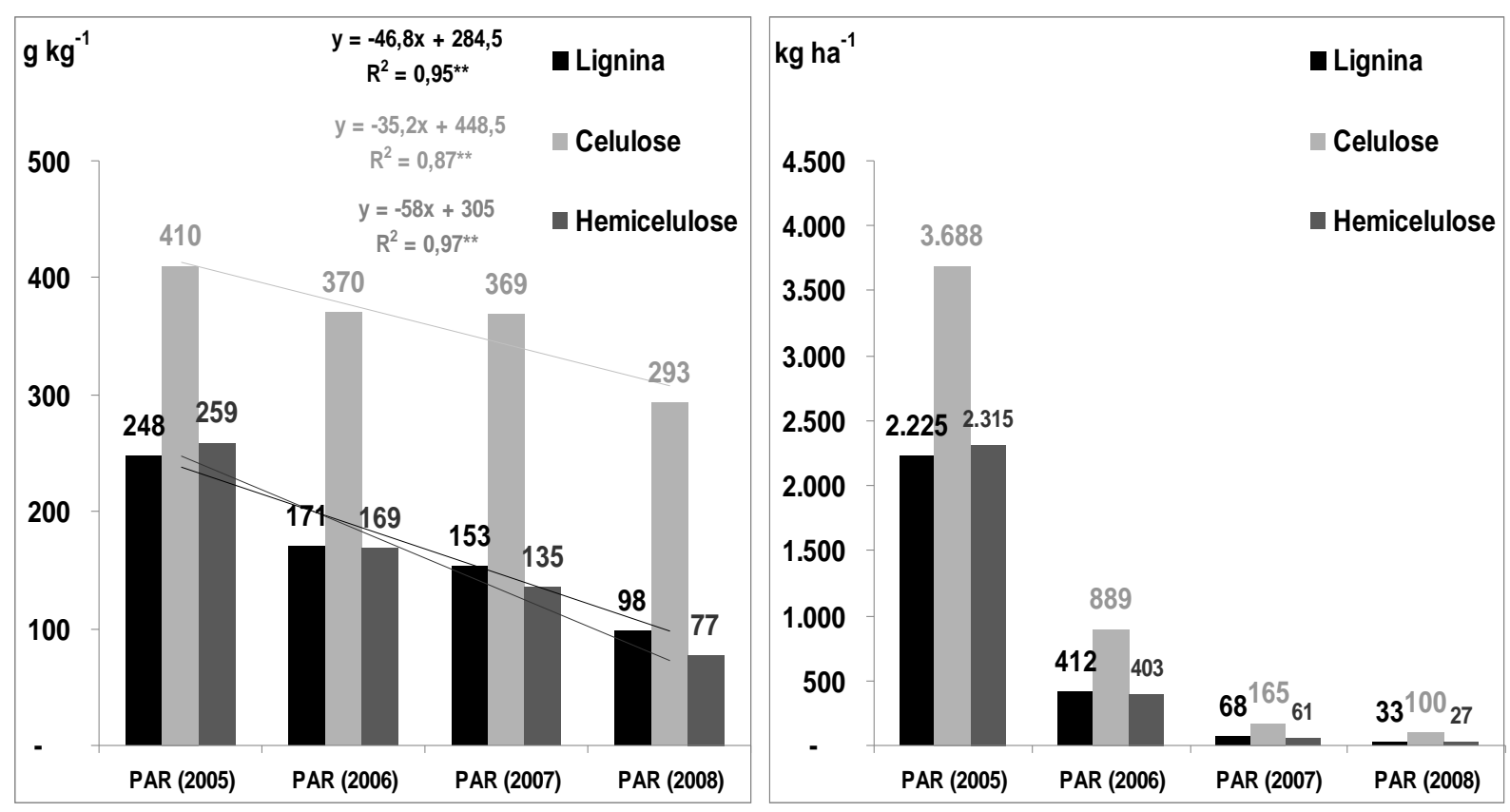

Figura 13 - Conteúdo $\left(\mathrm{g} \mathrm{kg}^{-1}\right)$ e quantidade por área $\left(\mathrm{kg} \mathrm{ha}^{-1}\right)$ de carboidratos estruturais (lignina, celulose e hemicelulose) da palhada anterior à reforma (PAR) dos sacos telados aplicados em cana-planta e após quatro ciclos consecutivos (2005 a 2008) 
Oliveira et al. (1999) verificaram que após um ano de permanência da palha da variedade SP79-1011 ( $2^{\circ}$ corte) no campo, houve redução na massa de aproximadamente $22 \%$ e que somente a hemicelulose apresentou decomposição. Oliveira et al. (2002) utilizando a variedade SP81-1842 na região de Piracicaba, obtiveram degradação de $22 \%$ da lignina, $57 \%$ da celulose e $81 \%$ da hemicelulose após onze meses de permanência da palhada no campo.

Em trabalho recente, Austin e Ballaré (2010) ressaltam que a lignina é um material recalcitrante (resistente à decomposição) e que sua degradação é relacionada principalmente à fotodegradação, ou seja, devido à absorção de radiação solar $\left(R^{2}=0,92\right)$. Já para a celulose a degradação está relacionada ao ataque microbiano.

A quantidade de nutrientes liberados (em $\mathrm{kg} \mathrm{ha}^{-1} \mathrm{e} \%$ ) após quatro ciclos foi de: N: 47,4 (93\%); P: 4,3 (91\%); K: 36,5 (99\%); Ca: 35,6 (95\%); Mg: 13,5 (96\%) e S: 5,5 (95\%). A média de liberação de macronutrientes apos 4 anos foi $94 \%$ sendo a maior liberação foi do K com 99\% e a menor do S com 91\% (Tabela 34 e Figura 14). Já Oliveira et al. (1999) no seu estudo por um ano obtiveram liberação de 85\%, 44\% e $39 \%$ dos nutrientes $\mathrm{K}$, $\mathrm{Ca}$ e $\mathrm{Mg}$, respectivamente.

Novamente cabe ressaltar que os teores e quantidades para nutrientes liberados foram obtidos da palhada remanescente dos sacos telados e que uma parte deste material pode ter se fragmentado em partículas menores que o diâmetro da malha de 0,03 $\mathrm{m}$ e perdeu-se do interior do saco telado. Além disso, este material fragmentado poderia não estar totalmente mineralizado e, conseqüentemente, não prontamente disponível para as plantas. 

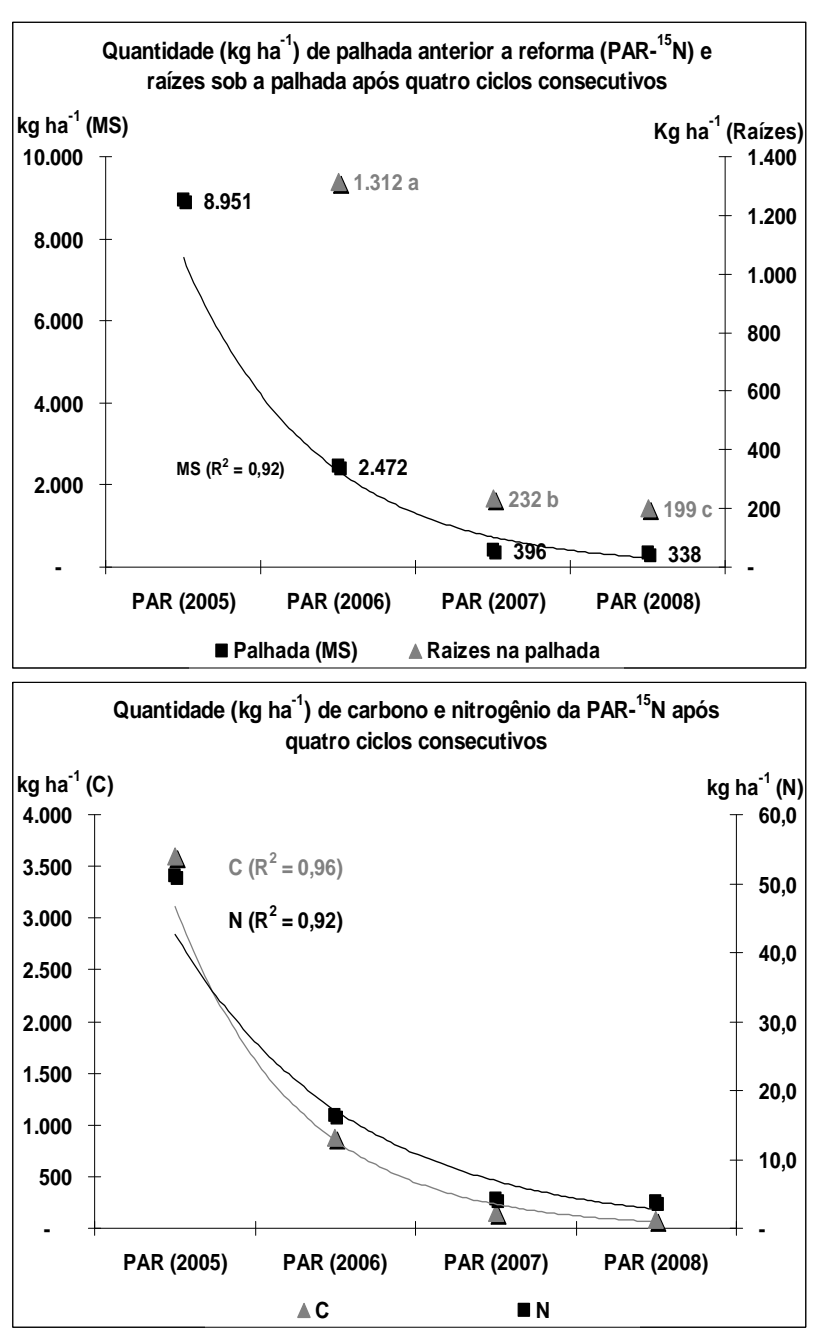

Figura 14 - Quantidade $\left(\mathrm{kg} \mathrm{ha}^{-1}\right)$ e teor $\left(\mathrm{g} \mathrm{kg}^{-1}\right)$ de carbono $(\mathrm{C})$, macronutrientes $(\mathrm{N}, \mathrm{P}, \mathrm{K}$ de raízes sob a palhada dos sacos telados aplicada em cana-planta $\left(2005\right.$, PAR- $\left.{ }^{15} \mathrm{~N}\right)$ após quatro ciclos consecutivos
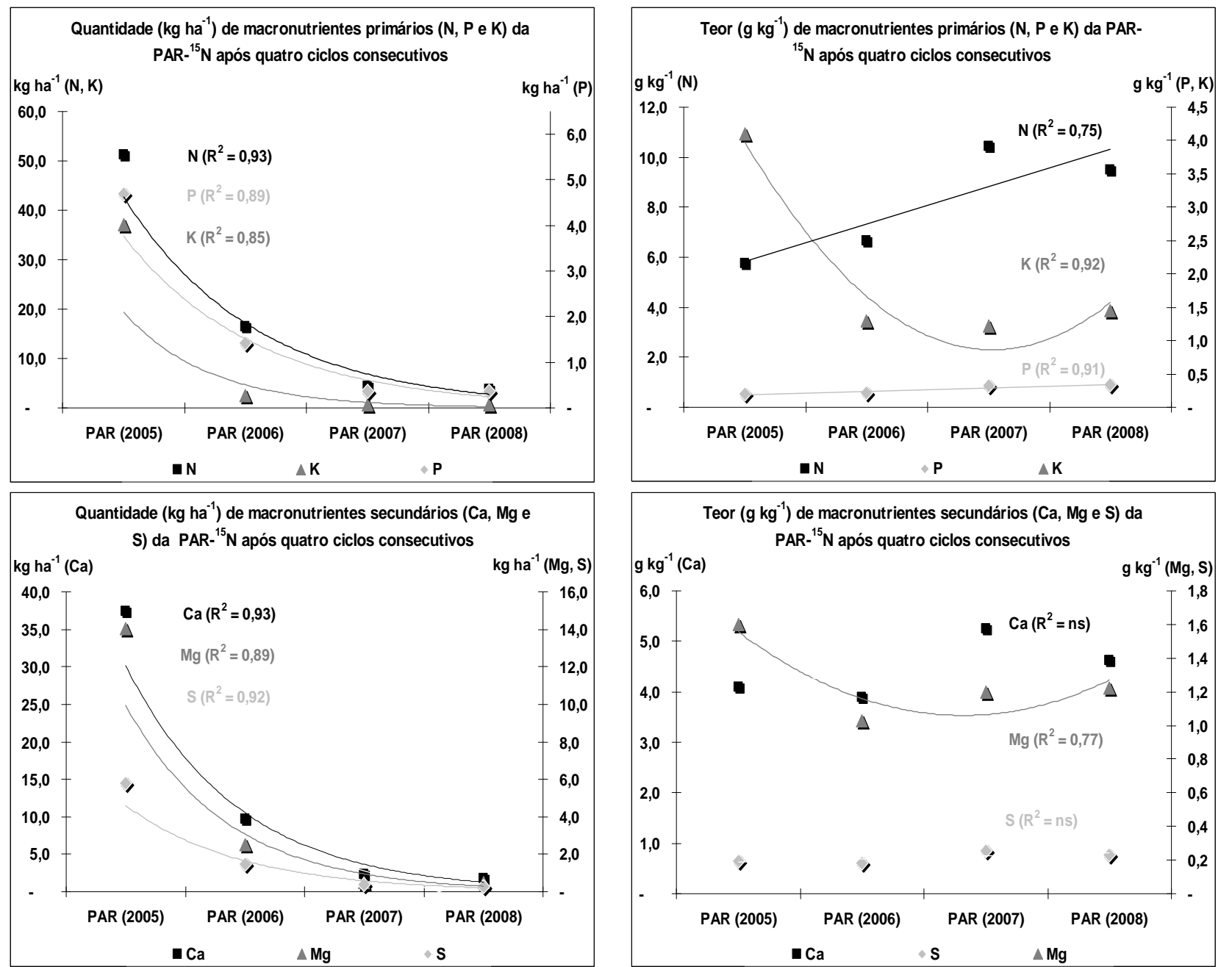
Oliveira et al. (1999) obtiveram redução somente para hemicelulose de $75 \%$ do conteúdo original da palhada (variedade SP79-1011); para lignina e celulose tiveram um ganho de $1 \%$ e $4,5 \%$ dos teores originais, provavelmente devido à incorporação de fungos e raízes no material. A liberação de nutrientes foi de $\mathrm{N}: 17 \%$; K: $85 \%$; Ca: $44 \%$; MG: $38 \%$ e S: $11 \%$. O P permaneceu estável na palhada. Oliveira et al. (2002) obtiveram as seguintes taxas de liberação de nutrientes de palhada de cana durante 11 meses: $\mathrm{N}$ ns; $\mathrm{K}$ 92\%; Mg e S 68\%; P e Ca $60 \%$. Observaram que $60 \%$ do $S$ da palhada foi mineralizado em 12 meses, em experimento de Piracicaba, $\mathrm{SP}, \mathrm{e}$, nas medidas feitas em Ribeirão Preto, SP, encontraram pouca liberação de S.

Cabe ressaltar que as diferenças entre taxas de degradação encontradas na literatura também podem estar relacionadas ao método de coleta e/ou instalação do material vegetal no campo (THORBURN; PROBERT; ROBERTSON, 2001). O contato entre a palhada e o solo no caso de sacos telados proporcionou condições ótimas para a decomposição.

Com o passar do tempo, pode-se observar intensa presença de microrganismos (micélio de fungos) e raízes de cana-de-açúcar que se desenvolveram junto à palhada. A quantidade de raízes obtidas pela técnica de diluição isotópica, após o primeiro ciclo, foi de aproximadamente de $53 \%$ do material seco remanescente dos sacos telados em 2006, isto é, $1.312 \mathrm{~g} \mathrm{~kg}^{-1}$ de raízes num total de $2.472 \mathrm{~g} \mathrm{~kg}^{-1}$ de palhada. No segundo ciclo a quantidade de raízes caiu drasticamente, aproximadamente $80 \%$ comparado ao ciclo anterior e permaneceu praticamente constante até o terceiro ciclo (Tabela 34 e Figura 14).

Sanomiya et al. (2006) também utilizaram palhada da variedade RB855536 para avaliar sua degradabilidade na presença de vinhaça e nitrogênio $\left(60 \mathrm{~kg} \mathrm{ha}^{-1} \mathrm{de}\right.$ $\mathrm{N}$ na forma de nitrato de amônio). Ressaltaram que a adição de palhada e vinhaça aumentaram a atividade respiratória do solo (Nitossolo argiloso) e das enzimas celulases enquanto que a adição de $\mathrm{N}$ diminuiu a respiração (emissão de $\mathrm{CO}_{2}$ ) provavelmente devido às mudanças no $\mathrm{pH}$ do solo. Outro fator pode se relacionar ao trabalho ter sido conduzido com palhada triturada finamente $(<1 \mathrm{~mm})$, diferente do presente trabalho que foi conduzido no campo e com palhada mais grosseira (50 - $100 \mathrm{~mm}$ ), visando simular a palhada após sua passagem pelo extrator primário e secundário das colhedoras mecânicas de cana (MANECHINI, 1997).

Além da liberação dos macronutrientes para o solo $\left(\mathrm{em} \mathrm{kg} \mathrm{ha}^{-1}\right)$, neste trabalho também foi considerada a concentração $\left(\mathrm{g} \mathrm{kg}^{-1}\right)$ dos nutrientes no material 
remanescente nos sacos telados. Notou-se aumento no teor de $\mathrm{N}$ ao longo dos anos, juntamente com $\mathrm{P}$, mas com menor incremento na concentração, embora os conteúdos tenham sido decrescentes (Tabela 34 e Figura 14).

Meier et al. (2006), utilizando microparcelas com palhada e fertilizante marcados com ${ }^{15} \mathrm{~N}$ também encontraram enriquecimento da palhada com $\mathrm{N}$, principalmente quando este resíduo fora enterrado, o que contribuiu para a diminuição da relação C:N de 100:1 para aproximadamente 25:1 em um ano de estudo, ou seja, um decréscimo de 75\%. Hemwong et al. (2009) verificaram enriquecimento no teor de $\mathrm{N}$ da palhada de soja, principalmente nos primeiros três meses iniciais do período de avaliação de 14 meses.

Para o nutriente $\mathrm{K}$ houve intensa liberação no primeiro ciclo (93\%), com posterior estabilização do segundo ao quarto ciclo, atingindo $98,6 \%$ ao final do período. O Mg apresentou queda nos dois primeiros ciclos e ligeiro incremento no terceiro ciclo. Para o Ca e S não houve efeito significativo ao longo do tempo, isto é, suas concentrações no substrato permaneceram constantes (Figura 14). Observouse, ainda, que a maior parte do sistema radicular sob a palhada foi formado no ciclo de cana-planta. Nas duas soqueiras subseqüentes a quantidade de MS via sistema radicular na palhada permaneceram constantes, embora a massa seca de palhada nas três soqueiras apresentou redução (2006 a 2008).

É esperado que ocorram modificações nos padrões de degradação da palhada devido às mudanças climáticas globais como elucidaram Coûteaux, Bottner e Berg (1995). Estes autores alertaram que o aumento da concentração de $\mathrm{CO}_{2}$ na atmosfera poderá alterar a composição de resíduos vegetais (especialmente $\mathrm{N}$ ) e 0 aquecimento da terra proporcionará maiores taxas de degradação da matéria orgânica. Ressaltaram, também, que, em condições tropicais, o clima é o principal fator de degradação da palhada, enquanto que em climas temperados a qualidade dos resíduos tem maior influência na decomposição.

Zhang et al. (2008) ressaltaram em sua revisão que a decomposição de resíduos vegetais é impactada por fatores diretos e indiretos como posição geográfica (latitude e altitude), clima (precipitação e temperatura médias anuais, evapotranspiração) e qualidade da liteira (nutrientes, relação $\mathrm{C}: \mathrm{N}$ e lignina). Avaliando modelos globais de predição/estimativa da decomposição de resíduos vegetais, estes autores elucidaram que as variáveis que mais afetam as taxas de degradação dos resíduos são o conteúdo de nutrientes totais e relação C:N 
$\left(R^{2}=0,70\right)$, tendo em vista que o teor de nutrientes totais foi proporcionou $R^{2}=39 \%$. Quando consideraram a combinação de latitude, longitude, temperatura média anual esta contribuição subiu para $R^{2}=88$.

A diferença marcante deste com vários outros trabalhos da literatura, além da avaliação de todos os componentes da palhada, foi esta ter permanecido no campo por quatro anos consecutivos. São raros os trabalhos como o de Basanta et al. (2003) que avaliam a recuperação de nutrientes proveniente de resíduos vegetais por mais de dois ciclos agrícolas. Outro aspecto é que os materiais avaliados em outros trabalhos (OLIVEIRA et al., 1999; 2002; FARONI et al., 2003, SPAIN; HODGEN, 1994; ROBERTSON; THORBURN, 2007b) geralmente foram de soqueiras de cana, ou seja, em pós colheita. Neste trabalho avaliou-se a contribuição de resíduos culturais ao longo de todo o sistema produtivo, portanto desde a reforma e plantio do canavial, até seus cortes mais avançados.

De maneira geral, o decréscimo na quantidade de MS da palhada de cana-deaçúcar após o período estudado foi exponencial, ou seja, com grande intensidade do primeiro para o segundo ano e estabilizando ao longo do tempo (Tabela 34 e Figura 14). Estes resultados estão coerentes com os de Gonçalves et al. (2010), embora os resíduos culturais (soja e milho), o período de avaliação (semanalmente durante 112 dias no período de "safrinha", outono - inverno) e o local (Estado do Paraná) tenham sido diferentes deste trabalho. 
4.3.3 Degradação da palhada pós colheita $\left(P P C-{ }^{15} \mathrm{~N}\right)$ no tratamento $80-0 \mathrm{~kg} \mathrm{ha}^{-1}$ de $\mathrm{N}$ em cana-planta e soqueiras, respectivamente e após três ciclos agrícolas consecutivos

Houve redução na matéria seca (MS) da PPC do primeiro para o segundo ano de $45 \%$ (10 a 4,5 $\left.\mathrm{Mg} \mathrm{ha}^{-1}\right)$ (2006 a 2007) e de 73\% (10 a 2,7 $\mathrm{Mg} \mathrm{ha}^{-1}$ ) do primeiro para o terceiro ano (2006 a 2008). $O$ teor de carbono $\left(\mathrm{g} \mathrm{kg}^{-1}\right)$ permaneceu estável do primeiro para o segundo ano, porém houve uma redução de $44 \%$ do conteúdo de $C$ original da PPC após os três ciclos agrícolas (444 para $248 \mathrm{~g} \mathrm{~kg}^{-1}$ ). Embora tenha acontecido um enriquecimento gradativo no teor de $\mathrm{N}\left(\mathrm{em} \mathrm{g} \mathrm{kg}^{-1}\right)$ no material dos sacos telados, também se pode observar liberação de $30 \%$ em relação à quantidade inicial (Tabela 35).

A palhada pós colheita (PPC) apresentou relação $\mathrm{C}: \mathrm{N}$ ligeiramente superior que a palhada anterior à reforma (PAR), 108:1 e 72:1 respectivamente, porém as taxas de degradação se mantiveram consistentes. Esta liberação do N-palhada está relacionada principalmente à degradação da matéria orgânica (massa seca) da palhada e contribui significativamente para o estoque deste nutriente no solo como verificado no item 3.3.3 deste trabalho e em outros trabalhos da literatura (BASANTA et al., 2003; GAVA et al., 2005).

Houve redução na relação C:N de $78 \%$ em três ciclos, de 108:1 para 23:1 (Tabela 35). Para a palhada anterior à reforma (PAR), esta queda foi menos pronunciada, ou seja, de $49 \%$ em três ciclos (70:1 para 35:1) e atingiu um equilíbrio após o quarto ciclo, com queda total de $68 \%$ na relação C:N (70:1 para 22:1) (Tabelas 34 e 35). Em comparação com resultados da literatura e considerando-se somente o primeiro ciclo para a PAR e PPC o decréscimo na relação C:N foi de $29 \%$ e $49 \%$ respectivamente, coerente com os resultados obtidos por Faroni et al. (2003), Oliveira et al. (1999) e Robertson e Thorburn et al. (2007b) que obtiveram valores na redução da relação C:N oscilando entre $30 \%$ a $68 \%$. 
Tabela 35 - Composição isotópica de ${ }^{15} \mathrm{~N}(\%)$, teores $\left(\mathrm{g} \mathrm{kg}^{-1}\right)$ e quantidades $\left(\mathrm{kg} \mathrm{ha}^{-1}\right)$ de resíduos vegetais, carbono, carboidratos estruturais e macronutrientes da palhada de sacos telados simulando palhada pós colheita (PPC- ${ }^{15} \mathrm{~N}$ ) instalados no tratamento $80-0 \mathrm{~kg} \mathrm{ha}^{-1}$ de $\mathrm{N}$ em cana-planta e soqueiras, respectivamente e após três ciclos consecutivos (2006 a 2008)

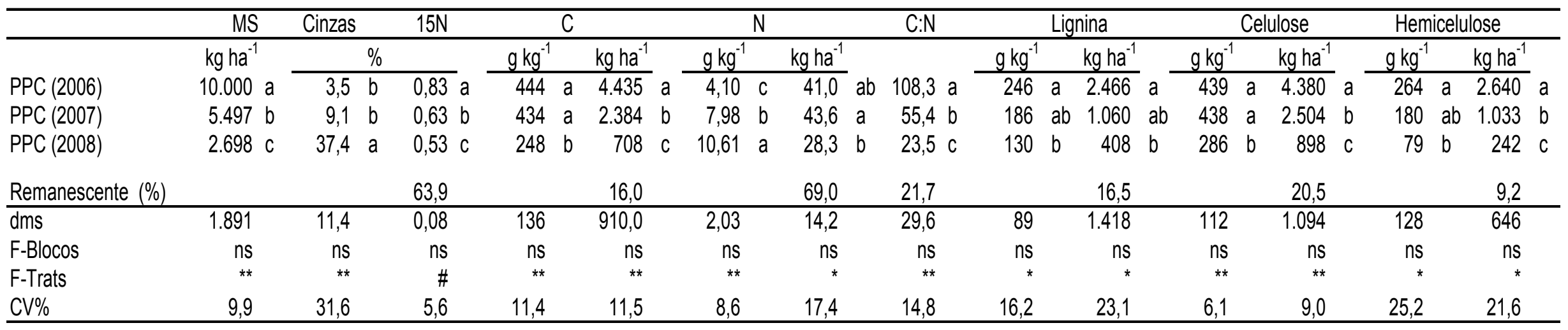

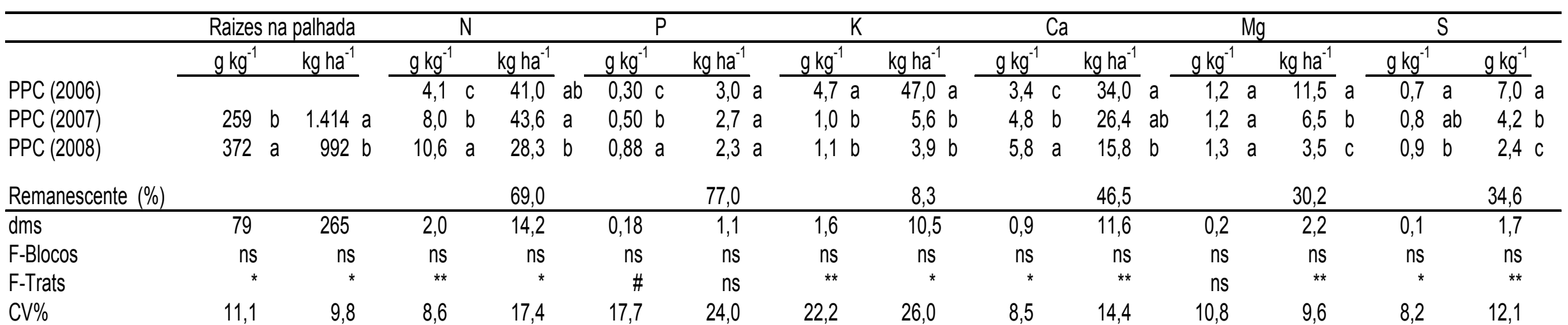

Legenda: $\mathrm{PPC}=$ palhada pós colheita (variedade SP81-3250); $\mathrm{C}=$ carbono; $\mathrm{N}=$ nitrogênio; $\mathrm{P}=$ fósforo, $\mathrm{K}=$ potássio; $\mathrm{Ca}=$ cálcio, $\mathrm{Mg}=$ magnésio; $\mathrm{S}=$ enxofre. 
Embora a PPC tenha apresentado maior relação $\mathrm{C}: \mathrm{N}$, sua degradação foi proporcionalmente maior que à PAR em três ciclos, provavelmente devido às condições climáticas ao longo dos anos. (Figura 1). Além disso, foi possível notar uma concentração total de nutrientes ligeiramente maior na PPC do que na PAR (11,6 vs. $10,7 \mathrm{~g} \mathrm{~kg}^{-1}$, Tabela 25). Zhang et al. (2009) elucidaram que, além da relação C:N, o teor de nutrientes totais foram fatores responsáveis por mais de $70 \%$ da degradação de diferentes tipos de palhada em escala global. Quando se consideram a latitude, temperatura média anual este valor aumentou para mais de $87 \%$.

As reduções nos teores $\left(\mathrm{g} \mathrm{kg}^{-1}\right)$ da lignina, celulose, hemicelulose na PPC após os três ciclos foram de $47 \%, 35 \% ; 70 \%$ e respectivamente (Tabela 35 e Figura 15). Em comparação à PAR, considerando somente os três primeiros ciclos, a quantidade remanescente foi $38 \%, 10 \%, 48 \%$ e respectivamente (Tabela 34 ).

Em trabalho recente, Austin e Ballaré (2010) elucidaram que acréscimos no conteúdo de lignina inibem a degradação biótica (microbiana), porém proporcionaram maior degradação por fotodecomposição, isto é, devido à ação da radiação solar.
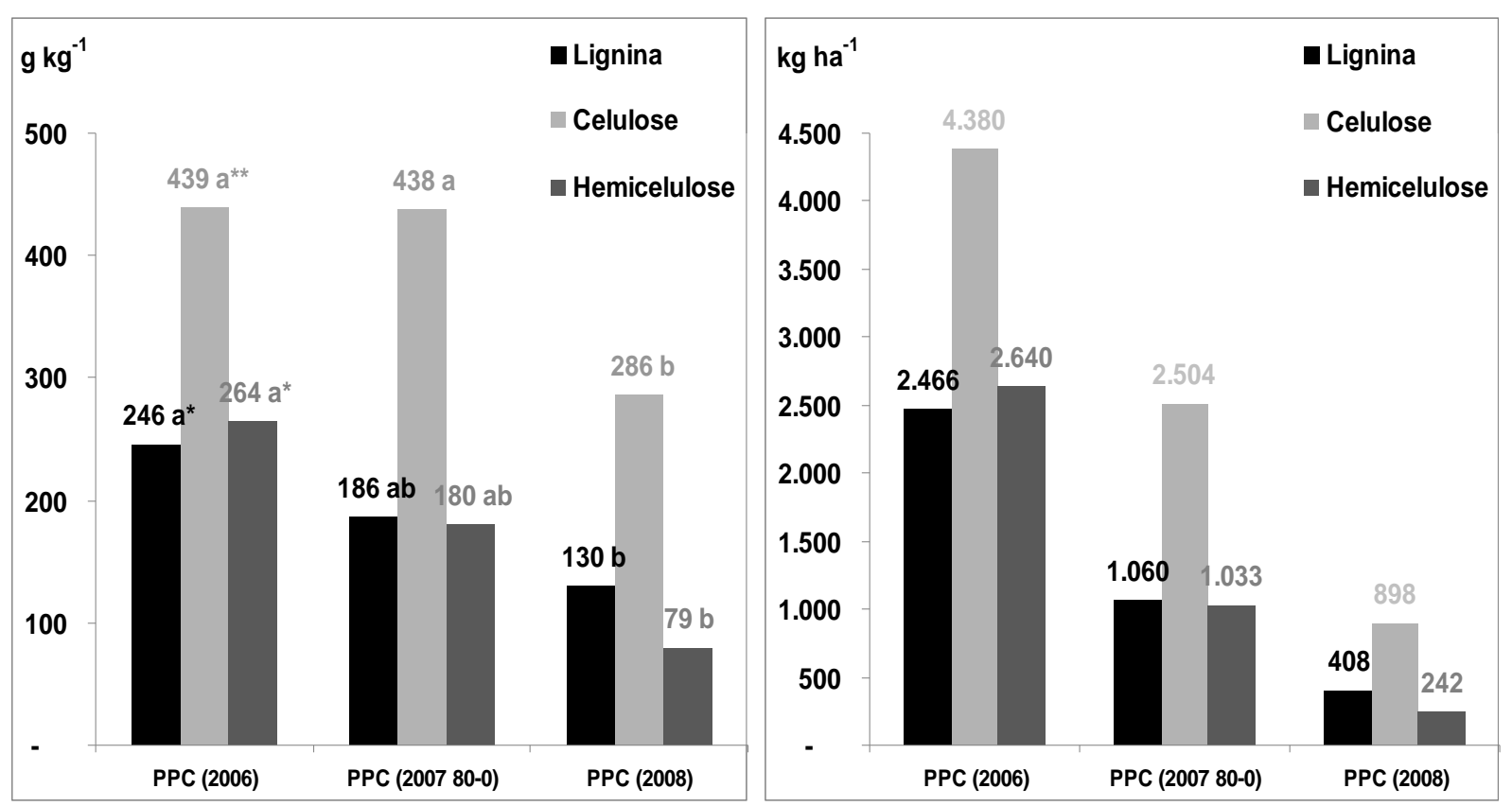

Figura 15 - Conteúdo $\left(\mathrm{g} \mathrm{kg}^{-1}\right)$ e quantidade por área $\left(\mathrm{kg} \mathrm{ha}^{-1}\right)$ dos carboidratos estruturais (lignina, celulose e hemicelulose) da palhada dos sacos telados adicionados em soqueira (2007) simulando palhada pós colheita, após três ciclos consecutivos (2007 a 2009) 
Tal efeito pode ter sido encontrado neste trabalho e por Faroni et al. (2003) que obtiveram degradação de 47 a $62 \%$ da lignina quando os sacos telados foram mantidos sobre a palhada e sobre o solo, respectivamente. Por outro lado, Jensen et al. (2005) avaliando a decomposição de materiais vegetais de 37 espécies verificaram que, ao contrário de outros trabalhos, a degradação de resíduos vegetais está pouco relacionada ao conteúdo de $C$ na lignina $\left(R^{2} 0,44\right.$ a 0,51$)$ mas sim ao conteúdo de $C$ na holocelulose (celulose + hemicelulose), $R^{2}=0,73$ a 0,82 , respectivamente.

A degradação da hemicelulose foi idêntica nas duas situações a PPC e PAR e corrobora com os resultados de Oliveira et al. (1999). Estes autores concluíram que a maior perda de MS esteve relacionada à degradação da hemicelulose e do conteúdo celular da palhada. Os compostos mais resistentes à degradação (lignina e celulose) apresentaram pequena variação, provavelmente decorrentes à composição química da palhada das diferentes variedades de cana e condições climáticas durante os ciclos avaliados (COÛTEAUX; BOTTNER; BERG, 1995; ROBERTSON, 2003).

Notou-se a maior concentração $\left(\mathrm{g} \mathrm{kg}^{-1}\right)$ de raízes na palhada em 2008 (ano mais seco), embora a quantidade em $\mathrm{kg} \mathrm{ha}^{-1}$ tenha sido menor. Isso indicou a intensa decomposição da palhada, provavelmente devido a alta evapotranspiração daquele ano como aventado por Robertson e Thorburn (2007b).

As concentrações iniciais de $\mathrm{C}$ e dos macronutrientes na PPC (em g kg ${ }^{-1}$ ) foram: C: 440; N: 4,1; P: 0,3; K: 4,7; Ca: 3,4; Mg: 1,2 e S: 0,7. Durante o período avaliado, verificaram-se diferenças na concentração de nutrientes da palhada, ou seja, houve intensa liberação de K, enriquecimento de $\mathrm{N}, \mathrm{P}$ e $\mathrm{Ca}$, enquanto $\mathrm{Mg}$ e $\mathrm{S}$ permaneceram constantes (Tabela 35). Spain e Hodgen (1994) obtiveram teores mais elevados $\left(\mathrm{g} \mathrm{kg}^{-1}\right)$ de alguns componentes como o $\mathrm{N}: 4,4 ; \mathrm{P}: 0,7 ; \mathrm{K}: 11 ; \mathrm{S}: 1,5 \mathrm{e}$ menores de outros como o C: 420; $\mathrm{Ca}$ : 0,6; $\mathrm{Mg}$ : 0,4, respectivamente. Outra diferença marcante da palhada utilizada por estes autores e a PPC foi a elevada relação C:N de 170:1 contra 103:1 no presente trabalho. Abramo Filho (1995) encontraram C: 376; N: 4,8; P: 0,4; K: 3,7; Ca: 2,4; Mg: 1,1 e S: 0,8 (em g kg ${ }^{-1}$ ).

Conde, Penatti e Bellinaso (2005) encontraram concentrações de nutrientes nas folhas secas de quatro variedades de cana (em $\mathrm{g} \mathrm{kg}^{-1}$ ) N: 3,2; $\mathrm{P}: 0,2 ; \mathrm{K}: 3,4$; Ca: 0,42; Mg: 0,19 e S: 0,11. Gloria et al. (2000) obtiveram a composição da palhada da variedade RB72454 (em $\mathrm{g} \mathrm{kg}^{-1}$ ) como sendo: C: 410; N: 3,7; P: 0,44; K: 5,2; 
Ca: 3,0; Mg: 1,2 e S: 1,5. Ressaltaram que nos tratamentos (vasos) onde a palhada foi mantida na superfície, a decomposição foi mais acelerada e os nutrientes $\mathrm{K}$, Ca e $\mathrm{Mg}$ apresentaram liberação mais acentuada. A perda de $\mathrm{K}$ pela palhada após um período de 147 dias foi em média de $70 \%$, ressaltando a rapidez de liberação deste nutriente da palhada tão logo ocorra sua deposição ao solo (SPAIN; HODGEN, 1994; NG KEE KWONG et al., 1987).

A liberação dos macronutrientes para o solo $\left(\mathrm{em} \mathrm{kg} \mathrm{ha}^{-1} \mathrm{e} \%\right.$ da quantidade inicial) após os três ciclos avaliados foi: N: 12,7 (31\%); P: 0,7 (23\%); K: 43,1 (92\%); Ca: 18,2 (54\%), Mg: 8 (70\%); e S: 4,6 (66\%). Em média, a porcentagem de liberação de macronutrientes pela palhada pós colheita em três ciclos consecutivos foi de $56 \%$ sendo a maior liberação do K, 92\%, e a menor do P com 23\% (Tabela 35). Conde, Penatti e Bellinaso (2005) obtiveram os seguintes valores de liberação de nutrientes da palhada de cana-de-açúcar (em \% da quantidade original): N: $55 \%$; P: $5 \%$; K: $76 \%$; Ca: $55 \%$; Mg: $26 \%$ e S: $15 \%$.

As diferenças nos teores de $\mathrm{C}$ e macronutrientes deste e dos demais trabalhos da literatura podem estar relacionada às variedades utilizadas, ambiente de produção e condições climáticas no crescimento da cana-de-açúcar.

4.3.4 Degradação da palhada pós-colheita $\left(P P C-{ }^{15} \mathrm{~N}\right)$ nos tratamentos $80-0$ e 80 $150 \mathrm{~kg} \mathrm{ha}^{-1}$ de $\mathrm{N}$ em cana-planta e soqueiras, respectivamente, após três ciclos agrícolas consecutivos

Embora não tenham ocorrido diferenças estatísticas na degradação da matéria seca (MS) na palhada remanescente dos sacos telados quando se aplicou ou não $150 \mathrm{~kg} \mathrm{ha}^{-1}$ de $\mathrm{N}$ em soqueiras, houve tendência de decréscimo nos valores absolutos para a PPC que recebeu N-mineral (Tabela 36). Quando a palhada recebeu a aplicação de $\mathrm{N}$, a redução após um período de um ano na MS inicial foi de $51 \%$ enquanto que na testemunha sem aplicação de $\mathrm{N}$ a redução foi de $45 \%$. 
Tabela 36 - Composição isotópica de ${ }^{15} \mathrm{~N}(\%)$, teores $\left(\mathrm{g} \mathrm{kg}^{-1}\right)$ e quantidades $\left(\mathrm{kg} \mathrm{ha}^{-1}\right)$ de resíduos vegetais, carbono, carboidratos estruturais e macronutrientes da palhada de sacos telados simulando palhada pós colheita (PPC- $\left.{ }^{15} \mathrm{~N}\right)$ instalados nos tratamento $80-0$ e $80-150 \mathrm{~kg} \mathrm{~N} \mathrm{ha}^{-1}$ em cana-planta e soqueiras, respectivamente e após um ciclo (2006 a 2007)

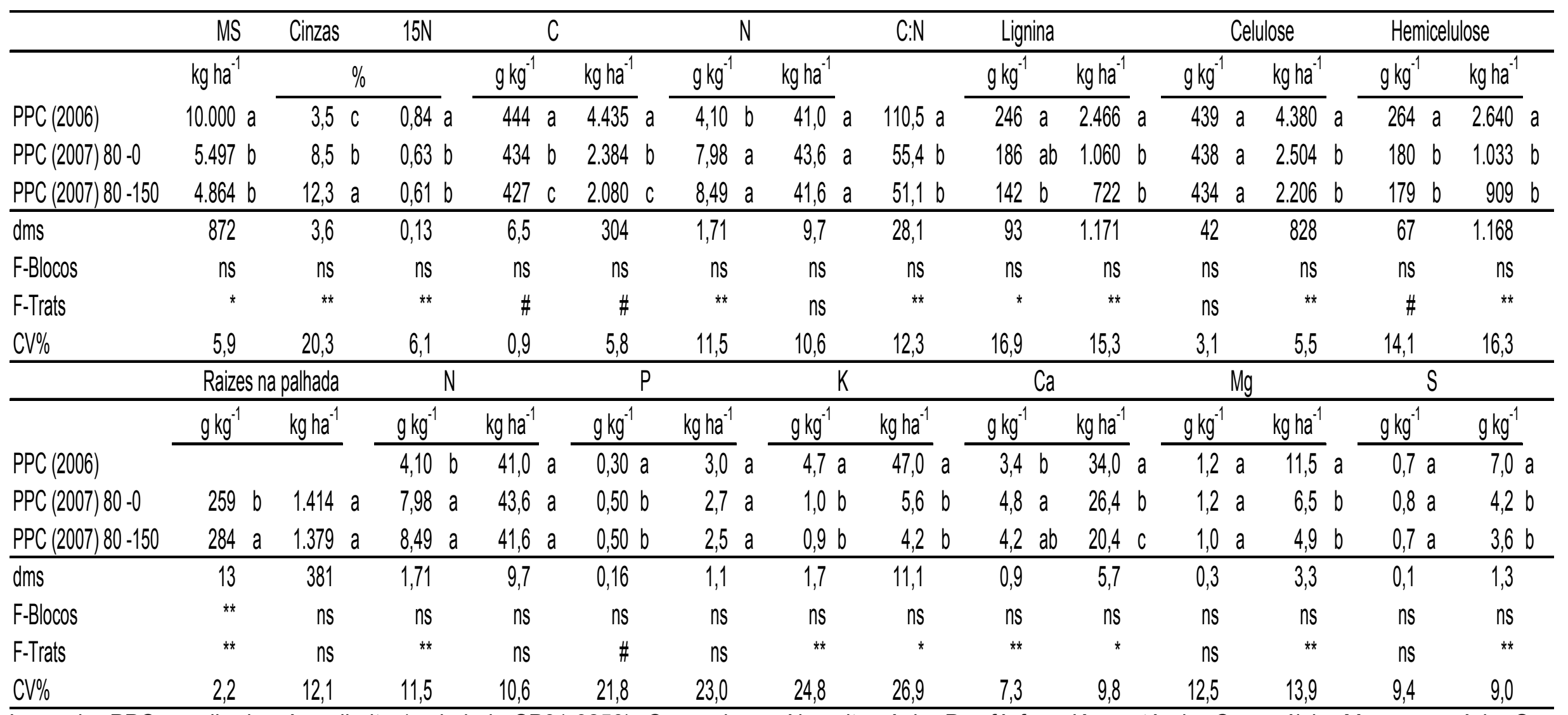

Legenda: PPC = palhada pós colheita (variedade SP81-3250); $\mathrm{C}=$ carbono; $\mathrm{N}=$ nitrogênio; $\mathrm{P}=$ fósforo, $\mathrm{K}=$ potássio; $\mathrm{Ca}=$ cálcio, $\mathrm{Mg}=\mathrm{magnésio;} \mathrm{S}=$ enxofre. 
Estes resultados estão coerentes com os de Bertol, Leite e Zoldan (2004) que obtiveram uma decomposição maior em palhada de milho quando aplicaram $100 \mathrm{~kg}$ $\mathrm{ha}^{-1}$ de $\mathrm{N}$ na forma de uréia sobre os resíduos. A redução na massa original $(8,8 \mathrm{Mg}$ ha $^{-1}$ ) foi de $53 \%$ quando se aplicou $\mathrm{N}$ e de $40 \%$ quando o resíduo não recebeu fertilizante, após 10 meses de avaliação. A relação $\mathrm{C}: \mathrm{N}$ do tratamento que não recebeu $\mathrm{N}$ foi $12 \%$ maior que o do adubado, indicando que a aplicação de $\mathrm{N}$ reduziu a relação C:N da palhada. Já no caso da palhada de cana deste trabalho (PPC) esta diferença foi de $8 \%$.

Por outro lado houve efeito significativo na concentração e na quantidade de carbono liberada por área, em $\mathrm{g} \mathrm{kg}^{-1} \mathrm{e} \mathrm{kg} \mathrm{ha-1}$, respectivamente (Tabela 36). Robertson (2003) ressaltou que a maior parte do $C$ contido em palhada de cana é eliminada (respirada) pela biomassa microbiana do solo e vai para a atmosfera na forma de $\mathrm{CO}_{2}$. Glória et al. (2000) obtiveram perdas de $\mathrm{CO}_{2}$ da palhada de cana incorporada ou sobre a superfície ao solo de 60 e $47 \%$ do total de $C$ contidos na palhada, respectivamente. Ressaltaram que nesse experimento de vaso, a perda do material orgânico original em cinco meses foi da ordem de $50 \%$.

Houve aumento significativo do teor de cinzas (\%) tanto da testemunha $(8,5 \%)$ quanto o tratamento que se aplicou $\mathrm{N}$ em soqueira $(12,3 \%)$. Isso pode ter ocorrido devido à incorporação de solo à palhada dos sacos telados após um ciclo, e devido à maior concentração de raízes $\left(\mathrm{g} \mathrm{kg}^{-1}\right)$ observada no tratamento $80-150$. Notou-se uma discreta diluição isotópica do ${ }^{15} \mathrm{~N}$ da palhada com tendência a ser maior para as doses maiores de $\mathrm{N}$ em cana-planta. $\mathrm{O}$ mesmo comportamento foi observado para o $\mathrm{N}$ adicionado ao solo via palhada $\left(\mathrm{kg} \mathrm{ha}^{-1}\right)$, ou seja, para $\mathrm{o}$ tratamento de $0 \mathrm{~kg} \mathrm{ha}^{-1}$ de $\mathrm{N}$ em soqueira houve menor mineralização do $\mathrm{N}$, embora sem diferenças estatísticas (Tabela 36 ).

Quanto aos carboidratos estruturais, observou-se degradação mais intensa somente para a lignina. Após o período de três ciclos e a quantidade que foi degradada deste composto foi de $24 \%$ onde não se aplicou $\mathrm{N}$ e de $42 \%$ onde se utilizou $150 \mathrm{~kg} \mathrm{ha}^{-1} \mathrm{de} \mathrm{N}$. Isso pode ter ocorrido uma vez que a hemicelulose já havia sido em parte consumida de maneira semelhante em ambos os tratamentos e a próxima fase seria a dos compostos mais resistentes ao ataque microbiano como a lignina (Tabela 36 e Figura 16).

Singh et al. (2008) observaram intensa degradação da lignina de $33 \%$ a $91 \%$ enquanto que a da celulose apresentou menor intensidade, $11 \%$ a $55 \%$, em 
experimento de incubação de palhada de cana com microrganismos celulolíticos durante 45 dias.

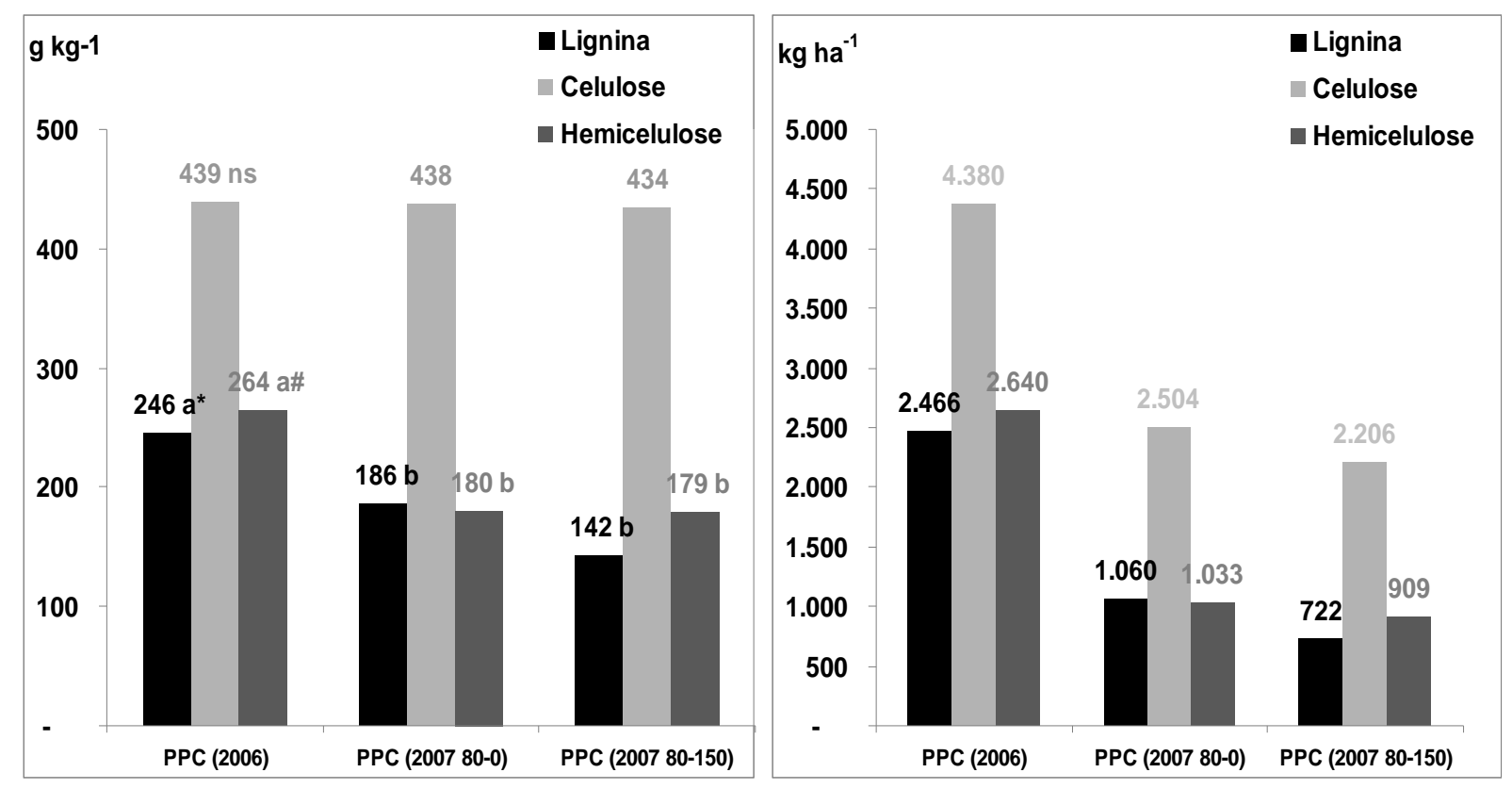

Figura 16 - Conteúdo $\left(\mathrm{g} \mathrm{kg}^{-1}\right)$ e quantidade por área $\left(\mathrm{kg} \mathrm{ha}^{-1}\right)$ dos carboidratos estruturais (lignina, celulose e hemicelulose) da palhada pós colheita após doses de $\mathrm{N}$ em soqueiras ( 80 e 0 e $80-150 \mathrm{~kg} \mathrm{~N}^{-1}$ ) e após três ciclos consecutivos e (2007 a 2009)

Não houve variação no teor $\left(\mathrm{g} \mathrm{kg}^{-1}\right)$ da celulose no período estudado e a mesma não foi influenciada pela aplicação de $\mathrm{N}$ em soqueira e se mantiveram praticamente constantes (Tabela 36 e Figura 16), como também constatado por Oliveira et al. (1999). Estes autores não observaram diferenças na decomposição da lignina, mas somente da hemicelulose.

Houve liberação significativa dos macronutrientes $\mathrm{P}, \mathrm{Ca}, \mathrm{Mg}$ e $\mathrm{S}$ da palhada original após um ciclo agrícola, independente do tratamento com e sem $\mathrm{N}$ em soqueira. $\mathrm{O} \mathrm{K}$ foi o que apresentou liberação mais significativa, em média $89 \%$, equivalente a 41,4 e 42,8 $\mathrm{kg} \mathrm{ha}^{-1}$ nos tratamentos sem e com aplicação de $\mathrm{N}$, respectivamente (Tabela 36). Esta intensa liberação foi devida a sua alta mobilidade e por este nutriente não fazer parte de componentes estruturais nem de compostos de alta estabilidade do tecido vegetal, não havendo, portanto necessidade de degradação da palhada para liberação do nutriente (NG KEE KWONG et al., 1987; SPAIN; HODGEN, 1994). 
Os macronutrientes de maneira geral não apresentaram diferenças estatísticas quanto a sua concentração no substrato $\left(\mathrm{g} \mathrm{kg}^{-1}\right)$ e liberação para o solo devido à aplicação de $\mathrm{N}$ em soqueira. Somente para o Ca houve diferença significativa e observou-se maior concentração deste nutrientes no conteúdo remanescente dos sacos telados. Houve liberação para o solo deste nutriente de $22 \%$ no tratamento sem aplicação de $N$ contra $40 \%$ quando se aplicou $\mathrm{N}$ em soqueira, isto é, liberação de 7,6 e 13,6 kg ha-1 de Ca respectivamente (Tabela 36). Spain e Hodgen (1994) observaram aumento dos teores de Ca da palhada de canade-açúcar após o período de ano no campo e correlações negativas entre a concentração deste nutriente e o conteúdo de lignina. Ressaltam que o enriquecimento com $\mathrm{Ca}$, bem como de outros elementos, pode estar relacionado ao enriquecimento da mesofauna do solo.

Este maior enriquecimento da palhada com Ca também pode ser explicado em parte pelo fato deste nutriente fazer parte do metabolismo da parede celular, e sua absorção ser sinérgica à disponibilidade de N (MALAVOLTA et al., 1997; PAULY; KEEGSTRA, 2008). Tal fato também se confirma devido à maior concentração de raízes $\left(\mathrm{g} \mathrm{kg}^{-1}\right)$ no tratamento que recebeu $150 \mathrm{~kg} \mathrm{~N} \mathrm{ha-1} \mathrm{em}$ soqueira (Tabela 36$)$.

Em média, a ordem de liberação dos nutrientes (\% da quantidade original em kg ha ${ }^{-1}$ ) foi: $\mathrm{K}: 89 \%>\mathrm{Mg}: 50 \%>\mathrm{S}: 44 \%>\mathrm{Ca}: 31 \%>\mathrm{P}: 13 \%$. Praticamente não houve liberação do $\mathrm{N}$ da palhada, mas até um ligeiro enriquecimento quando foi aplicado $\mathrm{N}$ em soqueiras (Tabela 36 ). Este resultado é coerente com os de Gloria et al. (2000) que não obtiveram resposta da adição de nitrogênio (dose $60 \mathrm{~kg} \mathrm{ha}^{-1}$ de N como nitrato de amônio) em vasos contendo palhada da variedade RB72454 num Latossolo Vermelho distrófico argiloso. Obtiveram uma decomposição média de $51 \%$ do material inicial após 147 dias, ou seja, praticamente a metade de um ciclo completo de cana-de-açúcar.

Coûteaux, Bottner e Berg (1995) elucidaram que a perda de massa dos restos vegetais segue dois processos fundamentais e simultâneos: a mineralização e humificação concomitantes da lignina, celulose e outros compostos por diferentes tipos de microrganismos e a lixiviação de compostos solúveis no perfil do solo, cujos C e $\mathrm{N}$ são ora mineralizados ora imobilizados. Na revisão os autores apontaram a evapotranspiração (temperatura e umidade) e o conteúdo de lignina como fatores chave nas taxas de degradação de resíduos vegetais em climas tropicais úmidos. 


\subsection{CONCLUSÕES}

Houve influência das doses de $\mathrm{N}$-mineral em cana-planta (PAR) e soqueiras (PPC) na decomposição da palhada dos sacos telados. As maiores diferenças foram notadas no conteúdo de MS e $\mathrm{C}$ e ocorreram principalmente devido à redução da relação C:N e do crescimento de raízes sob a palhada.

Os macronutrientes foram liberados de palhadas, em média, 94\% relativamente ao conteúdo inicial após quatro ciclos para a PAR e $56 \%$ para a PPC após três ciclos. As maiores liberações (\% da quantidade inicial dos nutrientes em $\mathrm{kg}$ ha $^{-1}$ ) foram do $\mathrm{K} 98 \%$ e $92 \%$; do $\mathrm{Mg} 97 \%$ e $70 \%$ e do Ca $95 \%$ e $55 \%$, aplicadas via PAR e PPC, respectivamente.

Os carboidratos estruturais lignina, celulose e hemicelulose apresentaram declínio ao longo dos ciclos, com redução dos seus teores $\left(\mathrm{g} \mathrm{kg}^{-1}\right)$ de $60 \%, 29 \%$ e $70 \%$ para a PAR e $47 \%$, 35\% e 70\% para a PPC, respectivamente.

As diferenças na degradação das palhadas PAR e PPC estiveram relacionadas às distintas variedades de cana-de-açúcar, condições climáticas durante os ciclos e aos teores de nutrientes totais presentes na palhada e, de maneira geral a degradação da MS da PPC não foi alterada devido à aplicação de $\mathrm{N}$ em soqueiras. Porém houve diferenças no conteúdo de cinzas, na liberação de $\mathrm{C}$, Ca e na decomposição da lignina. 


\section{CONSIDERAÇÕES FINAIS}

Com base nos resultados apresentados, foi possível chegar às seguintes conclusões gerais e implicações práticas:

1. Em situações desfavoráveis de condições climáticas ou econômicas (preço da cana, custos de produção e de insumos), a adubação nitrogenada não deve ser totalmente desconsiderada no manejo dos canaviais. Mesmo em solos com alto potencial de produção a fertilização com $\mathrm{N}$ mineral visa manter a longevidade do canavial;

2. A adubação nitrogenada em cana-planta e soqueiras em canavial colhido sem queima prévia da palhada proporcionou aumentos na produtividade agrícola $(\mathrm{TCH})$ e agroindustrial (TPH) da cana-de-açúcar durante os quatro ciclos agrícolas consecutivos (2006 a 2009). No acumulado dos quatro ciclos, os tratamentos que provaram os melhores resultados foram 120 - 100 e $40-150 \mathrm{~kg} \mathrm{ha}^{-1}$ de $\mathrm{N}$ em cana-planta e soqueiras, respectivamente. Já na análise econômica, o tratamento 120 - 50 foi o de melhor desempenho, ressaltando a importância da adubação com $\mathrm{N}$ no plantio especialmente sem solos de alto potencial produtivo (eutróficos e argilosos);

3. Os resultados econômicos foram influenciados significativamente pela $\mathrm{TCH}$ $\left(R^{2}=0,67\right)$ porém com maior intensidade pela TPH $\left(R^{2}=0,83\right)$. Isso ressalta a importância de se conhecer os ambientes de produção da unidade produtora para uma correta alocação varietal, o que otimiza sobremaneira a utilização dos insumos agrícolas seja fertilizantes, maquinários ou a própria mão de obra agrícola;

4. Embora a recuperação do $\mathrm{N}$-uréia pela cana-planta tenha sido considerada baixa ( $24,7 \mathrm{~kg} \mathrm{ha}^{-1}$ ou $31 \%$ da dose inicial aplicada) verificou-se que seu efeito perdurou pelos ciclos de soqueiras atingindo $34,3 \mathrm{~kg} \mathrm{ha}^{-1}(43 \%)$. Além disso, foi contabilizado no balanço de $\mathrm{N}$ que $20 \%\left(16 \mathrm{~kg} \mathrm{ha}^{-1}\right)$ do $\mathrm{N}$-uréia ainda permaneceu no solo após quatro ciclos, indicando que este $\mathrm{N}$ passou a fazer parte da matéria orgânica, micro e mesofauna do solo e poderá ser utilizado pela cultura em ciclos subsequentes;

5. A recuperação total do N-PAR e N-RAR foi de $21,6 \mathrm{~kg} \mathrm{ha}^{-1}$ após os quatro ciclos agrícolas avaliados. Este montante foi equivalente a $26 \%$ do total de $\mathrm{N}$ aplicado 
nesses resíduos (total de $84 \mathrm{~kg} \mathrm{ha}^{-1}$, somando-se N-PAR (51) + N-RAR (33), respectivamente). Segundo o balanço de N, o maior valor $42,6 \mathrm{~kg} \mathrm{ha}^{-1}$ (ou $51 \%$ ) permaneceu no solo como uma reserva ("pool") de $\mathrm{N}$ para a cultura e para a micro e meso fauna do solo;

6. A adubação nitrogenada em soqueira $\left(150 \mathrm{~kg} \mathrm{ha}^{-1}\right)$ realizada sobre a palhada de cana resultou em "primming effect", isto é, a aplicação de N-mineral aumentou a disponibilidade do $\mathrm{N}$ da palhada para recuperação da cultura, como elucidado por $\mathrm{Ng}$ Kee Kwong et al. (1987). Isto pode ser afirmado uma vez o aproveitamento do $\mathrm{N}-\mathrm{PPC}$ pela parte aérea da cultura praticamente dobrou quando comparado à testemunha sem $\mathrm{N}$;

7. É possível deduzir $40 \mathrm{~kg}$ de $\mathrm{K}_{2} \mathrm{O}$ das adubações minerais para cada 10 toneladas de palhada presente na superfície do solo, uma vez que contabilizou-se $37 \mathrm{~kg}$ deste nutriente para as $9 \mathrm{Mg} \mathrm{ha}^{-1}$ de palhada simulando a anterior a reforma (PAR) e $47 \mathrm{~kg}$ nas $10 \mathrm{Mg} \mathrm{ha}^{-1}$ da palhada simulando a pós colheita (PPC). Em média, $95 \%$ destes totais foram liberados para a cultura após os períodos avaliados. Portanto, devem ser continuadas as redes de experimentos para a recalibração da adubação NPK em cana crua como a publicada por Rossetto et al. (2010) e de outras instituições, levando em consideração os nutrientes contidos nos resíduos vegetais, com o objetivo de tornar a produção nacional cada vez mais competitiva e sustentável;

8. A decomposição da palhada de cana a longo prazo traz benefícios na nutrição da cultura, pois libera nutrientes e aumenta a fertilidade do solo. Além do $\mathrm{K}$, os nutrientes que foram liberados em maior quantidade pela PAR e PPC foram,

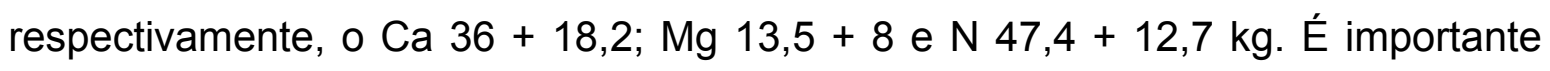
ressaltar que a produtividade de palhada é estritamente relacionada com a produção de colmos e que o benefício da palhada pode ser maior que o detectado neste trabalho uma vez que esses resíduos culturais são anualmente dispostos no agroecossistema reciclando nutrientes, além da manutenção da umidade e temperatura do solo em locais de alta evapotranspiração.

Nesse contexto, Liu et al. (2010) ressaltaram que em pesquisas recentes, em países subdesenvolvidos da África e da América do Sul, já ocorre "stress por falta de N", ou seja, este nutriente não é suficiente para atender a demanda nutricional da população desses países ( $\mathrm{N}<9 \mathrm{~kg}$ ano ${ }^{-1}$ per capita). Ressaltaram que somente $59 \%$ 
do $\mathrm{N}$ aplicado mundialmente é recuperado pelas culturas e resíduos vegetais. Portanto, $40 \%$ do $\mathrm{N}$ aplicado na agricultura é perdido nos ecossistemas o que representa alto potencial poluente e disperdício financeiro, uma vez que o $\mathrm{N}$ é o nutriente que consome maior energia fóssil na sua produção industrial.

Nesta linha, fica evidente a importância de trabalhos endereçados à conservação do solo, da água e de redução no consumo de fertilizantes minerais e combustíveis fósseis. Estes últimos são responsáveis por cerca de $50 \%$ dos custos de produção e das emissões de gases de efeito estufa, segundo Macedo, Seabra e Silva (2008). Portanto, em um sistema conservacionista de colheita mecanizada sem despalha a fogo e reforma de canavial sob cultivo mínimo (preparo reduzido), é esperado que ocorram menores perdas de $\mathrm{N}$ e que o consumo de diesel seja menor.

Finalmente, a aplicação de fertilizantes e resíduos culturais em ciclos subsequentes deverá promover um efeito residual de longo prazo e as doses de $\mathrm{N}$ atualmente utilizadas para a cultura poderão, possivelmente, ser reduzidas. Apesar disso, o $\mathrm{N}$-fertilizante é importante nos estágios iniciais de desenvolvimento da cultura, enquanto o $\mathrm{N}$ mineralizado do solo não é suficiente para atender a demanda da cultura, porém este deve ser aplicado racionalmente e com base em critérios técnicos, a fim que se evite a contaminação do ambiente e não se comprometa a viabilidade econômica da cultura. 


\section{REFERÊNCIAS}

ABIVEN, S.; RECOUS, S.; REYES, V.; OLIVER, R. Mineralisation of $C$ and $N$ from root, stem and leaf residues in soil and role of their biochemical quality Biology and Fertility of Soils, Berlin, v. 42, p. 119-128, 2005.

ABRAMO FILHO, J. Decomposição da palha de cana-de-açúcar em canavial colhido sem queima, mecanicamente. 199591 p. Dissertação (Mestrado em Biociências) - Instituto de Biociências, Universidade Estadual Paulista Julio de Mesquita Filho, Rio Claro, 1995.

ABRAMO FILHO, J.; MATSUOKA, S.; SPERANDIO, M.L.; RODRIGUES, R.C.D.; MARCHETTI, L.L. Resíduo da colheita mecanizada de cana crua. Álcool \& Açúcar, São Paulo, n. 67, p. 23-25, 1993.

ALLEN, R.G.; PEREIRA, L.S.; RAES, D.; SMITH, M. Crop evapotranspiration: guidelines for computing crop water requirements. Rome: FAO, 1998. 300 p. (FAO Irrigation and Drainage Paper, 56).

AMBROSANO, E.A.; TRIVELIN, P.C.O.; CANTARELLA, H.; AMBROSANO, G.M.B.; SCHAMMASS, E.A.; GUIRADO, N.; ROSSI, F.; MENDES, P.C.D.; MURAOKA, T. Utilization of nitrogen from green manure and mineral fertilizer by sugarcane. Scientia Agricola, Piracicaba, v. 62, p. 534-542, 2005.

AUSTIN, A.T.; BALLARÉ, C.L. Dual role of lignin in plant litter decomposition in terrestrial ecosystems Proceedings of the National Academy of Sciences of the USA, Washington, v. 107, n. 10, p. 4618-4622, 2010.

BALL-COELHO, B.; TIESSEN, H.; STEWART, J.W.B.; SALCEDO, I.H.; SAMPAIO, E.V.S.B. Residue management effects on sugarcane yield and soil properties in Northeastern Brazil. Agronomy Journal, Madison, v. 85, p. 1004-1008, 1993.

BARRIE, A.; PROSSER, S.J. Automated analysis of light-element stable isotopes by isotope ratio mass spectrometry. In: BOUTTON, T.W.; YAMSAHI, S. (Ed.). Mass spectrometry of soil. New York: Marcel Dekker, 1996. p. 1-46.

BASANTA, M.V.; DOURADO NETO, D.; REICHARDT, K.; BACCHI, O.O.S.; OLIVIERA, J.C.M.; TRIVELIN, P.C.O.; TIMM, L.C.; TOMINAGA, T.T.; CORRECHEL, V.; CÁSSARO, F.A.M.; PIRES, L.F.; MACEDO, J.R. Management effects on nitrogen recovery in a sugarcane crop grown in Brazil. Geoderma, Amsterdam, v. 116, n. 8, p. 235-248, 2003.

BELLINASO, I.F.; MORAES, E.E.; DONZELLI, J.L.; SILVA, P.C. Compactação de solos cultivados com cana-de-açúcar. In: SEMINÁRIO COPERSUCAR DE TECNOLOGIA AGRONÔMICA, 6., 1994, Piracicaba. Anais... Piracicaba: Copersucar, 1994. p. 3257-3267.

BERTOL, I.; LEITE, D.; ZOLDAN JUNIOR, W.A. Decomposição do resíduo de milho e variáveis relacionadas Revista Brasileira de Ciência do Solo, Viçosa, v. 28, p. 369-375, 2004. 
BODDEY, R.M.; URQUIAGA, S.; ALVES, B.J.R.; REIS, V. Endophitic nitrogen fixation in sugarcane: present knowledge and future applications. Plant and Soil, Dordrecht, v. 252, p. 139-149, 2003.

BOLOGNA-CAMPBELL, I. Balanço de nitrogênio e enxofre no sistema solocana-de-açúcar no ciclo de cana-planta. 2007. 112 p. Tese (Doutorado em Solos e Nutrição de Plantas) - Escola Superior de Agricultura Luiz de Queiroz, Universidade de São Paulo, Piracicaba, 2007.

BRASIL. Ministério da Agricultura, Pecuária e Abastecimento. Anuário estatístico da agroenergia. Brasília, DF, 2009. 161 p. Disponível em: http://www.agricultura.gov.br/images/MAPA/arquivos portal/anuario cana.pdf.

Acesso em: 13 Outubro 2009.

CANÇADO, J.E.D., SALDIVA, P.H.N., PEREIRA, L.A.A., LARA, L.B.L.S., ARTAXO, P., MARTINELLI, L.A., ARBEX, M.A., ZANOBETTI, A., BRAGA, A.L.F. The impact of sugar cane-burning emissions on the respiratory system of children and the elderly. Environmental Health Perspectives, Research Triangle Park, v. 114, p. 725-729, 2006.

CANTARELLA, H.; TRIVELIN, P.C.O.; VITTI, A.C. Nitrogênio e enxofre na cultura da cana-de-açúcar. In: YAMADA, T.; ABDALLA, S.R.S.; VITTI, G.C. (Ed.). Nitrogênio e enxofre na agricultura brasileira. Piracicaba: IPNI Brasil, 2007. cap. 12, p. 407464.

CARNEIRO, A.E.V.; TRIVELIN, P.C.O.; VICTORIA, R.L. Utilização da reserva orgânica e de nitrogênio do tolete de plantio (colmo-semente) no desenvolvimento da cana-planta. Scientia Agricola, Piracicaba, v. 53, n. 2, p. 199-209, 1995.

CARVALHO, A.M.; BUSTAMANTE, M.M.C.; SOUSA JUNIOR, J.G.A.; VIVALDI, L.J. Decomposição de resíduos vegetais em latossolo sob cultivo de milho e plantas de cobertura. Revista Brasileira de Ciência do Solo, Viçosa, v. 32, n. esp., p. 28312838, 2008.

CENTRO DE GESTÃO E ESTUdOS ESTRATÉGICOS - CGEE. Bioetanol combustível: uma oportunidade para o Brasil - Brasília, DF, 2009. 536 p.

CESAR, M.A.; SILVA, F.C. A cana-de-açúcar como matéria-prima para a indústria sucroalcooleira. Piracicaba: ESALQ, 1993. 108 p.

CHAPOLA, R.G.; HOFFMANN, H.P.; BASSINELLO, A.I.; FERNANDES JUNIOR, A.R.; BRUGNARO, C.; ROSA, J.R.B.F.; VIEIRA, M.A.S.; SCHIAVINATO, S.R. Censo varietal de cana-de-açúcar de São Paulo, Mato Grosso e Mato Grosso do Sul STAB. Açúcar, Álcool e Subprodutos, Piracicaba, v. 28, n. 4, p. 34-37, 2010.

CHAPMAN, L.S.; HAYSOM, M.B.C.; SAFFIGNA, P.G. N cycling in cane fields from ${ }^{15} \mathrm{~N}$ labelled trash and residual fertilizer. In: AUSTRALIAN SOCIETY OF SUGAR CANE TECHNOLOGISTS, 14., 1992, Brisbane. Proceedings... Brisbane: Watson Ferguson, 1992. p. 84-89. 
CHAPMAN, L.S.; HAYSOM, M.B.C.; SAFFIGNA, P.G. The recovery of ${ }^{15} \mathrm{~N}$ from labeled urea fertilizer in crop components of sugarcane and in soil profiles. Australian Journal of Agricultural Research, Melbourne, v. 45, p. 1577-1585, 1994.

CHAVES, I. TATRHA Gerenciamento de Custos STAB. Açúcar, Álcool e Subprodutos, Piracicaba, v. 25, n. 4, p. 12-14, 2007.

COLETI, J.T.; CASAGRANDE, J.C.; STUPIELLO, J.J.; RIBEIRO, L.D.; OLIVEIRA, G.R. Remoção de macronutrientes pela cana-planta e cana-soqueira em Argissolos, variedades RB835486 e SP813250. STAB. Açúcar, Álcool e Subprodutos, Piracicaba, v. 24, n. 5, p. 32-36, 2006.

CONDE, A.J.; PENATTI, C.P.; BELLINASO, I.F. Impacts on soil. In: HASSUANI, S.J.; LEAL, M.R.L.V.; MACEDO, I.C. Biomass power generation. Sugar cane bagasse and trash. CD-ROM. Piracicaba: PNUD-CTC, 2005. 217 p. (Série Caminhos para Sustentabilidade).

COPERSUCAR. Quinta geração de variedades de cana-de-açúcar. Piracicaba: Copersucar, 1995. (Boletim Técnico).

CONSELHO DOS PRODUTORES DE CANA-DE-AÇÚCAR, AÇÚCAR E ÁLCOOL DO ESTADO DE SÃO PAULO - CONSECANA-SP. Manual de Instruções. 5. ed. Piracicaba: CONSECANA, 2006. $112 \mathrm{p}$.

COÛTEAUX, M.M.; BOTTNER, P.; BERG, B. Litter decomposition, climate and litter quality. Trends in Ecology \& Evolution, Cambridge, v. 10, n. 2, 1995.

DEMATTÊ, J.L.I. Recuperação e manutenção da fertilidade dos solos. Visão Agrícola, Piracicaba, v. 1, p. 48-59, 2004.

DINARDO-MIRANDA, L.L.; FERREIRA, J.M.G.; CARVALHO, P.A.M. Influência da época de colheita e do genótipo de cana-deaçúcar sobre a infestação de Mahanarva fimbriolata (Stal) (Hemiptera:Cercopidae). Neotropical Entomology, Londrina, v. 30, n. 1, p. 145-149, 2001.

EMBRAPA. Sistema brasileiro de classificação de solos. 2. ed. Brasília: Embrapa Informação Tecnológica, 2006. v. 1, 306 p.

ESPIRONELLO, A.; RAIJ, B.; PENATTI, C.P.; CANTARELLA, H.; MORELLI, J.L.; ORLANDO FILHO, J.; LANDELL, M.G.A.; ROSSETTO, R. Cana-de-açúcar. In: RAIJ, B.; CANTARELLA, H.; QUAGGIO, J.A.; FURLANI, A.M.C. (Ed.). Recomendações de adubação e calagem para o Estado de São Paulo. Campinas: Fundação IAC, 1996. p. 237-239. (Boletim, 100).

O ESTADO DE SAO PAULO. Entenda como a crise econômica afeta o Brasil. 0 Estado de São Paulo, São Paulo, 18 set. 2008. Economia. Disponível em: http://www.estadao.com.br/economia/not_eco244262,0.htm. Acesso em: 10 maio 2010. 
FARONI, C.E. Eficiência agronômica das adubações nitrogenadas de plantio e após o primeiro corte avaliada na primeira soqueira da cana-de-açúcar. 2008. 191 p. Tese (Doutorado em Solos e Nutrição de Plantas) - Escola Superior de Agricultura "Luiz de Queiroz", Universidade de São Paulo, Piracicaba, 2008.

FARONI, C.E.; TRIVELIN, P.C.O.; SILVA, P.H.; BOLOGNA, I.R.; VITTI, A.C.; FRANCO, H.C.J. Marcação da Fitomassa de cana-de-açúcar com aplicação de solução de uréia marcada com ${ }^{15} \mathrm{~N}$. Pesquisa Agropecuária Brasileira, Brasília, v. 42, p. 1-7, 2007.

FARONI, C.E.; VITTI, A.C.; GAVA, G.J.C.; MANZONI, C.S.; PENATTI, C.P.; TRIVELIN, P.C.O. Degradação da palha $\left({ }^{15} \mathrm{~N}\right)$ de cana-de-açúcar em dois anos consecutivos. In: CONGRESSO BRASILEIRO DE CIÊNCIA DO SOLO, 29., 2003, Ribeirão Preto. Anais... Ribeirão Preto: UNESP; SBCS, 2003. 1 CD-ROM.

FERNANDES, A.C. Cálculos na agroindústria de cana-de-açúcar. 2. ed. Piracicaba: STAB, 2003. 240 p.

FERREIRA, D.F. Manual do sistema Sisvar para análises estatísticas. Lavras: UFLA, Departamento de Ciências Exatas, 2000. 66 p.

FIORIN, C.E. Excesso de chuva prejudica a qualidade da cana nesta safra. Canavieiro Paulista, Piracicaba, n. 120 p. 6, 2009. Disponível em: http://www.cana.com.br/Canavieiro\%20Paulista\%20-\%20Setembro\%20\%20Outubro\%202009.pdf. Acesso em: 10 maio 2010.

FOLHA ONLINE. Petróleo crava novo recorde e fecha acima de US\$145 em NY. Folha Online, São Paulo, 3 jul. 2008. Dinheiro. Disponível em: http://www1.folha.uol.com.br/folha/dinheiro/ult91u418916.shtml. Acesso em: 10 maio 2010.

FONSECA, M.B.; SUÁREZ RODRÍGUEZ, J.A.; BOIZÁN, M.F. Elaboración de una metodología para el estudio experimental de la digestión anaerobia de agroresiduos en particular residuos cañeros. In: SEMINÁRIO EURO LATINOAMERICANO DE SISTEMAS DE INGINIERÍA, 5., 2009, Quito,Ecuador. Anais... Quito, Ecuador: Escuela Politécnica Nacional, 2009. Disponível em: http://biee.epn.edu.ec.

FORTES, C.; TRIVELIN, P.C.O.; VITTI, A.C.; FERREIRA, D.A.; FRANCO, H.C.J.; OTTO, R. Recovery of nitrogen $\left({ }^{15} \mathrm{~N}\right)$ by sugarcane from previous crop residues and urea fertilisation under minimum tillage system In: INTERNATIONAL SOCIETY OF SUGARCANE TECHNOLOGISTS CONGRESS , 27., 2010, Veracruz, Mexico, 2010. Proceedings... Vera Cruz, Mexico: ISST, 2010. 1 CD-ROM.

FORTES, C.; CAMPOS, L.H.F.; SILVA, J.S. Yield response of sugarcane ratoons after trash management systems in two sites of central São Paulo State, Brazil. In: INTERNATIONAL SOCIETY OF SUGARCANE TECHNOLOGISTS AGRONOMY WORKSHOP, 30., 2009, Uberlândia. Proceedings... Uberlândia: ISST, 2009. 1 CDROM. 
FORTES, C.; TRIVELIN, P.C.O.; SIMÕES, M.S.; PENATTI, C.P. Volatilização de amônia da uréia, aplicada em solo coberto por palhada, em época seca e produtividade de cana soca. In: CONGRESSO NACIONAL DA STAB, 9., 2008, Maceió. Anais... Macéio: STAB, 2008. 1 CD-ROM.

FRANCO, H.C.J. Eficiência agronômica da adubação nitrogenada de canaplanta. 2008. 112 p. Tese (Doutorado em Solos e Nutrição de Plantas) - Escola Superior de Agricultura "Luiz de Queiroz", Universidade de São Paulo, Piracicaba, 2008.

FRANCO, H.C.J.; TRIVELIN, P.C.O.; FARONI, C.E.; OTTO, R.; VITTI, A.C.; OLIVEIRA, E.C.A. Nitrogen in sugarcane derived from fertilizer. In: INTERNATIONAL SOCIETY OF SUGARCANE TECHNOLOGISTS CONGRESS, 27., Vera Cruz, Mexico. Proceedings... Veracruz, Mexico: ISST 2010. 1 CD-ROM.

FRANCO, H.C.J.; VITTI, A.C.; FARONI, C.E.; CANTARELLA, H.; TRIVELIN, P.C.O. Estoque de nutrientes em resíduos culturais incorporados ao solo na reforma de áreas com cana-de-açúcar. STAB. Açúcar, Álcool e Subprodutos, Piracicaba, v. 25, n. 6, p. 32-36, 2007.

GALDOS, M.V.; CERRI, C.C.; CERRI, C.E.P. Soil carbon stocks under burned and unburned sugarcane in Brazil. Geoderma, Amsterdam, v. 153, p. 347-352, 2009a.

GALDOS, M.V.; CERRI, C.C.; CERRI, C.E.P.; PAUSTIAN, K.; VAN ANTWERPEN, $\mathrm{R}$. Simulation of sugarcane residue decomposition and aboveground growth. Plant and Soil, Dordrecht, v. 326, p. 243-259, 2010. DOI 10.1007/s11104-009-0004-3.

GAVA; G.J.C.; TRIVELIN, P.C.O.; VITTI. A.C.; OLVEIRA, M.W. Urea and sugarcane straw nitrogen balance in a soil-sugarcane crop system. Pesquisa Agropecuária Brasileira, Brasília, v. 40, n. 7, p. 689-695, 2005.

GLORIA, N.A.; MATTIAZO, M.E.; OLIVEIRA, F.C.; OLIVEIRA, L.M.C.P. Decomposição e liberação de nutrientes pelos resíduos da colheita de cana-deaçúcar, colhida sem queimar. STAB. Açúcar, Álcool e Subprodutos, Piracicaba, v. 19 , n. 1, p. 30-33, 2000.

GONÇALVES, S.L.; SARAIVA, O.F.; FRANCHINI, J.C.; TORRES, E. Decomposição de resíduos de milho e soja em função do tempo e do manejo do solo. Londrina: Embrapa Soja, 2010. (Boletim de Pesquisa e Desenvolvimento, $3)$.

GRAHAM, M.H.; HAYNES, R.J.; MEYER, J.H. Soil organic matter content and quality: effects of fertilizer applications, burning and trash retention on long-term sugarcane experiment in South Africa. Soil Biology \& Biochemistry, Oxford, v. 34, p. 93-102, 2002.

HEMWONG, S.; TOOMSAN, B.; CADISCH, G.; V. LIMPINUNTANA, V.; VITYAKON, $P$.; PATANOTHAI, A. Sugarcane residue management and grain legume crop effects on $\mathrm{N}$ dynamics, $\mathrm{N}$ losses and growth of sugarcane Nutrient Cycling in Agroecosystems, Dordrecht, v. 83, p. 135-151, 2009. 
JADHAV, S.B. Effect of incorporation of sugarcane trash on cane productivity and soil fertility. In: INTERNATIONAL SOCIETY OF SUGAR CANE TECHNOLOGISTS CONGRESS, 22., 1995, Cartagena, Colombia. Proceedings... Cali: Tecnicanã, 1996. r. 2.

JANK, M.S. Resultados do Protocolo Ambiental da Cana-de-Açúcar. (Apresentações). São Paulo: União da Indústria de Cana-de-Açúcar - UNICA, 2009. Disponível em: http://www.unica.com.br. Acesso em: 20 jan. 2010.

JENSEN, L.S.; SALO, T.; PALMASON, F.; BRELAND, T.A.; HENRIKSEN, T.M.; BO STENBERG, B.; PEDERSEN, A.; LUNDSTROM, C.; ESALA, M. Influence of biochemical quality on $\mathrm{C}$ and $\mathrm{N}$ mineralization from a broad variety of plant materials in soil. Plant and Soil, Dordrecht, v. 273, p. 307-326, 2005.

KHAN, S.A.; MULVANEY, R.L.; ELLSWORTH, T.R.; BOAST, C.W. The myth of nitrogen fertilization for soil carbon sequestration. Journal of Environmental Quality, Madison, v. 36, p. 1821-1832, 2007.

KORNDÖRFER, G.H.; VALLE, M.R.; MARTINS, M.; TRIVELIN, P.C.O. Aproveitamento do nitrogênio da uréia pela cana-planta. Revista Brasileira de Ciência do Solo, Viçosa, v. 21, p. 23-26, 1997.

KORNDÖRFER, G.H.; MARTINS, M. Importância da adubação na qualidade da cana-de-açúcar. STAB. Açúcar, Álcool e Subprodutos, Piracicaba, v. 10, n. 3, p. 26-31, 1992.

KORNDORFER, G.H.; COLOMBO, C.; CHIMELLO, M.A.; LEONE, P.L.C. Desempenho de variedades de cana-de-açúcar cultivadas com e sem nitrogênio STAB. Açúcar, Álcool e Subprodutos, Piracicaba, v. 20, n. 3, p. 28-31, 2002.

KUMAR, K.; GOH, K.M.; SCOTT, W.R.; FRAMPTON, C.M. Effects of ${ }^{15} \mathrm{~N}$-labelled crop residues and management practices on subsequent winter wheat yields, nitrogen benefits and recovery under field conditions. Journal of Agricultural Science, Cambridge, v. 136, p. 35-53, 2001.

LIU, J.; YOU, L.; AMINI, M.; OBERTSTEINER, M.; HERRERO, M.; ZEHNDER, A.J.B.; YANG, H. A high-resolution assessment on global nitrogen flows in cropland Proceedings of the National Academy of Sciences of USA, Washington, v. 107, n. 17 , p. $8035-8040,2010$.

LUCA, E.F.; FELLER, C.; CERRI, C.C.; BARTHĖS, B.; CHAPLOT, V. CAMPOS, D.C.; MANECHINI, C. Avaliação de atributos físicos e estoques de carbono e nitrogênio em solos com queima e sem queima de canavial Revista Brasileira de Ciência do Solo, Viçosa, v. 32, p. 789-800, 2008.

MACEDO, I.C.; SEABRA, J.E.A.; SILVA, J.E.A.R. Green house gases emissions in the production and use of ethanol from sugarcane in Brazil: the 2005/2006 averages and a prediction for 2020. Biomass and Bioenergy, Amsterdam, v. 32, p. 582-595, 2008. 
MALAVOLTA, E.; MORAES, M.F. Fundamentos do nitrogênio e do enxofre na nutrição mineral das plantas cultivadas. In: YAMADA, T.; ABDALLA, S.R.S.; VITTI, G.C. (Ed.). Nitrogênio e enxofre na agricultura brasileira. Piracicaba: IPNI Brasil, 2007. cap. 6, p. 189-249.

MALAVOLTA, E. Fertilizing for high yield sugarcane. Basel: International Potash Institute, 1994. 104 p. (Bulletin 14).

MALAVOLTA, E.; VITTI, G.C.; OLIVEIRA, S.A. Avaliação do estado nutricional de plantas. 2. ed. Piracicaba: Potafos, 1997. 319 p.

MANECHINI, C. Manejo agronômico da cana crua. In: SEMINÁRIO COPERSUCAR DE TECNOLOGIA AGRONÔMICA, 7., 1997, Piracicaba. Anais... Piracicaba: Copersucar, 1997. p. 309-327.

MANECHINI, M.; RICCI JÚNIOR, A.; DONZELLI, J.L. Benefits and problems of trash left in the field. In: HASSUANI, S.J.; LEAL, M.R.L.V.; MACEDO, I.C. Biomass power generation. Sugar cane bagasse and trash. 1 CD-Rom. Piracicaba: PNUDCTC, 2005. 217 p. (Série Caminhos para Sustentabilidade).

MEIER, E.A.; THORBURN, P.J.; WEGENER, M.K.; BASFORD, K.E. The availability of nitrogen from sugarcane trash on contrasting soils in the wet tropics of North Queensland. Nutrient Cycling in Agroecosystems, Dordrecht, v. 75, p. 101-114, 2006.

MYERS, R.J.K.; PALM, C.A.; CUEVAS, E.; GUNATILLEKE, I.U.N.; BROSSARD, M. The synscronization of nutrient mineralization and plant nutrient demand. In: WOOMER, P.L.; SWIFT, M.J. (Ed.). The biological management of soil fertility. New York: Wiley-Sayce 1994. p. 81-116.

NG KEE KWONG, K.F.; DEVILLE, J. The course of fertilizer nitrogen uptake by rain fed sugarcane in Mauritius. Journal of Agricultural Science, Cambridge, v. 122, p. 385-391, 1994.

NG KEE KWONG, K.F.; DEVILLE, J.; CAVALOT, P.C.; RIVIERE, V. Value of cane trash in nitrogen nutrition of sugarcane. Plant and Soil, Dordrecht, v. 102, p. 79-83, 1987.

OLIVEIRA, M.W.; BARBOSA, M.H.P.; MENDES, L.C.; DAMASCENO, C.M. Matéria seca e nutrientes na palhada de dez variedades de cana-de-açúcar STAB. Açúcar, Álcool e Subprodutos, Piracicaba, v. 21, n. 3, p. 30-31, 2003.

OLIVEIRA, M.W.; TRIVELIN, P.C.O.; KINGSTON, G.; BARBOSA, M.H.P.; VITTI, A.C. Decomposition and release of nutrients from sugarcane trash in two agricultural environments in Brazil. In: AUSTRALIAN SOCIETY OF SUGAR CANE TECHONOLOGISTS, 24., 2002, Cairns. Proceedings... Cairns: D.M. Hogarth, 2002. p. 40. 
OLIVEIRA, M.W.; TRIVELIN, P.C.O.; PENATTI, C.P.; PICCOLLO, M.C. Decomposição e liberação de nutrientes da palhada de cana-de-açúcar em campo. Pesquisa Agropecuária Brasileira, Brasília, v. 34, p. 2359-2362, 1999.

ORLANDO FILHO, J.; CARMELLO, Q.A.C.; PEXE, C.A.; GLÓRIA, A.M. Adubação de soqueiras de cana-de-açúcar sob dois tipos de despalha: cana crua $\mathrm{x}$ cana queimada. STAB. Açúcar, Álcool e Subprodutos, Piracicaba, v. 1, n. 4, p. 7-11, 1994.

ORGANIZAÇÃO DE PLANTADORES DE CANA DA REGIÃO CENTRO SUL DO BRASIL - ORPLANA. Custos de Produção, Piracicaba, SP, 2010. Disponível em: http://www.oricana.com.br/orplana/login.php?pagina=/orplana/custos.php. Acesso em: 15 maio 2010.

ORLANDO FILHO, J.; RODELLA, A.A.; BELTRAME, J.A.; LAVORENTI, N.A. Doses, fontes e formas de aplicação de nitrogênio em cana-de-açúcar. STAB. Açúcar, Álcool e Subprodutos, Piracicaba, v. 17, n. 4, p. 39-41, 1999.

OTTO, R.; OLIVEIRA, E.C.A.; FRANCO, H.C.J.; MARIANO, E. SARTORI, R.H.; FORTES, C.; TRIVELIN, P.C.O.; VITTI, A.C. Atributos químicos de solos cultivados com cana-de-açúcar em ciclos consecutivos e sob níveis de fertilização nitrogenada In: CONGRESSO BRASILEIRO DE CIÊNCIA DO SOLO, 32., 2009, Fortaleza. Anais... Fortaleza: SBCS, 2009a.

OTTO, R.; TRIVELIN, P.C.O.; FRANCO, H.C.J.; FARONI, C.E.; VITTI, A.C. Root system distribution of sugar cane as related to nitrogen fertilization, evaluated by two methods: monolith and probes. Revista Brasileira de Ciência do Solo, Viçosa, v. 33, p. 601-611, 2009b.

PAULY, M.; KEEGSTRA, K. Cell-wall carbohydrates and their modification as a resourcefor biofuels. The Plant Journal, Oxford, v. 54, p. 559-568, 2008.

PENATTI, C.P.; FORTI, J.A. Doses de vinhaça versus doses de nitrogênio em canasoca. In: SEMINÁRIO DE TECNOLOGIA AGRONÔMICA, 7., 1997, Piracicaba. Anais... Piracicaba: Copersucar, 1997. p. 328-339.

PIRES, A. O mercado e o preço do álcool. AgroAnalysis, São Paulo, v. 26, n.6, jun. $2006 . \quad$ Disponível em: http://www.agroanalysis.com.br/index.php?area=conteudo\&esp_id=3\&from=especial \&epc_id=7. Acesso em: 10 maio 2010.

PLANALSUCAR. Cultivo mínimo para cana-de-açúcar. Boletim Técnico Planalsucar, Piracicaba, v. 6, n. 1, p. 5-42, 1985.

PRADO, R.M.; PANCELLI, M.A. Resposta de soqueiras de cana-de-açúcar à aplicação de nitrogênio em sistema de colheita sem queima. Bragantia, Campinas, v. 67, n. 4, p. 951-959, 2008. 
RAIJ, B. van; CANTARELLA, H.; QUAGGIO, J.A.; FURLANI, A.M.C. Recomendações de adubação e calagem para o Estado de São Paulo. 2. ed. Campinas: Instituto Agronômico; Fundação IAC, 1997. 285 p.

RAIJ, B. van; ANDRADE, J.C.; CANTARELLA, H.; QUAGGIO, J.A.. (Ed.). Análise química para avaliação da fertilidade de solos tropicais. Campinas: Instituto Agronômico de Campinas, 2001. 285 p.

RESENDE A.S.; XAVIER, R.P.; OLIVEIRA, O.C.; URQUIAGA, S.; ALVES, B.J.R.; BODDEY, R.M. Long-term effects of pre-harvest burning and nitrogen and vinasse applications on yield of sugar cane and soil carbon and nitrogen stock on a plantation in Pernambuco, NE Brazil. Plant and Soil, Dordrecht, v. 281, p. 339-351, 2006.

ROBERTSON, F. Sugarcane trash management: consequences for soil carbon and nitrogen. Final Report to the CRC for Sustainable Sugar Production of the project Nutrient Cycling in Relation to Trash Management. Townville: CRC for Sustainable Sugar Production, 2003.

ROBERTSON, F.A.; THORBURN, P.J. Decomposition of sugarcane harvest residue in different climatic zones. Australian Journal of Soil Research, Melbourne, v. 45, p. 1-11, 2007a.

ROBERTSON, F.A.; THORBURN, P.J. Management of sugarcane harvest residues: consequence for soil carbon and nitrogen. Australian Journal of Soil Research, Melbourne, v. 45, p. 13-23, 2007b.

ROLIM, G.S.; SENTELHAS, P.C.; BARBIERI, V. Planilhas no ambiente EXCELTM para os cálculos de balanços hídricos: normal, sequencial, de cultura e de produtividade real e potencial. Revista Brasileira de Agrometeorologia, Santa Maria, v. 6, n. 1, p. 133-137, 1998.

ROLIM, G.S.; CAMARGO, M.B.P.; LANIA, D.G.; MORAES, J.F.L. Classificação climática de Köppen e de Thornthwaite e sua aplicabilidade na determinação de zonas agroclimáticas para o estado de São Paulo. Bragantia, Campinas, v. 66, n. 4, p. 711-720, 2007.

ROSSETTO, R.; DIAS, F.L.F.; LANDELL, M.G.A.; CANTARELLA, H.; TAVARES, S.; VITTI, A.C.; PERECIN, D. $N$ and $K$ fertilisation of sugarcane rations harvested without burning. In: INTERNATIONAL SOCIETY OF SUGAR CANE TECHNOLOGISTS CONGRESS, 27., 2010, Veracruz, Mexico. Proceedings... Veracruz, Mexico: D.M. Hogarth, 2010. 1 CD-ROM.

SANOMIYA, L.T.; ASSIS, L.C.; OLIVEIRA, J.A.; NAHAS, E. Mineralización de la paja de caña de azúcar en suelo adicionado con viñaza (subproducto de la industria del alcohol de caña de azúcar) y fertilizante nitrogenado. Agricultura Técnica, Santiago, Chile, v. 66, n. 1, p. 90-97, 2006.

SILVA, D.J.; QUEIROZ, A.C. Análise de alimentos: métodos químicos e biológicos. 3. ed. Viçosa: UFV, 2006. 235 p. 
SILVA, P.A. Avaliação da qualidade técnica e econômica do preparo de solo para plantio de cana-de-açúcar. 2010. Monografia (Especialização em Solos e Nutrição de Plantas) - Escola Superior de Agricultura "Luiz de Queiroz", Universidade de São Paulo, Piracicaba, 2010.

SINGH, P.; SUMAN, A.; TIWARI, P.; ARYA, N.; GAUR, A.; SHRIVASTAVA, A.K. Biological pretreatment of sugarcane trash for its conversion to fermentable sugars. World Journal of Microbiology and Biotechnology, Oxford, v. 24, p. 667-673, 2008.

SIQUEIRA, J.O.; FRANCO, A.A. Biotecnologia do solo: fundamentos e perspectivas. Brasília: MEC; ABEAS; ESAL; FAEPE, 1988. 236 p.

SMITH D.M.; INMAN-BAMBER N.G.; THORBURN, P.J. Growth and function of the sugarcane root system. Field Crops Research, Amsterdam, v. 92, p. 169-183, 2005.

STOLF, R. Metodologia de avaliação de falhas nas linhas de cana-de-açúcar. STAB. Açúcar, Álcool e Subprodutos, Piracicaba, v. 4, n. 6, p. 22-36, 1986.

THORBURN, P.J.; PROBERT, M.E.; LISSON, S.; WOOD, A.W.; KEATING, B.A. Impacts of trash retention on soil nitrogen and water: an example from the Australian sugarcane industry. Proceedings of the South Africa Sugar Technologists Association, Johannesburg, v. 73, p. 75-79, 1999.

THORNTHWAITE, C.W.; MATHER, J.R. The water balance. Centerton, NJ: Drexel Institute of Technology, Laboratory of Climatology, 1955. 104 p. (Publications in Climatology, v. 8, n. 1).

TREVETHAN, N.; BROUGH, D. Preços das commodities têm melhor ano desde 1973. Estadão.com.br, São Paulo, 31 dez. 2009. Disponível em: http://www.estadao.com.br/estadaodehoje/20100101/not_imp489238,0.php. Acesso em: 10 maio 2010.

TRIVELIN, P.C.O. Rendimento da cana-de-açúcar em ciclos consecutivos associado ao efeito residual e às transformações de $\mathrm{N}$ e $\mathrm{S}$ no solo, em sistema conservacionista. Primeiro Relatório Científico - Projeto Temático. São Paulo: FAPESP, 2005. (Processo n ${ }^{\circ}$. 2002/10.534-8).

TRIVELIN, P.C.O.; RODRIGUES, J.C.S.; VICTORIA, R.L. Utilização por soqueira de cana-de-açúcar de início de safra do nitrogênio da aquamônia- ${ }^{15} \mathrm{~N}$ e uréia- ${ }^{15} \mathrm{~N}$ aplicado ao solo em complemento à vinhaça. Pesquisa Agropecuária Brasileira, Brasília, v. 31, n. 2, p. 89-99, 1996.

TRIVELIN, P.C.O.; LARA CABEZAS, W.A.R.; VICTORIA, R.L.; REICHARDT, K. Evaluation of a ${ }^{15} \mathrm{~N}$ plot design for estimating plant recovery of fertilizer nitrogen applied to sugar cane. Scientia Agricola, Piracicaba, v. 51, n. 2, p. 226-234, 1994.

TRIVELIN, P.C.O.; OLIVEIRA, M.W.; VITTI, A.C.; GAVA, G.J.C.; BENDASSOLLI, J.A. Perdas do nitrogênio da uréia no sistema solo-planta em dois ciclos de canade-açúcar. Pesquisa Agropecuária Brasileira, Brasília, v. 37, p.193-201, 2002a. 
TRIVELIN, P.C.O.; VITTI, A.C.; OLIVEIRA, M.W.; GAVA, G.J.C.; SARRIÉS, G.A. Utilização de nitrogênio e produtividade da cana-de-açúcar (cana-planta) em solo arenoso com incorporação de resíduos da cultura. Revista Brasileira de Ciência do Solo, Viçosa, v. 26, n. 3, p. 637-646, 2002b.

TUFAILE NETO, M.A. Characterization of sugar cane trash and bagasse. In: HASSUANI, S.J.; LEAL, M.R.L.V.; MACEDO, I.C. Biomass power generation. Sugar cane bagasse and trash. 1 CD-Rom. Piracicaba: PNUD-CTC, 2005. 217 p. (Série Caminhos para Sustentabilidade).

UNIÃO DOS PRODUTORES DE BIOENERGIA - UDOP. Valores do ATR praticados durante as Safras 00/01 a 10/11. Olímpia, SP, 2010. Disponível em: http://www.udop.com.br/cana/tabela_consecana_site.pdf. Acesso em: 12 mar. 2010.

URQUIAGA, S.; BODDEY, R.; OLIVEIRA, O.C. de; LIMA, E.; GUIMARÃES, D.H.V. A importância de não queimar a palha na cultura da cana-de-açúcar. Seropédica: EMBRAPA, CNPBS, 1991. 6 p. (Comunicado Técnico, 5).

VALE, D.W.; PRADO, R.M.; PANCELLI, M.A. Análise econômica da adubação nitrogenada em soqueiras de cana-de-açúcar. STAB. Açúcar, Álcool e Subprodutos, Piracicaba, v. 28, n. 2, p. 32-34, 2009.

VALLIS, I.; PARTON, W.J.; KEATING, B.A.; WOOD, A.W. Simulation of the effects of trash and $\mathrm{N}$ fertilizer management on soil organic matter levels and yields of sugarcane. Soil \& Tillage Research, Amsterdam, v. 38, p. 115-132, 1996.

VAN SOEST, P. J.; ROBERTSON, J. B.; LEWIS, B. A. Methods for dietary fiber, neutral detergent fiber, and non starch polyssacarides in relation to animal nutrition. Journal of Dairy Science, Lancaster, v. 74, n. 10, p. 3583-3597, 1991.

VITTI, A.C. Adubação nitrogenada da cana-de-açúcar (soqueira) colhida mecanicamente sem a queima prévia: manejo e efeito na produtividade. 2003. 114 p. Tese (Doutorado em Ciências) - Centro de Energia Nuclear na Agricultura, Universidade de São Paulo, Piracicaba, 2003.

VITTI, A.C.; TRIVELIN, P.C.O.; CANTARELLA, H.; FARONI, C.E.; FRANCO, H.C.J.; OTTO, R.; TRIVELIN, M.O.; TOALIARI, J.G. Mineralização da palhada e desenvolvimento de raízes de cana-de-açúcar relacionados à adubação nitrogenada de plantio. Revista Brasileira de Ciência do Solo, Viçosa, v. 32, n. esp., p. 27572762, 2008a.

VITTI, A.C.; TRIVELIN, P.C.O.; FRANCO, H.C.J.; OTTO, R.; FARONI, C.E.; CANTARELLA, $\mathrm{H}$. Recuperação pela cana-de-açúcar do $\mathrm{N}$ dos resíduos culturais e da adubação nitrogenada de plantio. In: CONGRESSO NACIONAL DA STAB, 9., 2008, Maceió. Anais... Macéio: STAB, 2008b. 1 CD-ROM.

VITTI, A.C.; TRIVELIN, P.C.O.; GAVA, G.J.C.; PENATTI, C.P.; BOLOGNA, I.R.; FARONI, C.E.; FRANCO, H.C.J. Produtividade da cana-de-açúcar relacionada ao nitrogênio residual e do sistema radicular Pesquisa Agropecuária Brasileira, Brasília, v. 42, n. 2, p. 249-256, 2007. 
WIEDENFELD, R.P. Previous-crop effects on sugarcane responses to nitrogen fertilization. Agronomy Journal, Madison, v. 90, p. 161-165, 1998.

WIEDENFELD, R.P. Water stress during different sugarcane growth periods on yield and response to $\mathrm{N}$ fertilization. Agricultural Water Management, Amsterdam, v. 43, p. 173-182, 2000.

WOOD, A.W. Management of crop residues following green harvesting of sugarcane in north Queensland. Soil \& Tillage Research, Amsterdam, v. 20, p. 69-85, 1991.

ZHANG, D.; HUI, D.; LUO, Y.; ZHOU, G. Rates of litter decomposition in terrestrial ecosystems: global patterns and controlling factors Journal of Plant Ecology, Oxford, v. 1, n. 2., p. 85-93, 2008. 
APÊNDICES 
APENNDICE A: CROQUI DO EXPERIMENTO - CANA-PLANTA

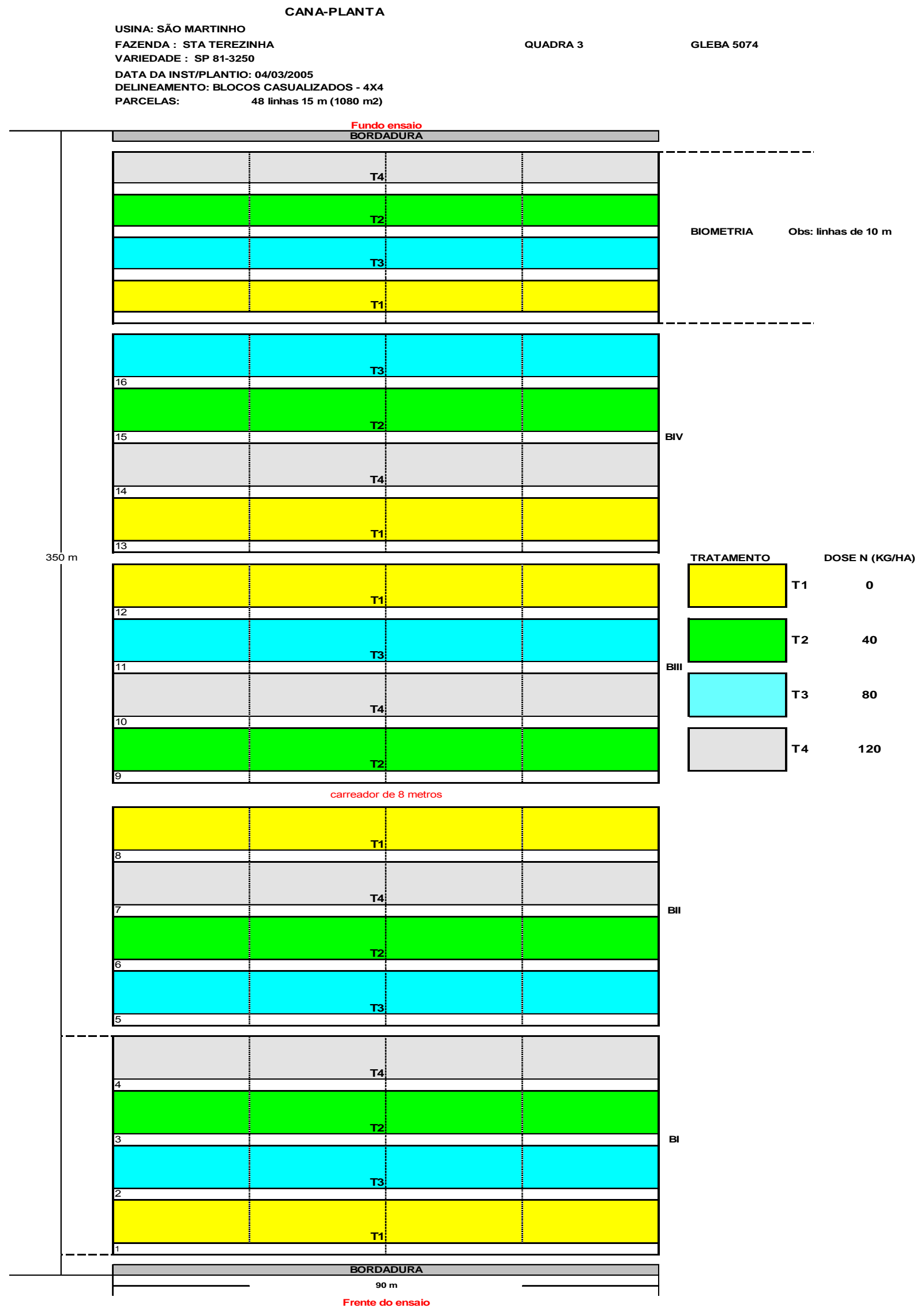


APÊNDICE B: CROQUI DO EXPERIMENTO $-1^{\text {a }}$ a $3^{\text {a }}$ SOQUEIRAS

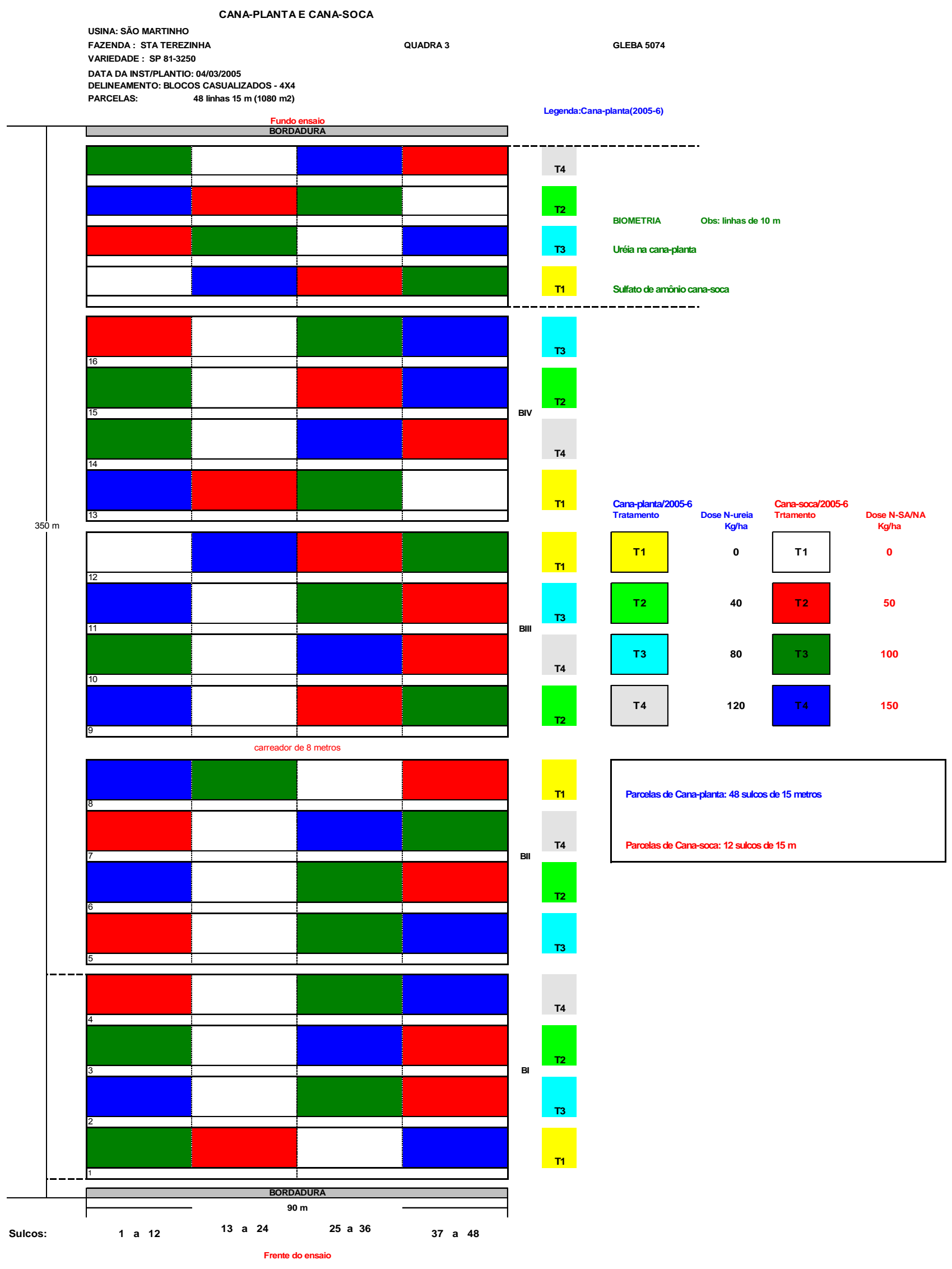


APÊNDICE C: EXTRATOS DOS BALANÇOS HÍDRICOS DA CANA-PLANTA E TRÊS SOQUEIRAS CONSECUTIVAS, USINA SÃO MARTINHO, JABOTICABAL, SP.

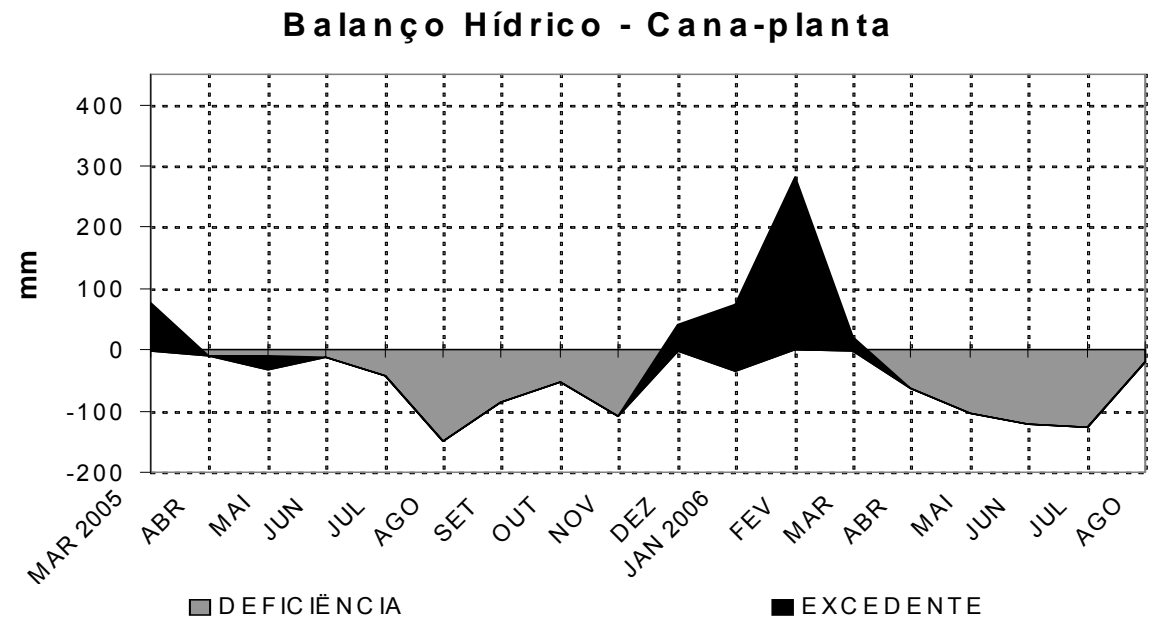

Balanço Hídrico - 2a Cana-soca

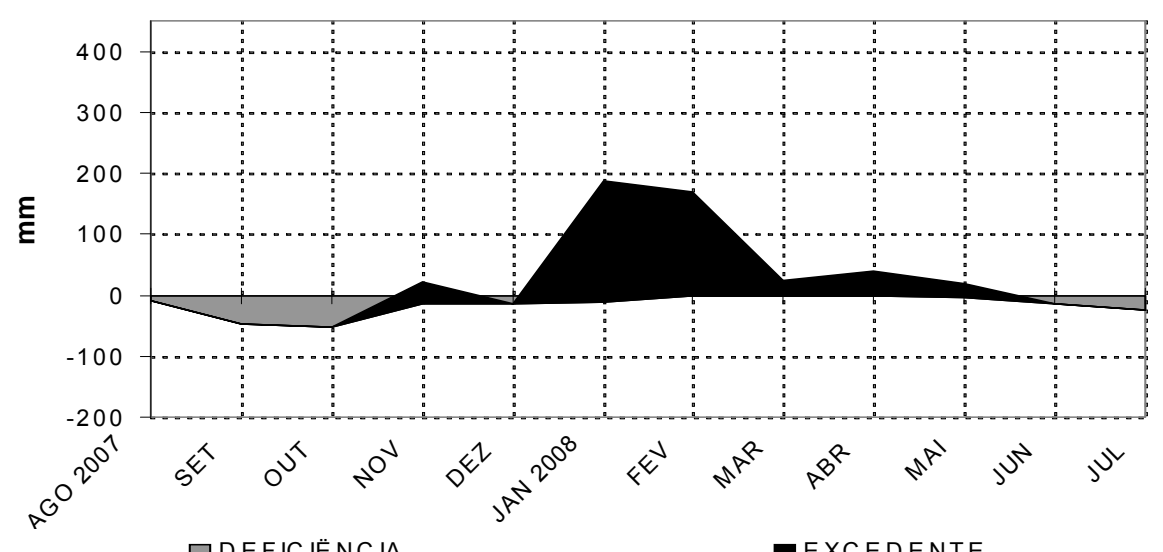

$\square D E F I C I E ̈ N C I A$

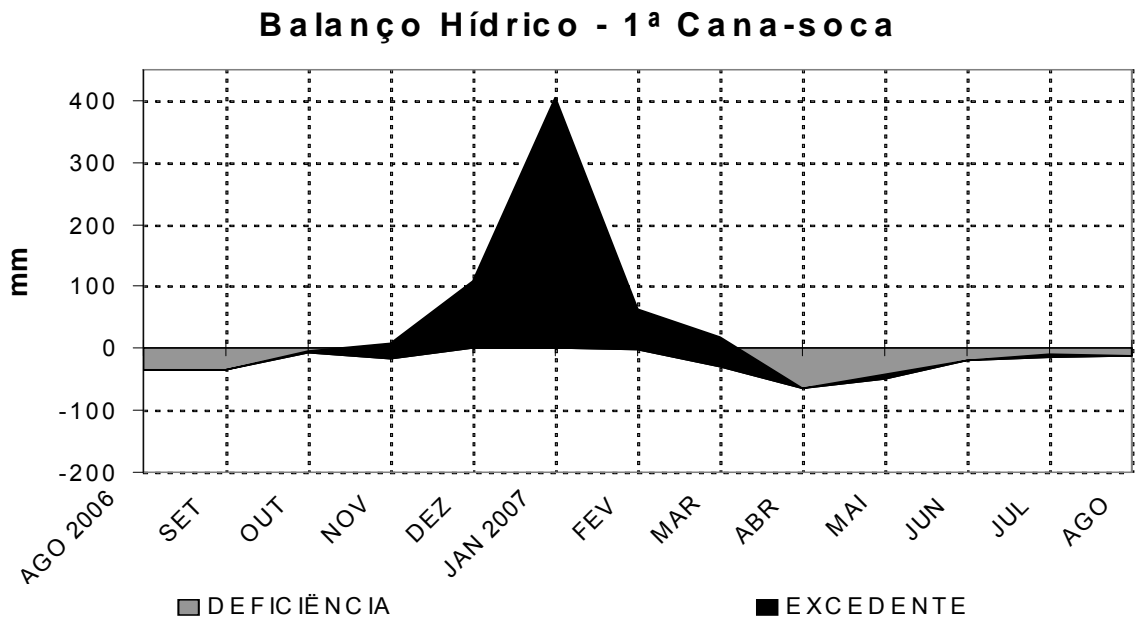

Balanço Hídrico - $3^{\text {a }}$ Soqueira

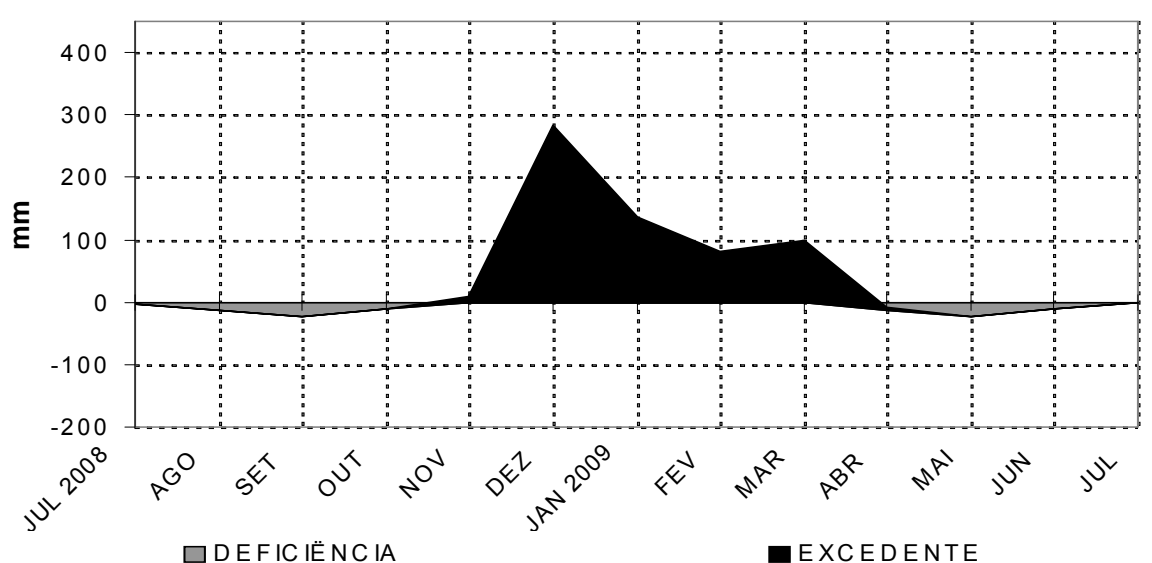


